University of Rhode Island

DigitalCommons@URI

1998

\title{
A STUDY OF THE RHEOLOGICAL PROPERTIES OF SOME OF THE GELS COMMONLY USED IN THE PHARMACEUTICAL, FOOD AND COSMETIC INDUSTRIES AND THEIR INFLUENCE ON MICROBIAL GROWTH
}

Jorge A. Mendoza

University of Rhode Island

Follow this and additional works at: https://digitalcommons.uri.edu/theses

\section{Recommended Citation}

Mendoza, Jorge A., "A STUDY OF THE RHEOLOGICAL PROPERTIES OF SOME OF THE GELS COMMONLY USED IN THE PHARMACEUTICAL, FOOD AND COSMETIC INDUSTRIES AND THEIR INFLUENCE ON MICROBIAL GROWTH" (1998). Open Access Master's Theses. Paper 268.

https://digitalcommons.uri.edu/theses/268

This Thesis is brought to you for free and open access by DigitalCommons@URI. It has been accepted for inclusion in Open Access Master's Theses by an authorized administrator of DigitalCommons@URI. For more information, please contact digitalcommons-group@uri.edu. 
A STUDY OF THE RHEOLOGICAL PROPERTIES OF SOME OF THE GELS COMMONLY USED IN THE PHARMACEUTICAL, FOOD AND COSMETIC INDUSTRIES AND THEIR INFLUENCE ON MICROBIAL GROWTH

BY

JORGE A. MENDOZA

A THESIS SUBMITTED IN PARTIAL FULFILLMENT OF THE

REQUIREMENTS FOR THE DEGREE OF

MASTER OF SCIENCE

IN

PHARMACEUTICS

UNIVERSITY OF RHODE ISLAND

1998 
MASTERS OF SCIENCE THESIS

OF

JORGE ALFONSO MENDOZA

\section{APPROVED}

Thesis committee

Major Professor

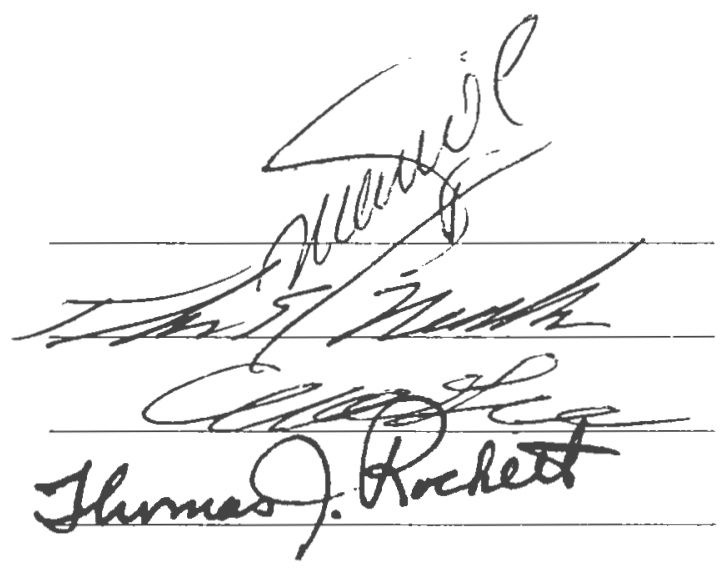

DEAN OF GRADUATE SCHOOL

UNJVERSITY OF RHODE ISLAND

1998 


\begin{abstract}
In the first paper of this work, lambda and kappa carrageenan, guar gum, Water Locks A-100 and DD-223 and Carbopol 971 were selected based on their rheological properties to study of the effects of gel concentration, osmotic pressure and rheological properties as determined by oscillatory viscometry on the growth rate of Pseudomonas aeruginosa, Escherichia coli, Staphylococcus aureus and Candida albicans. The object of this study was to determine the contributions of gel rheology on the growth of microorganisms that commonly contaminate such gels, and assess the influence of the rheology on their self-preserving properties. The rheological properties of the gels were determined by oscillatory viscometry at a stress range of $0-100 \mathrm{~Pa}$ and a frequency of $0.05 \mathrm{~Hz}$ using a $1 \mathrm{~mm}$ gap. Their viscoelastic properties were determined by applying a stress range of $0-100 \mathrm{~Pa}$ and deformation of the gels were observed until the elasticity dissipated. The rheological parameters measured were the elastic modulus $\left(\mathrm{G}^{\prime}\right)$, the viscous modulus $\left(\mathrm{G}^{\prime \prime}\right)$, the complex viscosity $\left(\eta^{*}\right)$ and the phase angle $(\alpha)$. The parameters used to determine any influence of the rheological properties on the microbial growth rate were $G^{\prime}$ and $G^{\prime \prime}$ at the critical region, the critical stress $\left(\sigma_{c}\right)$ at $G^{\prime}$ and $G^{\prime \prime}$, the time to reach $\sigma_{\mathrm{c}}$ at $\mathrm{G}^{\prime}$ and $\mathrm{G}^{\prime \prime}$. The microbial growth rates were determined by following division during a 24 hour period taking measurements at $0,6,12$ and 24 hours. By the use of multiple regression analysis, the growth rates were correlated with the aforementioned parameters. The growth rates of $S$. aureus and E. coli were found to be influenced by the rheological parameters described earlier, whereas a trend was visible for
\end{abstract}


the growth rate of $P$. aeruginosa. The growth rate of $C$. albicans was not affected by these parameters.

In the second paper, the rheological properties of nine different gels, namely carrageenan, guar gum, pectin. sodium carboxymethylcellulose, methylcellulose, hydroxypropyl methyl cellulose. Carbopol 971, Water Lock and bentonite were studied. Oscillatory viscometry was used to study the elastic modulus, viscous modulus and the phase angle in the linear and critical regions at a stress range of $0-100 \mathrm{~Pa}$ and a frequency of $0.05 \mathrm{~Hz}$. The gel macrostructures included long linear chains of the cellulose derivatives; natural gels forming helix and ribbon structures such as carrageenans, guar gum and pectin; cross-linked gels such as Carbopol 971; grafted ones like Water Locks and suspended particles like bentonite. Their flow behavior followed either shear thinning or thickening properties. Five concentration ranges used varied from $0.3 \%$ to $7.0 \%$ with no less than a 3 fold increment in the concentration range. The critical stress $\left(\sigma_{\mathrm{C}}\right)$, where the elasticity of the gel begins to dissipate was also determined with the intention of using it as a parameter to describe the gel strength. Within the concentration ranges studied, the critical stress was found to be a linear function of the concentration within $95 \%$ confidence. The model proposed is applicable to gels of different chemical structure, molecular weight, molecular weight distribution, chain structure and viscosity types. It is also considered as a universal model to describe gel strength and offers a practical and simple description useful for the formulation scientists. In addition. "concentration sensitivity", another parameter described, may enable formulators to replace one gel with another to make necessary concentration-gel strength adjustments to food, cosmetics and pharmaceuticals. 


\section{ACKNOWLEDGEMENTS}

I would like to express my deep appreciation to Dr. M. Serpil Kislalioglu for acting as my major professor. Without her, the road would have been a different one. She guided me through my path not only as a student but also as a friend. To her I owe my newfound abilities, my newfound knowledge and my newfound hunger for the sciences.

I would like to thank the company CHEMEXC, Tegucigalpa. Honduras, who supported me financially throughout my residence in the United States of America. I would like to thank Dr. Denisse Suazo (Laboratorios El Planetario, Honduras) for sharing her knowledge and expertise in the microbiological area with me.

I would like to thank Dr. T. Needham (Department of Applied Pharmaceutical Sciences, URI), Dr. J. Wang (Department of Industrial Engineering, URI) and Dr. C. Lee (Department of Food Science and Nutrition, URI) for serving $\leqslant n$ my thesis committee. My special thanks to Dr. J. Sperry (Department of Microbiology, URI) for allowing me to consult with him through most of the final stages of my preparation. I would also like to extend my gratitude to Ms. Kathleen Hayes (Secretary, Department of Applied Pharmaceutical Sciences) who was always present when I needed her and always made everything seem easier. I extend my special thanks to Ann West, Director of the International Students Office at URI, who gave me her unconditional support during every step of my way.

To God; to my father Jorge Sr. and my mother Mercy, the greatest influences in my life, whose love, sacrifice and care pushed me to excel in every aspect, to my brother and sister and the rest of my family, and to my friends everywhere, thank you. I am a reflection of you all. 


\section{PREFACE}

This work was prepared in the manuscript format option for thesis preparation, as outlined in section 11-3 of the Graduate Manual of the University of Rhode Island. Contained within is a body divided into three sections.

Included in section I is an introduction, which introduces the reader to the subject of the thesis and the specific objectives of the research. Section II is comprised of two manuscripts, containing the findings of the research made throughout this thesis. These two manuscripts are presented in the format required by the journals to which they will be submitted. Section III contains appendices, ancillary data (information essential to, but not usually publishable in the manuscripts) and any other details pertinent to the well understa Jing of the work presented in Section II. A final presentation of the complete listings of the works cited in this thesis. arranged in alphabetical order by the author's last name follows at the end of this section and closes this thesis. 
TABLE OF CONTENTS

$\begin{array}{lr} & \text { Page } \\ \text { ABSTRACT } & \text { ii } \\ \text { ACKNOWLEDGEMENTS } & \text { iv } \\ \text { PREFACE } & \text { v } \\ \text { LIST OF TABLES } & \text { vii } \\ \text { LIST OF FIGURES } & \text { viii }\end{array}$

SECTION I

INTRODUCTION 1

$\begin{array}{lr}\text { SECTION II } & 6\end{array}$

MANUSCRIPT I

$\begin{array}{ll}\text { Appendix to Manuscript } 1 & 36\end{array}$

$\begin{array}{lr}\text { MANUSCRIPT II } & 57\end{array}$

$\begin{array}{ll}\text { Appendix to Manuscript } 2 & 106\end{array}$

$\begin{array}{lr}\text { SECTION III } & 173\end{array}$

$\begin{array}{ll}\text { APPENDIX } & 173\end{array}$

$\begin{array}{lr}\text { BIBLIOGRAPHY } & 187\end{array}$ 
LIST OF TABLES

Page

SECTION II

MANUSCRIPT I

$\begin{array}{ll}\text { Table I } & 13\end{array}$

$\begin{array}{ll}\text { Table II } & 18\end{array}$

Table III $\quad 26$

$\begin{array}{ll}\text { Table IV } & 27\end{array}$

$\begin{array}{lr}\text { Table V } & 29\end{array}$

$\begin{array}{ll}\text { Table VI } & 32\end{array}$

MANUSCRIPT II

$\begin{array}{ll}\text { Table I } & 68\end{array}$

$\begin{array}{ll}\text { Table II } & 74\end{array}$

$\begin{array}{lr}\text { Table III } & 96\end{array}$

Table IV 103 


\section{LIST OF FIGURES}

\section{SECTION II}

\section{MANUSCRIPT I}

$\begin{array}{ll}\text { Figure } 1 & 20\end{array}$

$\begin{array}{ll}\text { Figure } 2 & 21\end{array}$

$\begin{array}{ll}\text { Figure } 3 & 24\end{array}$

MANUSCRIPT II

Figure 1 61

$\begin{array}{ll}\text { Figure } 2 & 63\end{array}$

$\begin{array}{ll}\text { Figure } 3 & 66\end{array}$

$\begin{array}{ll}\text { Figure } 4 & 77\end{array}$

$\begin{array}{lr}\text { Figure } 5 & 81\end{array}$

$\begin{array}{lr}\text { Figure } 6 & 83\end{array}$

$\begin{array}{ll}\text { Figure } 7 & \mathbf{8 7}\end{array}$

$\begin{array}{lr}\text { Figure } 8 & 91\end{array}$

$\begin{array}{ll}\text { Figure } 9 & 97\end{array}$

$\begin{array}{ll}\text { Figure } 10 & 98\end{array}$

$\begin{array}{lr}\text { Figure } 11 & 99\end{array}$

$\begin{array}{ll}\text { Figure } 12 & 100\end{array}$

$\begin{array}{ll}\text { Figure } 13 & 101\end{array}$ 


\section{Section I}

\section{Introduction}

This thesis consists of two papers. The first paper dealt with the effects of the rheological properties, primarily, the viscous and elastic moduli in their linear critical regions, the time at which the viscous and elastic modulus at their critical region is presented, and the concentration and the osmotic pressure of lamda and kappa carrageenans, guar gum, Water Locks A-100 and DD-223 and Carbopol 971 on the growth rates of Pseudomonas aeruginosa, Staphylococcus aureus, Escherichia coli and Candida albicans. Among factors such as $\mathrm{pH}$, water activity and osmotic pressure, macromolecules have also been known to affect microbial growth. The growth of microorganisms is highly dependent on the availability of water and nutritional sources (Schlegel, 1993), which are readily available in many natural gels.

If the microorganisms can cleave and use the carbon, oxygen and water sources of the growth media, the chemical structure may be a factor affecting the growth of microorganisms. Yanagi and Onishi (1971) using myristic and adipic acid esters, reported a decrease in microbial growth rate with increasing branching of the compounds. Guiselly (1989) discussed the importance of the gel structure of alginate as well as iota and kappa carrageenans. It was noted that diffusion of the nutrients and toxic byproducts produced by the microorganisms may be hindered by solid macromolecular structures. Therefore, this study may suggest a possible relationship between the gel strength and initial the growth of microorganisms rates.

The influence of the viscosity of the growth medium as a factor affecting microbial growth was also of interest to some authors. Stecchini et al. (1998) while working with Bacillus cereus using an agar medium with polyvinyl pyrrholidone to 
modify the viscosity, found out that the colony size decreased with increased viscosity in the range of $1-40 \mathrm{cP}$. Lawrence et al. (1992), on the other hand, reported no changes in the growth rates of Vibrio parahaemolyticus while comparing viscous environments of up to $200 \mathrm{cP}$. Other authors like Ferrero and Lee (1987) have studied cell motility in relation to increased viscosity. They found significant changes in the cell motility while studying $C$. jejiju in viscosity ranges of $10 \mathrm{cP}$ and more.

There have been no studies in the literature that examined the effects of varying viscosity types and different degrees of viscosities, from free flowing to highly elastic gels. The studies outlined in the first paper explore the contributions of gel concentration, rheological properties and osmotic pressure on the growth rates of $P$. aeruginosa, $S$. aureus, E. coli and C. albicans, all of which are commonly found in the pharmaceutical, food and cosmetics industries.

The second paper, dealt with the effects of the rheological and physical chemical properties of various gels on the viscoelastic properties of carrageenan, guar gum, pectin, sodium carboxy methyl cellulose, methyl cellulose, hydroxypropyl methyl cellulose. Carbopol 971, Water Lock and bentonite, which are used in the pharmaceutical, cosmetics and food industries. A new parameter, which characterizes gels and directly relates to the concentration regardless of the gel strength and concentration differences, was introduced.

The rheology of the polymer solutions may depend upon the combination of factors such as the molecular weight, molecular weight distribution, monomer and segment distribution, the presence of hydrophobic and hydrophilic functional groups and macrostructure of the chains (McCormick, 1991). Oscillatory rheometry is one of the 
suitable methods to sturty the gel properties because it provides information on the internal structure withou breaking it, unlike rotational viscometry. It offers a variety of geometrical combination; which enables us to study of the least structured and the most structured gels

Davis (1971, a, b) described the viscoelastic properties of pharmaceutical semisolids using both destructive and non-destructive oscillatory testing. In destructive oscillatory testing, the sistem is sheared until the elasticity breaks. In non-destructive oscillatory testing. the viscous and elastic responses of a gel body are studied at increasing frequencies in the stress range where these moduli remains constant. Among many other authors who ave studied polymer rheology, Ferry (1974) was one of the first to characterize polymer rheology by the use oscillatory viscometry.

Parameters like the complex viscosity $\left(\eta^{*}\right)$, the phase angle $(\alpha)$, the viscous modulus $\left(G^{\prime}\right)$ and the elastic modulus $\left(G^{\prime \prime}\right)$ have been traditionally determined and used to characterize the viscoelastic properties of polymer solutions (Chereminisoff, 1993). The critical stress $\left(\sigma_{c}\right)$ is a calculated parameter which describes the stress at which the polymer solution's struc ure starts to dissipate. Giboreau et al. (1994) working with locust bean gum, xanthar gum and a modified starch (Col-Flo) described this point as the point where a "catastrophic" destruction of the system occurs. Therefore, the overall internal gel structure ma! be characterized by the use of the critical stress. 


\section{References}

Davis, S., Viscoelastic properties of pharmaceutical semisolids III: Destructive oscillatory testing, Journal of Pharmaceutical Sciences, 60:1357-1360, (1971b)

Davis, S., Viscoelastic properties of pharmaceutical semisolids III: Non-destructive oscillatory testing, Journal of Pharmaceutical Sciences, 60:1351 - 1355, (1971a)

Feery, J., Viscoelastic properties of polymers, 3rd ed., Wiley and Sons, NY, 1980

Giboreau, A., Cuvelier, G. and launay, B., Rheological behavior of three biopolymer/water systems, with emphasis on yield stress and viscoelastic properties, Journal of Texture Studies, 25:119-137 (1994)

McCormic, C. Structural design of water soluble polymers, in Water-Soluble Polymers, Synthesis, Solution Properties and Applications (S. Shalaby, C. MacCormick, G. Butler, eds.) pp. 2 - 24, ACS, Washington, (1991)

Ferrero, R.L. and Lee, A., Motility of Campylobacter jejuni in viscous environments: comparison with rod shaped bacteria, Journal of General Microbiology, 134:53 - 59. (1988)

Guiselly, K.B., Chemical and physical properties of algal polysaccharides used for cell immobilization, Enzyme Microbial Technology, 11:706 - 716, (1989)

Lawrence, J.R., Korber, D.R. and Caldwell, D.E., Behavioral analysis of Vibrio parahaemolyticus variants in high and low viscosity microenvironments by use of digital image processing, Journal of Bacteriology, 174:5732 - 5739, (1992)

Schlegel, H., General microbiology, 2nd ed., Cambridge University Press, 1993

Stecchini, M.L., Torre, M., Sorais, I., Soro, O., Messina, M. and Maltini, E., Influence of structural properties and kinetic constraints on Bacillus cereus growth, Applied and Environmental Microbiology, 64:1075 - 1078, (1998) 
Yanagi and Onishi G., Assimilation of selected cosmetic ingredients by microorganisms, Journal of the Society of Cosmetic Chemists. 22:851, (1971) 


\section{Section II}

\section{Paper I}

"The effects of gel concentration, osmotic pressu re and rheological properties on the growth rate Pseudomonas aeruginosa, Escherichia coli, Staphylococcus aureus and Candida albicans." 


\section{Summary}

The effects of rheology, gel concentration and osmotic pressure of lambda and kappa carrageenans, guar gum. Water Locks A-100 and DD-223 and Carbopol 971 on the growth rate of Pseudomonas aeruginosa, Escherichia coli, Staphylococcus aureus and Candida albicans were studied. The rheological properties of the gels were determined by the use of oscillatory viscometry at a stress range of $0-100 \mathrm{~Pa}$, a frequency of 0.05 $\mathrm{Hz}$ and a strain range of 0.00075 to $15 \mathrm{~mm}$ using a $1 \mathrm{~mm}$ gap. Their viscoelastic properties were determined using destructive oscillatory measurements. The rheological parameters measured were the elastic modulus $\left(G^{\prime}\right)$, the viscous modulus $\left(G^{\prime \prime}\right)$, the complex viscosity $\left(\eta^{*}\right)$ and the phase angle $(\alpha)$. The parameters used to determine the influence of the rheological properties on the microbial growth rate were $G^{\prime}$ and $G^{\prime \prime}$ in the critical region, the critical stress $\left(\sigma_{\mathrm{c}}\right)$ at $G^{\prime}$ and $G^{\prime \prime}$, the time to reach $\sigma_{\mathrm{c}}$ at $G^{\prime}$ and $G^{\prime \prime}$. Microbial growth rates were determined by following division during a 24 hour period taking measurements at $0,6,12$ and 24 hours. Multiple regression analysis was used to correlate the growth rates with the aforementioned parameters. The growth rates of $S$. aureus and $E$. coli were found to be influenced by the rheological parameters described earlier, whereas a trend was visible for the growth rate of $P$. aeruginosa. The growth rate of $C$. albicans was not affected by these parameters. The deviations of the growth rates of the latter two microorganisms were explained by the strong metabolizing ability of $P$. aeruginosa and extremely large size of C. albicans. 


\section{Introduction}

Macromolecules, especially natural gums like tragacanth. have been known to affect the microbial growth. since they provide a nutritious, structurally suitable environment. Yanogi and Onishi (Dec. 1971) found that the microorganisms could easily utilize materials like liquid paraffin, oleyl alcohol, stearyl alcohol, propylene glycol, isopropyl myristate and stearic acid. Natural gels, because of their polysaccharide structure, can provide an optimum carbon source that the bacteria can use as a nutrient to fully grow and develop (Schlegel, 1993). Some of the synthetic and semisynthetic gels may provide nitrogen sources. The growth of microorganisms is dependent on water availability because the substances which they utilize are usually dissolved in water. They can break down almost all organic matters (Schelegel, 1993).

Chemical structure is also important for the growth of microorganisms. Generally it is agreed that for any given carbon number, the degradation of a compound becomes slower with increased branching. Yanagi and Onishi (Dec., 1971) reported that the growth rate of microorganisms in myristic and adipic acid esters and in glycerol esters decreased by increasing branching of the compounds. Furthermore, Guiselly (1989) reviewed the chemical and physical properties of algal polysaccharides such as agar, algin and carrageenan used for cell immobilization, and stated that the diffusion of nutrients is hindered by the complex molecular structures of algin and carrageenan. The gel would further affect the accumulation of toxic by-products of the microorganisms. and thus their growth.

In addition, these molecules, due to their large structures and related surface activity, can also interact with the preservatives, minimizing preservative efficacy. Esiman et al. (1957) found that the presence of gum tragacanth in the pharmaceutical 
formulations neutralized the effect of chlorobutanol, p-hydroxybenzoate and quaternary ammonium compounds. McCarthy et al. (1974) further studied the deactivation of preservatives by gum tragacanth.

$\mathrm{pH}$ plays an important role in bacterial growth sometimes hindering their growth. In a range of $5.5-7.0, \mathrm{pH}$ has very little effect on the growth rate; but most pharmaceutical and topical preparations are formulated at a pH range of $5.5-8.0$, which is optimal for most bacterial growth (Schlegel, 1993).

Besides $\mathrm{pH}$ and chemical structure of the polymer, an increase in the osmotic pressure of the solution also influences microbial growth, since microorganisms are tolerant to higher osmotic stress (Csonka 1989). The effects of physical factors on the growth of Staphylococcus aureus were discussed by Ballesteros et al. (1993). They found that the water activity, regardless of the nature of the ions used, influenced the cell growth.

Water activity is expressed as:

$\mathrm{Aw}=\mathrm{P} / \mathrm{Po}$

And can be related to the osmotic pressure for ideal solutions through Van Hoff's equation,

$\pi=\mathrm{RT} / \mathrm{V} * \operatorname{Ln}(\mathrm{Po} / \mathrm{P})$

where Po is the vapor pressure of the pure solvent, $\mathrm{P}$ is the vapor pressure of the solution, $\mathrm{R}$ is the ideal gas constant, $\mathrm{T}$ is the absolute temperature and $\mathrm{V}$ is the volume of the solution.

Osmotic pressure also has a direct effect in reducing the water activity of a solution. Theoretically water activity changes from 0 to 1 . The lowest water activity 
tolerated by many bacteria is 0.90 , whereas at a water activity of 0.85 the growth of many yeasts is inhibited. Fungi can endure water activities as low as 0.80 (Schelegel, 1993). Ketz et al (1996), working with sucrose, glycerol and poly(ethylene)glycol of molecular weights of 200, 400 and 4,000 and using Pseudomonas putida as the test microorganism found that minimal decreases in the water activities from 0.99 to 0.9875 and 0.9800 ceased the growth of microorganisms.

Stecchini et al. (1998) found correlations between the microbial growth of Bacillus cereus and the viscosity of agar. She reported a decrease in the colony size as the viscosity of agar was increased from $1 \mathrm{cP}$ to $40 \mathrm{cP}$ using different concentrations of polyvinyl pyrrholidone (PVP), without mentioning the effect PVP may have had on the water activity and osmotic pressure of agar. However, Ballesteros et al. (1993) argued that sucrose had the highest increase on the viscosity of the media when comparing water activities, but had the least inhibitory effect on the growth of $S$. aureus when compared to sodium chloride, propylene glycol, butylene glycol and various polyethylene glycols.

Lawrence et al. (1992) found no changes in the growth rate of Vibrio parahaemolyticus, a flagellated bacteria, when comparing the upper and lower ends of low viscosity environments up to $200 \mathrm{cP}$ during the first 6 hours of growth. Ferrero and Lee (1987) have noted the relationship between the cell motility and apparent viscosity using a flow viscometer. They observed an increase in the mean velocity of $C$. jejuji at the $1-10 \mathrm{cP}$ range, which decreased rapidly at viscosities higher than $10 \mathrm{cP}$. Atsumi et al. (1996) also noted that the speed of lateral flagellated $V$. algininolyticus increased from $20 \mu \mathrm{m} / \mathrm{s}$ at $1 \mathrm{cP}$ to $40 \mu \mathrm{m} / \mathrm{s}$ at $5 \mathrm{cP}$ and then decreased as the viscosity was increased. Greenberg and Canole-Parola, (1997), working with V. parahaemolyticus and Lawrence 
et al. (1992), working with $E$. coli found that the mean immobilizing viscosity for these bacteria were of $60 \mathrm{cP}$ and $1.000 \mathrm{cP}$ respectively. However, all of the studies mentioned above used low Newtonian viscosity media. The studies discussed above show relationships between viscosity, cell motility, nutrient diffusion and growth rate. There are no studies in the literature which determine the effect of rheological behavior on the microbial growth in high viscosity environments.

In order to test the effect of rheology on the growth of microorganisms, oscillatory viscometry was utilized. Two natural gels, carrageenan and guar gum, a semisynthetic, Water Lock and a synthetic polymer, Carbopol 971, were used to investigate the effects of rheology on the growth of microorganisms rate. The microbiological experiments were carried out using one Gram (+) bacteria, Staphylococcus aureus, two Gram (-) bacteria, Escherichia coli and Pseudomonas aeruginosa, and a yeast, Candida albicans, as model microorganisms, since they are the most representative of those commonly found in the raw materials and the finished products.

S. aureus is a spherical, non-motile prokariotic bacteria (Cohn, 1972). $P$. aeruginosa is a rod, straight or curved, $4 \mu \mathrm{m}$ in length, motile with one or more polar flagella and containing pilli or fimbrae (Richmond, 1975). E. coli is also a flagellated rod containing fimbriae with which they transfer genetic material and act as adherent factors when colonizing other organisms and solid materials. These three bacteria have a cell size of about $5 \mu \mathrm{m}$ (Niedhart, 1987). Candida albicans is a yeast, that is a fungi with unicellular mode of development. Candidas are eukariotic cells that multiply by the production of buds from blastophores. Its size greatly varies from the bacteria studied in 
that they about $500 \mu \mathrm{m}$ in diameter and their buds can be elongated several times more (Odds, 1988).

\section{Materials and Methods}

The chemical structures, molecular weights and nature of the gels studied are given in Table I. Carbopol 971 is a cross linked poly(acrylic)acid with wide applications in the pharmaceutical and cosmetics industry. It is also a suspension/emulsion stabilizing agent. It is highly hydrophilic in nature and highly swellable in water and other polar solvents. Carrageenans are the water extracts from various members of the Solicracae families of red sea weed. The different types of carrageenans vary on the degree of sulfation in their repeating unit. Their viscous properties depend mainly on their unbranched, linear macromolecular structure and highly electrolytic nature. They are widely used in the pharmaceutical, cosmetics and food industries. Guar gum is a carbohydrate polymer, which is useful as a thickening agent for water. Water Locks are long chained semisynthetic polymers obtained from wheat proteins. They are used as skin conditioners and water fixing agents. They are able to bind large quantities of water at low concentrations.

Carbopol 971 NF, Carrageenan RLV and VV71P, Guar Gum U-NF and Water Lock A-100 and DD-223 were used to form gels and mucilages. Gelose Nutritive (Diagnostics Pasteur) was included in the culture broth as a nutrient in aid of preparation of the microorganism suspensions. The culture broth contained 1 gram of meat extract, 2 grams of yeast extract, 5 grams of peptone, 5 grams of sodium chloride and 15 grams of agar per liter of distilled water as described by the manufacturer. Candida albicans (ATCC 10231), Escherichia coli (ATCC 8739), Pseudomonas aeruginosa (ATCC 9027) and Staphylococcus aureus (ATCC 6538) were provided by the Universidad Nacional Autonoma de Honduras. College of Microbiology. 
Table I. Chemical Structures, Molecular Weights and Nature of the Gels Studied.

\begin{tabular}{|c|c|c|c|c|c|}
\hline Polymer & Chemical Structure & $\begin{array}{c}\text { Average } \mathrm{M}_{\mathrm{w}} \text { (Daltons } \\
\left.\qquad \times 10^{5}\right)\end{array}$ & $\begin{array}{l}\text { Structure } \mathrm{n} \text { Gel } \\
\text { Form }\end{array}$ & Chemical Composition & $\begin{array}{c}\text { Selected } \\
\text { Concetrations } \\
\text { W/W \% }\end{array}$ \\
\hline $\begin{array}{l}\text { Carbopol } 971 \\
\text { (BF Goodrich, } \\
\text { Cleveland, OH, } \\
\text { Lot \# AJ01066) }\end{array}$ & 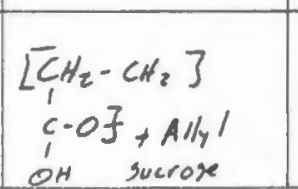 & $10-40$ at $2 \%$ & $\begin{array}{l}\text { Highly } \\
\text { crosslinked } \\
\text { chains }\end{array}$ & $\begin{array}{l}\text { poly(acrylic)acid cross linked with allyl } \\
\text { sucrose }\end{array}$ & $0.5,2.0,4.0$ \\
\hline $\begin{array}{l}\text { Water Lock A- } \\
100 \text { (Grain } \\
\text { Processing Co., } \\
\text { Muscatine, IA } \\
\text { Lot } \$ 9613001 \text { ) }\end{array}$ & 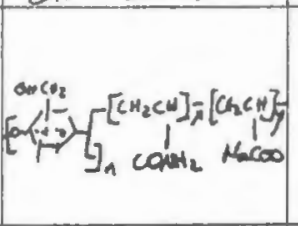 & $\mathrm{NA}^{*}$ & $\begin{array}{c}\text { Graft } \\
\text { copolymer } \\
\text { (branched) }\end{array}$ & $\begin{array}{l}\text { a starch backbone and grafted side chains of } \\
\text { poly (2-propenamide-co-2-propenoic acid) }\end{array}$ & $0.3,0.5,0.7$ \\
\hline $\begin{array}{l}\text { Water Lock } \\
\text { DD-223 (Grain } \\
\text { Processing Co., } \\
\text { Muscatine, IA } \\
\text { Lot } \\
\text { \#W9501401) }\end{array}$ & 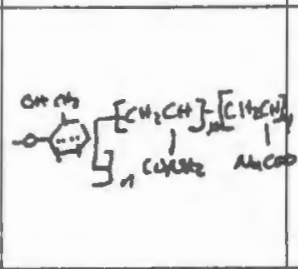 & $\mathrm{NA}^{*}$ & $\begin{array}{c}\text { Graft } \\
\text { copolymer } \\
\text { (branched) }\end{array}$ & $\begin{array}{l}\text { a starch backbone and grafted side chains of } \\
\text { poly (2-propenamide-co-2-propenoic acid) }\end{array}$ & $0.7,1.0,1.3$ \\
\hline
\end{tabular}


Table I. Continued

\begin{tabular}{|c|c|c|c|c|c|}
\hline Polymer & Chemical Structure & $\begin{array}{c}\text { Average } \mathrm{M}_{\mathrm{w}} \text { (Daltons } \\
\left.\times 10^{5}\right)\end{array}$ & $\begin{array}{c}\text { Structure in Gel } \\
\text { Form }\end{array}$ & Chemical Composition & $\begin{array}{c}\text { Selected } \\
\text { Concetrations } \\
\text { W/W \% }\end{array}$ \\
\hline $\begin{array}{l}\text { Guar gum } \\
\text { (Hercules, } \\
\text { Wilmington, } \\
\text { DE, Lot \# } \\
\text { A6362B) }\end{array}$ & 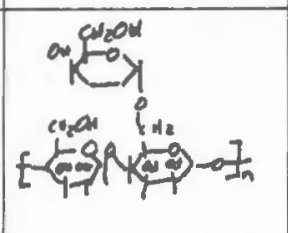 & $18-20$ & $\begin{array}{c}\text { Linear, } \\
\text { alternating } \\
\text { copolymer }\end{array}$ & $\begin{array}{l}\text { linear chain of } \beta \text {-D-mannopyranosyl 1,4-linked } \\
\text { with a single member } \alpha \text {-D-galactopyranosyl } \\
\text { unit occurring as side branches linked }(1 \rightarrow 6) \\
\text { which makes it }\end{array}$ & $1.50,1.75,2.0$ \\
\hline $\begin{array}{c}\text { Lambda } \\
\text { Carrageenan } \\
\text { (Type RLV } \\
\text { Genugel, } \\
\text { Hercules, } \\
\text { Wilmington, } \\
\text { DE Lot } \\
\text { \#627240) } \\
\end{array}$ & & 4 & $\begin{array}{c}\text { Long linear } \\
\text { chains forming } \\
\text { double helices }\end{array}$ & $\begin{array}{l}\text { Linear polysaccharides built up of alternating } \\
\beta \text {-D-galactopyranosyl and } 1,4 \text {-linked } \alpha \text {-D- } \\
\text { galactopyranosyl units with sulfate } \\
\text { substitutions in the } 2,5 \text { positions of } \beta \text {-D- } \\
\text { galactopyranosyl and of the } \alpha \text {-D- } \\
\text { galactopyranosyl }\end{array}$ & $3.0,5.0,7.0$ \\
\hline $\begin{array}{l}\text { Kappa } \\
\text { Carrageenan } \\
\text { (Type VV71P } \\
\text { Genugel, } \\
\text { Hercules, } \\
\text { Wilmington, } \\
\text { DE Lot } \\
\text { \#627220) }\end{array}$ & & 3 & $\begin{array}{l}\text { Long linear } \\
\text { chains forming } \\
\text { double helices }\end{array}$ & $\begin{array}{l}\text { Linear polysaccharides built up of alternating } \\
\beta \text {-D-galactopyranosyl and } 1,4 \text {-linked } \alpha \text {-D- } \\
\text { galactopyranosyl units with a sulfate } \\
\text { substitution in the } 4 \text { position of } \beta \text {-D- } \\
\text { galactopyranosyl and a } 1,4 \text {-linked 3,6-anhydro- } \\
\text { D-galactose }\end{array}$ & $3.0,5.0,7.0$ \\
\hline
\end{tabular}

NA* Manufacturing company could not provide molecular weight data 


\section{Preparation of the gels}

After screening fourteen different polymer solutions, six were selected based on their flow behavior and rheological strength. They either exhibited similar flow behavior with different rheological strength or had similar rheological strength with different flow behavior. The concentrations shown in Table I provided similar rheological behavior within the measuring limits of the instrument used.

The gels were prepared by adding sterilized distilled water to the polymer powder to obtain the pre-selected gel concentration in $w / w$. The mixtures were left to swell for $24 \mathrm{hr}$. and then homogenized using a Fisher Scientific (Pittsburgh, PA) model Dyna-mix stirrer at $1000 \mathrm{rpm}$ for $1 \mathrm{hr}$. The $\mathrm{pH}$ was measured using a Fisher Scientific (Pittsburgh, PA) model Accumet $20 \mathrm{pH}$ meter. Except for Carbopol 971, no pH adjustments were made. The $\mathrm{pH}$ of carbopol 971 was adjusted to the $\mathrm{pH}$ range of 5.1 using a $1 \mathrm{~N} \mathrm{NaOH}$ solution.

\section{Characterization of the Physical-Chemical Properties of the Gels.}

Water activity and osmotic pressure: Using an Aqualab Model CX-2 instrument, the water activities of the gels were measured at each concentration. This instrument measures the vapor pressure of water and the gel solution which were observed as different degrees of condensation on a calibrated mirror. It calculates the water activity value from equation (1). The osmotic pressure of the gels was measured at each concentration using an Osmette "A" Automatic Osmometer (Precision systems Inc., Matick, MA).

Rheological properties: The rheological behavior of the gels was characterized at each concentration using a Bohlin Instruments Rheometer Model CVO (Cranbury, NY). 
Elastic modulus $\left(G^{\prime}\right)$, viscous modulus $\left(G^{\prime \prime}\right)$, complex viscosity $\left(\eta^{*}\right)$,complex modulus $\left(G^{*}\right)$, the strain $(\gamma)$ and phase angle $(\alpha)$ were measured using a stainless steel, plate and plate spindle number 4 , a strain range of $0.00075-15 \mathrm{~mm}$, a frequency of $0.05 \mathrm{~Hz}$, a 1 mm gap and at a constant temperature of $25^{\circ} \mathrm{C}$. Results such as the critical stress $\left(\sigma_{\mathrm{c}}\right)$ at G' and G", and the time to reach these $\sigma_{\mathrm{c}}$ were further tabulated.

\section{Microbiological Studies.}

Inoculation of the gels: The gels were prepared at each pre-determined concentration by preparing a $90 \mathrm{~g}$ which is the amount of water that would be equal to the amount in the inoculating suspension. A $9 \mathrm{~g}$ sample was taken from this gel and $1 \mathrm{~mL}$ of the microorganism suspension containing $1 \times 10^{7}$ microorganisms $/ \mathrm{ml}$ was added to it. The inoculated gel was then homogenized and kept at $22{ }^{\circ} \mathrm{C}$. The microorganism concentration was measured at 434 nm using a Siemens BX4 microbiological spectrophotometer.

Preparation of the calibration curves. The calibration curves were prepared using the McFarland scale. Each different gel at its respective concentrations was inoculated with the test microorganisms at the Mcfarland scale of 2, 4, 8 and 10 which corresponded to $6.0 \times 10^{8}, 1.2 \times 10^{9}, 2.4 \times 10^{9}$, and $3.0 \times 10^{9}$ microorganisms $/ \mathrm{ml}$ respectively. Their absorbance was then measured at $434 \mathrm{~nm}$. These measurements were used to construct the calibration curves.

Determination of the bacterial growth rate: The changes in the microorganism density of the inoculated gels were measured at $0,6,12$ and 24 hours. Each sample was prepared in quadruplicate. The rate of microorganism growth was determined by means of calculating the inverse of the slope using a linear regression as described by Orth (1980). 
A mean growth rate for each gel concentration is defined as the mean growth rate of all the growth rates of the bacteria used. This value was used in rheological property correlations. The growth obtained after 24 hours, these are the values obtained on the $2^{\text {nd }}$, $3^{\text {rd }}$ and $4^{\text {th }}$ days were not used because the bacteria had visibly modified the rheological properties of the gels after this period.

\section{Statistical Evaluation}

The microorganism growth rate was statistically evaluated using the Pearson correlation parameter. The relationship between the growth rate and the parameters of interest $\left(G^{\prime}\right.$ and $G^{\prime \prime}$ at the linear region, critical stress at $\left(G^{\prime}\right.$ and $\left.G^{\prime \prime}\right)$, time at these critical stresses, osmotic pressure and concentration) was studied with Minitab v. 8.01 software. Multiple regression analysis was performed to study the significance of all the variables. The contribution of the significant variables was further tested by best subset and stepwise regression analysis in order to deduce any statistical significance and the relationship between growth the rate and the aforementioned variables.

\section{Results and Discussion}

Water activity and Osmotic Pressure of the gels: Since the microorganisms used in this study can grow in substances with water activities of 0.95 and more, all of the gels could provide suitable growth environments for the test microorganisms used. They all had similar affinities for water molecules (see Table II), making them extremely suitable for microbial growth.

Since the water activity measured in our systems provided a narrow range between 0.987 to 0.998 , Table II, while the osmotic pressure varied from 2.75 to 416.5 m-Osm, the osmotic pressure provided a more sensitive parameter than the water activity to be used in microbial growth evaluations. 
Table II. Rheological Parameters taken at $0.05 \mathrm{~Hz}$, the gel pHs, Osmotic Pressures, Water Activities and the Mean Growth ratesat the Different Gel Concentrations Used.

\begin{tabular}{|c|c|c|c|c|c|c|c|c|c|c|c|}
\hline Gel & Concentration & $\begin{array}{c}\text { Critical } \\
\text { Stress at } G^{\prime \prime} \\
\text { (Pa) }\end{array}$ & $\begin{array}{c}\text { Crittcal } \\
\text { Stress at } G^{\prime} \\
(P a)\end{array}$ & PH & $\begin{array}{l}\text { Osmotic } \\
\text { Pressure } \\
\text { (mOsm) }\end{array}$ & $\begin{array}{l}\text { Water } \\
\text { Activity }\end{array}$ & $\begin{array}{c}\text { Mean } \\
\text { Bacterial } \\
\text { Growth } \\
\text { Rate } \\
\text { (Hours/1 log } \\
\text { increase) }\end{array}$ & $\begin{array}{l}\text { Time at G" } \\
\text { Crittcal } \\
\text { Stress } \\
\text { ( seconds) }\end{array}$ & $\begin{array}{c}\text { Time at G' } \\
\text { Critical } \\
\text { Stress } \\
\text { ( seconds) }\end{array}$ & $\begin{array}{l}\text { G" at the } \\
\text { Linear } \\
\text { Region }\end{array}$ & $\begin{array}{l}G^{\prime} \text { at the } \\
\text { Linear } \\
\text { Region }\end{array}$ \\
\hline $\begin{array}{c}\text { Kappa } \\
\text { Carrageenan } \\
\text { (ViviP) }\end{array}$ & $\begin{array}{l}3.0 \% \\
5.0 \% \\
70 \%\end{array}$ & $\begin{array}{l}178 \\
20.57 \\
48.43\end{array}$ & $\begin{array}{l}6.05 \\
30.94 \\
69.52\end{array}$ & $\begin{array}{l}6.8 \\
\quad 7.3 \\
7.4\end{array}$ & $\begin{array}{c}18.75 \\
37.75 \\
53.0\end{array}$ & $\begin{array}{l}0.992 \\
0.992 \\
0.991\end{array}$ & $\begin{array}{l}39.7 \\
45.7 \\
71.9\end{array}$ & $\begin{array}{l}442.5 \\
683.7 \\
723.9\end{array}$ & $\begin{array}{l}563.1 \\
723.9 \\
764.1\end{array}$ & $\begin{array}{c}31.9 \\
319.3 \\
1,164.2\end{array}$ & $\begin{array}{c}222.4 \\
2.832 .9 \\
7.6717\end{array}$ \\
\hline $\begin{array}{c}\text { Water Lock A. } \\
100\end{array}$ & $\begin{array}{l}0.3 \% \\
05 \% \\
0.7 \%\end{array}$ & $\begin{array}{l}0.07 \\
0.23 \\
2.35\end{array}$ & $\begin{array}{l}0.11 \\
0.50 \\
3.45\end{array}$ & $\begin{array}{l}7.9 \\
7.9 \\
7.9\end{array}$ & $\begin{array}{c}2.75 \\
7.0 \\
11.5\end{array}$ & $\begin{array}{l}0.995 \\
0.994 \\
0.993\end{array}$ & $\begin{array}{l}31.6 \\
26.2 \\
26.0\end{array}$ & $\begin{array}{l}80.5 \\
201.2 \\
442.5\end{array}$ & $\begin{array}{l}120.7 \\
280.8 \\
482.7\end{array}$ & $\begin{array}{l}27.1 \\
89.1 \\
112.7\end{array}$ & $\begin{array}{l}70.7 \\
196.5 \\
582.7\end{array}$ \\
\hline $\begin{array}{l}\text { Water Lock } \\
\text { DD-223 }\end{array}$ & $\begin{array}{l}0.7 \% \\
1.0 \% \\
1.3 \%\end{array}$ & $\begin{array}{l}4.85 \\
7.11 \\
23.3\end{array}$ & $\begin{array}{l}15.23 \\
23.3 \\
47.8\end{array}$ & $\begin{array}{l}6.9 \\
6.9 \\
7.0\end{array}$ & $\begin{array}{l}9.75 \\
20.5 \\
25.5\end{array}$ & $\begin{array}{l}0.995 \\
0.994 \\
0.993\end{array}$ & $\begin{array}{l}16.8 \\
19.6 \\
30.5\end{array}$ & $\begin{array}{l}524.6 \\
563.1 \\
683.6\end{array}$ & $\begin{array}{l}645.1 \\
683.6 \\
764.2\end{array}$ & $\begin{array}{l}14.25 \\
39.9 \\
44.9\end{array}$ & $\begin{array}{l}908 \\
4616 \\
496.6\end{array}$ \\
\hline Carbopol 971 & $\begin{array}{l}0.5 \% \\
2.0 \% \\
4.0 \%\end{array}$ & $\begin{array}{l}0.89 \\
9.27 \\
33.99\end{array}$ & $\begin{array}{l}7.05 \\
24.95 \\
63.87\end{array}$ & $\begin{array}{l}5.1 \\
5.1 \\
5.2\end{array}$ & $\begin{array}{c}15.25 \\
36.25 \\
70.5\end{array}$ & $\begin{array}{l}0.994 \\
0.993 \\
0.990\end{array}$ & $\begin{array}{c}53.2 \\
92.6 \\
173.8\end{array}$ & $\begin{array}{l}281.5 \\
403.8 \\
482.5\end{array}$ & $\begin{array}{l}522.8 \\
564.8 \\
643.3\end{array}$ & $\begin{array}{l}4.86 \\
11.42 \\
247\end{array}$ & $\begin{array}{l}4929 \\
123.3 \\
1884\end{array}$ \\
\hline $\begin{array}{l}\text { Lambda } \\
\text { Carrageenan } \\
\text { (RLV) }\end{array}$ & $\begin{array}{l}3.0 \% \\
5.0 \% \\
7.0 \%\end{array}$ & $\begin{array}{l}0.34 \\
1.05\end{array}$ & $\begin{array}{l}0.49 \\
1.05\end{array}$ & $\begin{array}{l}5.6 \\
5.4 \\
6.8\end{array}$ & $\begin{array}{l}170.75 \\
298.0 \\
416.5\end{array}$ & $\begin{array}{l}0.992 \\
0.990 \\
0.987\end{array}$ & $\begin{array}{l}40.6 \\
28.9\end{array}$ & $\begin{array}{l}241.3 \\
362.0\end{array}$ & $\begin{array}{l}281.5 \\
362.0\end{array}$ & $\begin{array}{l}15.84 \\
16.1\end{array}$ & $\begin{array}{l}293 \\
56.1 \\
654\end{array}$ \\
\hline Guar gum & $\begin{array}{l}1.5 \% \\
175 \% \\
2.5 \%\end{array}$ & $\begin{array}{l}0.3 \\
0.89 \\
785\end{array}$ & $\begin{array}{l}5.46 \\
11.29 \\
33.57\end{array}$ & $\begin{array}{l}7.4 \\
7.5 \\
77\end{array}$ & $\begin{array}{l}13.5 \\
20.0 \\
4(1.0\end{array}$ & $\begin{array}{l}0.998 \\
0.997 \\
\text { 0) } 9196\end{array}$ & $\begin{array}{l}143.8 \\
41.7 \\
40.0\end{array}$ & $\begin{array}{l}160.9 \\
281.5 \\
52.31\end{array}$ & $\begin{array}{l}482.9 \\
563.0 \\
68.37\end{array}$ & $\begin{array}{l}4.67 \\
14.6 \\
29 \mathrm{~h}\end{array}$ & $\begin{array}{l}1.9 \\
118 \\
241\end{array}$ \\
\hline
\end{tabular}


The osmotic pressure data showed significant differences between the gels. The highest osmotic pressures were obtained with Carrageenan type RLV, having 171.8, 298.0 and $416.5 \mathrm{~m}-\mathrm{Osm}$ at $3.0 \%, 5.0 \%$ and $7.0 \%$ concentrations respectively. The lowest osmotic pressure was provided by Water Lock A-100, having 2.8, 7.0 and $11.5 \mathrm{~m}-\mathrm{Osm}$ at $0.3 \%, 0.5 \%$ and $0.7 \%$ concentrations respectively. Except Water Lock DD-223, all of the gels demonstrated a linear dependence of the osmotic pressure on the concentration, regardless of their physical-chemical differences (Figure 1). When the osmotic pressure differences of Carrageenan VV71P and RLV are compared, it is seen that the latter has an osmotic pressure 10 times higher than Carrageenan VV71P (Table II). The reason can be explained by the higher ionization potential of Carrageenan RLV. It has more $\left(-\mathrm{OSO}_{3}\right)$ groups than Carrageenan VV71P.

Rheological Characteristics of the gels. Figures $2 \mathrm{~A}$ and $\mathrm{B}$ are representative of the rheological behavior of the gels studied. They can be classified in two groups. Figure $2 \mathrm{~A}$ is an example of the rheological profiles of the first group, where the viscous modulus (G") increases with increasing stress. Carrageenan VV71P and RLV, Carbopol 971 and Water Lock DD-223 demonstrated the same behavior and were included in this group. Figure 2B illustrates rheological behavior of the second group. which included guar gum and Water Lock A-100. The viscous modulus $\left(G^{\prime \prime}\right)$ of those gels decreased with increasing stress. Their rheological profiles indicate a shear thinning behavior within 0.05-100 Pascal stress range.

In the first group of gels, there is an increase in the G" with increasing stress, whereas G" of the second group of gels decreases with increasing stress (Figure 2B). In the first group the critical stress $\left(\sigma_{c}\right)$, the point where the elastic modulus $\left(G^{\prime}\right)$ starts to 


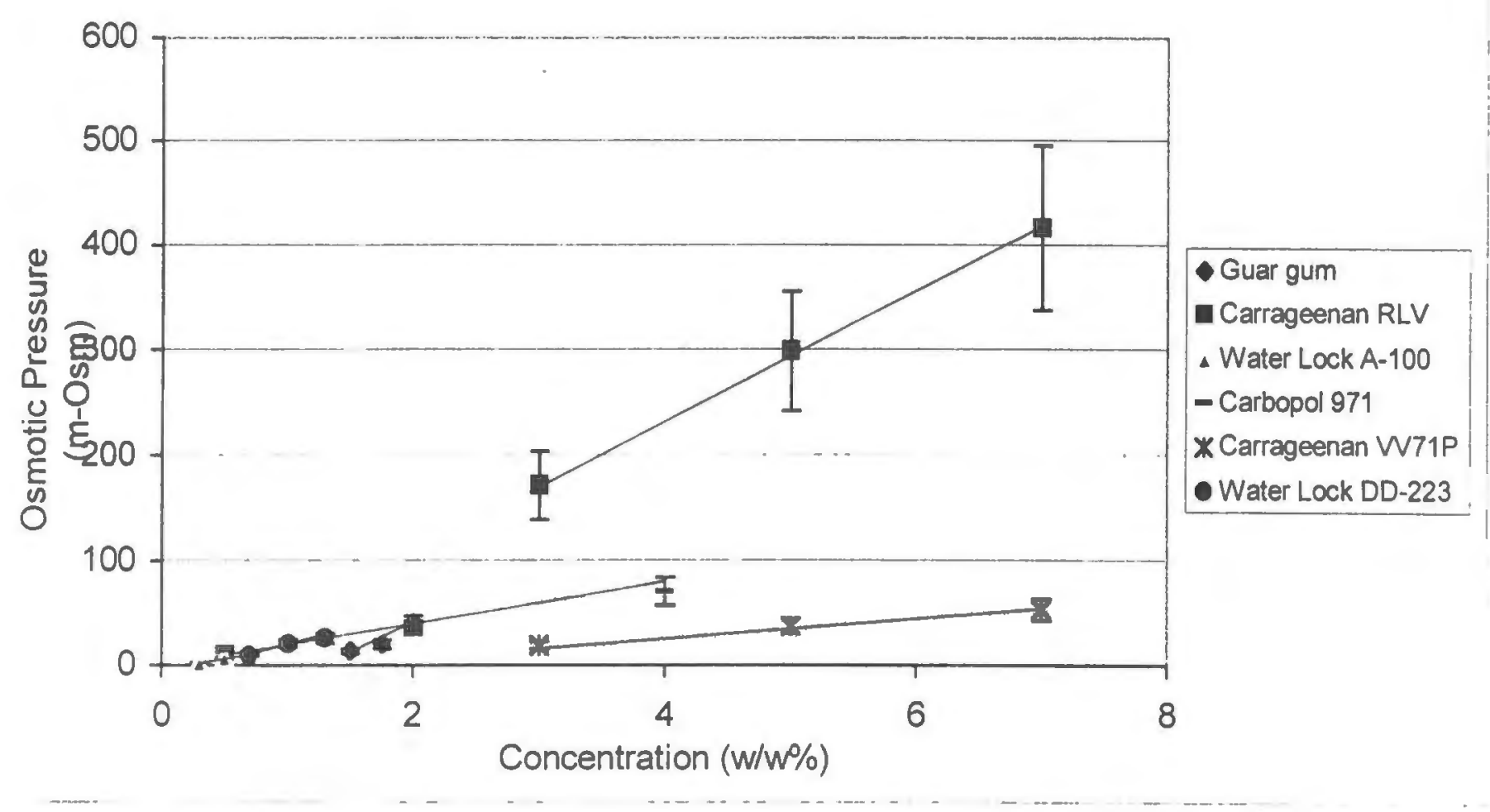

Figure 1. The Concentration Dependence of Osmotic Pressure for the gels studied 


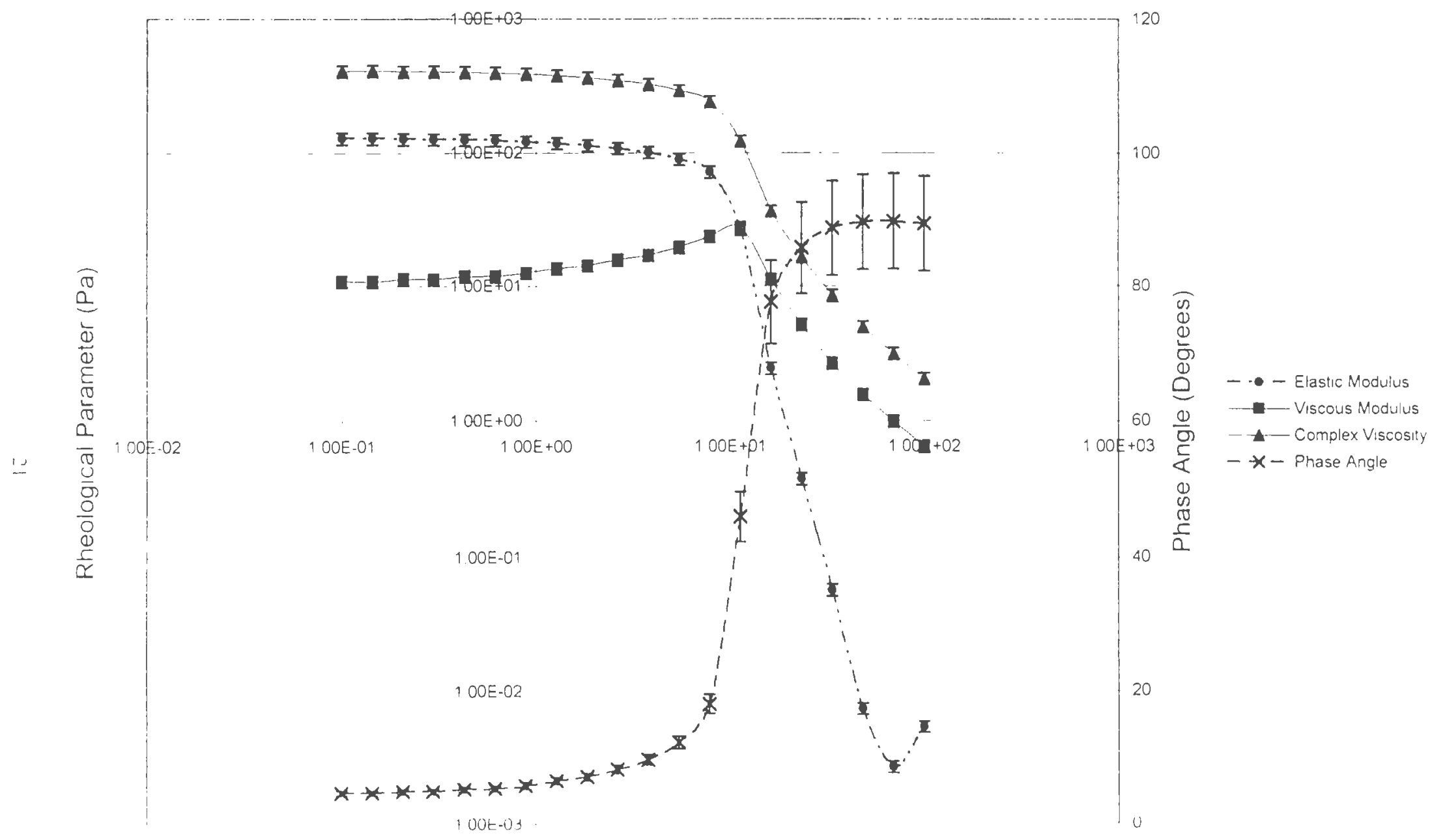

Figure $2 \mathrm{~A}$.

Shear Stress $(\mathrm{Pa})$

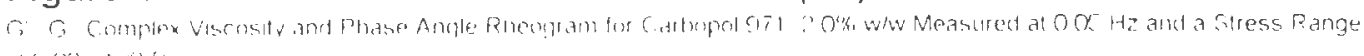

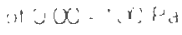




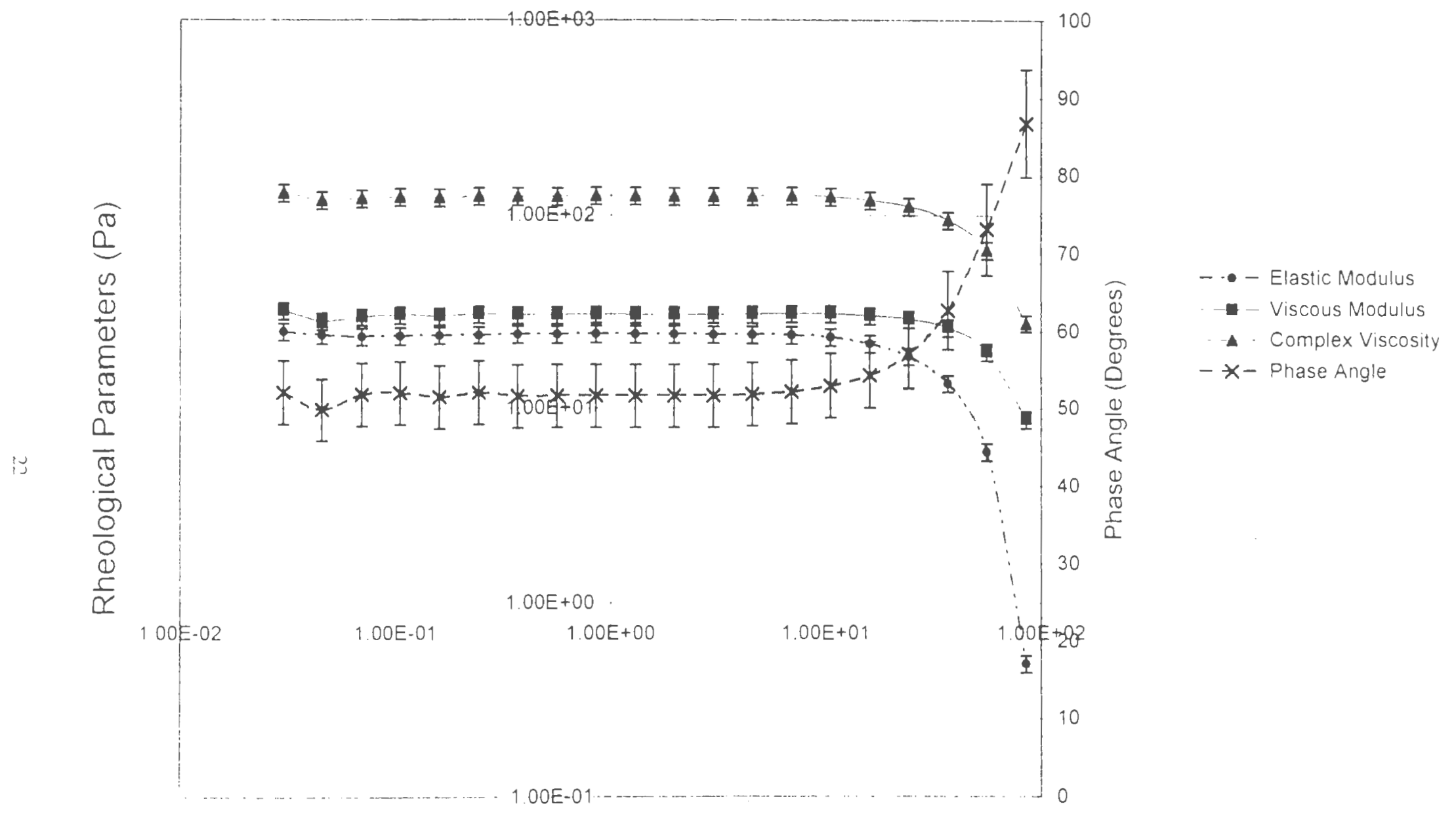

Figure 2B.

Shear Stress $(\mathrm{Pa})$

$G^{\prime \prime}, G^{\prime}$. Complex Viscosity and Phase Angle Rheogram for Guar gum $2.0 \% \mathrm{w} / \mathrm{W}$ Measured at $0.05 \mathrm{~Hz}$ and a Stress Range of $0.00-100 \mathrm{~Pa}$ 
dissipate, coincides with the maximum structural buildup in the viscous modulus (G"). Such behavior may indicate an increased entanglement of the molecules, resulting in rigid centers, which in turn may cause eventual breakage.

Table II also includes the critical stresses $\left(\sigma_{\mathrm{c}}\right)$ at which the elastic and the viscous moduli begin to diminish, indicating destruction of the microenvironment, disentanglement of the chains and breakage of the weak intermolecular bonds. The critical stresses for G' and G" are time dependant.

Microorganism growth observed. Figures $3 \mathrm{~A}$ and B demonstrate the growth pattern of the test microorganisms in Carbopol 971 and guar gum. The growth rates were calculated from the slopes of the profiles and are shown in Table III.

No information was available as to whether or how the selected microorganisms utilized the gels as a nutritional source. The availability of the functional groups that could be metabolized by the microorganisms was not known. Therefore, this fact could not be quantified and included in the statistical analysis.

Multiple regression analysis was used to seek the significance of the relationship of the growth rate with each variable shown in Table II. These variables were G" and G" at the linear region, the critical stress at $G^{\prime \prime}$ and $G^{\prime}$, the time at the critical stress at $G^{\prime \prime}$ and $\mathrm{G}^{\prime}$, the concentration and the osmotic pressure. Table IV demonstrates the relationship between the growth rate of each microorganism in all of the gels studied.

For $S$. aureus $\mathrm{R}^{2}=0.861$, adjusted $\mathrm{R}^{2}=0.737$ and $\mathrm{P}=0.004$, and for $E$. coli $\mathrm{R}^{2}=0.84$, adjusted $\mathrm{R}^{2}=0.698$ and $\mathrm{P}=0.008$. Tikere is a significant influence of all the variables studied, including the rheological parameters. 


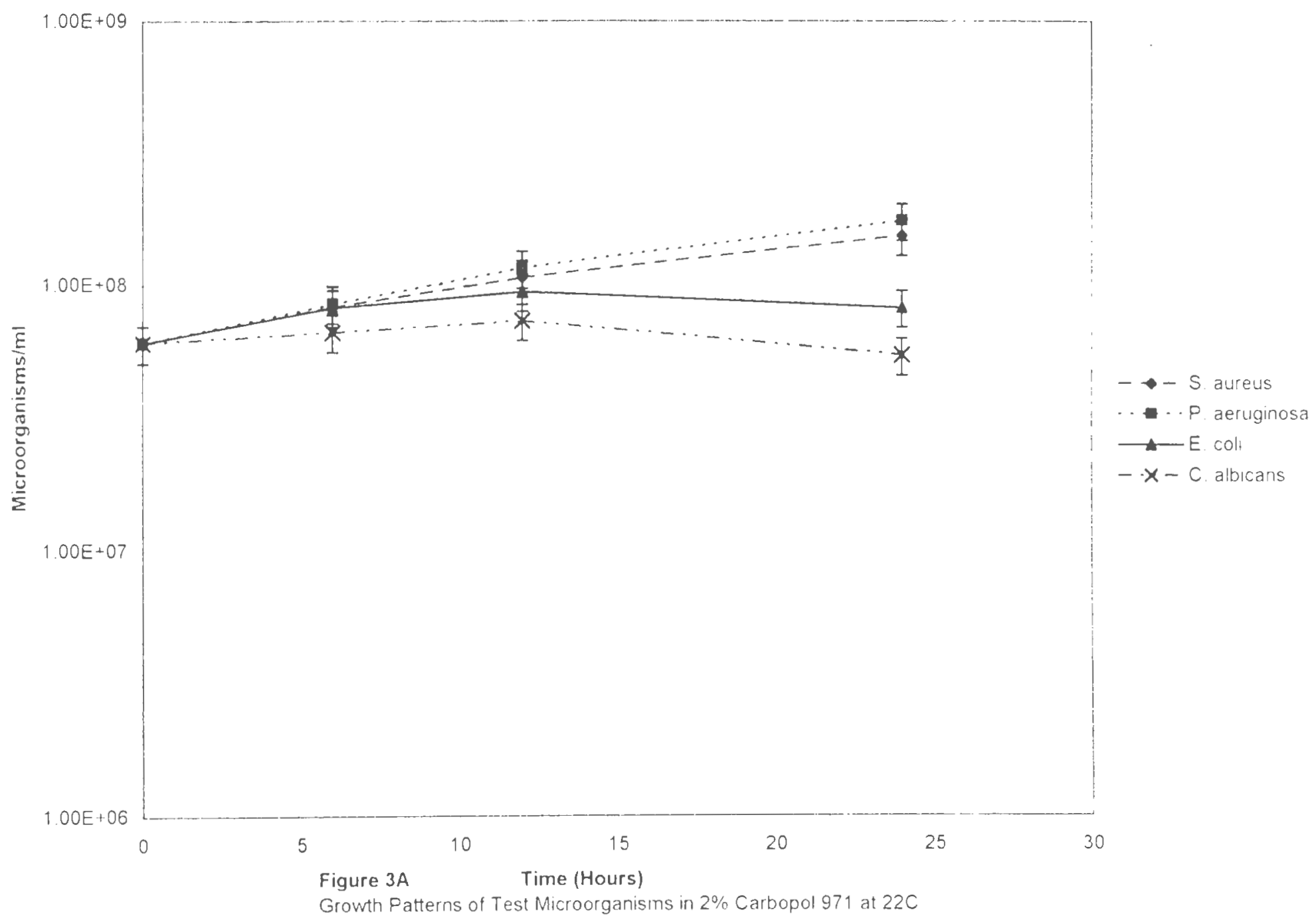



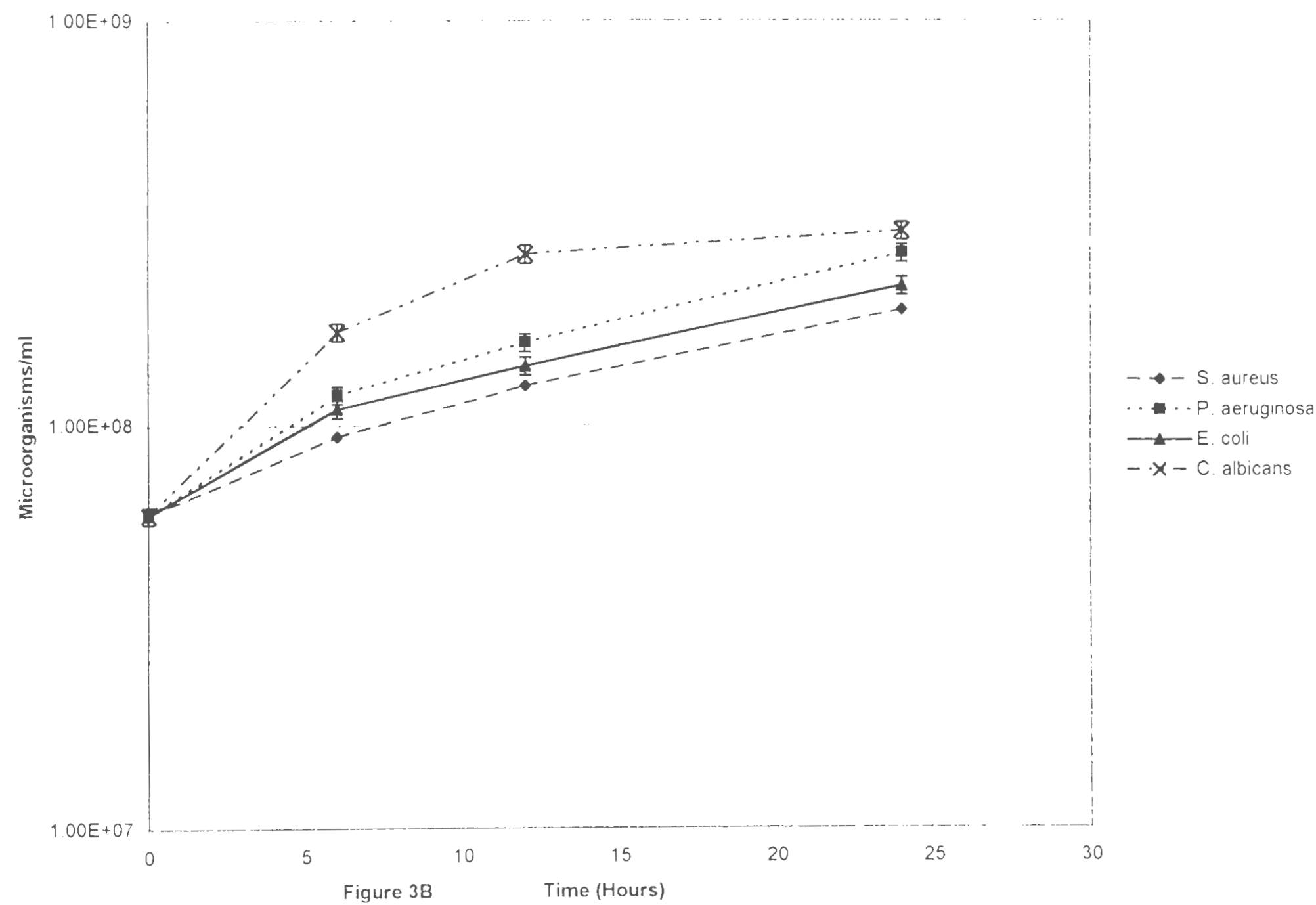

Growth Patterns of Test Microorganisms in $2 \%$ guar gum at $22 \mathrm{C}$ 
Table III. Growth Rates of the Test Microorganisms (hours / 1 log increase) at Three Different (iel Coneentrations. Higher Values of (irowth Rate Indicate Slower Growth.

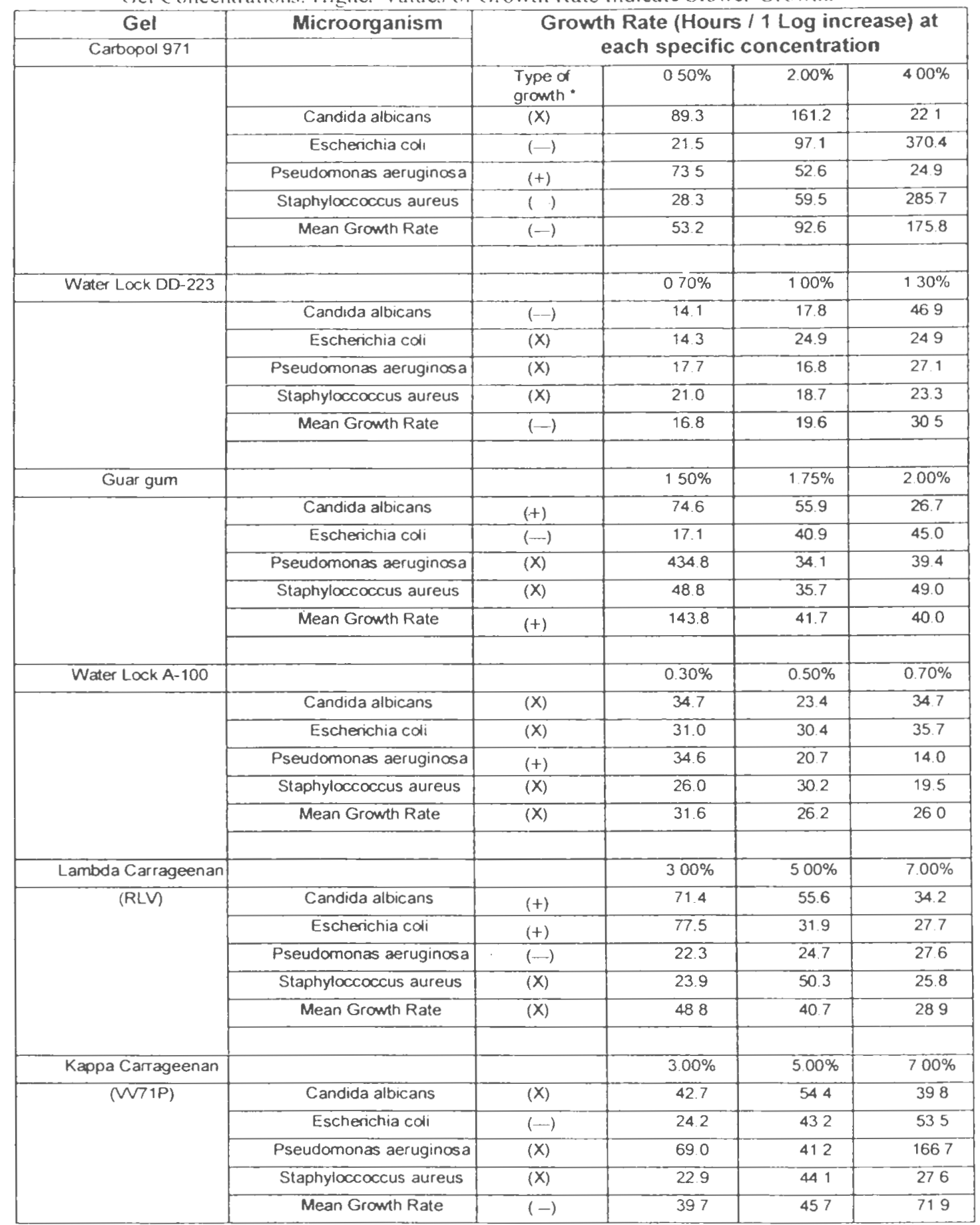

* $(+)$ indicates increasing growth rate with increasing concentration, $(-)$ indicates docreasing growth rate with increasing concentration, $(X)$ denotes no pattern of growth with concentration. 
Table IV. Statistical evaluation between the microorganism growth rate and the selected variables through multiple regression analysis $(n=8)$.

\begin{tabular}{|c|c|c|c|c|c|c|c|c|}
\hline \multirow[t]{2}{*}{ Predictor } & \multicolumn{2}{|c|}{ S. aureus } & \multicolumn{2}{|c|}{ E. coli } & \multicolumn{2}{|c|}{$\mathrm{P}$. aeruginosa } & \multicolumn{2}{|c|}{ C. albicans } \\
\hline & Coeff. & $P$ & Coeff. & $P$ & Coeff. & $P$ & Coeff. & $\mathrm{P}$ \\
\hline Constant & 35.08 & 0.35 & 67.63 & 0.22 & 5.1 & 0.96 & 73.12 & 0.16 \\
\hline Concentration & 2309 & 0.07 & 3191 & 0.08 & -518 & 0.88 & 363 & 0.82 \\
\hline Time at $G^{\prime \prime} \sigma_{c}$ & -0.17 & 0.19 & -0.09 & 0.61 & -1.01 & 0.02 & -0.17 & 0.30 \\
\hline Time at $G^{\prime} \sigma_{c}$ & 0.05 & 0.71 & -0.10 & 0.62 & 0.91 & 0.04 & 0.06 & 0.72 \\
\hline $\mathrm{G}^{\prime \prime}$ linear & 0.22 & 0.49 & 0.33 & 0.47 & -0.26 & 0.78 & -0.41 & 0.34 \\
\hline $\mathrm{G}^{\prime}$ linear & -0.08 & 0.14 & -0.11 & 0.16 & 0.06 & 0.69 & 0.07 & 0.36 \\
\hline$\sigma_{c}$ at $G^{\prime \prime}$ & 8.69 & 0.08 & 10.20 & 0.13 & 7.60 & 0.55 & -1.99 & 0.74 \\
\hline$\sigma_{\mathrm{c}}$ at $\mathrm{G}^{\prime}$ & -1.43 & 0.57 & -1.01 & 0.77 & -4.67 & 0.52 & 1.09 & 0.74 \\
\hline $\begin{array}{l}\text { Osmotic } \\
\text { pressure }\end{array}$ & -0.30 & 0.16 & -0.46 & 0.13 & 0.19 & 0.73 & -0.04 & 0.87 \\
\hline $\mathrm{P}$ & & & & & & & & \\
\hline $\mathrm{R}^{2}$ & & & & & & & & \\
\hline Adjusted $\mathrm{R}^{2}$ & & & & & & & & \\
\hline
\end{tabular}


P. aeruginosa, $\mathrm{R}^{2}=0.574$. adjusted $\mathrm{R}^{2}=0.195$ and $\mathrm{P}=0.274$, as well as $C$. albicans, $\mathrm{R}^{2}=0.239$, adjusted $\mathrm{R}^{2}=0.000$ and $\mathrm{P}=0.921$ demonstrated a poor model.

In order to determine the degree of contribution of the variables, two more statistical analysis were applied on the systems. Best subset analysis provided key information as to which subset of variables may provide the best correlating model. Stepwise regression analysis was also used to include or discard variables in the model according to their influence. First the $95 \%$ confidence level $(\mathrm{P}=0.05)$ was accepted, and the models were selected based on their adjusted $\mathrm{R}^{2}$.

An example of the selection and use of the statistical method is show for E. coli. In Table V.A the use of all the variables to explain the growth was found significant $(\mathrm{P}=0.008)$. The significance was improved further by the use of a stepwise regression analysis $\left(P=0.000, R 2=0.754\right.$, adjusted $\left.R^{2}=0.701\right)$, Table V.B. But the best subset analysis allowed us to further improve the model with an $R^{2}$ of 0.835 , adjusted $R^{2}=0.744$ and $\mathrm{P}=0.001$ (Table V.C), therefore, because of the improvement of the statistical parameters, the model selected by the best subset analysis was accepted.

For all the microorganisms used the three tests were used as detailed in Table VA, B, and C. Additional data is given in Appendix 2. The following models best describe the contributions of the factors studied (Table II) on the growth rate of S. aureus, E. coli and $P$. aeruginosa. No model was found suitable to represent $C$. albicans.

$(S$. aureus $) \mathrm{GR}=54.1+2188^{*} \mathrm{C}-0.171^{*} \mathrm{G}$ ' $\mathrm{T}-0.0451^{*} \mathrm{G} ' \mathrm{~L}+6.36^{*} \mathrm{G}$ 'C $0.2792 * \mathrm{OP}$

$\mathrm{R}^{2}=0.85$, adjusted $\mathrm{R}^{2}=0.788, \mathrm{P}=0.000$ 
Table V Selection of the best model to represent the growth rate of E. coli Table V.A Regression Analysis using all variables for E. coli

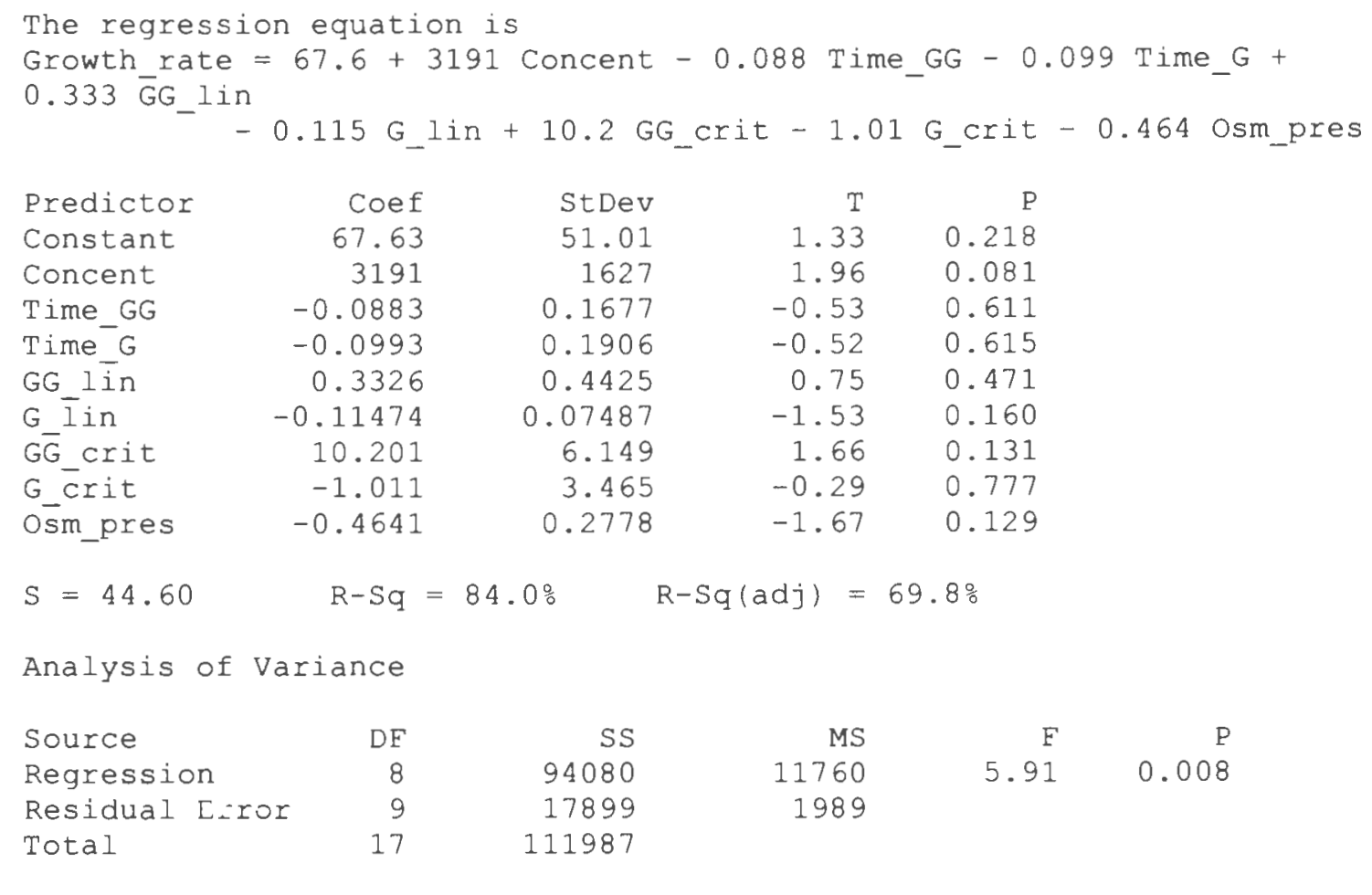

Table V.B Regression Analysis using stepwise regresion analysis for $E$. coli

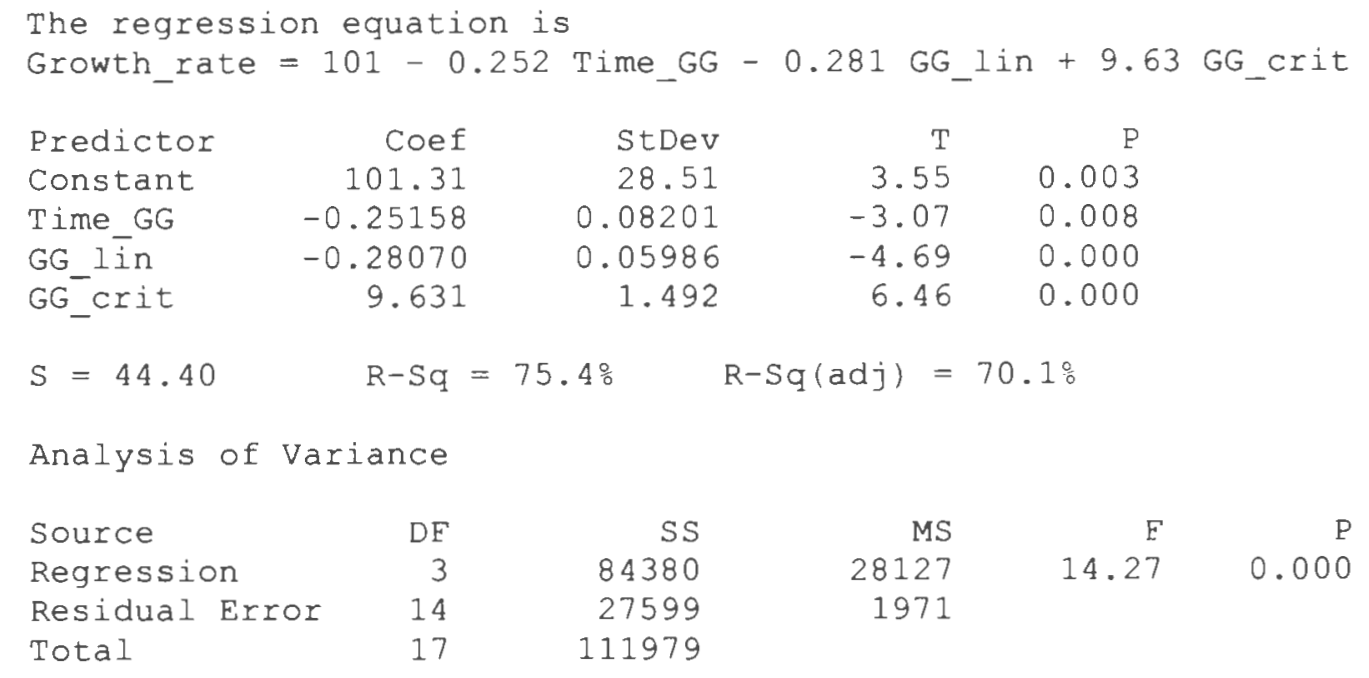




\section{Table V.C Regression Analysis using best subset analysis for $E$. coli}

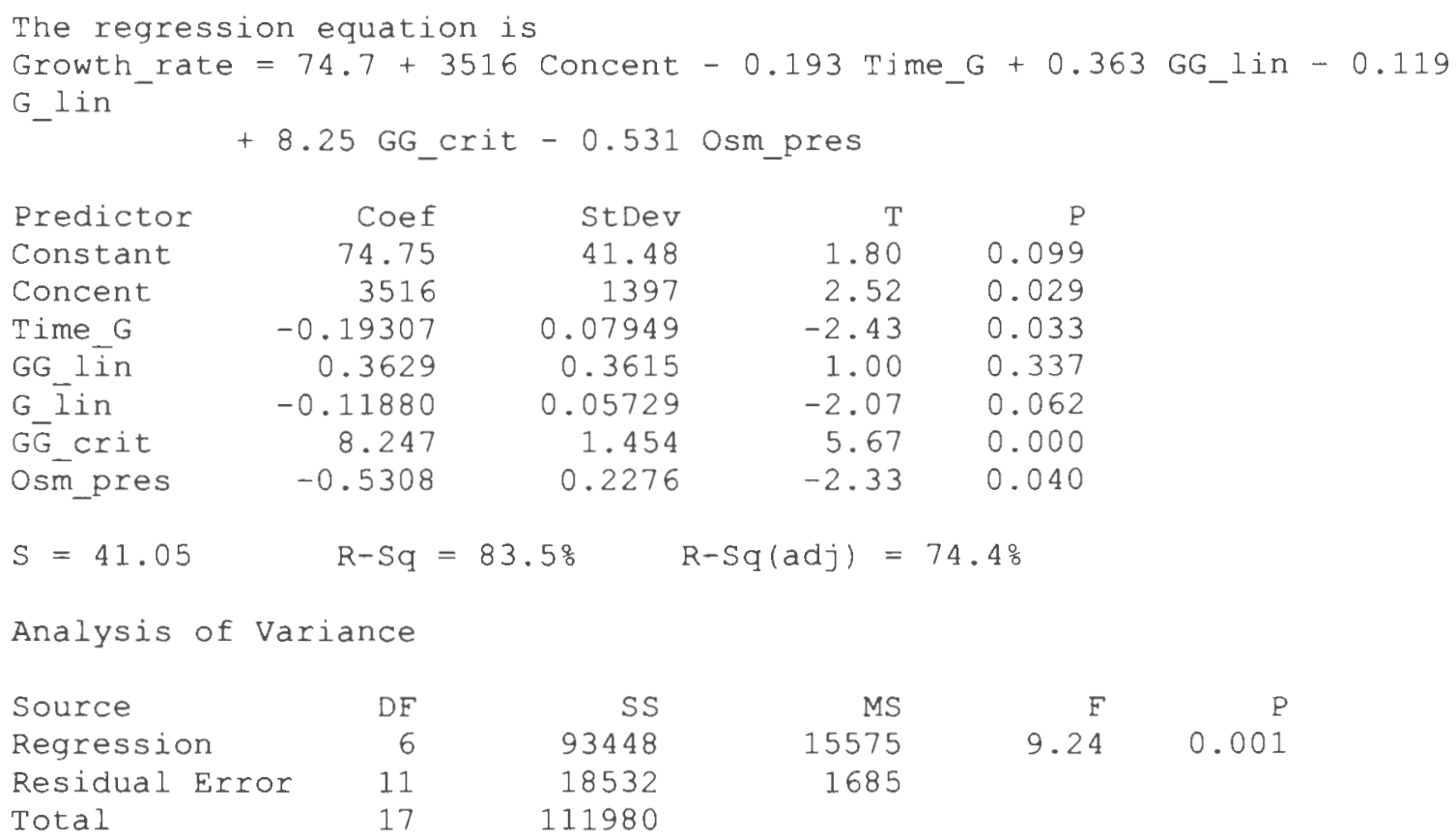


(E. coli) $\mathrm{GR}=74.7+3516^{*} \mathrm{C}-0.193^{*} \mathrm{G}^{\prime} \mathrm{T}+0.363^{*} \mathrm{G}^{\prime \prime} \mathrm{L}+0.119^{*} \mathrm{G}^{\prime} \mathrm{L}+8.24^{*} \mathrm{G}^{\prime \prime} \mathrm{C}-$

$0.53 * \mathrm{OP}$

$\mathrm{R}^{2}=0.835$, adjusted $\mathrm{R}^{2}=0.744, \mathrm{P}=0.001$

$(P$. aerugunosa $) \quad \mathrm{GR}=48.0-0.859^{*} \mathrm{G}$ ' $\mathrm{T}+0.655^{*} \mathrm{G}{ }^{\prime} \mathrm{T}+$

$0.0323 * \mathrm{G}^{\prime} \mathrm{L}$

$\mathrm{R}^{2}=0.52$, adjusted $\mathrm{R}^{2}=0.417, \mathrm{P}=0.014$

Where GR is the growth rate of the respective microorganism, $\mathrm{C}$ is the concentration of the gel, G"L is $G^{\prime \prime}$ at the linear region, $G^{\prime} L$ is $G^{\prime}$ at the linear region, $G^{\prime \prime} C$ is the critical stress at $G^{\prime \prime}, G^{\prime} C$ is the critical stress at $G^{\prime}, G^{\prime \prime} T$ is the time of the critical stress at $G^{\prime \prime}, G^{\prime} T$ is the time of the critical stress at $\mathrm{G}^{\prime}$ and $\mathrm{OP}$ is the osmotic pressure of the gel at the given concentration.

Table VI further summarizes the contributions of each variable studied. Except for $C$. albicans the elasticity of the gels appears to be the commonly shared characteristic that affects the growth rate of the microorganisms studied, $S$. aureus, E. coli and $P$. aeruginosa. The viscosity of the system at critical shear appears to be a significant factor, so does the time at $G^{\prime \prime} \sigma_{c}$ and time at $G^{\prime} \sigma_{c}$. The elastic strength of the gels $\left(G^{\prime} \sigma_{c}\right)$ is not considered to be any influence on the growth rate models. Although not as influential as the concentration of the gels, the osmotic pressure appears to be a significant factor. 
Table VI. Statistical Test of the Significance of the Variables in the Models Used to Relate the Rheological Parameters and Bacterial Growth Rate.

Gel Property

\begin{tabular}{|c|c|c|c|c|c|c|c|c|}
\hline Bacterial Growth & Concentrati & Time at G" & Time at $\mathrm{G}^{\prime}$ & $G^{\prime \prime}$ at the & $\mathrm{G}^{\prime}$ at the & $G^{\prime \prime} \sigma_{c}$ & $\mathrm{G}^{\prime} \sigma_{c}(\mathrm{~Pa})$ & Osmotic \\
\hline \multirow[t]{2}{*}{ Rate } & on $(w / w \%)$ & $\sigma_{c}(\sec )$. & $\sigma_{c}(\mathrm{sec})$ & Linear & Linear & $(\mathrm{Pa})$ & & Pressure \\
\hline & & & & Region $(\mathrm{Pa})$ & Region (Pa) & & & $(\mathrm{m}-\mathrm{Osm})$ \\
\hline C. albicans & $\overrightarrow{(N S)}$ & (NS) & (NS) & (NS) & $(\mathrm{NS})$ & (NS) & $(\mathrm{NS})$ & (NS) \\
\hline E. coli (Eq. 3) & $0.029\left(2^{\text {nd }}\right)$ & (NS) & $0.033\left(3^{\text {rd }}\right)$ & $0.337^{(\mathrm{NS})}$ & $0.062^{(\mathrm{NS})}$ & $0.000\left(1^{\mathrm{st}}\right)$ & (NS) & $0.040\left(4^{\text {ih }}\right)$ \\
\hline P. aeruginosa & $(\mathrm{NS})$ & $0.002\left(1^{\mathrm{st}}\right)$ & $0.006\left(2^{\text {nd }}\right)$ & (NS) & $0.020\left(3^{\text {rd }}\right)$ & (NS) & $(\mathrm{NS})$ & (NS) \\
\hline $\begin{array}{l}\text { S. aureus } \\
\text { (Eq. } 5 \text { ) }\end{array}$ & $0.030\left(4^{\text {th }}\right)$ & $0.007\left(3^{\text {rd }}\right)$ & (NS) & (NS) & $0.000\left(1^{\mathrm{st}}\right)$ & $0.000\left(2^{\text {nd }}\right)$ & (NS) & $0.073^{(\mathrm{NSS})}$ \\
\hline
\end{tabular}


The negative and positive dependence on the growth rate by the concentration was also analyzed statistically. The cases where the growth rate decreased with increasing concentration seemed to fit the models with great significance $\left(\mathrm{R}^{2}=0.837\right.$, $\mathrm{P}=0.000$ ). On the other hand, the cases where the growth rate increases with increasing concentration do not fit the proposed models $\left(\mathrm{R}^{2}=0.357, \mathrm{P}=0.748\right)$. The mean growth rates observed in Table III show that the gels with more solid properties such as Carbopol 971, Water Lock DD-223 and Carrageenan VV71P provided decreasing growth rates at increasing concentrations. This observation verifies the effect of elasticity. The reason why P. aeruginosa and C. albicans have not demonstrated rheology-dependent growth rate may be explained by the strong metabolizing ability of $P$. aeruginosa, which can even metabolize aromatic carbohydrates, and the extremely large size of $C$. albicans (more than 100 times larger than the rest of the microorganisms).

Overall, this study demonstrated that the rheological properties have some influence on the growth rate of some microorganisms, regardless of the chemical structure, nature and varying concentration of the gels studied. 


\section{References}

Atsumi, T., Maekawa, Y., Yamada, T., Kawagishi, I., Inae. Y. and Hamma, M., Effect of viscosity on swimming by the lateral and polar flagella of Vibrio alginoliticus, Journal of Bacteriology, 178:5024 - 5026, (1996)

Ballesteros, S.A., Chirife, J. and Bozzini, J., Specific solute effects on Staphylococcus aureus cells subjected to reduced water activity, International Journal of Food Microbiology, 20:51 - 66, (1993)

Clarke, P. and Richmond, C., Genetics and biochemistry of Pseudomonas, John Wiley and Sons, NY, 1975

Cohn, J., The Staphylococci, Wiley Interscience, NY, 1972

Csonka, L.N., Physiological and genetic responses of bacteria to osmotic stress, Microbiological Reviews, 53:121 - 147, (1989)

D.S. Orth, Establishing cosmetic preservative efficacy by use of D-values, Journal of the Society of Cosmetic Chemists. 31: 165-172, (1980)

Eisman, P., Cooper, J. and Jaconia, P., Influence of gum tragacanth on the bacteria activity of preservatives, Journal of The American Pharmaceutical Association, $46: 144-147,(1957)$

Ferrero, R.L. and Lee, A., Motility of Campylobacter jejuni in viscous environments: comparison with rod shaped bacteria, Journal of General Microbiology, 134:53 - 59, (1988)

Greenberg, E.P., Canale-Parola, E., Relationship between cell coiling and motility of spirochetes in viscous environments, Journal of Bacteriology, $131: 960$ - 969, (1977) 
Guiselly, K.B., Chemical and physical properties of algal polysaccharides used for cell immobilization, Enzyme Microbial Technology, 11:706 - 716, (1989)

Kets, E.P., de Bont, J.A.M. and Heipieper, H., Physiological responses of Pseudomonas putida 512 subjected to reduced water activity, Microbiology Lelters, 139:133 - 137, (1996)

Lawrence, J.R., Korber, D.R. and Caldwell, D.E., Behavioral analysis of Vibrio parahaemolyticus variants in high and low viscosity microenvironments by use of digital image processing, Journal of Bacteriology, 174:5732 - 5739, (1992)

McCarthy, T.J. and Myburgh, J.A., The effect of tragacanth gel on preservative activity, Pharmaceutisch Weekblad, 109:265 - 268, (1974)

McFarland, J., The Nephelometer, Journal of the American Medical Association, 49:1176, 1907

Niedhart, F., E. coli and Salmonella typimurin, cellular and molecular biology, American Society for Microbiology, Washington, 1987

Odds, F.C., Candida and Candidiosis, 2nd ed. Bailliere Tindall, Toronto, Ca., 1988

Schlegel, H., General microbiology, 2nd ed., Cambridge University Press, 1993

Stecchini, M.L., Torre, M., Sorais, I., Soro, O., Messina, M. and Maltini, E., Influence of structural properties and kinetic constraints on Bacillus cereus growth, Applied and Environmental Microbiology, 64:1075 - 1078, (1998)

Yanagi and Onishi G., Assimilation of selected cosmetic ingredients by microorganisms, Journal of the Society of Cosmetic Chemists. 22:851, (1971) 
Appendix 1

(Growth Rate Curves) 


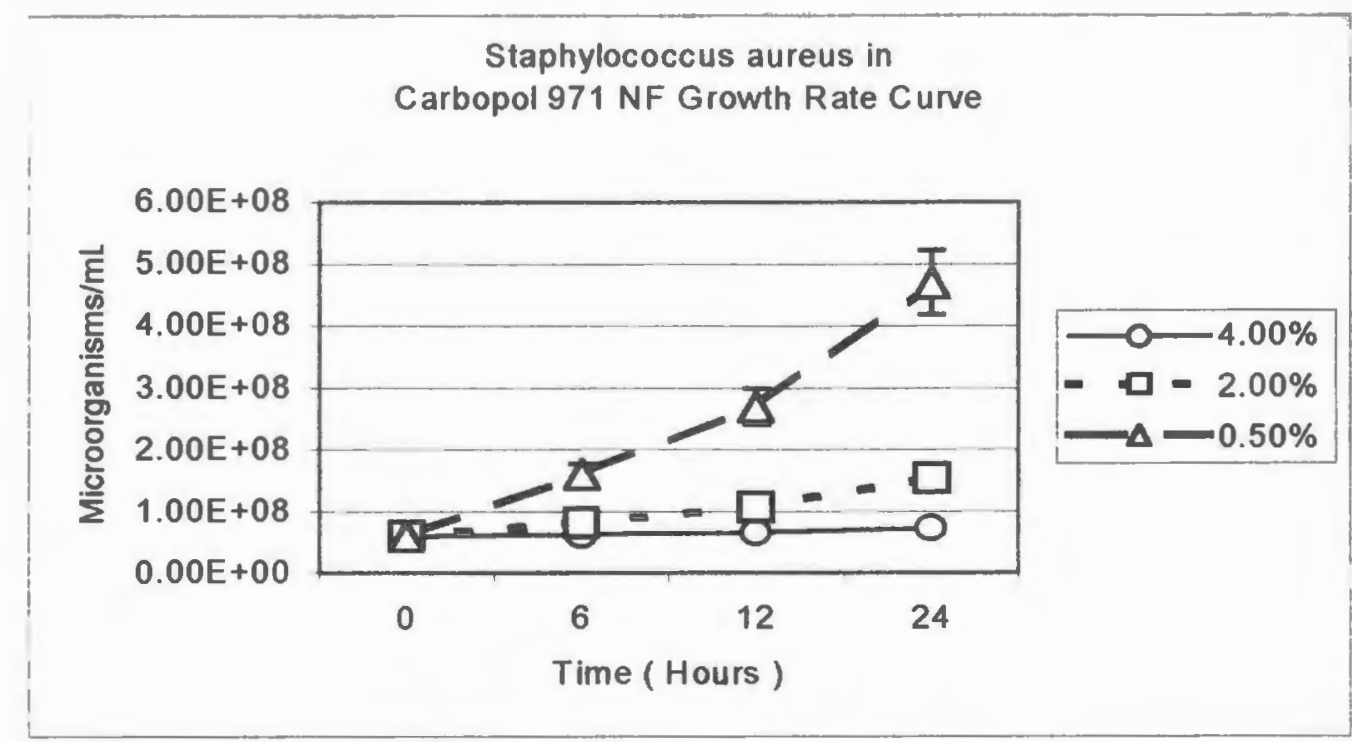

a)

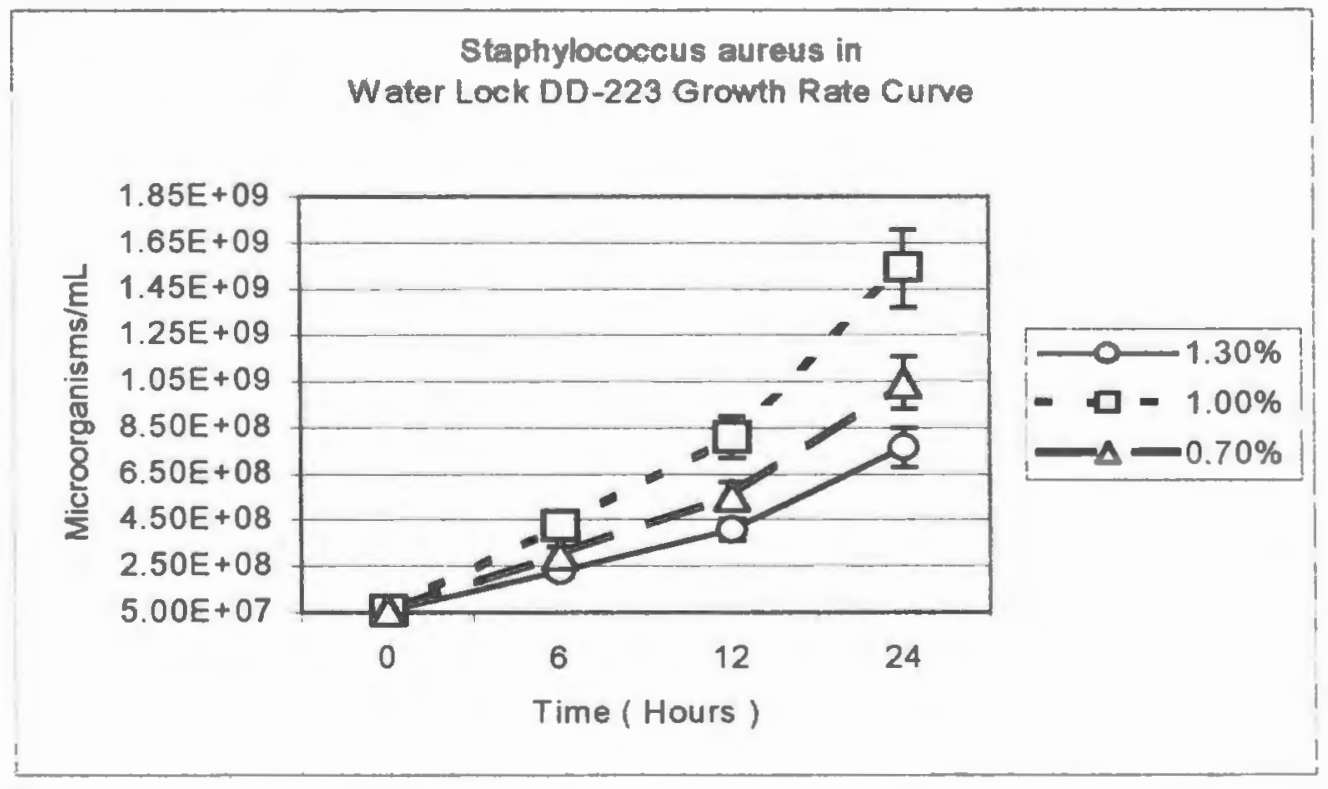

b)

Figure A1.1 Bacterial growth rate observed for S. aureus in a) Carbopol 971, b) Water Lock DD-223 


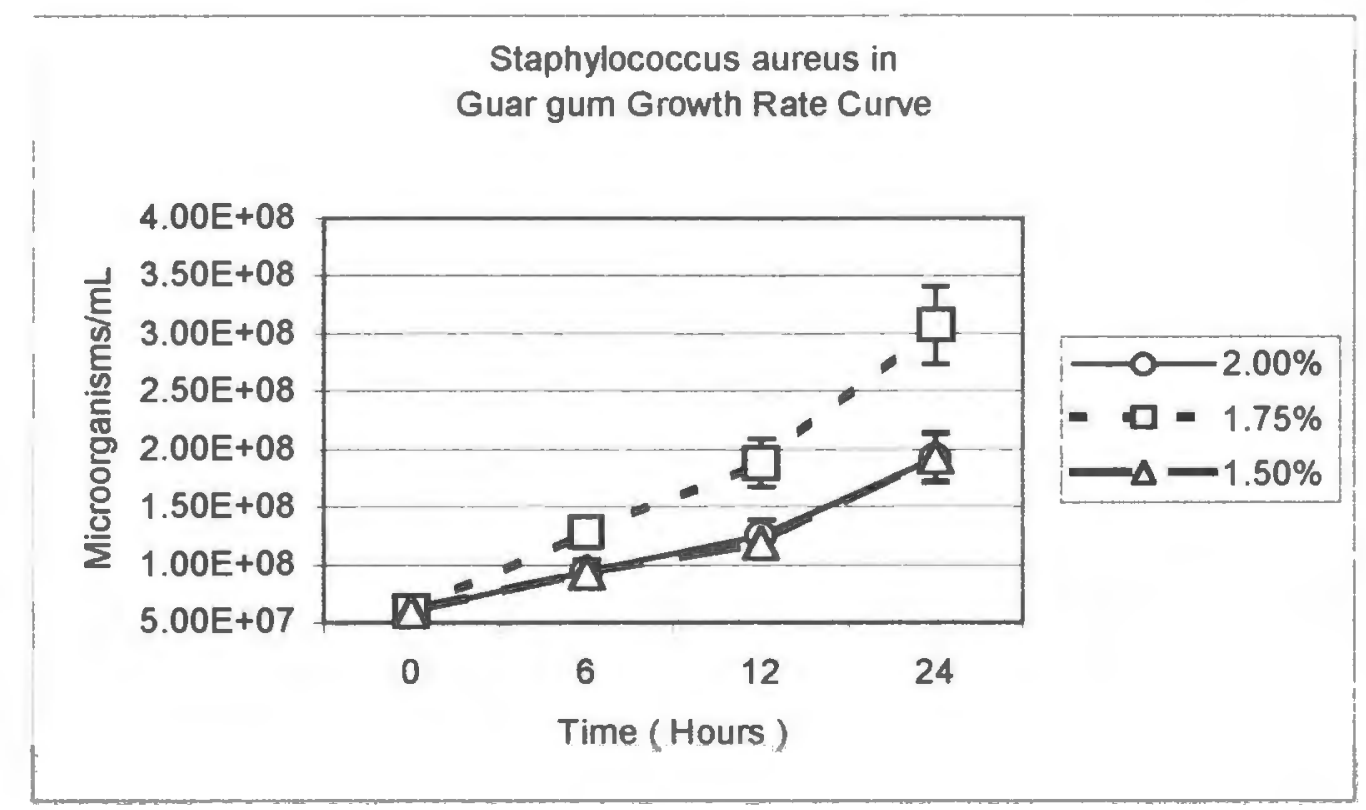

a)

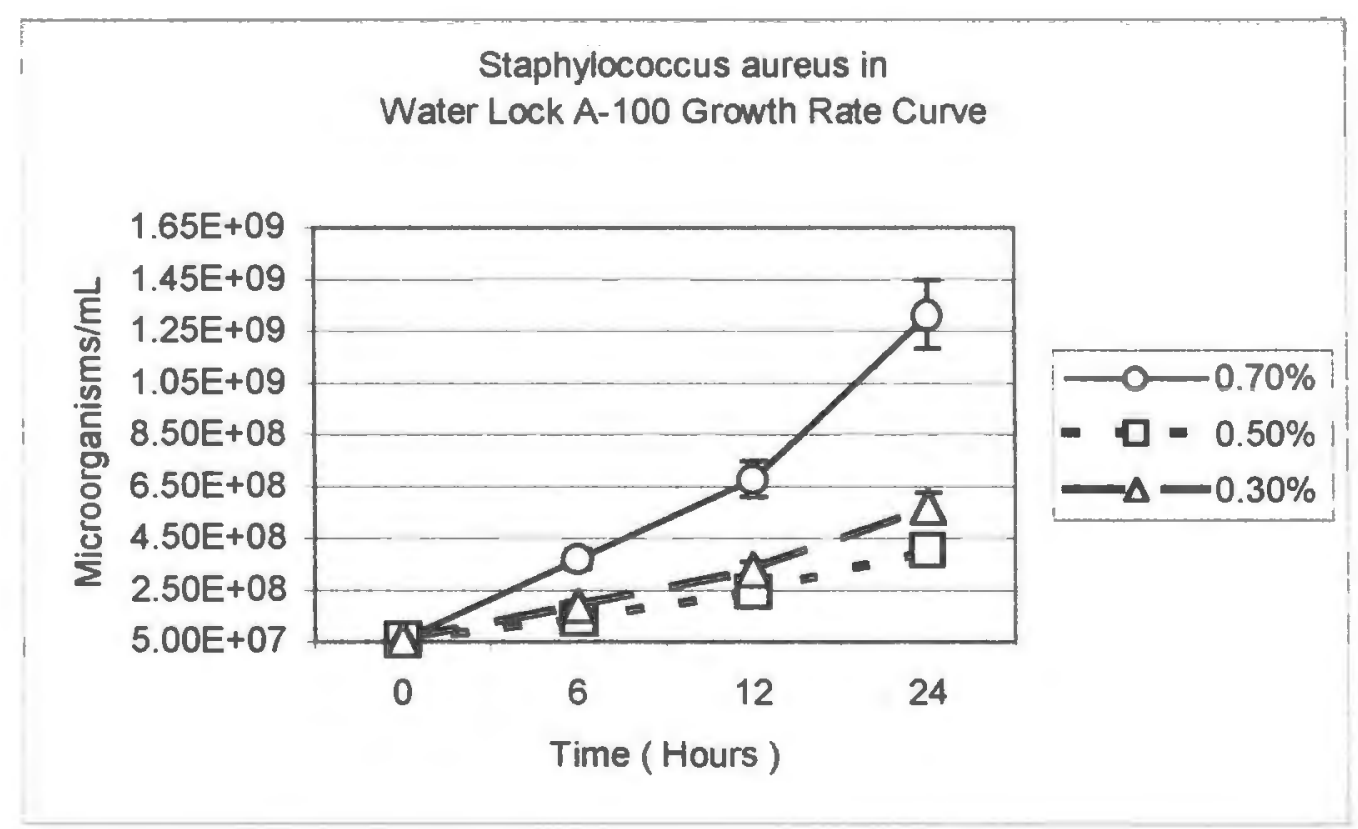

b)

Figure A1.2 Bacterial growth rate observed for $S$. cureus in a) Guar gum, b) Water Lock A-100 


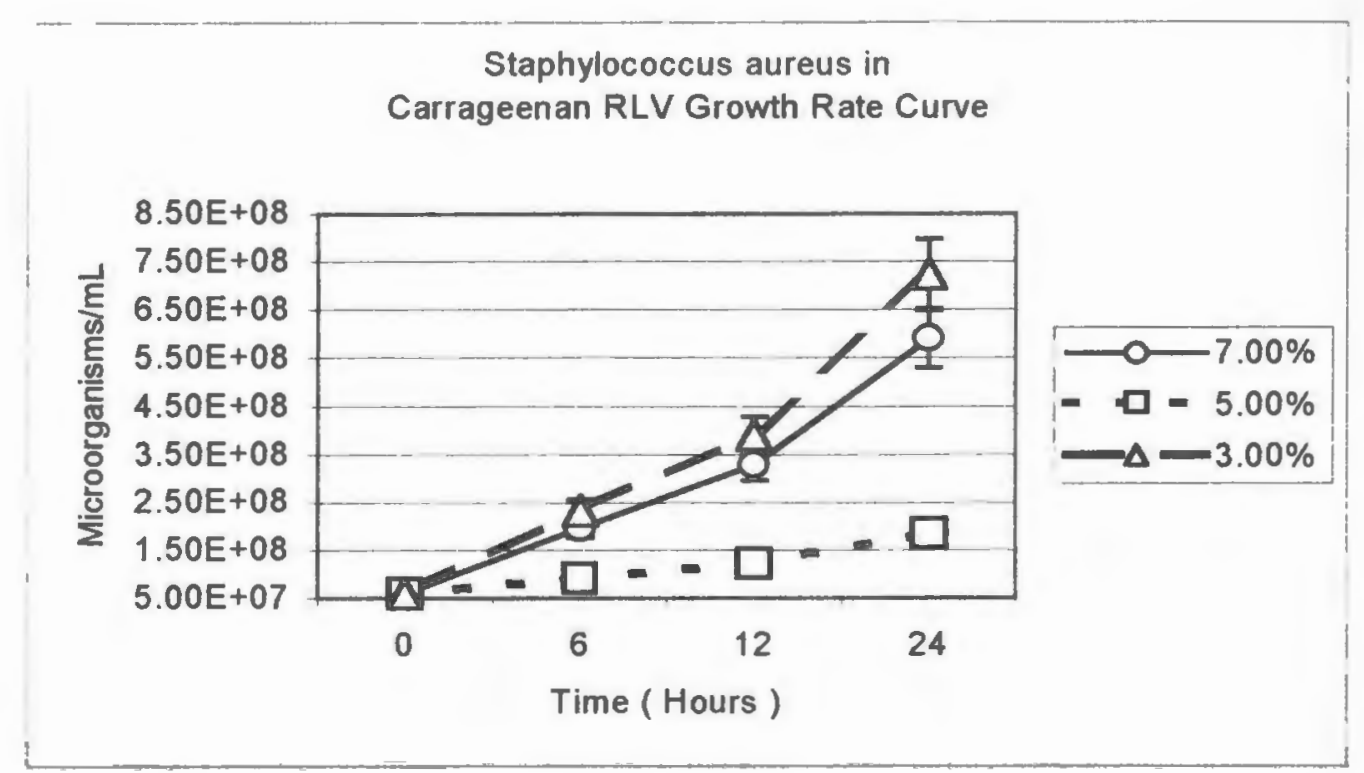

a)

\section{Staphylococcus aureus in \\ Carrageenan W71P Growth Rate Curve}

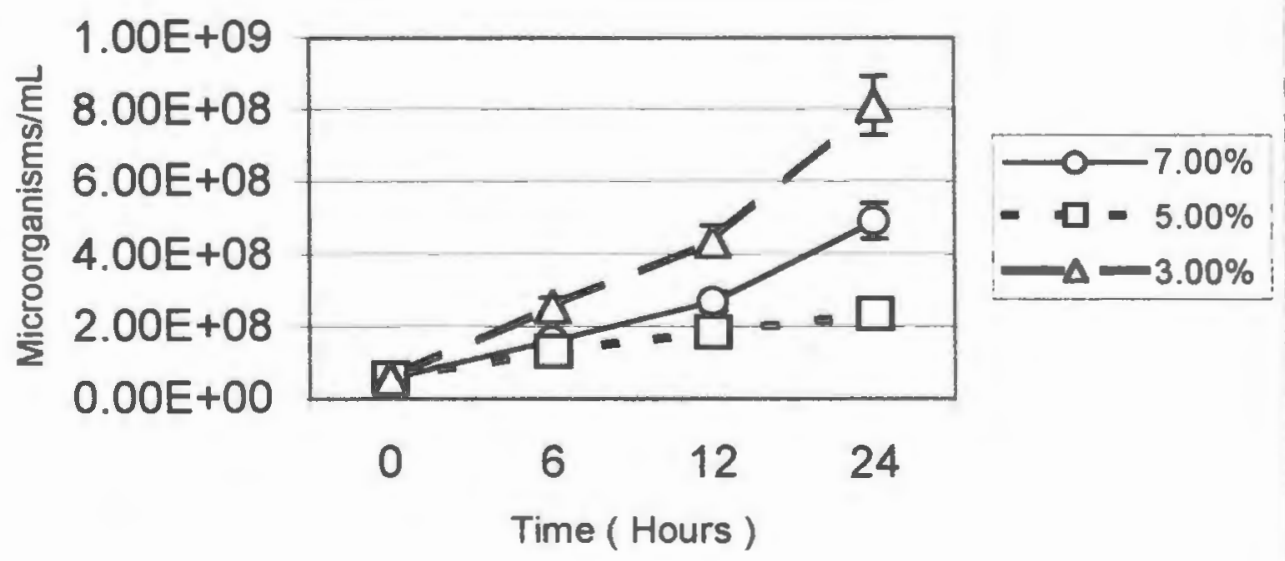

b)

Figure A1.3 Bacterial growth rate observed for $S$. aureus in a) Carrageenan RLV, b) Carrageenan VV71P 
Escherichia coli in

Carbopol 971 NF Growth Rate Curve

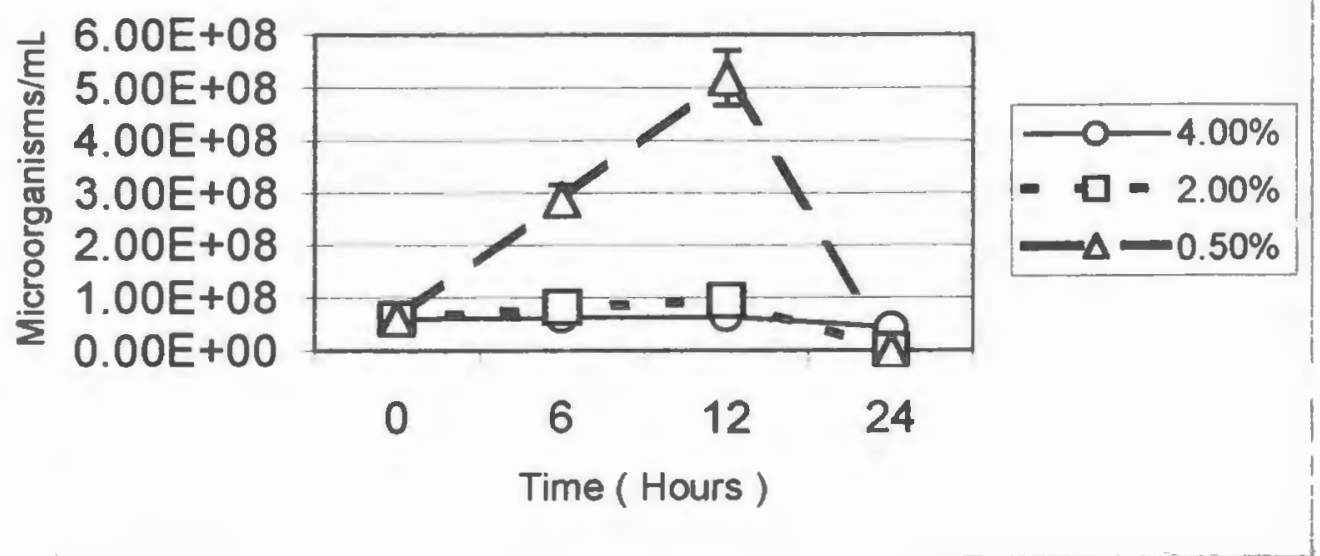

a)

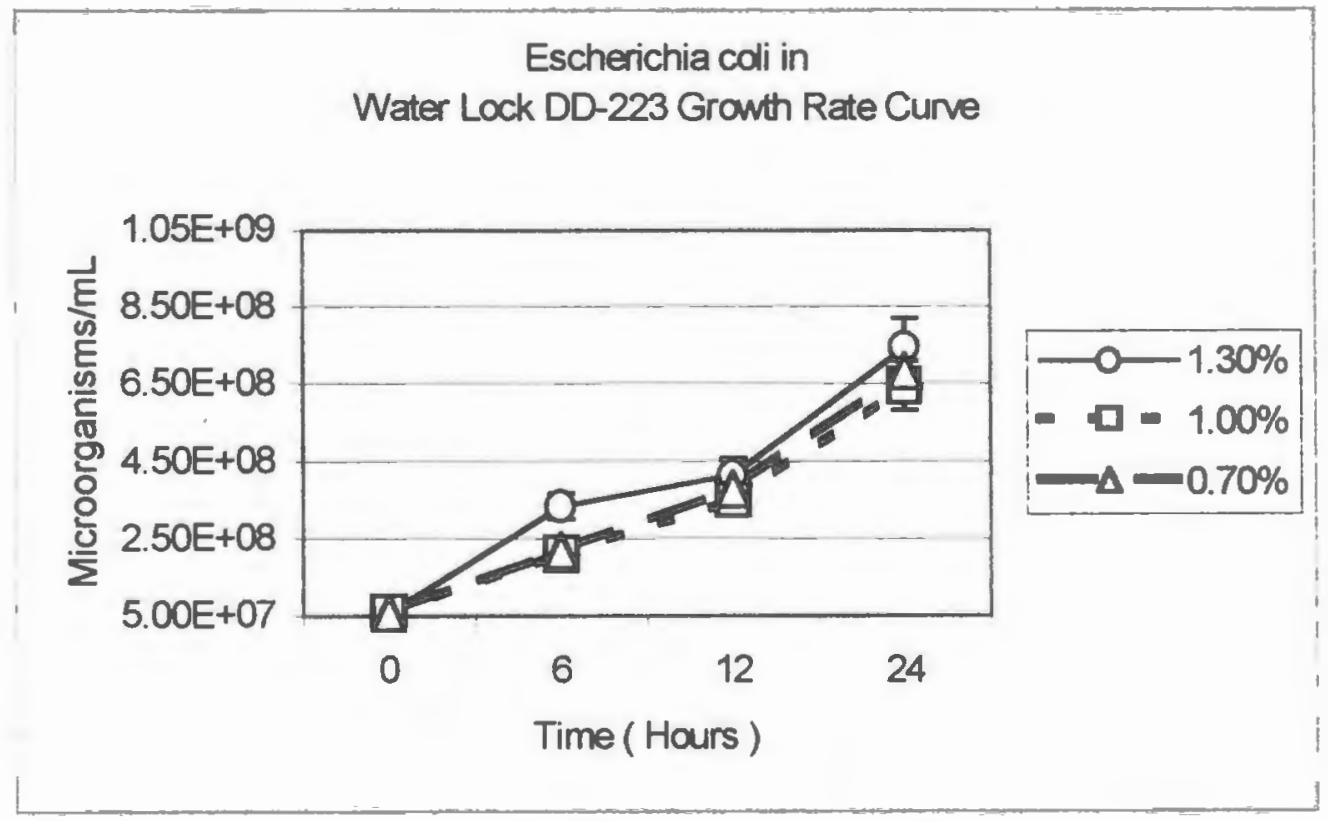

b)

Figure A1.4 Bacterial growth rate observed for E. coli in a) Carbopol 971, b) Water Lock DD-223 


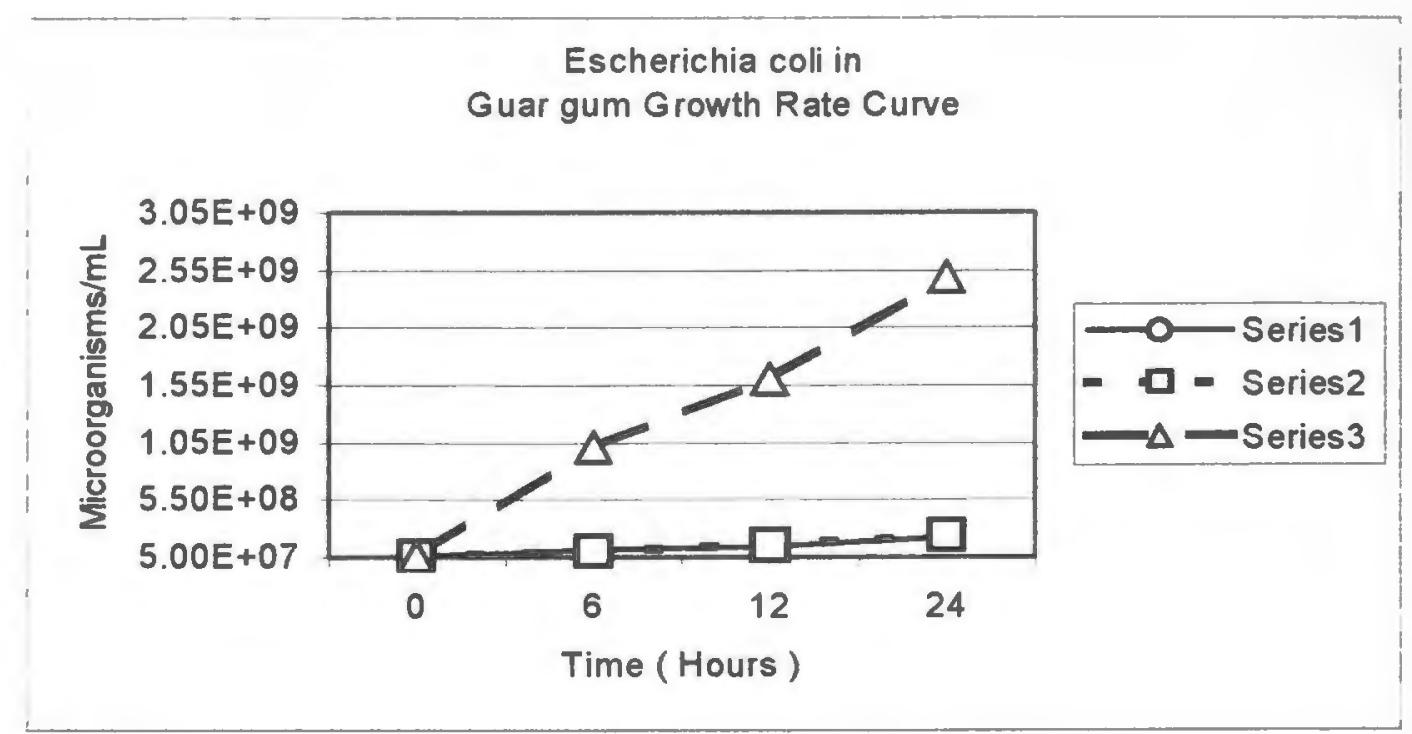

a)

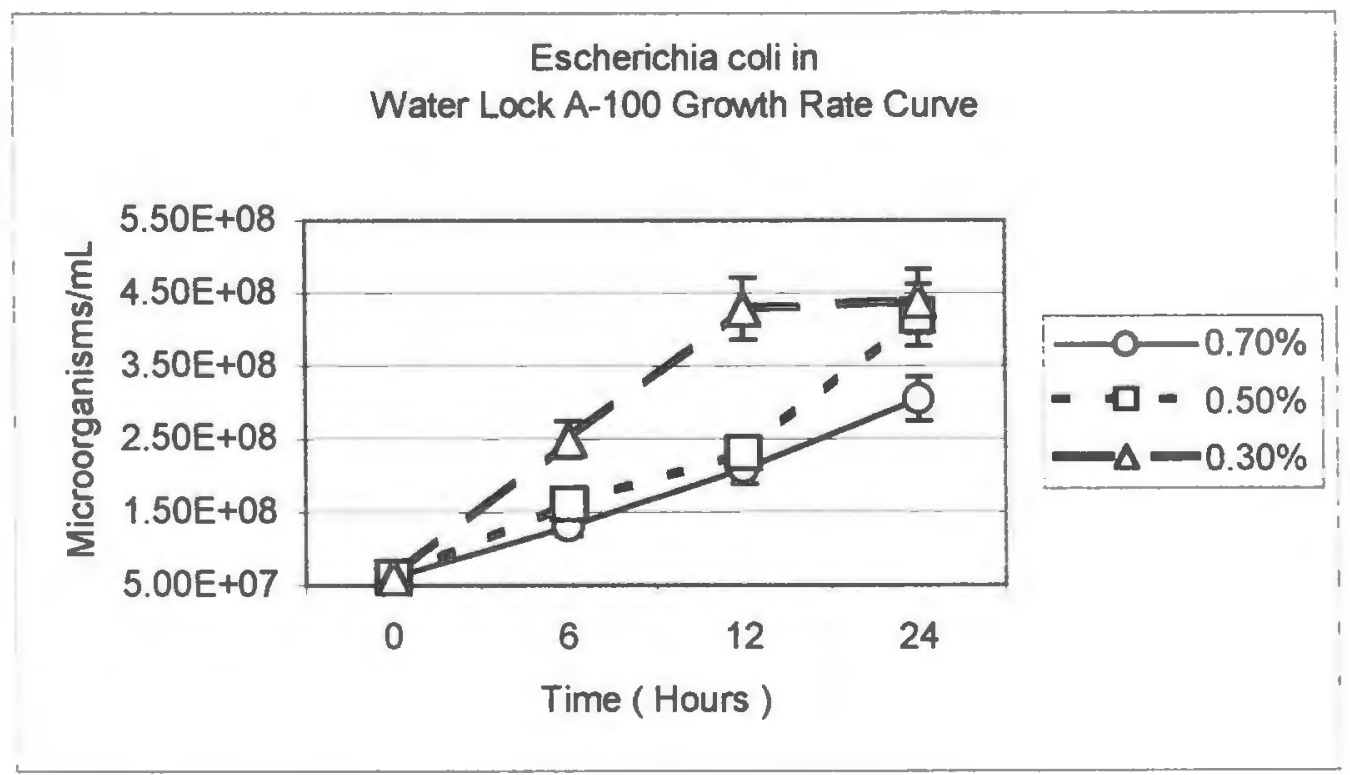

b)

Figure A1.5 Bacterial growth rate observed for E. coli in a) Guar gum, b) Water Lock A-100 


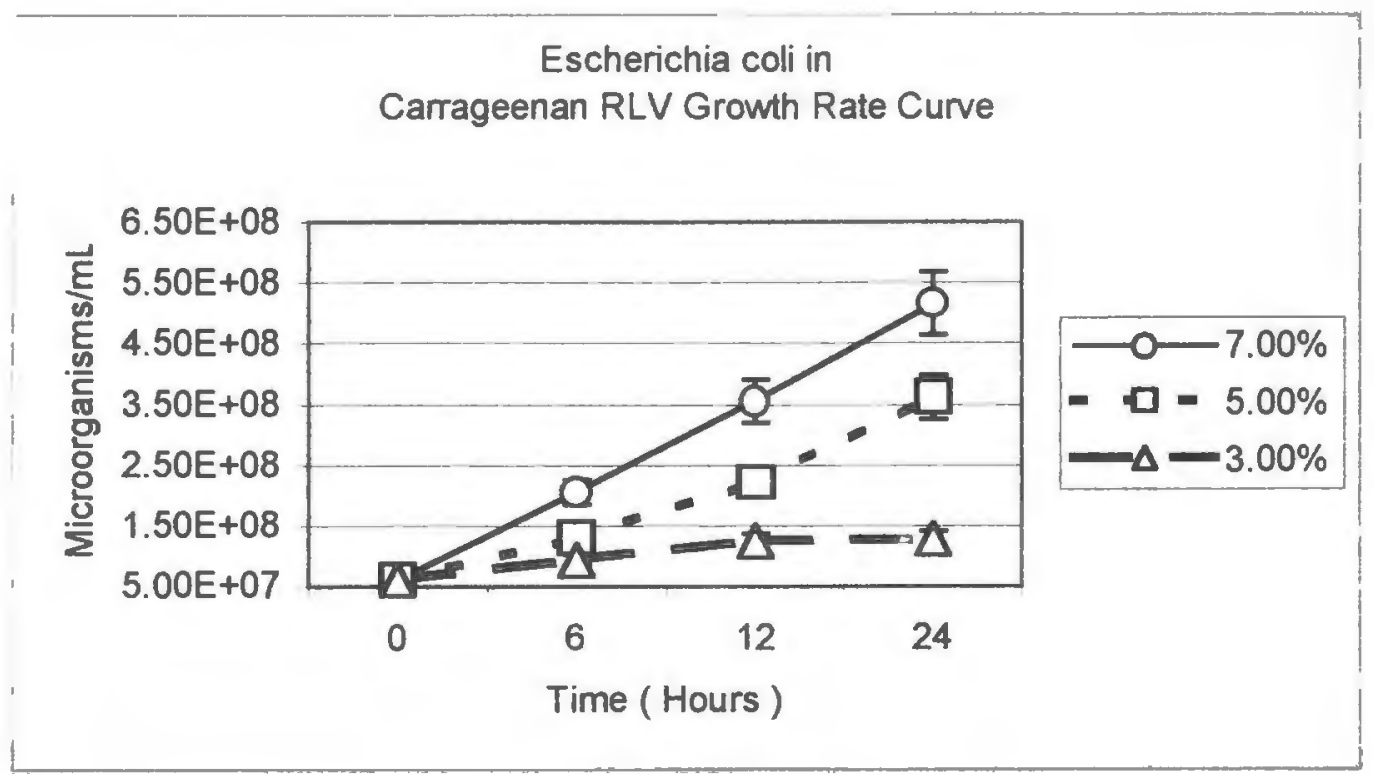

a)

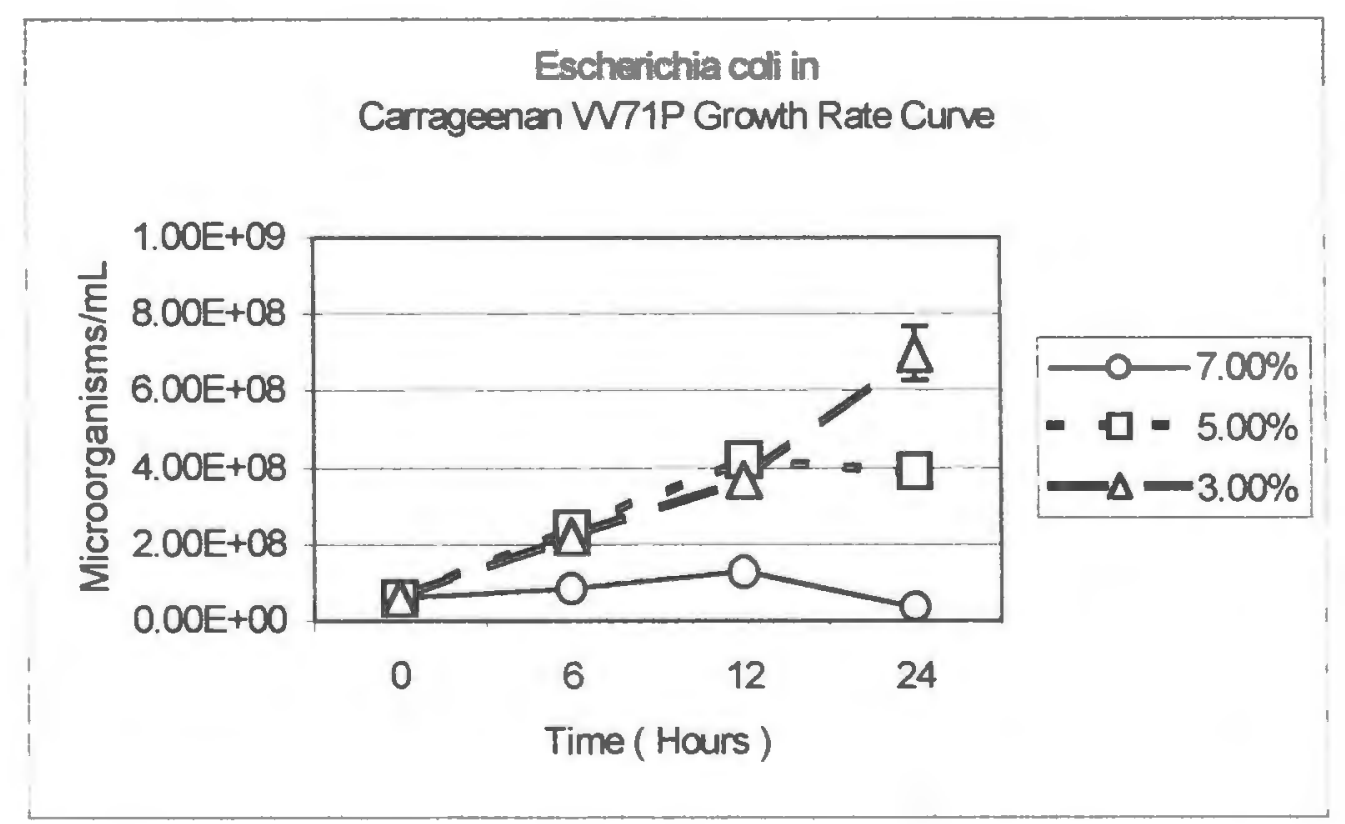

b)

Figure A1.6 Bacterial growth rate observed for $E$. coli in a) Carrageenan RLV, b) Carrageenan VV71P 


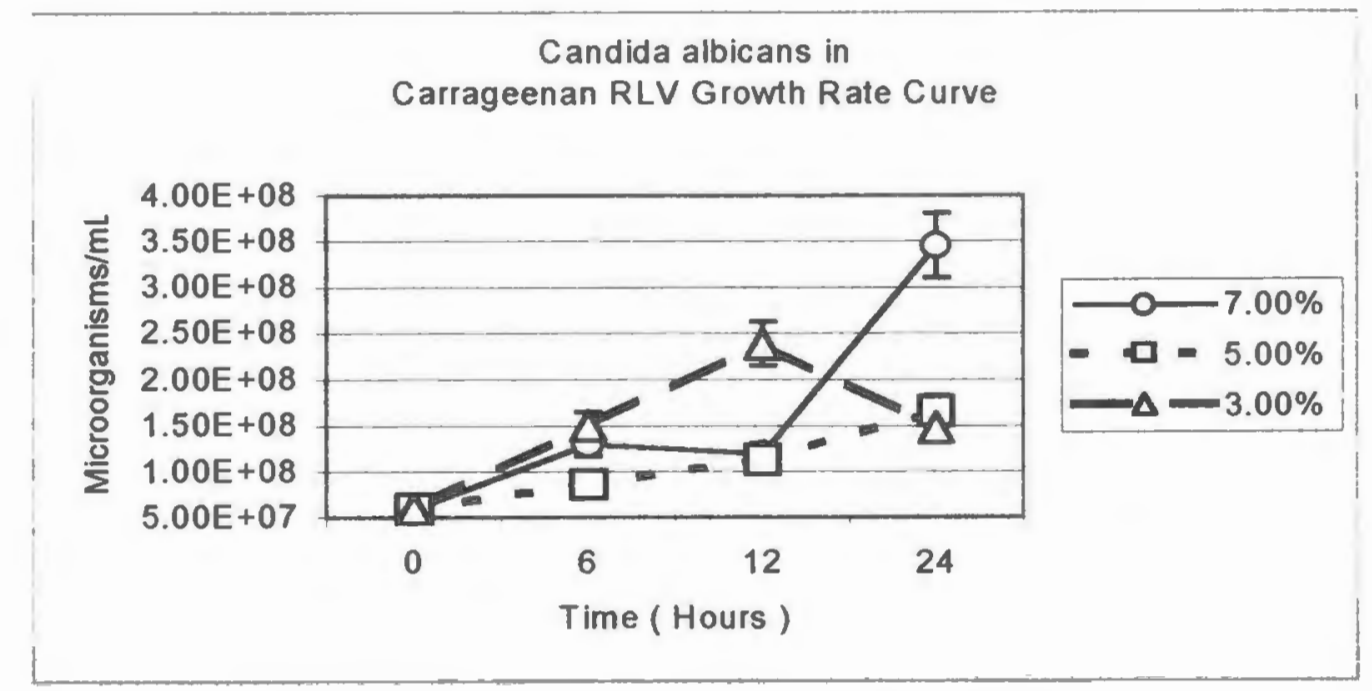

a)

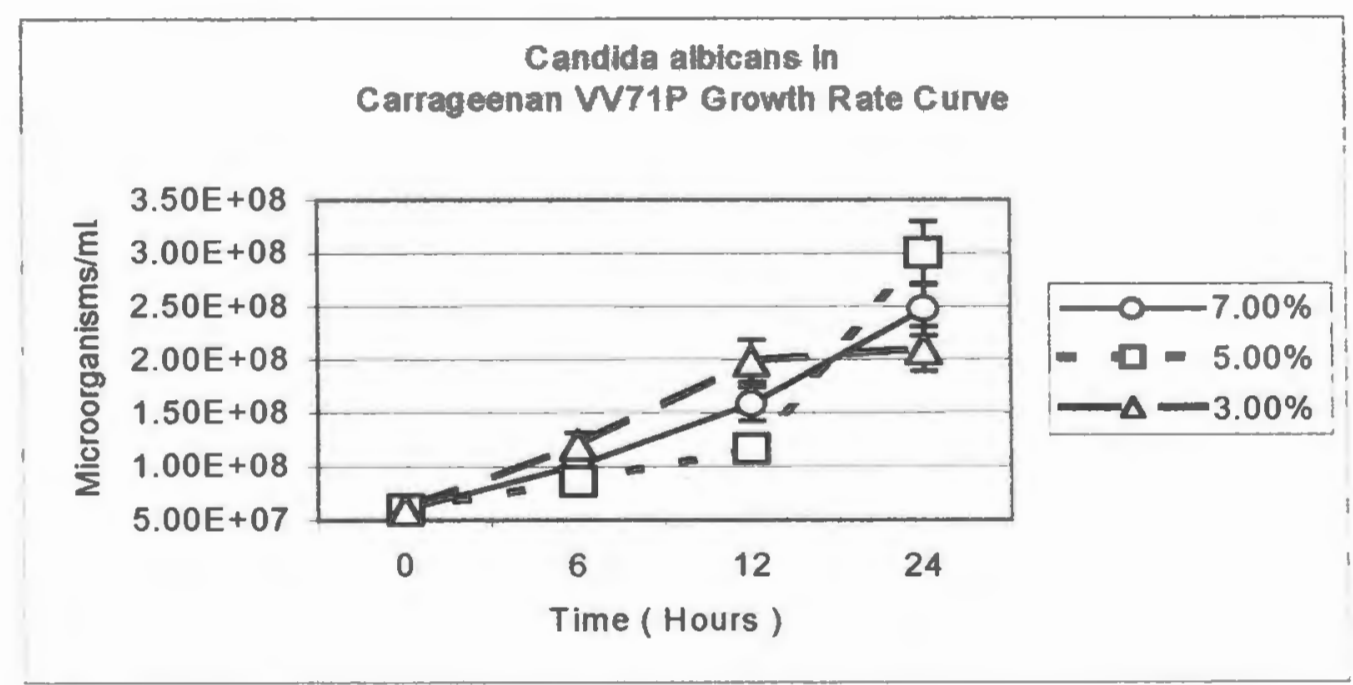

b)

Figure 2.3 Bacterial growth rate observed for $C$. albicans in a) Carrageenan RLV, b) Carrageenan VV71P 


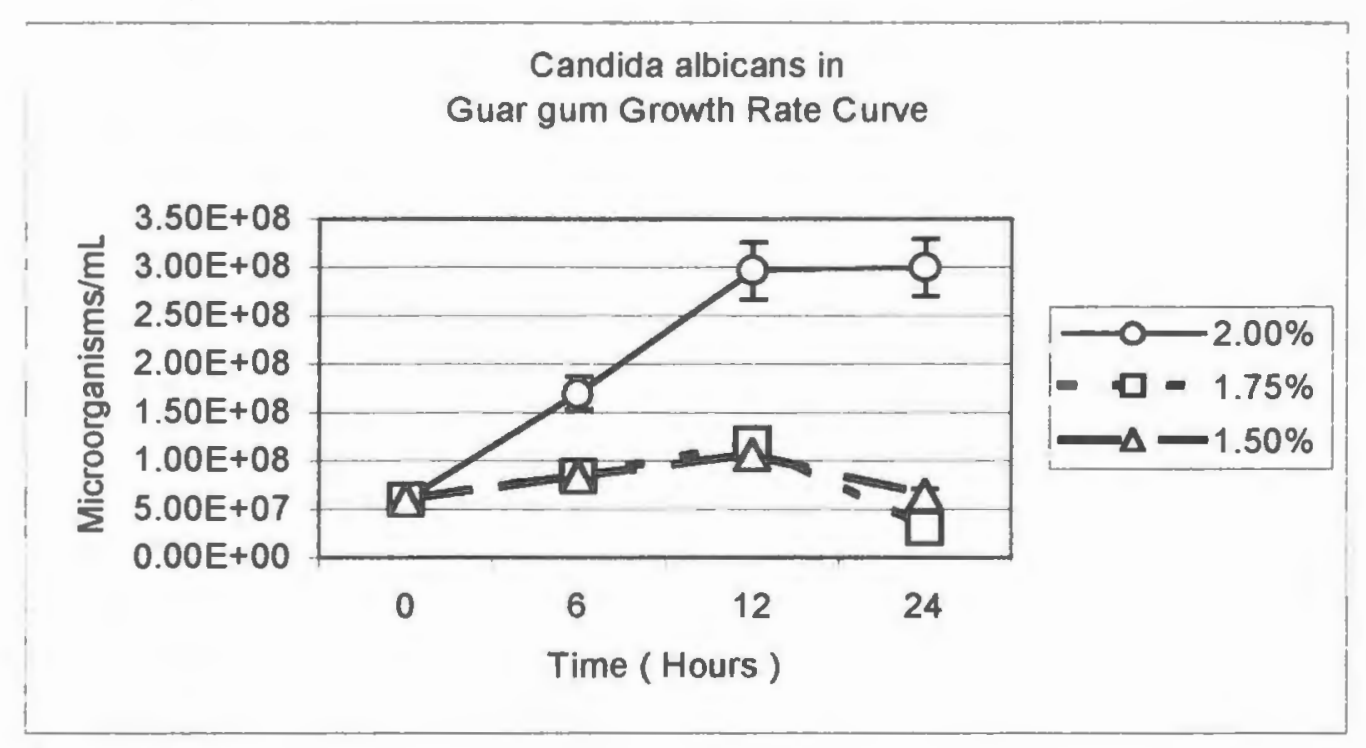

a)

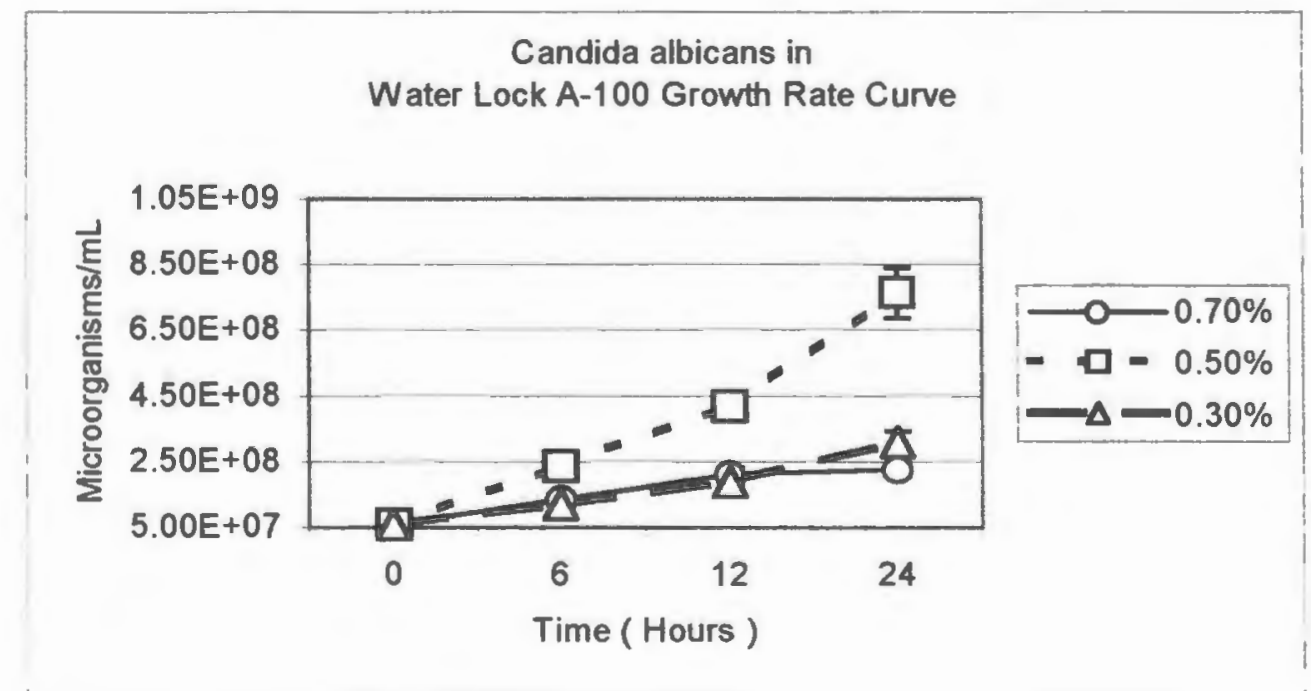

b)

Figure 2.2 Bacterial growth rate observed for C. albicans in a) Guar gum, b) Water Lock A-100 


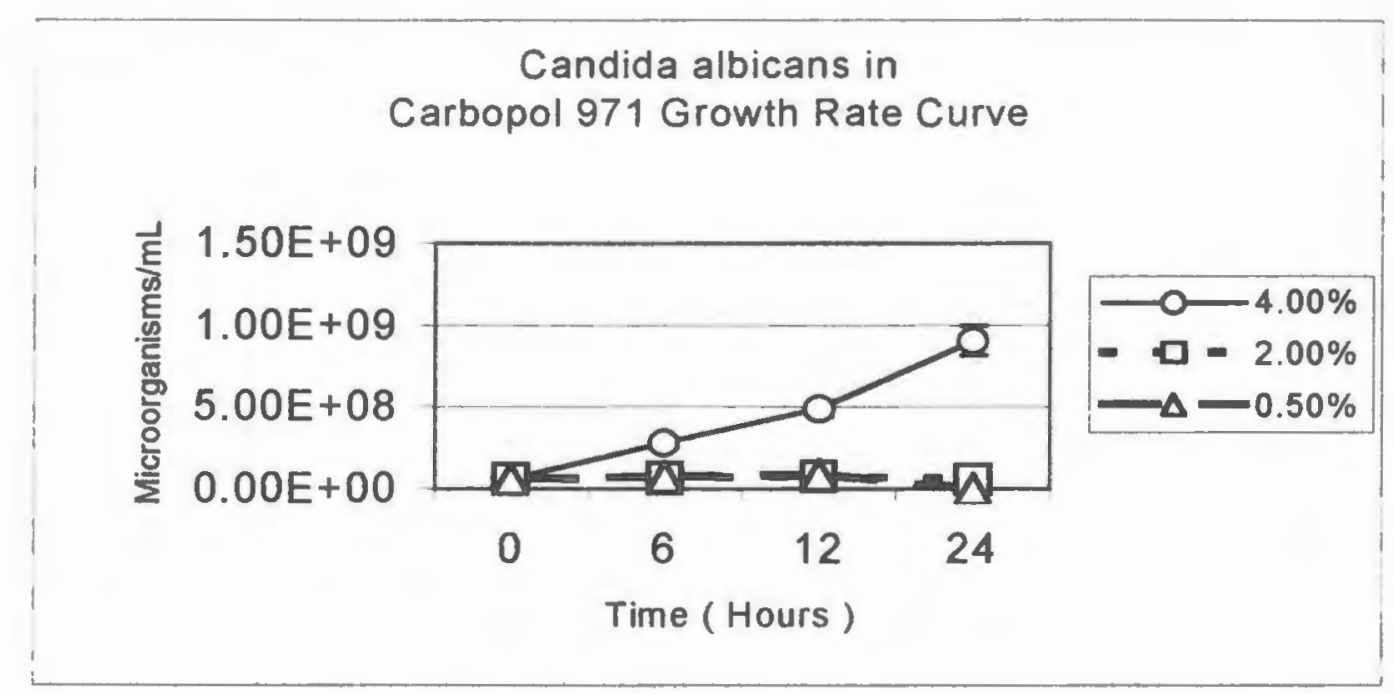

a)

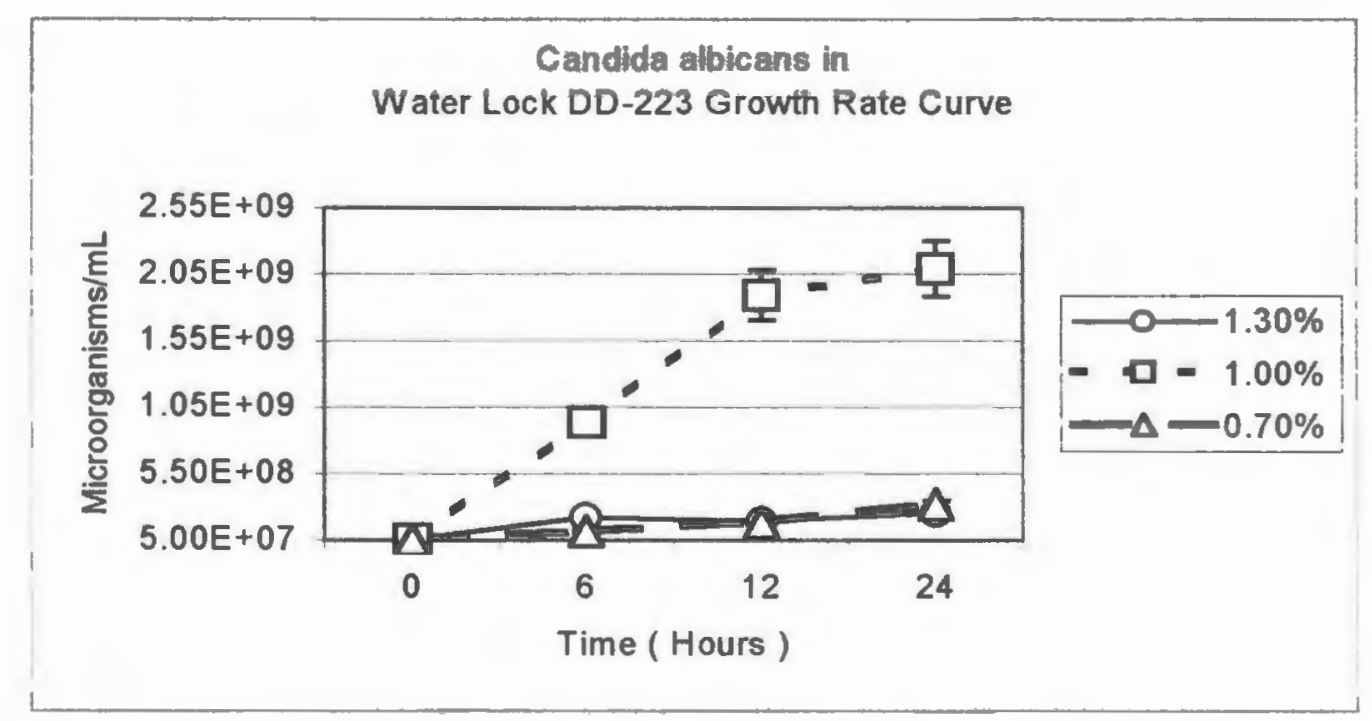

b)

Figure 2.1 Bacterial growth rate observed for C. albicans in a) Carbopol 971, b) Water Lock DD-223 


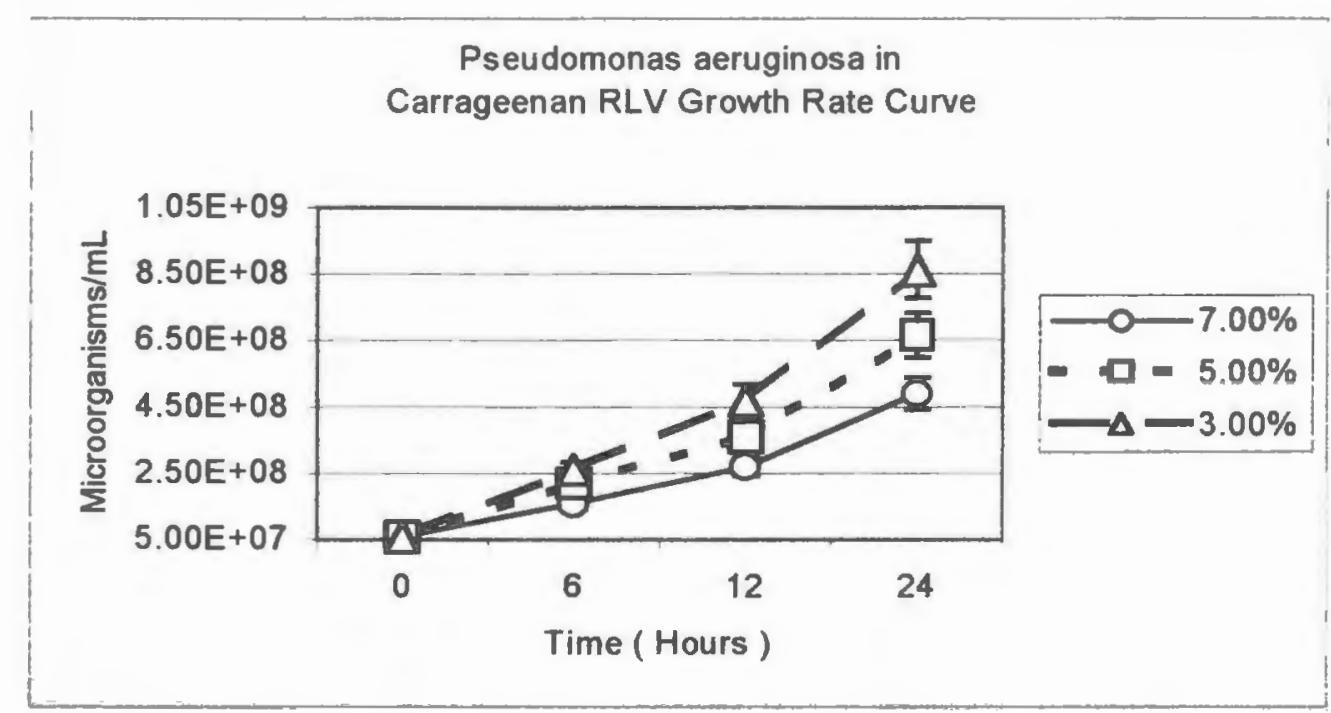

a)

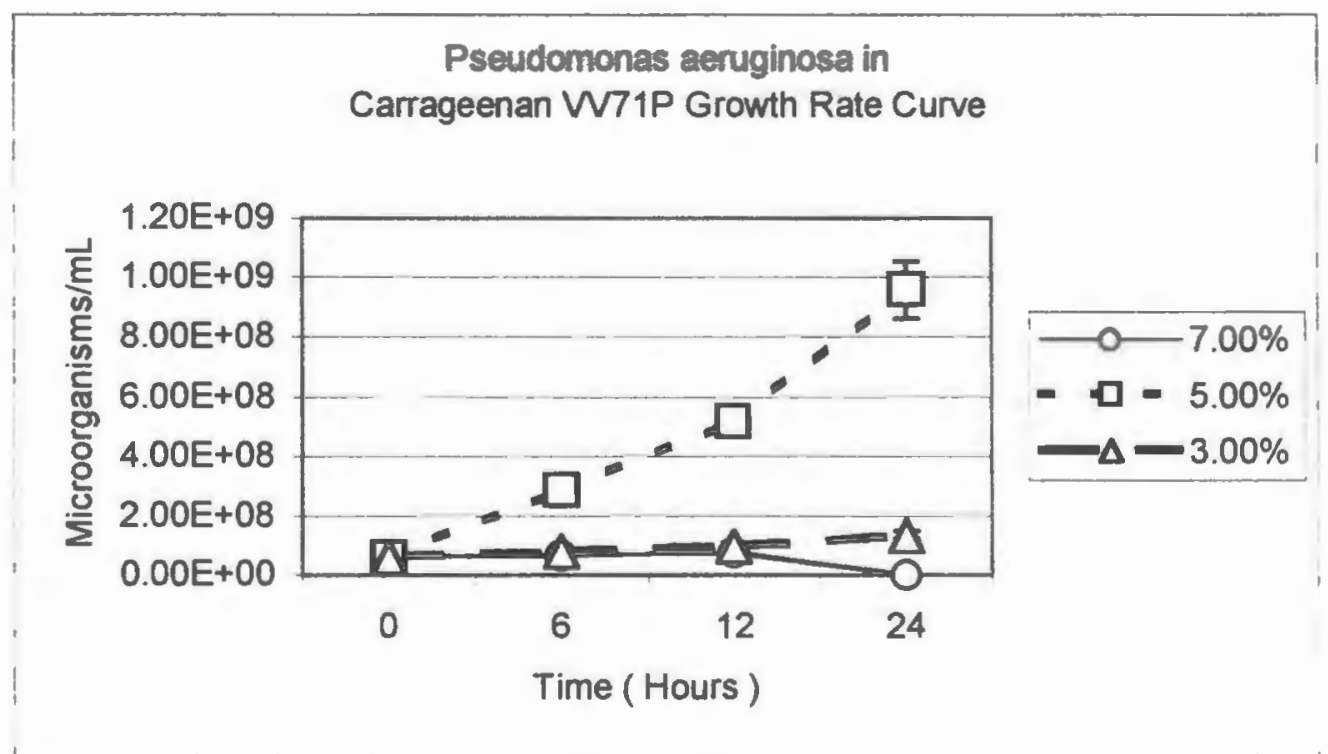

b)

Figure 4.3 Bacterial growth rate observed for Ps. aeruginosa in a) Carragenan RLV, b) Carrageenan VV71P 


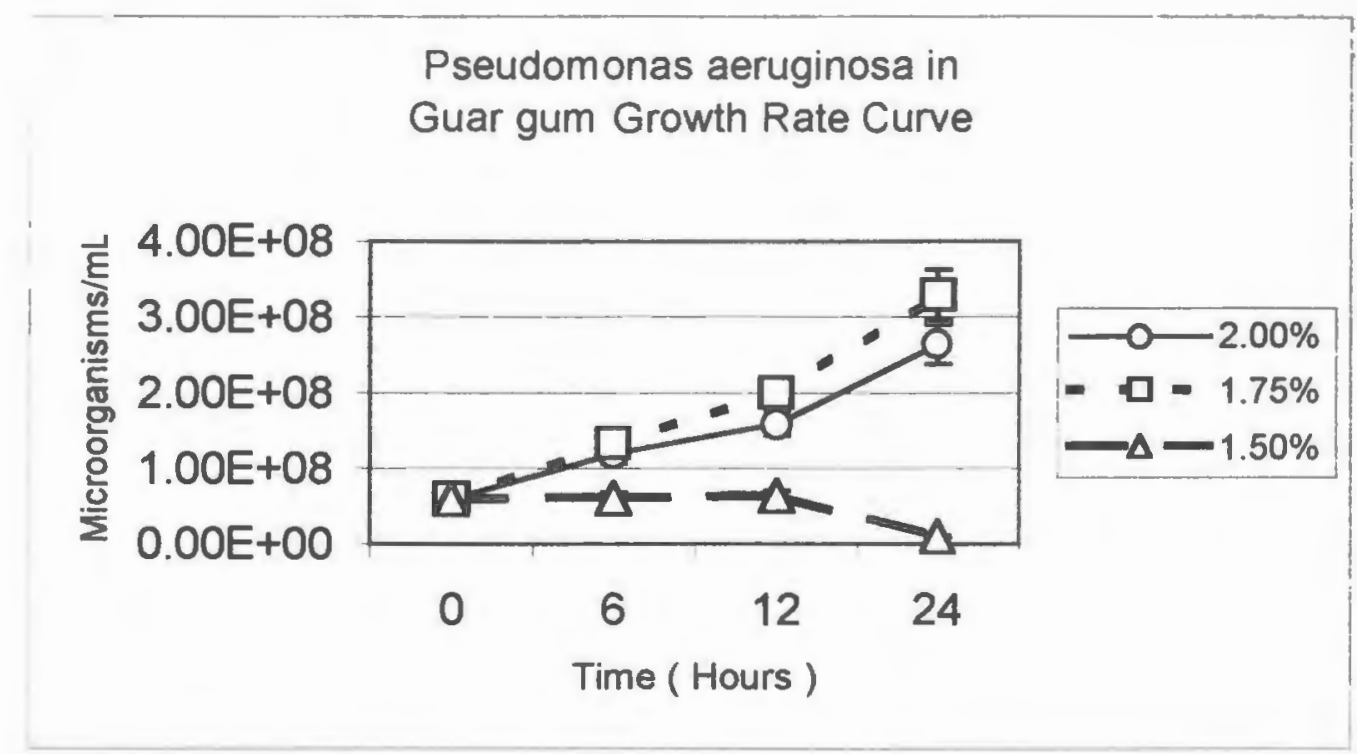

a)

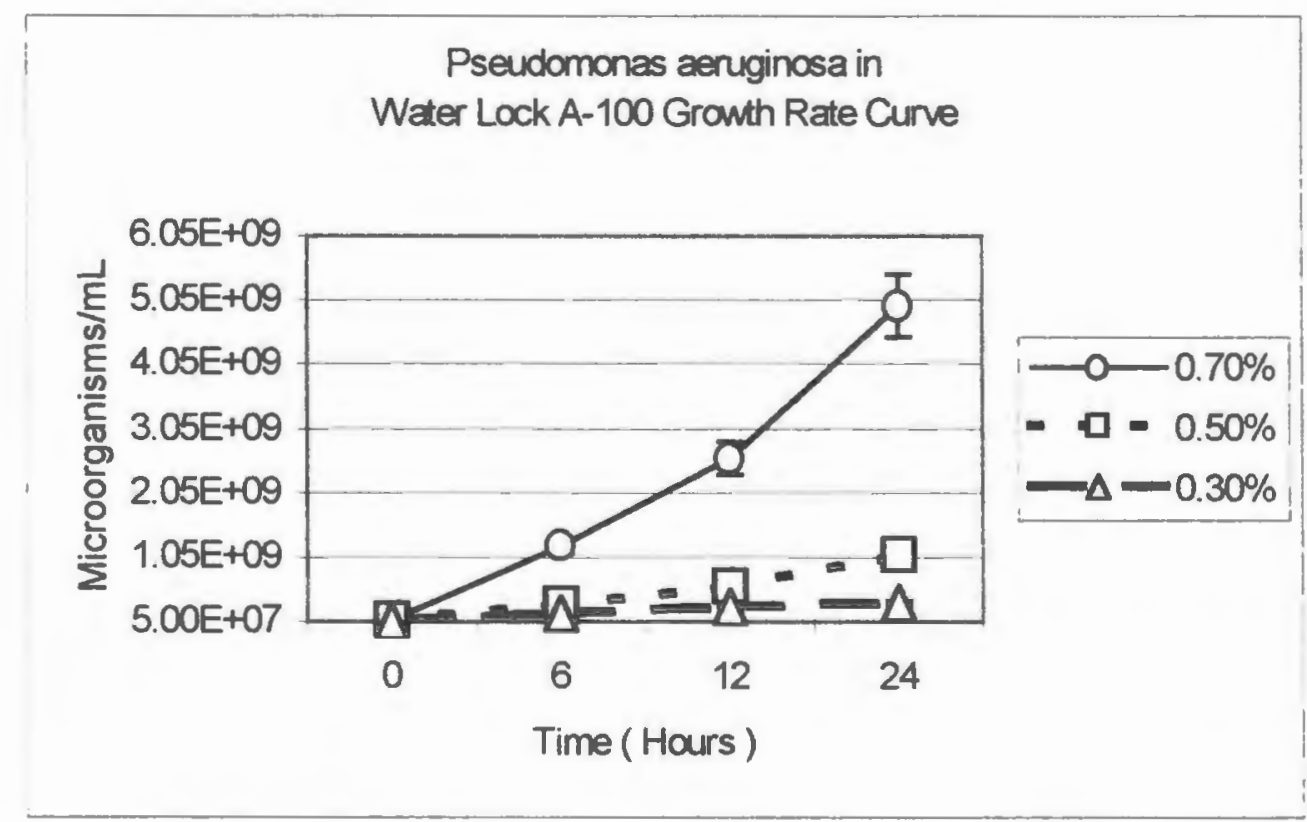

b)

Figure 4.2 Bacterial growth rate observed for $P$. aeruginosa in a) Guar gum, b) Water Lock A-100 
Pseudomonas aeruginosa in

Carbopol 971 NF Growth Rate Curve

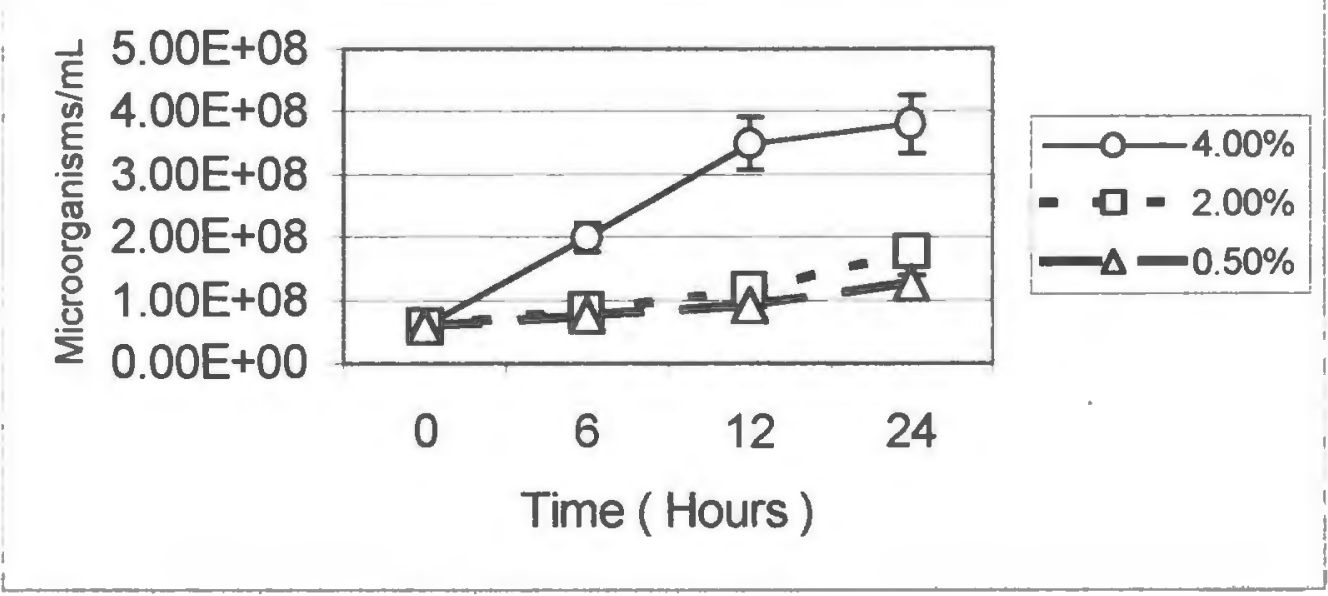

a)

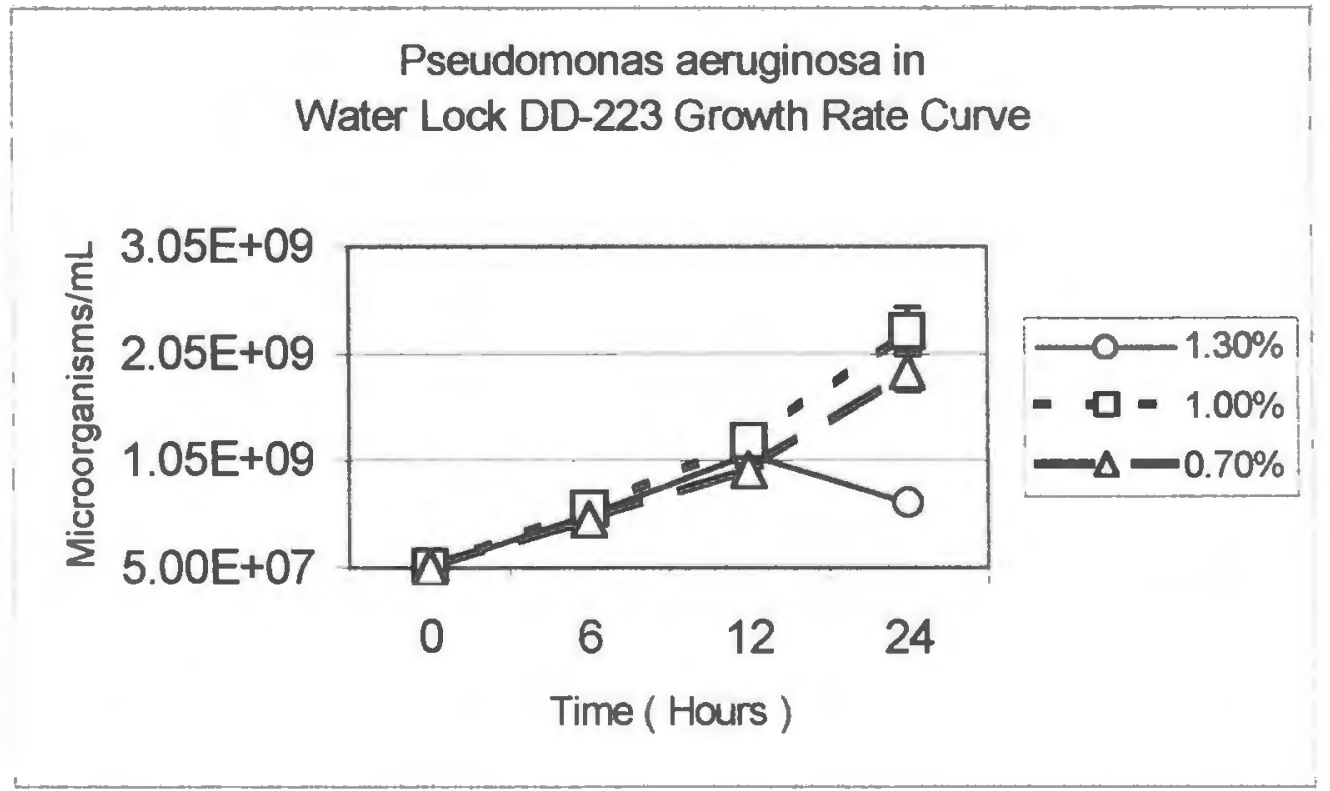

b)

Figure 4.1 Bacterial growth rate observed for $P$. aeruginosa in a) Carbopol 971, b) Water Lock DD-223 
Appendix 2

(Multiple regression, stepwise and best subset analysis) 
A) P. aeruginosa - regression analysis using multiple techniques

\section{Regression Analysis using all variables}

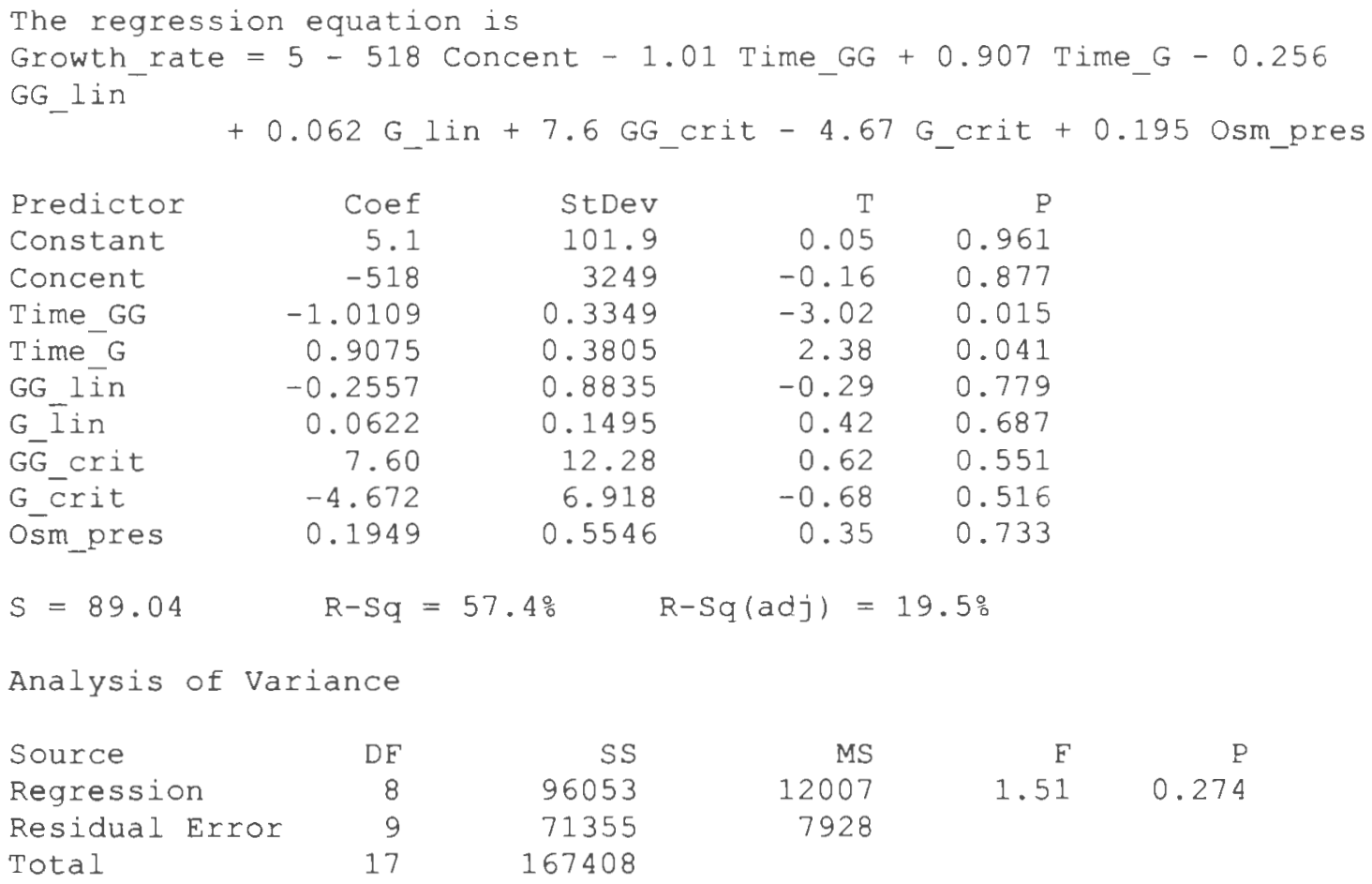

\section{Regression Analysis using best subset analysis}

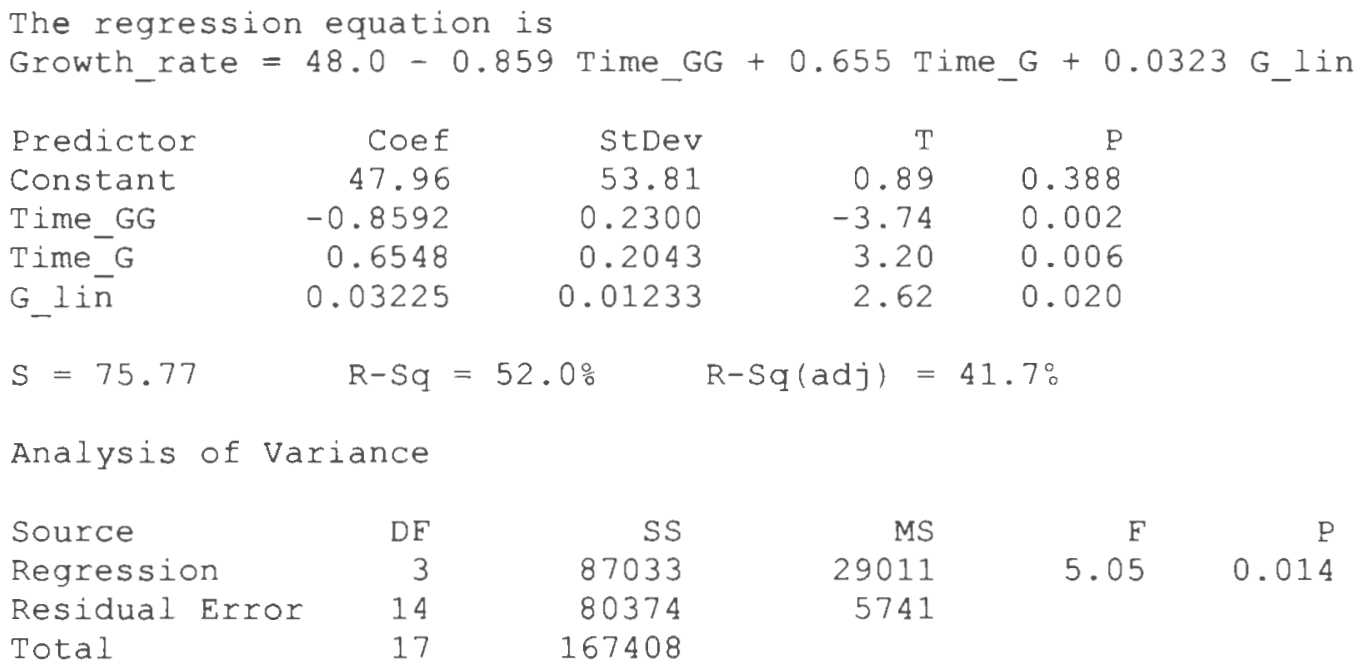


B) S. aureus - regresion analysis using multiple techniques

\section{Regression Analysis using all variables}

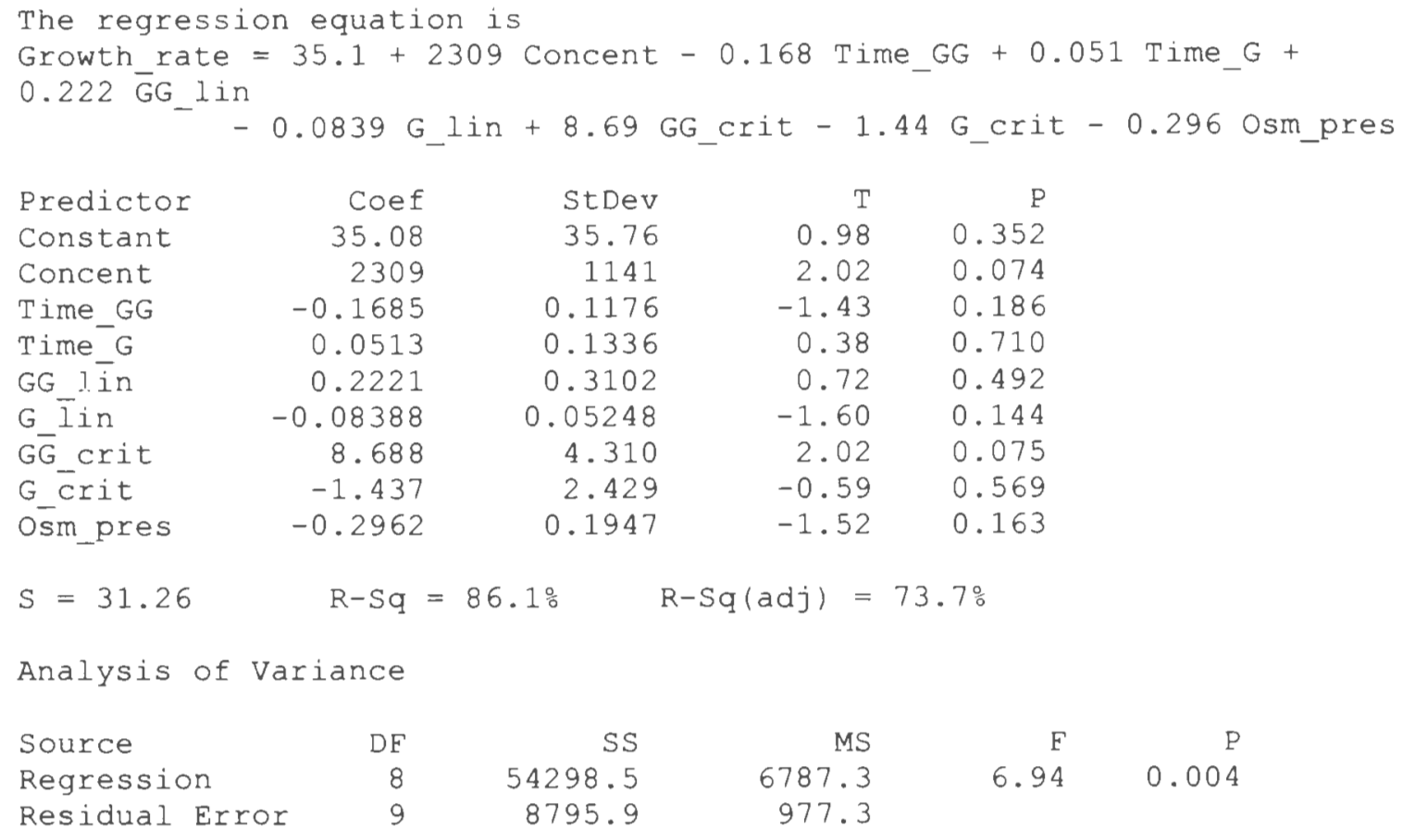

\section{Regression Analysis using stepwise regresion analysis}

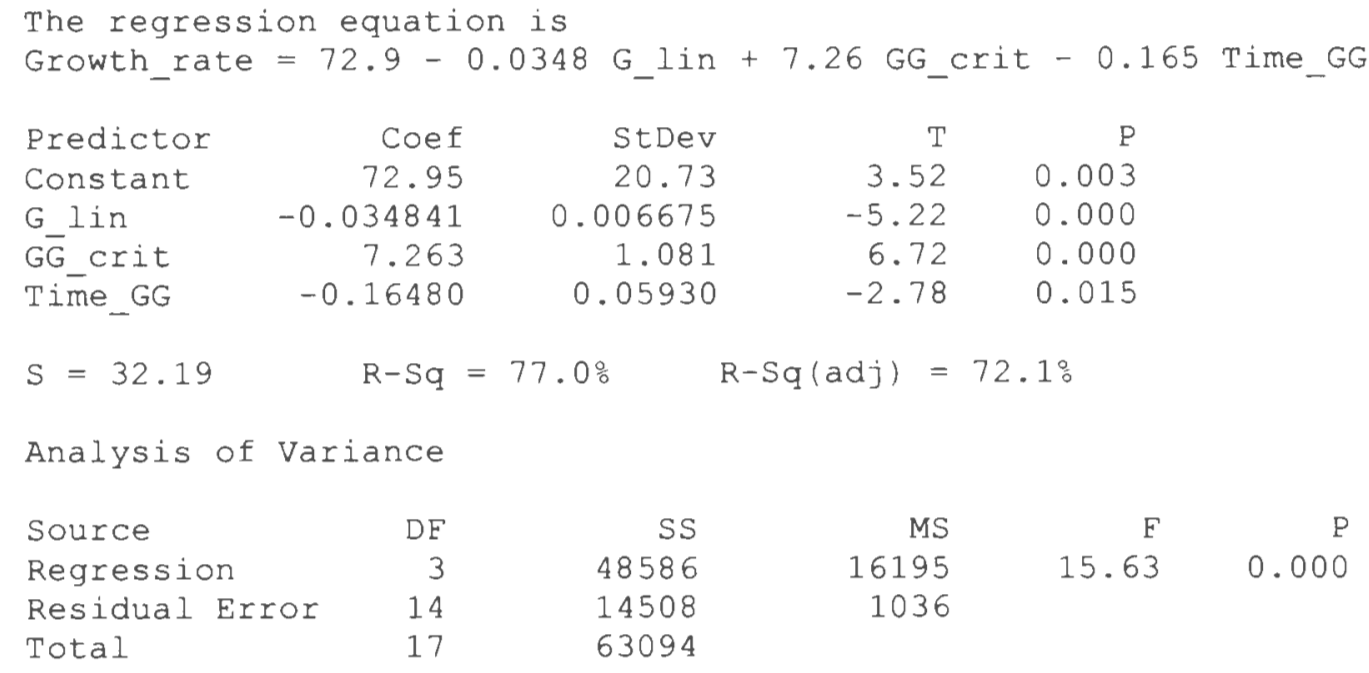


B) S. aureus - regresion analysis using multiple techniques

\section{Regression Analysis using best subset analysis}

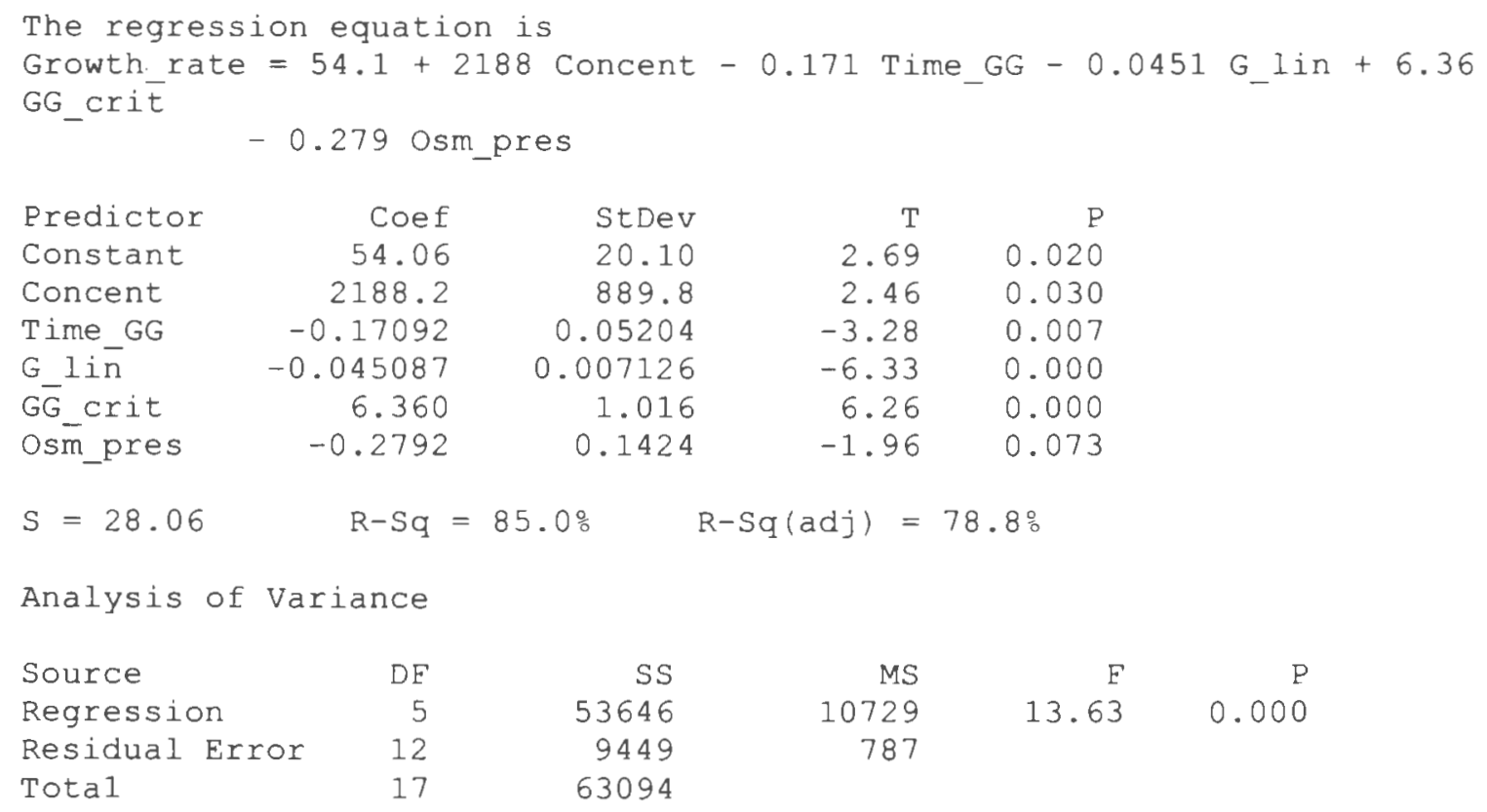


C) Decrease Growth Rate with Increasing Concentration - regression analysis using multiple techniques

\section{Stepwise Regression for bacteria showing decreasing growth rate with increasing concentration}

\begin{tabular}{|c|c|c|c|c|c|}
\hline F-to-Enter: & \multicolumn{2}{|c|}{4.00} & E-to-Remove: & \multicolumn{2}{|c|}{4.00} \\
\hline Response is & Grw_rate & e on & predictors, & with $\mathrm{N}$ & 27 \\
\hline Step & 1 & 2 & 3 & 4 & 5 \\
\hline Constant & 1.855 & 105.560 & 97.013 & 103.395 & 103.450 \\
\hline G_crit & 2.30 & 4.38 & 4.77 & 0.24 & \\
\hline T-Value & 3.74 & 6.28 & 7.16 & 0.11 & \\
\hline Time GG & & -0.340 & -0.321 & -0.274 & -0.271 \\
\hline T-value & & -4.11 & -4.18 & -3.69 & -4.19 \\
\hline GG_lin & & & -0.108 & -0.225 & -0.231 \\
\hline T-V̄alue & & & -2.28 & -3.25 & -4.74 \\
\hline GG_crit & & & & 8.3 & 8.7 \\
\hline T-Value & & & & 2.19 & 8.21 \\
\hline S & 66.7 & 52.2 & 48.1 & 44.6 & 43.6 \\
\hline$R-S q$ & 35.93 & 62.40 & 69.31 & 74.82 & 74.80 \\
\hline
\end{tabular}

\section{Regression Analysis}

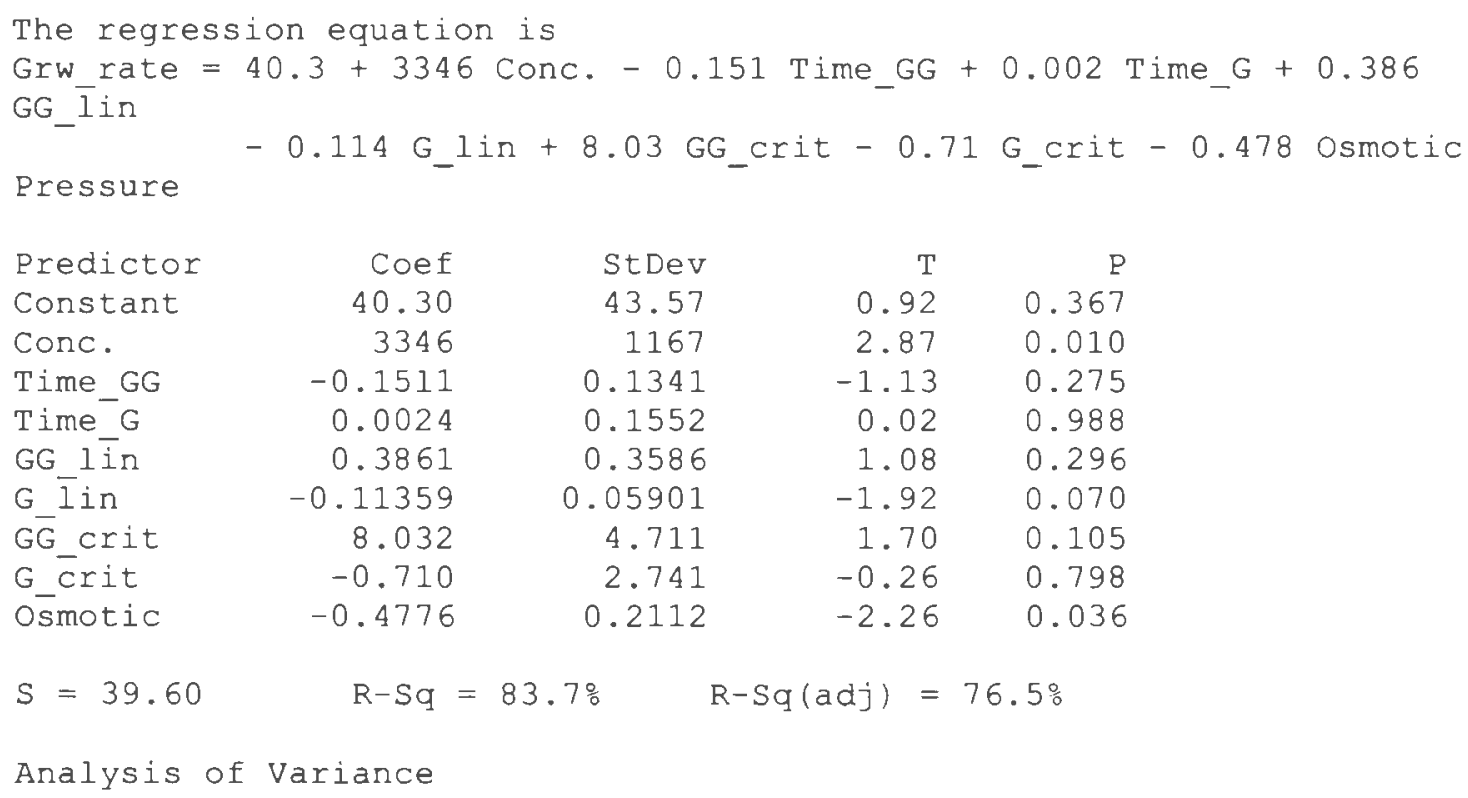




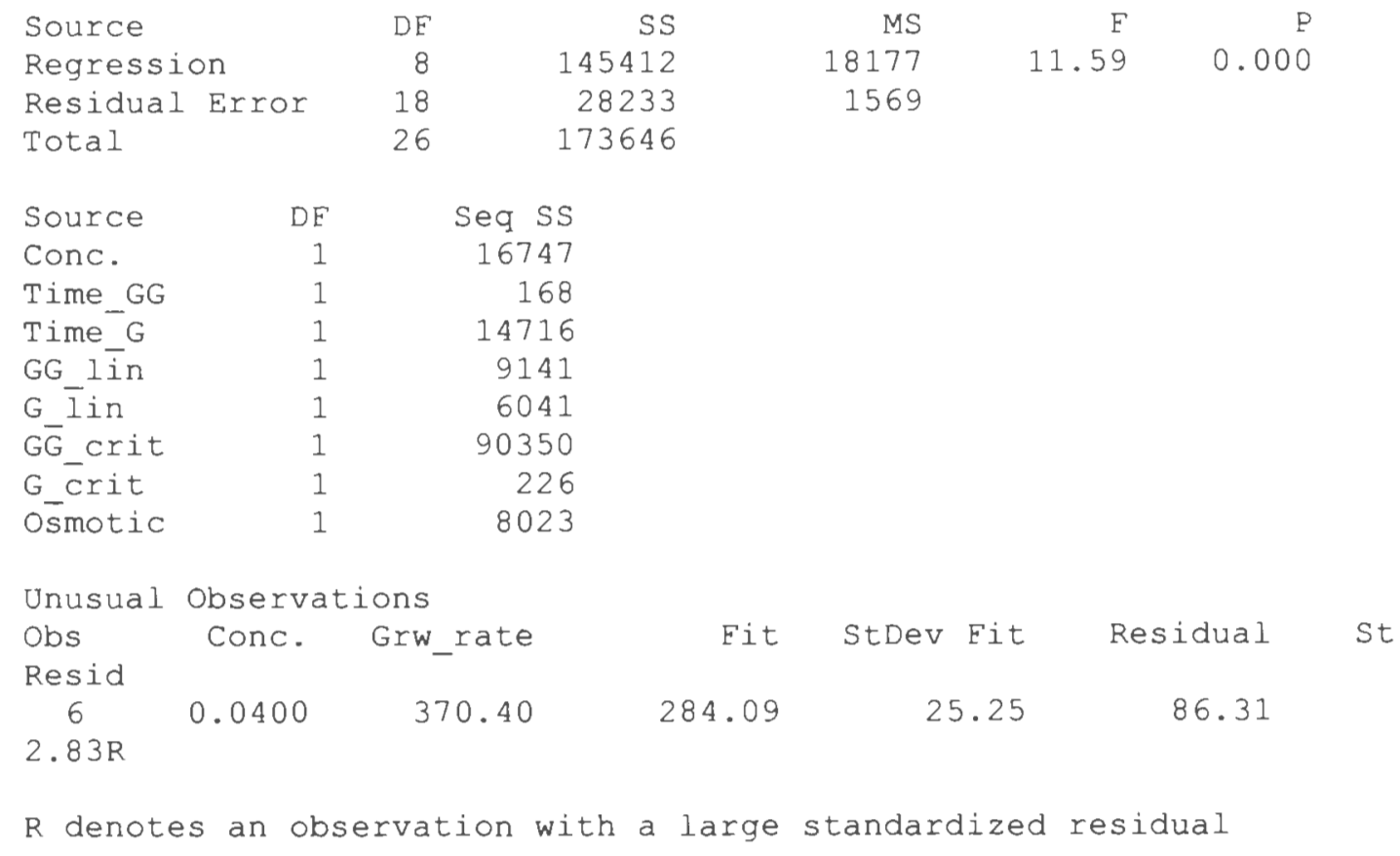

\section{Best Subsets Regression}

Response is Grw_rate

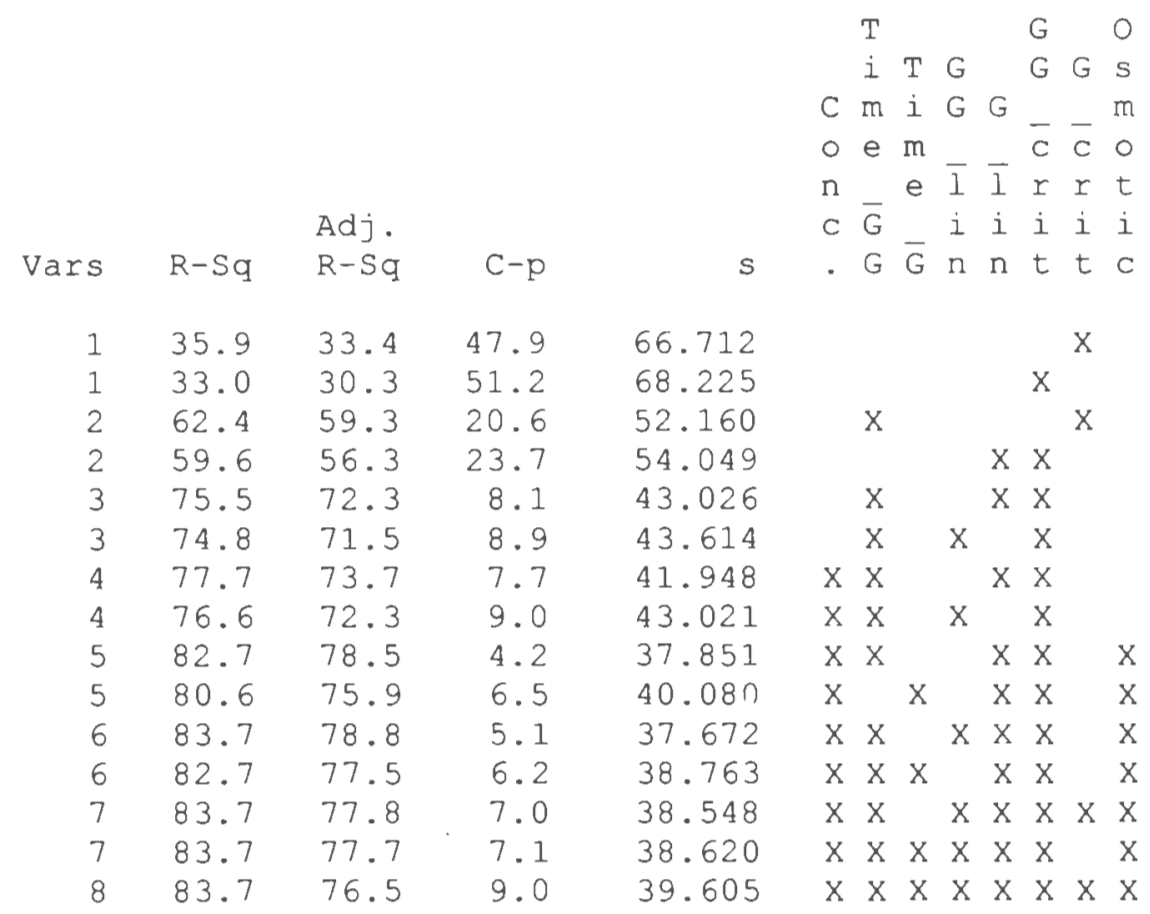

Saving file as: C: \WINDOWS \DESKTOP \Minitab P=values \decreasing GR.MPJ * NOTE * Existing file replaced. 
Worksheet size: 100000 cells

Retrieving project from file: C: \WINDOWS \DESKTOP\MINITAB \DECREA 1. MPJ

\section{Regression Analysis}

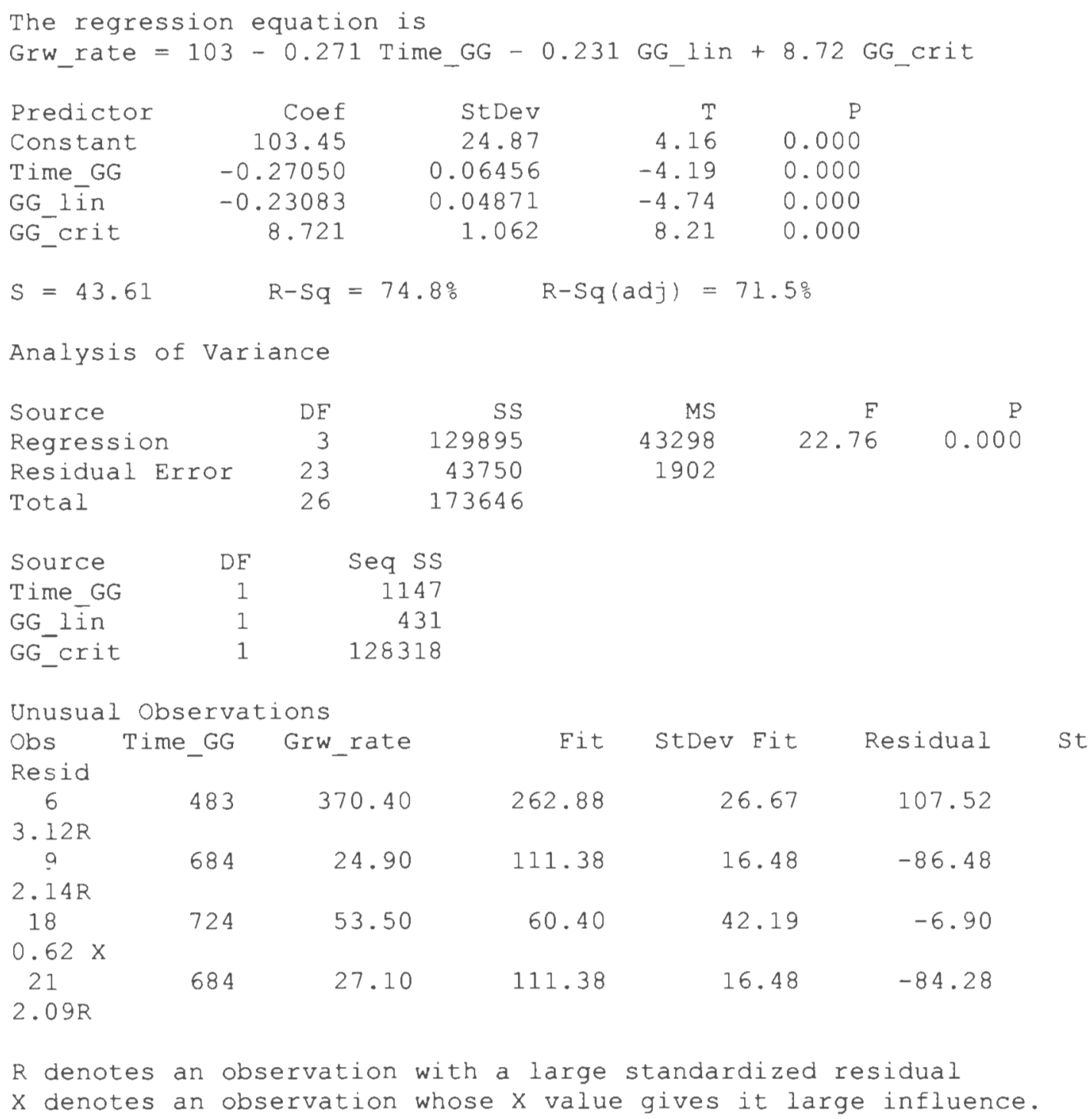

\section{Regression Analysis}

The regression equation is Grw_rate $=41.2+3321$ Conc. -0.163 Time_GG +0.363 GG_lin -0.107 G 1 in

$$
+6.85 \text { GG_crit - } 0.463 \text { Osmotic Pressure }
$$

$\begin{array}{lllll}\text { Predictor Coef } & \text { StDev } & \text { T }\end{array}$ 


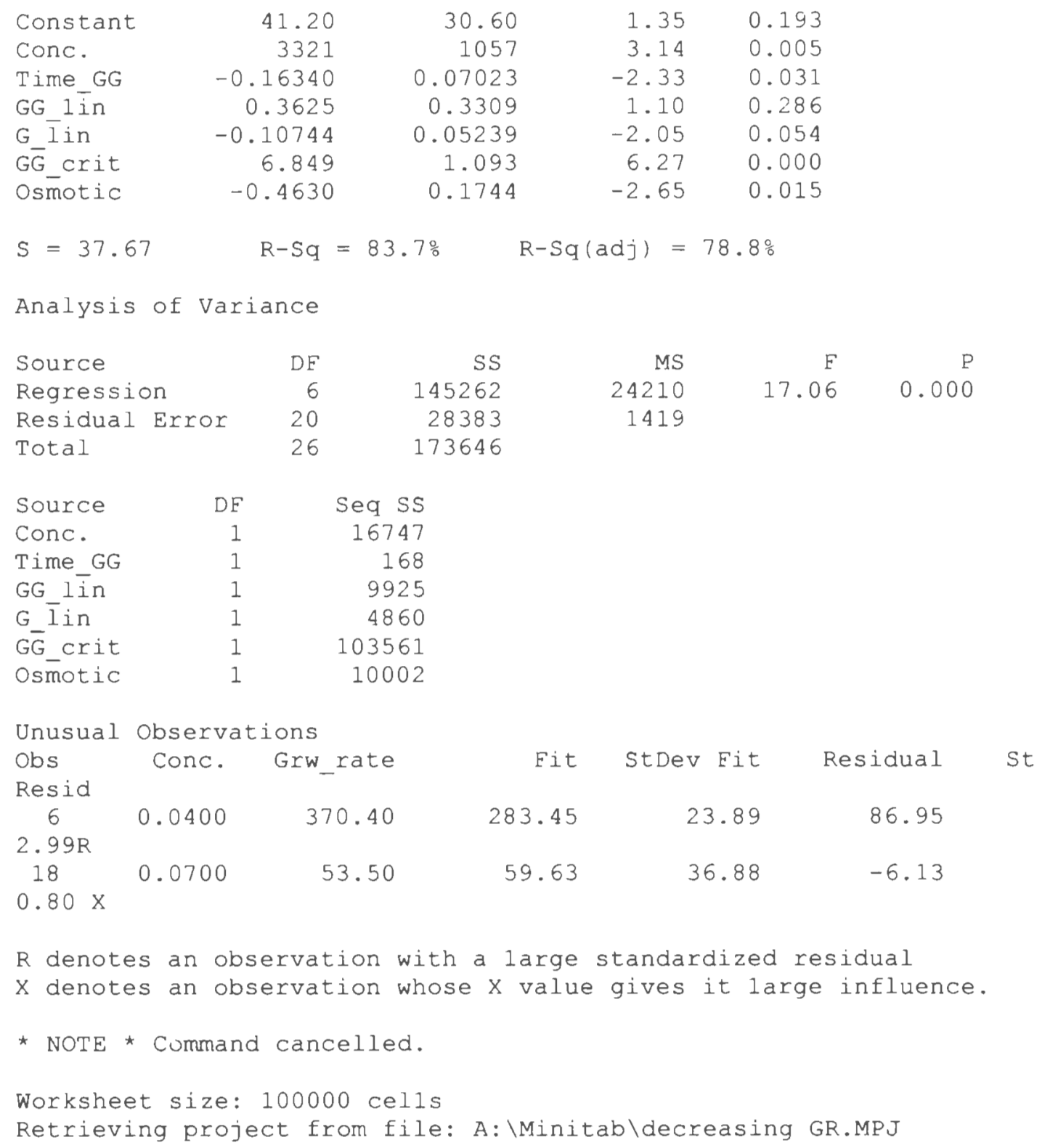




\section{Paper II}

“Importance of destructive oscillatory viscometry in the characterization of some of the gels commonly used in the cosmetics, pharmaceutical and food industries." 


\section{Summary}

In this paper the rheological properties of nine different gels, namely carrageenan, guar gum, pectin, sodium carboxy methyl cellulose, methyl cellulose, hydroxypropyl methyl cellulose, Carbopol 971, Water Lock and bentonite were characterized. Oscillatory viscometry was used to determine the elastic and viscous moduli and the phase angle at the linear and critical stress regions at a stress range of $0-100 \mathrm{~Pa}$ and a frequency of $0.05 \mathrm{~Hz}$. The macrostructures of the gels varied from long linear chains, grafted and cross-linked chains, natural gels forming helix and ribbon structures and suspended particles. The concentration ranges used varied from $0.3 \%$ to $7.0 \%$ with no less than a 3 fold increment in the concentration ranges. Five different concentrations per gel were used. The viscosity types found were both shear thinning and shear thickening in behavior. The gel strengths varied from $0.001 \mathrm{~Pa}$ to $7,600 \mathrm{~Pa}$. The critical stress $\left(\sigma_{\mathrm{c}}\right)$ was determined to test its use in describing the gel strength. The linear, exponential, logarithmic and power functions were tested as models to describe the relationship between the critical stress and gel concentration. Within the concentration ranges studied, the critical stress was found to be linearly dependent $\left(\sigma_{\mathrm{c}}=\mathrm{al}+\mathrm{blC}\right)$ on the concentration with $95 \%$ certainty. The model proposed was applicable to gels of different chemical structures, molecular weights, molecular weight distributions, chain structure and viscosity types; therefore, it can be accepted as a universal model to describe gel strength and offers a practical and simple description useful for the formulator. In the model described, the slope (b1) can be used to characterize the "concentration sensitivity". This parameter may enable formulators to replace one gel with another in order to make necessary concentration-gel strength adjustments in cosmetics, pharmaceuticals and food gels. 


\section{Introduction}

Viscoelastic parameters commonly used in oscillatory viscometry are the elastic modulus (G'), the viscous modulus (G'), the phase angle $(\alpha)$ and the complex viscosity $\left(\eta^{*}\right)$. The elastic modulus denotes the energy stored while the molecules stretch and the viscous modulus denotes the energy lost when the molecules go back to their original conformation. The phase angle denotes the degree of viscoelasticity of the polymer solution, $0^{\circ}$ being a purely elastic material and $90^{\circ}$ a purely viscous fluid, anywhere in between $0^{\circ}$ and $90^{\circ}$ denotes the viscoelastic flow. The equation relating linear viscoelasticity can be written as follows:

$\operatorname{Tan}(\alpha)=\mathrm{G}^{\prime \prime} / \mathrm{G}^{\prime}$

$\sigma=2 \eta^{*} \gamma$

where $\sigma$ is the shear stress, $\gamma$ is the shear rate and $\eta^{*}$ is the complex dynamic viscosity which consists of a real and an imaginary part that can be expressed as:

$\eta^{*}=\eta^{\prime}+\mathrm{iG} / \omega$, or

$\eta^{*}=G^{\prime} / \omega+i G^{\prime} / \omega$

where $\eta$ ' is the dynamic viscosity, $G^{\prime}$ is the elastic modulus, $G$ " is the viscous modulus, $\omega$ is the frequency and $i$ is the square root of negative one $(\sqrt{-1})$. For a purely viscous fluid $\eta$ ' becomes independent of the shear stress applied to the system (Chereminisoff, 1993).

Davis (1971a,b) described the viscoelastic properties of pharmaceutical semisolids using both destructive and non-destructive oscillatory testing. In destructive oscillatory testing a low stress is applied on the body until the elasticity $\left(G^{\prime}\right)$ breaks down. 
This value is called the critical stress $\left(\sigma_{c}\right)$. In non-destructive oscillatory testing, the linear region where $G^{\prime}$ is independent of the shear stress is chosen and frequency studies are carried out. Davis (1971a,b) detailed the importance of these tests and mentioned their use in storage stability tests of semisolid products, effects of consistency on the percutaneous absorption of drugs and the effects of formulation on consistency and prediction of flow behavior under manufacturing conditions.

Non-destructive oscillatory testing may have the advantage over transient methods of covering a far wider time scale, therefore allowing one to assess the processes taking place at the molecular level with more confidence. On the other hand, destructive oscillatory testing provides useful information for the quality control and correlation of the physical properties with consumer perception attributes.

Most aqueous polymer solutions, when subjected to low frequencies tend to denote viscoelastic behavior as a result of their large molecular weights, sometimes in the order of $10^{6}$ or higher. The long branches of the molecules tend to store energy like a spring and at the same time are able to move and flow through the solvent: therefore the monomer deposition and the segment deposition along with the high molecular weight also affect the viscous behavior of the solution. As shown in Figure 1, the monomer disposition in the polymers can be alternate (1A), random (1B), block (1C) or grafted (1D). The monomer disposition as well as the polymer segments, which could be linear, branched or cross-linked, will also affect the viscosity and viscosity type (McCormic, 1991). 
$\mathrm{ABABABABABABAB}$

$1 \mathrm{~A}$. alternating copolymer

AAABBBAAABBBAAA

1C. block copolymer
AABBBAABABABBBA

1B. random copolymer

AAAAAAAAAAAAAA

B B $B$

B $\quad$ B $\quad$ B

B B $\quad$ B

1D. graft copolymer

Figure 1. Schematic representation of the monomer disposition in a polymer chain 
In more concentrated solutions, intermolecular attractions tend to increase the apparent viscosity. The shape and size of the hydrated molecule in solution is determined by the placement of the charged groups, hydrogen bonds, hydrophobic moieties and restriction rings. Functional groups impart water solubility because of their ability to form hydrogen bonds. Some of the groups that impart water solubility are (- NHR), ($\mathrm{N}=),\left(-\mathrm{COO}^{-} \mathrm{M}^{\top}\right),\left(-\mathrm{NR}_{2}{ }^{+} \mathrm{HX}\right),(-\mathrm{OH}),(-\mathrm{COOH}),\left(-\mathrm{SO}_{3}{ }^{-} \mathrm{M}^{+}\right),\left(-\mathrm{NR}_{3}{ }^{+} \mathrm{HX}\right),(-\mathrm{O}-),(-$ $\left.\mathrm{NHC}(=\mathrm{NH}) \mathrm{NH}_{2}\right), \quad\left(\mathrm{NH}_{3}{ }^{+} \mathrm{X}^{-}\right)$, and $\left(-\mathrm{NHC}(=\mathrm{O}) \mathrm{NH}_{2}\right)$. These factors affect polymer viscosity by creating layers of water molecules that move along as the polymer chain moves, or by creating attraction, repulsion or rigidity between the chains (McCormic. 1991).

Ferry (1980) using oscillatory viscometry studied and discussed the creep compliance, stress relaxation modulus and storage modulus, the loss modulus, the dynamic viscosity, the storage compliance, the loss compliance and the loss tangent of polymer solutions. He was able to point specific rheological characteristics of each polymer type. He classified eight types of viscoelastic behavior in polymers (Figure 2). Those were polystyrene, a dilute polymer solution (2A), polyvinyl acetate, an amorphous polymer of low molecular weight (2B) and atactic polymethyl methacrylate, an amorphous polymer of high molecular weight $(2 \mathrm{C})$, poly-n-octyl methacrylate, an amorphous polymer of high molecular weight with long side groups (2D), polymethyl methacrylate, an amorphous polymer of high molecular weight below its glass transition temperature (2E), havea rubber, a lightly cross linked amorphous polymer (2F), random styrene co-butadiene, a very lightly cross linked amorphous polymer (2G) and linear polyethylene, a highly crystalline polymer $(2 \mathrm{H})$. 


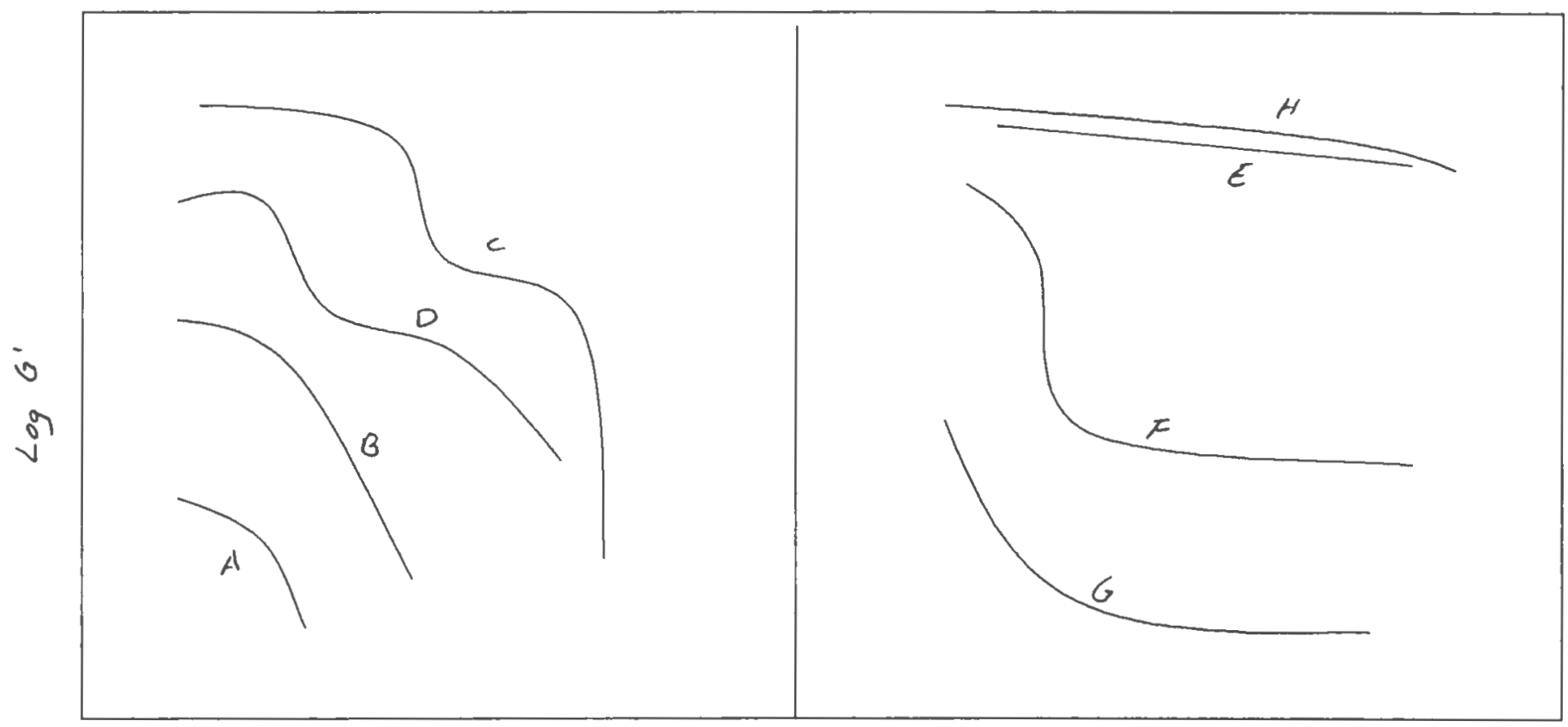

\section{Log Stress or Time}

Figure 2. Schematic representation of elastic modulus $\left(\mathrm{G}^{\prime}\right)$ dependence of viscoelastic polymer solutions on stress as described by Ferry (1980). A) Dilute polymer solution, B) amorphous polymer of low molecular weight C) amorphous polymer of high molecular weight D) amorphous polymer of high molecular weight with long side groups E) amorphous polymer of high molecular weight below its glass transition temperature F) lightly cross-linked amorphous polymer $\mathrm{G}$ ) very lightly cross-linked polymer $\mathrm{H}$ ) highly crystalline polymer. 
Ferry's use of the elastic modulus is used to study the effects of the critical stress of the polymers structures used in this study. For linear or branched polymers $G$ ' reaches a point where it decreases rapidly pinpointing the critical stress (Figures $2 \mathrm{~A}$ and $2 \mathrm{~B}$ ). In molecular terms, it corresponds to the breakage of the macromolecular coils, which have completely freed themselves from the original constraints and start to flow. The relaxation time is the time at which the critical stress is reached and can also be used to define destructive oscillatory rheology. Among the properties such as chain length, degree of cross linkage, molecular weight, the molecular weight distribution is also important on the critical stress. If the molecular weight distribution is broad, $\sigma_{c}$ is not as well defined and the breakage may occur broadly or in two stages (Figures 2C and 2D). For glassy and crystalline polymers (not used in this study) there is very little stress relaxation over many decades of logarithmic time.

Barry and Eccleston (1973a,b) utilized oscillatory rheology in order to test $\mathrm{O} / \mathrm{W}$ emulsions with the purpose of investigating the effects of surfactant chain length over the emulsion and found that the rheological properties of the emulsions were related to the viscoelastic networks present in the continuous phase. Pans et al. (1993) reached similar conclusions when studying the viscoelastic properties of gel-emulsions and pointed out that the elastic modulus was related to the structure of the emulsions while the viscous modulus was related to the continuous phase and volume fraction of the emulsion.

Rochefort and Middleman (1987) have used oscillatory and steady shear experiments to prove the effectiveness of dynamic oscillatory viscometry for studying gels and successfully investigated xanthan gum rheology to demonstrate that it is affected by the addition of salt in different ways, depending on the concentration regime studied. 
In more recent studies, Giboreau et al. (1994) used a modified starch, xanthan gum and locust bean gum and discussed the usefulness of the yield stress when characterizing the rheological behavior of gels. Using a modified starch to observe the critical stress level, they described this point as being a point where "catastrophic" destruction of the structure of the system occurs. Chen and Dickinson (1998) when studying the viscoelastic properties of heat-set whey protein found that the protein concentration is the main factor affecting gel strength as a factor of the elastic modulus. They found that it was more sensitive to concentration increases at lower concentrations. Terrisse et al. (1993) used destructive oscillatory testing to characterize and evaluate $\mathrm{W} / \mathrm{O} / \mathrm{W}$ multiple emulsions and predict their stability.

In this paper, the use of the critical stress in the characterization of the rheological behavior of 9 gels commonly used in the cosmetics, pharmaceutical and food industries was studied because the critical gel strength (described by the critical stress at $G^{\prime}$ ) was hypothesized to be the overall representative of the internal gel strength. The chemical structure. molecular weight, molecular weight distribution, degree of cross-linking, steric conformation and micro and macromolecular structure of the chains, all influence the internal gel structure. Some of these properties are influenced by the concentration, therefore, any relationship between the critical stress and the concentration would provide means of simplifying and comparing the rheological behavior of the gels. The critical stress can be determined from the point where $\mathrm{G}^{\prime}$ starts to dissipate, as shown in Figure 3. 


\section{At Concentration "X"}

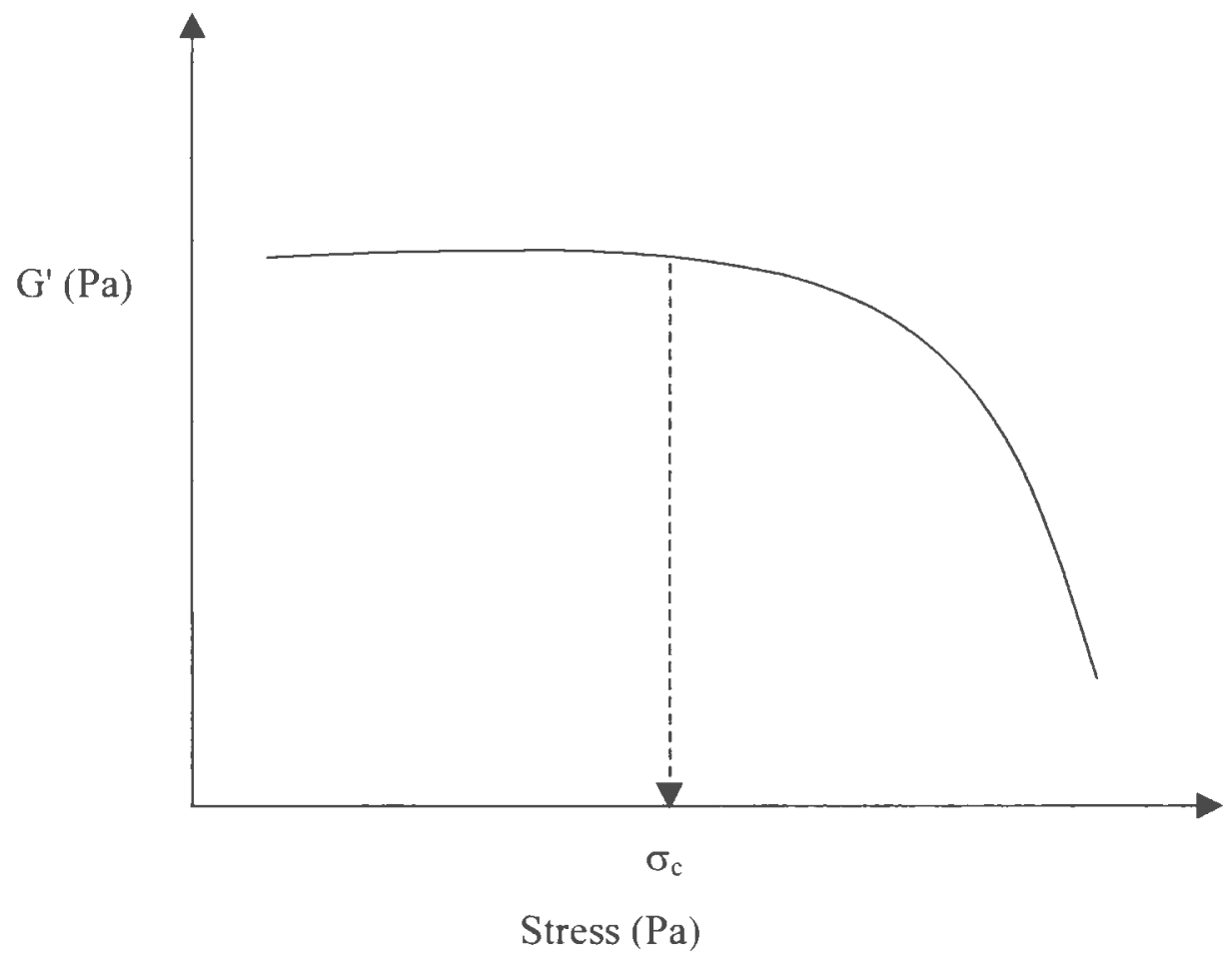

Figure 3. Schematic representation of critical stress determination. 


\section{EXPERIMENTAL}

\section{MATERIALS}

Polymers used: The structures, molecular weights and nature of the gels studied are given in Table 1. Cellulose is a naturally occurring polymer of $\beta$-D-glucopyranose. Cellulose derivatives used in this study were sodium carboxymethylcellulose (Na CMC), methyl cellulose (Methocel A4C) and hydroxypropyl methyl cellulose (Methocel K4M). They have a common polymeric backbone of cellulose made up of $\beta$-anhydroglucose unit with one primary and two secondary hydroxyl groups at the $\mathrm{C}_{2}, \mathrm{C}_{3}$ and $\mathrm{C}_{5}$ positions. They form linear homopolymers, very hydrophilic in nature and having a $\mathrm{pH}$ of about 7 in dilute solutions. A sodium carboxymethyl substituent has replaced one or more of the hydroxyl groups to have a degree of substitution of about $0.5-1.0$. In methylcellulose, methyl groups have been introduced to the $C_{3}$ and $C_{5}$ positions. Methocel $A 4 C$ has a degree of substitution of approximately 1.8. In hydroxypropyl methylcellulose a hydroxypropyl methyl group has been introduced to $\mathrm{C}_{2}$ and $\mathrm{C}_{5}$ positions. Methocel K4M has a degree of substitution of about 1.4 (Kamide and Saito, 1987). Cellulose derivatives used in this study form free flowing transparent gels at the lower end of the concentration used. At higher concentrations they form elastic gels. The transparency is due to the completely amorphous state of the chains in their macromolecular structure.

Carrageenans are linear polysaccharides of alternating $\beta$-D-galactopyranosyl and 1,4-linked $\alpha$-D-galactopyranosyl units. They exist in three basic forms as, lambda, kappa and iota carrageenans. Lambda carrageenan is a non-gelling carrageenan with about $70 \%$ sulfated pyranosyl units (sulfate substitutions in the 2,5 positions of $\beta$-Dgalactopyranosyl and of the $\alpha-\mathrm{D}$-galactopyranosyl). 
Table I. Chemical Structures, Molecular Weights and Nature of the Gels Studied.

\begin{tabular}{|c|c|c|c|c|}
\hline Polymer & Chemical Structure & $\begin{array}{c}\text { Average } \mathrm{M}_{\mathrm{w}} \\
\text { (Daltons } \times 10^{5} \text { ) }\end{array}$ & $\begin{array}{l}\text { Structure in Gel } \\
\text { Form }\end{array}$ & Chemical Composition \\
\hline $\begin{array}{l}\text { Lambda } \\
\text { Carrageenan (Type } \\
\text { RLV Genugel, } \\
\text { Hercules, } \\
\text { Wilmington, DE, Lot } \\
\text { \#627240) }\end{array}$ & & $3-5$ & $\begin{array}{l}\text { long lincar } \\
\text { chains forming } \\
\text { double hulices }\end{array}$ & $\begin{array}{l}\text { Linear polysaucharides having } \\
\text { altemating } \beta-D \text { - } \\
\text { galactopıranosyl and I.4-linked } \\
\alpha \text {-D-galactopyranosyl units } \\
\text { with sul fate substitutions in the } \\
2.5 \text { positions of } \beta-D \text { - } \\
\text { galactopyranosyl and of the } \alpha \text { - } \\
\text { D-galactopyranosyl }\end{array}$ \\
\hline $\begin{array}{l}\text { Kappa Carrageenan } \\
\text { (Type VV7IP } \\
\text { Genugel, Hercules, } \\
\text { Wilmington, DE Lot } \\
\# 627260 \text { ) }\end{array}$ & & $3-5$ & $\begin{array}{l}\text { Long linear } \\
\text { chains forming } \\
\text { double helices }\end{array}$ & $\begin{array}{l}\text { Linear polysaccharides having } \\
\text { alternating } \beta \text {-D- } \\
\text { galactop!ranosyl and 1.4-linked } \\
\alpha \text {-D-galactopyranosyl units } \\
\text { with a sul fate substitution in the } \\
\text { 4 position of } \beta \text {-D- } \\
\text { galactopyranosyl and a 1.4- } \\
\text { linked 3.6-anhydro-D-galactose }\end{array}$ \\
\hline $\begin{array}{l}\text { lota Carrageenan } \\
\text { (Type VVIIPF } \\
\text { Genugel, Hercules, } \\
\text { Wilmington. DE Lot } \\
\text { \#627220) }\end{array}$ & & $3-5$ & $\begin{array}{l}\text { Long linear } \\
\text { chains forming } \\
\text { double helices }\end{array}$ & $\begin{array}{l}\text { Linear polysaccharides having } \\
\text { alternating } \beta \text {-D- } \\
\text { galactopıranosyl and 1.4-linked } \\
\text { \&-D-galactopyranosyl units } \\
\text { with a sulfate substitution in the } \\
2.4 \text { positions of } \beta \text {-D- } \\
\text { galactopyranosyl and a 1.4- } \\
\text { linked 3.6-anhydro-D-galactose }\end{array}$ \\
\hline $\begin{array}{c}\text { Pectin } \\
\text { (Hercules. } \\
\text { Wilmington, DE, } \\
\text { Lot\#FP1013478) }\end{array}$ & & $0.1-1.3$ & $\begin{array}{l}\text { Long linear } \\
\text { chains forming } \\
\text { the double ribbon } \\
\text { conformation }\end{array}$ & $\begin{array}{c}\alpha-1 \rightarrow 4 \text { linked } D \text {-galacturonic } \\
\text { acid with traces of L-rhamose } \\
\text { residues }\end{array}$ \\
\hline $\begin{array}{l}\text { Water Lock A-100 } \\
\text { (Grain Processing } \\
\text { Co., Muscatine. IA } \\
\text { Lot } \$ 9613001 \text { ) }\end{array}$ & $\left.-\left[\mathrm{H}_{2} \mathrm{CN}_{1}\right]-[\mathrm{CH}, \mathrm{N})\right]$ & $\mathrm{NA}^{*}$ & $\begin{array}{c}\text { Graft copolymer } \\
\text { (Branched) }\end{array}$ & $\begin{array}{l}\text { a starch backbone and grafted } \\
\text { side chains of poly (2- } \\
\text { propenamide-co-2-propenoic } \\
\qquad \text { acid) }\end{array}$ \\
\hline
\end{tabular}


Table 1. Continued.

\begin{tabular}{|c|c|c|c|c|}
\hline $\begin{array}{l}\text { Water I ock A-180 } \\
\text { (Grain Procassing } \\
\text { Co., Muscaline, IA } \\
\text { (.ot } \$ 9614021 \text { ) }\end{array}$ & 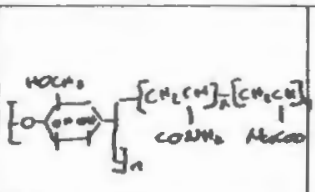 & $\mathrm{N} \wedge^{*}$ & $\begin{array}{l}\text { Ciraft copolymer } \\
\text { (Branched) }\end{array}$ & $\begin{array}{l}\text { a starch backbonc and grafled } \\
\text { side chains of poly (2- } \\
\text { propenamide-oo-2-propenoic } \\
\text { acid) }\end{array}$ \\
\hline $\begin{array}{l}\text { Water l.ock DD-223 } \\
\text { (Grain Processing } \\
\text { Co.. Muscatinc. IA } \\
\text { Lot HW9501401) }\end{array}$ & cores & $\mathrm{NA}^{*}$ & $\begin{array}{l}\text { Graft copolymer } \\
\text { (Branched) }\end{array}$ & $\begin{array}{l}\text { a starch hackbonc and grafted } \\
\text { sick chains of poly (2- } \\
\text { propenamide-co-2-propenoic } \\
\text { acid) }\end{array}$ \\
\hline $\begin{array}{l}\text { Water Lock G-400 } \\
\text { (Grain Processing } \\
\text { Co., Muscatine, IA } \\
\text { Lot } \# 9512002 \text { ) }\end{array}$ & 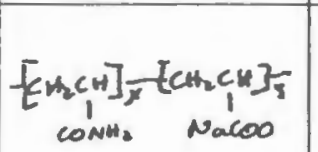 & NA* & Linear copolymer & $\begin{array}{l}\text { poly (2-propenamide-co-2- } \\
\text { propenoic acid) }\end{array}$ \\
\hline $\begin{array}{l}\text { Guar gum } \\
\text { (Hercules, } \\
\text { Wilmington, DE, } \\
\text { Lot \# A6362B) }\end{array}$ & & $18-20$ & $\begin{array}{l}\text { I. inear alternating } \\
\text { copolymer }\end{array}$ & $\begin{array}{c}\text { Linear chain of } \beta-D \text { - } \\
\text { mannopyranosyl } 1,4-\text { linked with } \\
\text { a single member } \alpha-D \text { - } \\
\text { galactopyranosyl unit occurring } \\
\text { as side branches linked }(1 \rightarrow 6) \\
\text { which makes it }\end{array}$ \\
\hline $\begin{array}{c}\text { Na CMC } \\
\text { (Hercules, } \\
\text { Wilmington, DE, } \\
\text { Lot\#FPI013593), }\end{array}$ & & $2-4$ & $\begin{array}{c}\text { Linear } \\
\text { homopolymer }\end{array}$ & $\begin{array}{l}\beta \text {-D-glucopyranose with } \\
\text { Sodium Carboxymethyl } \\
\text { substitutions }\end{array}$ \\
\hline $\begin{array}{l}\text { Hydroxypropyl } \\
\text { Methyl cellulose } \\
\text { (DOW Corp.. } \\
\text { Midiand Mich., } \\
\text { Lot\#MM9004112K) }\end{array}$ & Castects & 0.9 & $\begin{array}{c}\text { Linear } \\
\text { homopolymer }\end{array}$ & $\begin{array}{l}\beta \text {-D-glucopyranose with } \\
\text { hydroxypropyl methyl } \\
\text { substitutions in the } C_{2} \text { and } C_{5} \\
\text { positions }\end{array}$ \\
\hline $\begin{array}{l}\text { Methyl cellulose } \\
\text { (DOW Corp., } \\
\text { Midland Mich.. } \\
\text { Lot\#MM94 10402A) }\end{array}$ & ${ }_{\text {Cats }}$ & 0.4 & $\begin{array}{c}\text { Linear } \\
\text { homopolymers }\end{array}$ & $\begin{array}{l}\text { Sodium Carboxymethyl with } \\
\text { methyl groups substitutions in } \\
\text { the } C_{3} \text { and } C_{3} \text { positions }\end{array}$ \\
\hline $\begin{array}{l}\text { Carbopol 971 } \\
\text { (BF Goodrich, } \\
\text { Cleveland, OH, Lot } \\
\text { H AJ01066) }\end{array}$ & 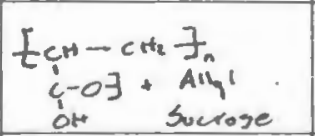 & $10-40$ at $2 \%$ & $\begin{array}{l}\text { Highly cross- } \\
\text { linked chains }\end{array}$ & $\begin{array}{l}\text { Poly(acrylic)acid cross linked } \\
\text { with allyl sucrose }\end{array}$ \\
\hline $\begin{array}{l}\text { Bentonite RV } \\
\text { (Rheox Co., } \\
\text { Highstown, NJ. } \\
\text { 1.ot\#AS189A }\end{array}$ & $\begin{array}{c}\mathrm{Na}_{03}(\mathrm{Mg} \\
(\mathrm{i})_{3} \mathrm{Si}_{4} \mathrm{O}_{10}(\mathrm{~F} . \mathrm{OH})\end{array}$ & 0.5 & $\begin{array}{c}\text { Suspended } \\
\text { hectorite particles } \\
\text { with } \\
\text { characteristics of } \\
\text { low concentration } \\
\text { polymers }\end{array}$ & Suspension \\
\hline
\end{tabular}

*NA: Manufacturing company could not provide molecular wcight dara 
Kappa carrageenan has a sulfate substitution in the 4 position of $\beta$-Dgalactopyranosyl and a 1,4-linked 3,6-anhydro-D-galactose. Iota carrageenan has the same structure as kappa carrageenan with an extra sulfate substitution in the 2 position of the 3,6-anhydro-D-galactose. Their viscous properties depend mainly on their unbranched, linear macromolecular structure and ionizing potential. The repulsion of the ester sulfated groups along the polymer chain causes the molecule to be rigid and extended while their hydrophobic nature causes them to be surrounded by a sheath of immobilized water molecules. Kappa and iota carrageenans gel by forming a double helix structure (Clark and Ross-Murphy, 1987). Carrageenans used in this study form free flowing gels at lower concentrations. At higher concentrations a more viscous gel characterized by higher elasticity is formed. The gels are brown opaque in color. The opaqueness is due to the double helix conformation of the chains, which tends to scatter light through the gel.

Guar gum is a carbohydrate polymer, which is useful as a thickening agent for water. It is a linear chain of $\beta$-D-mannopyranosyl 1,4-linked with a single member $\alpha$-Dgalactopyranosyl unit occurring as side branches linked $(1 \rightarrow 6)$ which makes it a linear, alternating copolymer (Davidson, 1980). Guar gum gels are free flowing gels at low concentrations and become more viscous with a green hue as the concentration is increased. They are opaque in nature due to the same macromolecular conformation as carrageenans. Pectins are polysaccharides that are found in nature as structural components of cell walls in fruits. Although they are branched in their native form, the one used in this study was a linear polymers of $\alpha-1 \rightarrow 4$ linked D-galacturonic acid interrupted occasionally by L-rhamose residues. Their macrostructures form the double 
ribbon conformation similar to that of alginates (Davidson. 1980). Pectins form free flowing gels at the lower end of the concentration and slowly increase their viscous properties as the concentration is increased. The form gels with a brown hue. They are opaque in nature due to the double ribbon conformation of the macromolecular structure of the chains which scatters light.

Water Lock A-100, A-180 and DD-223 are semi synthetic polymers composed of a starch backbone and grafted side chains of poly (2-propenamide-co-2-propenoic acid) mixed with sodium and/or aluminum salts. Their molecular weight was unavailable during this study due to the fact that these products are new in the market. They are able to bind large quantities of water at low concentrations. Water Lock G-400 is a totally synthetic polymer composed only of linear chains of the poly (2-propenamide-co-2propenoic acid). Water Locks are solid elastic gels even at low concentrations. They have a brown hue and their opacity is increased as the concentration increases. Carbopol 971 is made of poly(acrylic)acid cross linked with allyl sucrose. Carbopols are widely used in the cosmetics and pharmaceutical industries for a variety of purposes changing from adhesive to water binding agents (Lochhead and Fron, 1993). They form elastic gels even at low concentrations. They are transparent in nature due to their amorphous state in the cross-linked swollen state. Bentonite RV is a mineral from the montmorillonite group with chemical composition of $\mathrm{Na}_{0.33}\left(\mathrm{Mg}, \mathrm{Li}_{3} \mathrm{Si}_{4} \mathrm{O}_{10}(\mathrm{~F}, \mathrm{OH})_{2}\right.$. It forms clay suspensions rheologically similar to those produced by low concentration polymer solutions. They are opaque liquid suspensions at low concentrations but their viscosity rapidly increases as the concentration is increased (Roberts et al., 1974). 
Bentonite RV, sodium carboxy methyl cellulose, methyl cellulose (Methocel A4C), hydroxypropyl methyl cellulose (Methocel KM4), pectin USP-100, Carbopol 971 NF, Carrageenan RLV, VV11PF and VV71P, guar gum U-NF and Water Lock A-100, A-1 180, DD-223 and G-400 were used to form gels.

\section{METHODS}

Preparation of the gels: All the gels except Carbopol 971 were prepared by adding sterilized distilled water to the polymer powder to obtain the pre-selected weight by weight concentration. The mixture was left to swell for $24 \mathrm{hr}$., then the gels were homogenized using a Fisher Scientific (Pittsburgh, PA) model Dyna-mix stirrer at 1000 rpm for $1 \mathrm{hr}$.

Their $\mathrm{pH}$ was measured using a Fisher Scientific (Pittsburgh, PA) model Accumet $20 \mathrm{pH}$ meter prior to the rheological measurements. Carbopol 971 was prepared to a neutral $\mathrm{pH}$ by using the appropriate amount of $\mathrm{NaOH} 1 \mathrm{~N}$ solution for each gel concentration. 
Rheometric measurements: All of the measurements were taken within 24-48 hours of preparation. The rheological behavior of the gels was characterized at each concentration using a Bholin instruments rheometer model CVO. The elastic modulus $\left(\mathrm{G}^{\prime}\right)$, the viscous modulus $\left(G^{\prime \prime}\right)$, the complex viscosity $\left(\eta^{*}\right)$, the complex modulus $\left(G^{*}\right)$, the strain $(\gamma)$ and phase angle $(\alpha)$ were measured using a stainless steel, plate and plate spindle number 4 , at a strain range of $0.00075-15 \mathrm{~mm}$, a frequency of $0.05 \mathrm{~Hz}$ and a $1 \mathrm{~mm}$ gap. Measurements were taken at a constant temperature of $25^{\circ} \mathrm{C}$. The critical stress $\left(\sigma_{\mathrm{c}}\right)$ at G' was further calculated for every gel concentration using the instrument's output.

\section{RESULTS AND DISCUSIONS}

Description and Comparison of Flow Properties of the gels: The rheograms obtained for each gel at each concentration are 70 . The gel concentrations varied from $0.3 \%$ to $7.0 \%$ allowing at least a three fold concentration range for each gel. The rheograms of five different concentrations of each gel were determined, Table II. Their consistencies changed from free flowing to hard elastic gels. Due to the volume of the data obtained, only the rheological parameters at the linear region, the phase angles and the rheological parameters at the critical stress are presented in Table II. The rheograms obtained demonstrated two types of rheological behavior: those which demonstrated a decrease in G" with increasing stress and those which demonstrated an increase in G" with increasing stress. 
Table II. Rheological parameters of the gels studied at frequency of $0.05 \mathrm{~Hz}$ and a stress range of $0-100 \mathrm{~Pa}$.

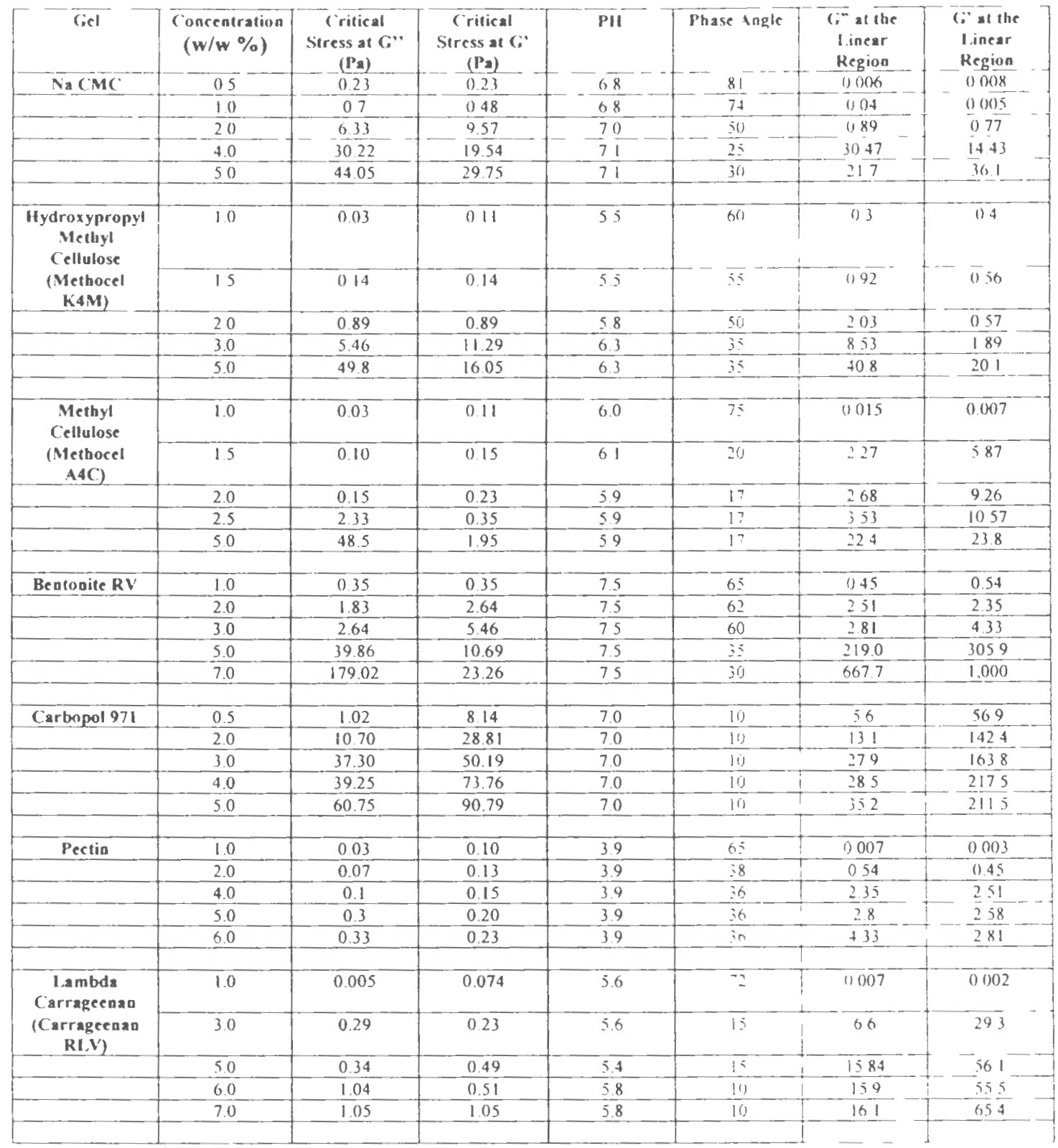


Table II. Continued

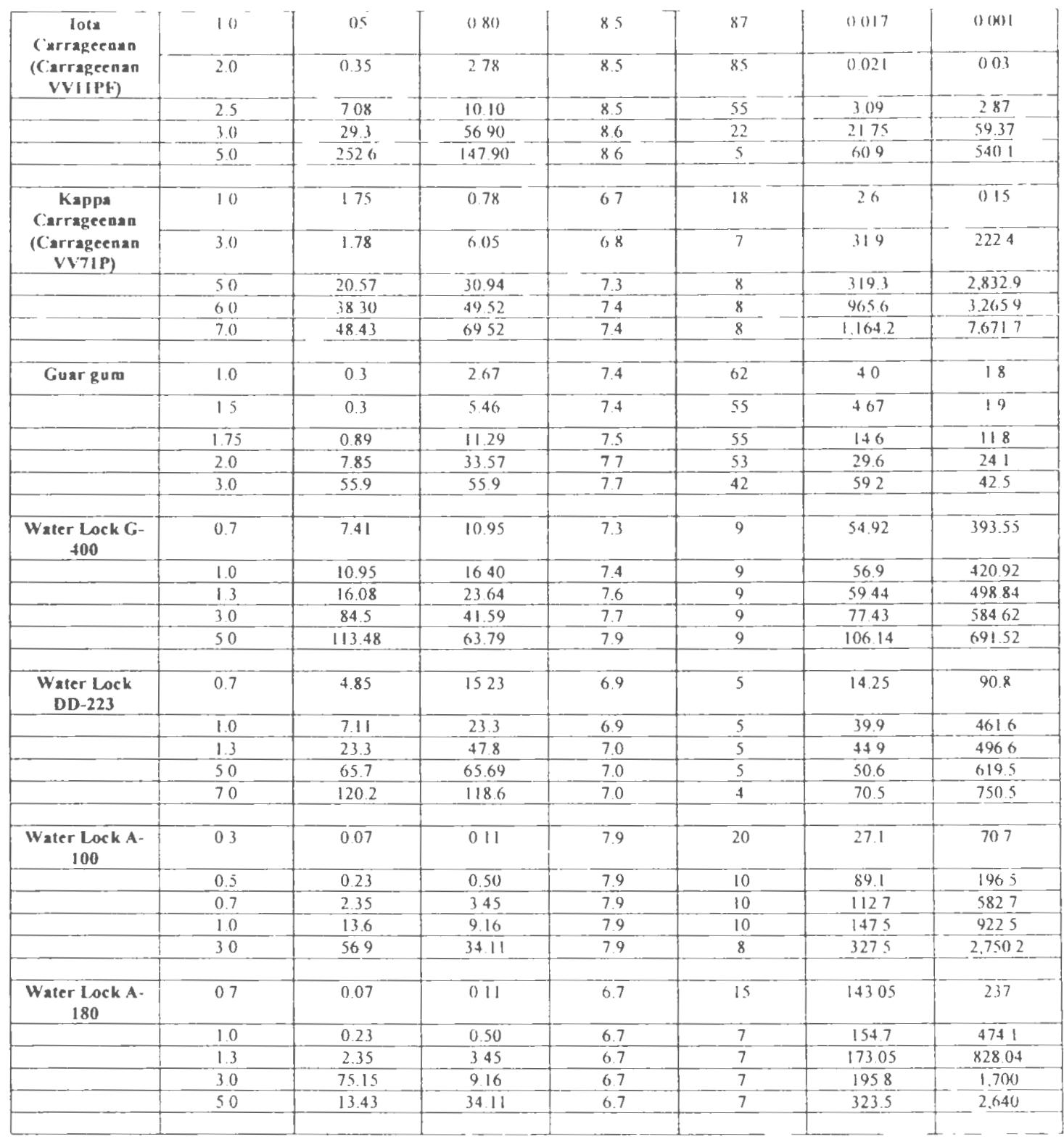


Sodium carboxy methyl cellulose, methyl cellulose, pectin and guar gum can be included in the first group and are shown in Figure 4A, B, C and D. Their $\alpha$ values are in the range of $40^{\circ}$ to $90^{\circ}$. Sodium CMC presents higher G" than $G^{\prime}$ at lower concentrations, indicating a predominantly viscous body. At $2 \%$ concentrations the phase angle $(\alpha)$ is in the order of $50^{\circ}$ also demonstrating the viscous nature of the gel. But at $4 \%$ concentration the G' becomes higher than G" and $\alpha$ goes down to $25^{\circ}$ (Table II). This is probably due to entanglement of the chains, which hardens the structure. Hydroxypropyl methyl cellulose (Methocel K4M) tends to denote a two step decrease in G', similar to Ferry's description for the uncross-linked polymers of high molecular weight (Figures 4A and B). Pectin has a G' almost equal as G' also denoting a viscous nature, corroborated with a high $\alpha\left(40^{\circ}\right)$, however at $6 \%$ concentration $G^{\prime}$ becomes higher than G" and $\alpha$ decreases significantly (Table II). Pectin is also showing a very soft, but early drop in G' showing a linear low molecular weight polymer with a wide molecular weight distribution.

Bentonite RV (Figures 5A and B) on the other hand is a clay suspension showing the behavior of a low molecular weight polymer having higher G" than G'. The gel is free flowing at $1 \%$, where there is not much change in $\alpha$ at $1 \%$, demonstrating a broader, less steep increase at a range of 65 to $90^{\circ}$, whereas the phase angle $\alpha$ at $5 \%$ concentration shows a steep increase with increased stress at around $40 \mathrm{~Pa}$.

Gels like Carbopol 971 demonstrated shear thickening behavior in their viscous modulus, $\mathrm{G}^{\prime \prime}$ with increased stress (Figures 6A, B and C). This behavior is accentuated with increasing concentration. However, the concentration has not influenced the phase 


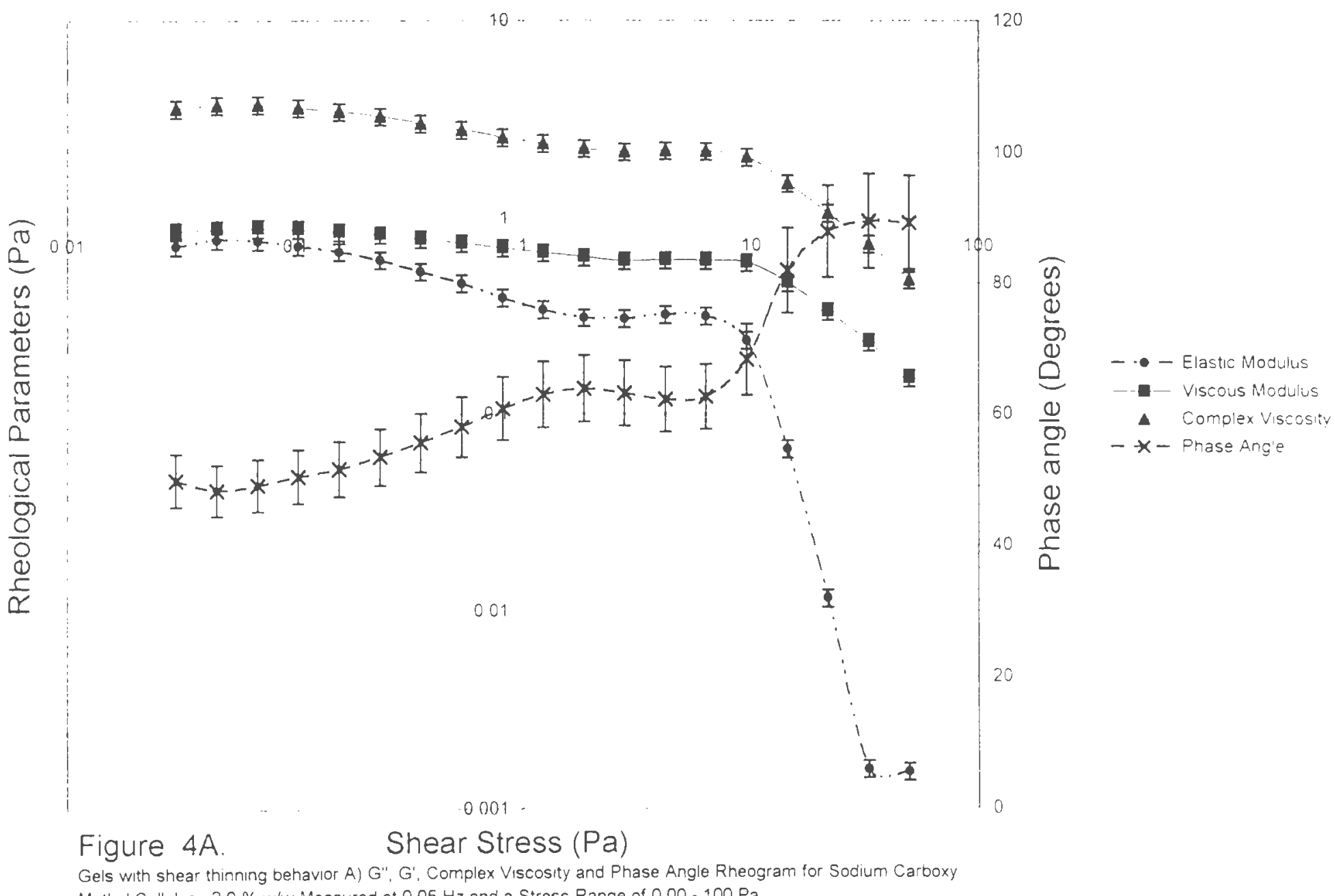

Gels with shear thinning behavior A) G', G', Complex Viscosity and Phase Angle Rheogram for Sodium Carboxy Methyl Cellulose $20 \%$ w/w Measured at $005 \mathrm{~Hz}$ and a Stress Range of $000-100 \mathrm{~Pa}$ 


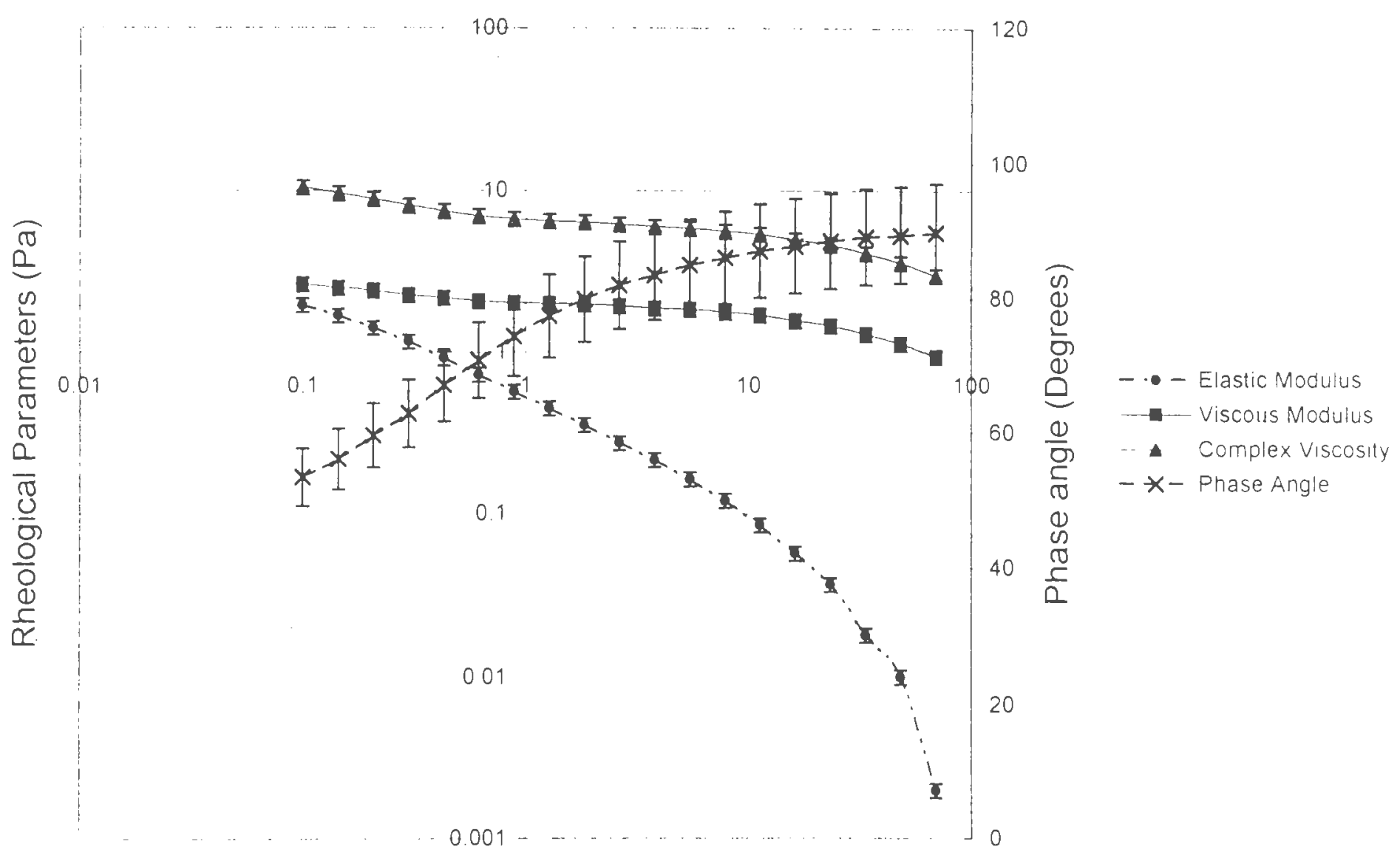

Figure $4 B$

Shear Stress ( $\mathrm{Pa})$

Geis showing shear thinning behavior $G^{\prime \prime} G^{\prime}$ Complex Viscosity and Phase Angle Rheogram for Hydroxypropyl Nethyl Cellulose $20 \%$ w/w Measured at $005 \mathrm{~Hz}$ and a Stress Range of $000-100 \mathrm{~Pa}$ 


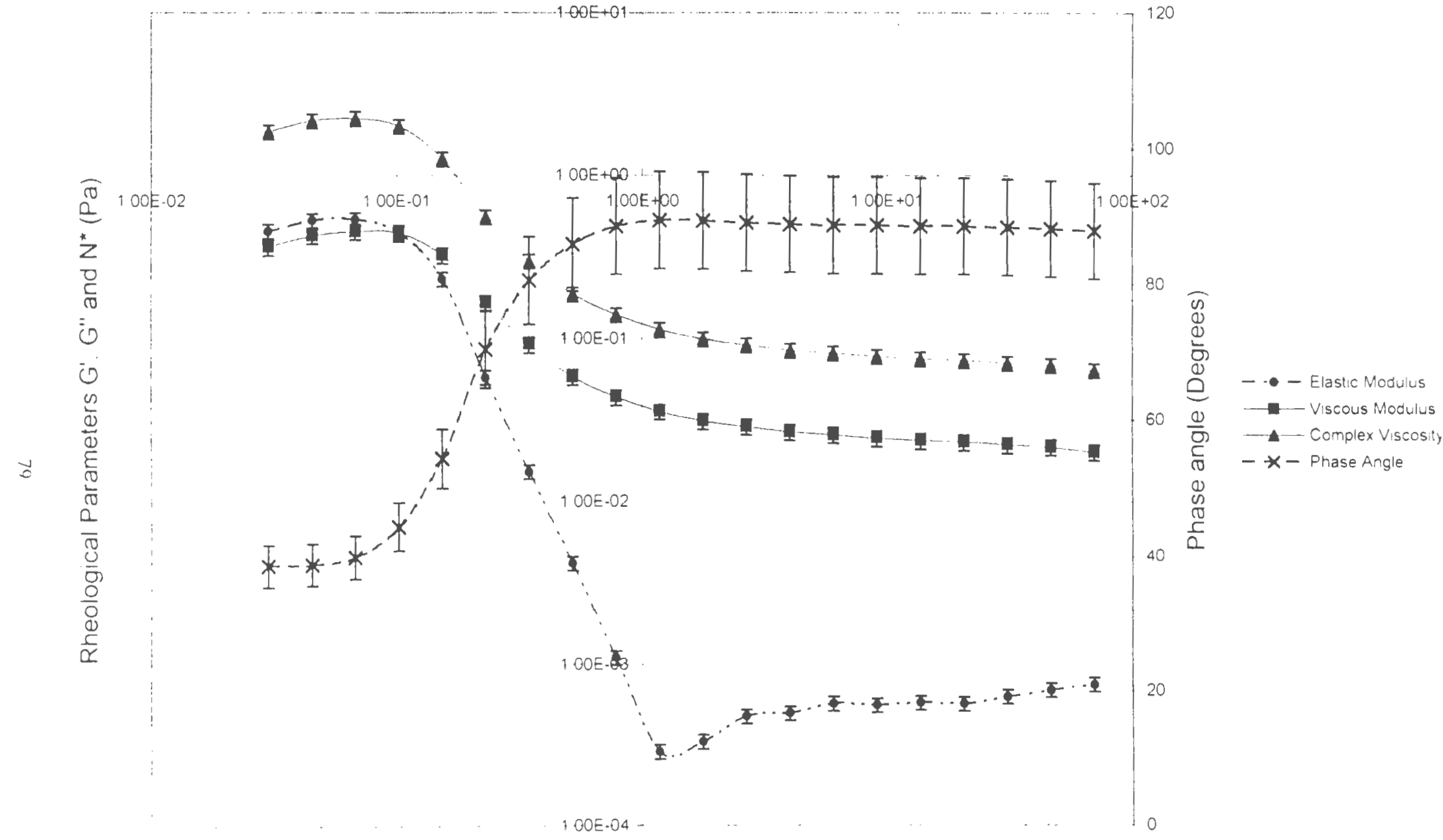

Figure 4C.

Shear Stress $(\mathrm{Pa})$

Gels with shear thinning behavior $G{ }^{*} G$ Complex Viscosity and Phase Angle Rheogram for Pectin $20 \%$ w/w Measured at

O JE r z ard a SHess Range of $000 \cdot 100 \mathrm{~Pa}$ 


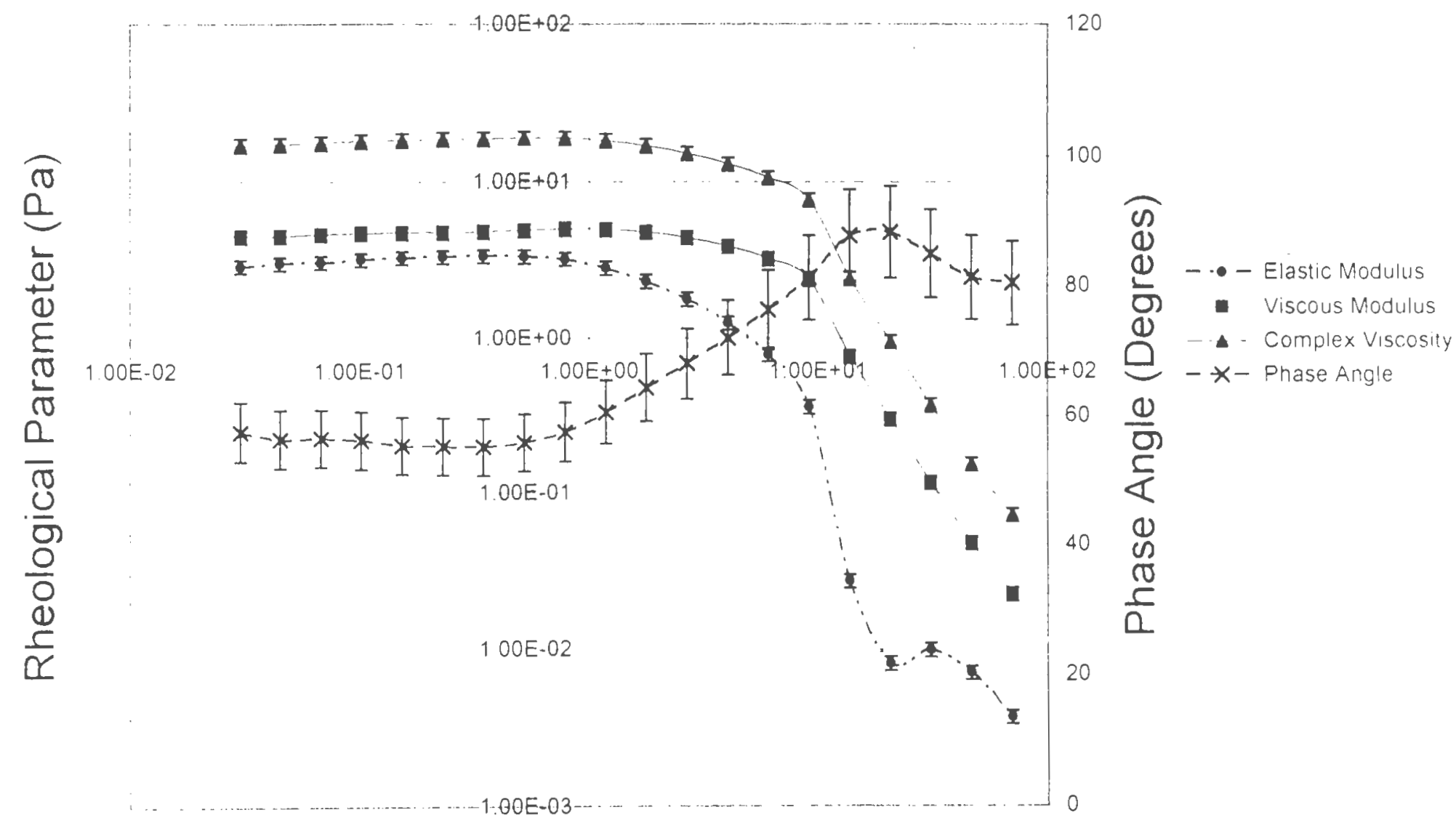

Figure 4D

Shear Stress (Pa)

G'. G' Complex Viscosity and Phase Angle Rheogram for Guar Gum 1 5\% w/w Measured at $0.05 \mathrm{~Hz}$ and a Stress Range of $0.00-100 \mathrm{~Pa}$ 


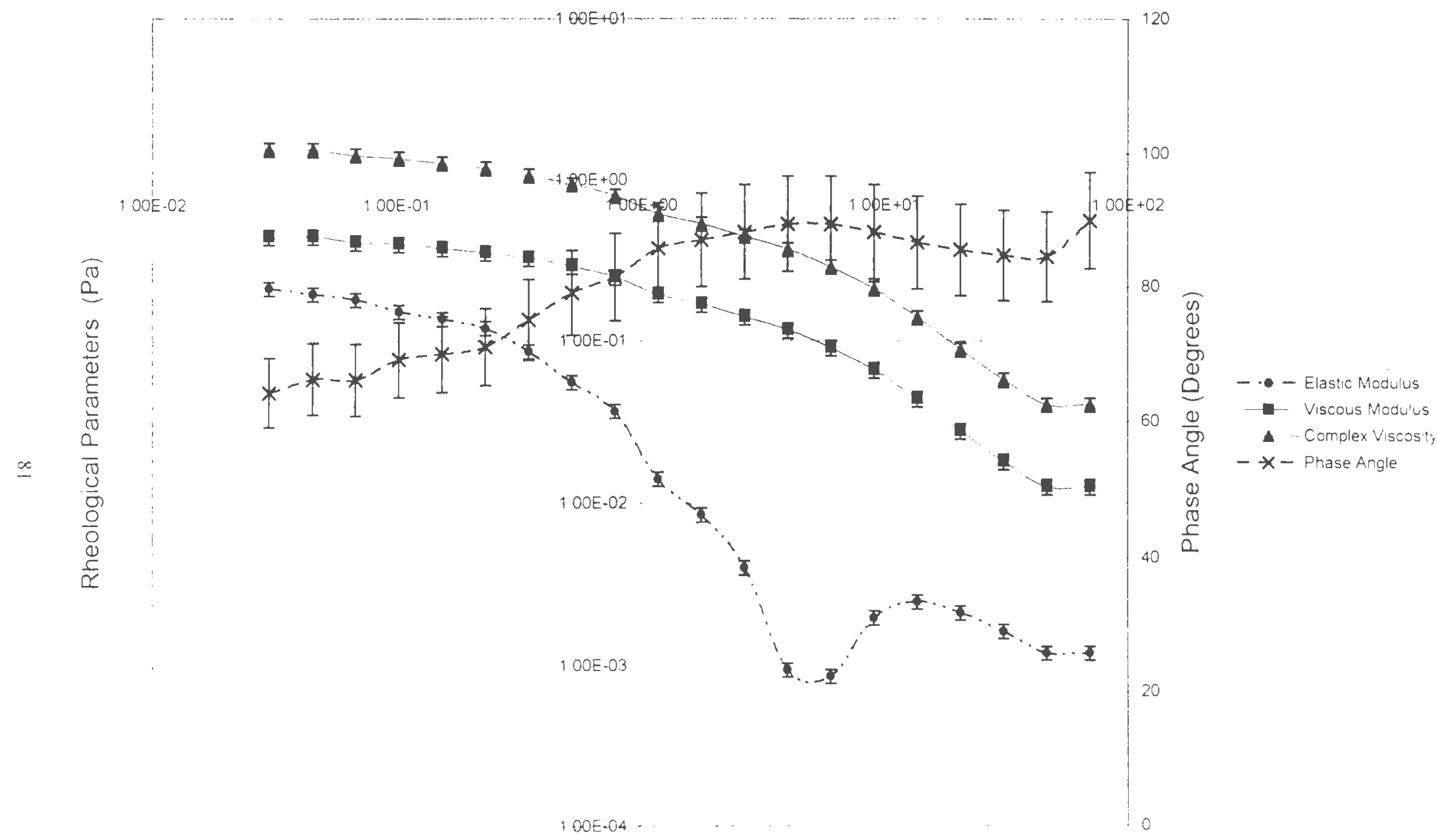

Figure 5A.

Shear Stress (Pa)

G. G Complex Viscosity and Phase Angle Rheogram for Bentonite RV $10 \%$ w/w Measured at $005 \mathrm{~Hz}$ and a Stress Pange of $0 \times 0.100 \mathrm{~Pa}$ 


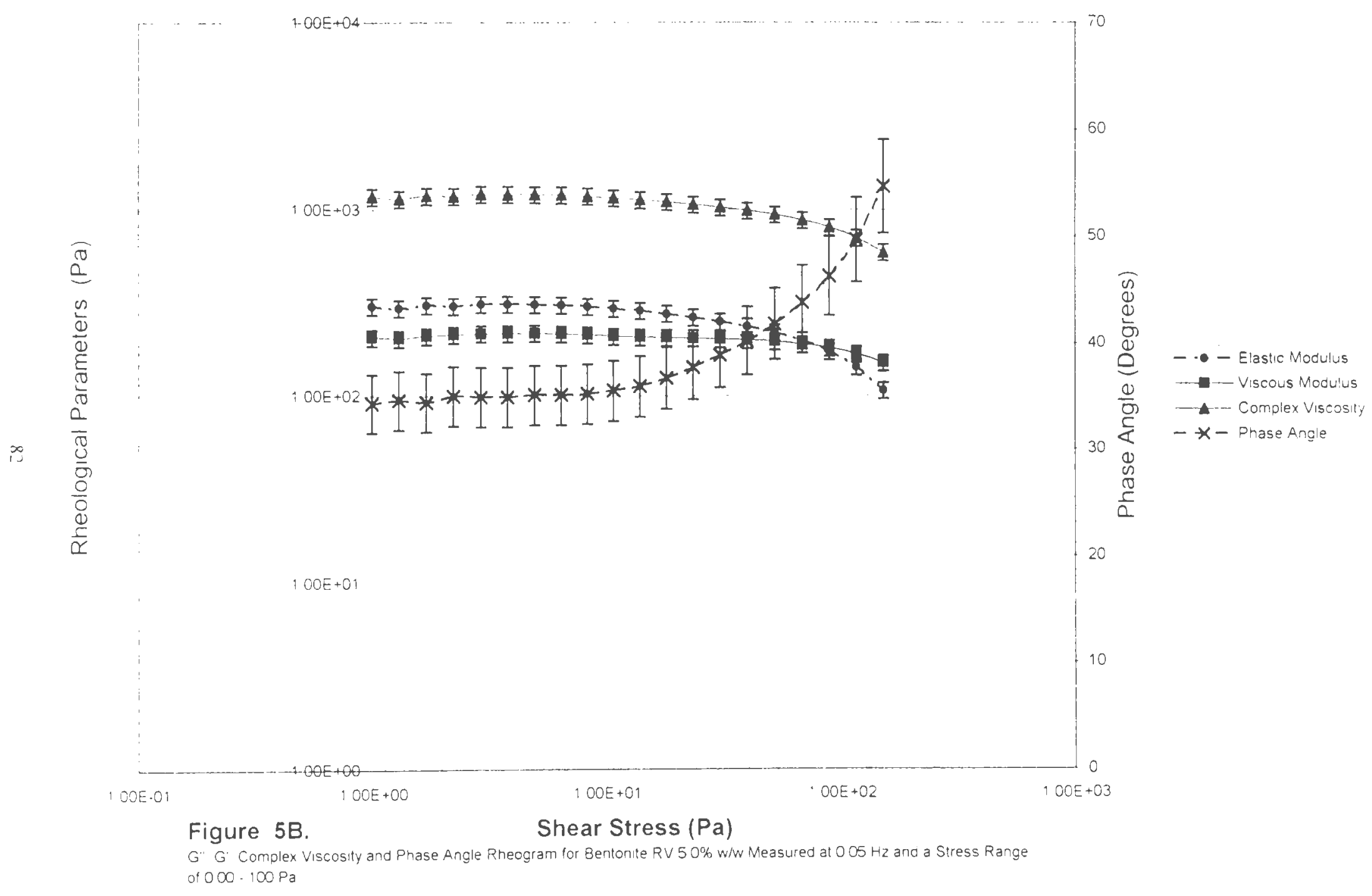




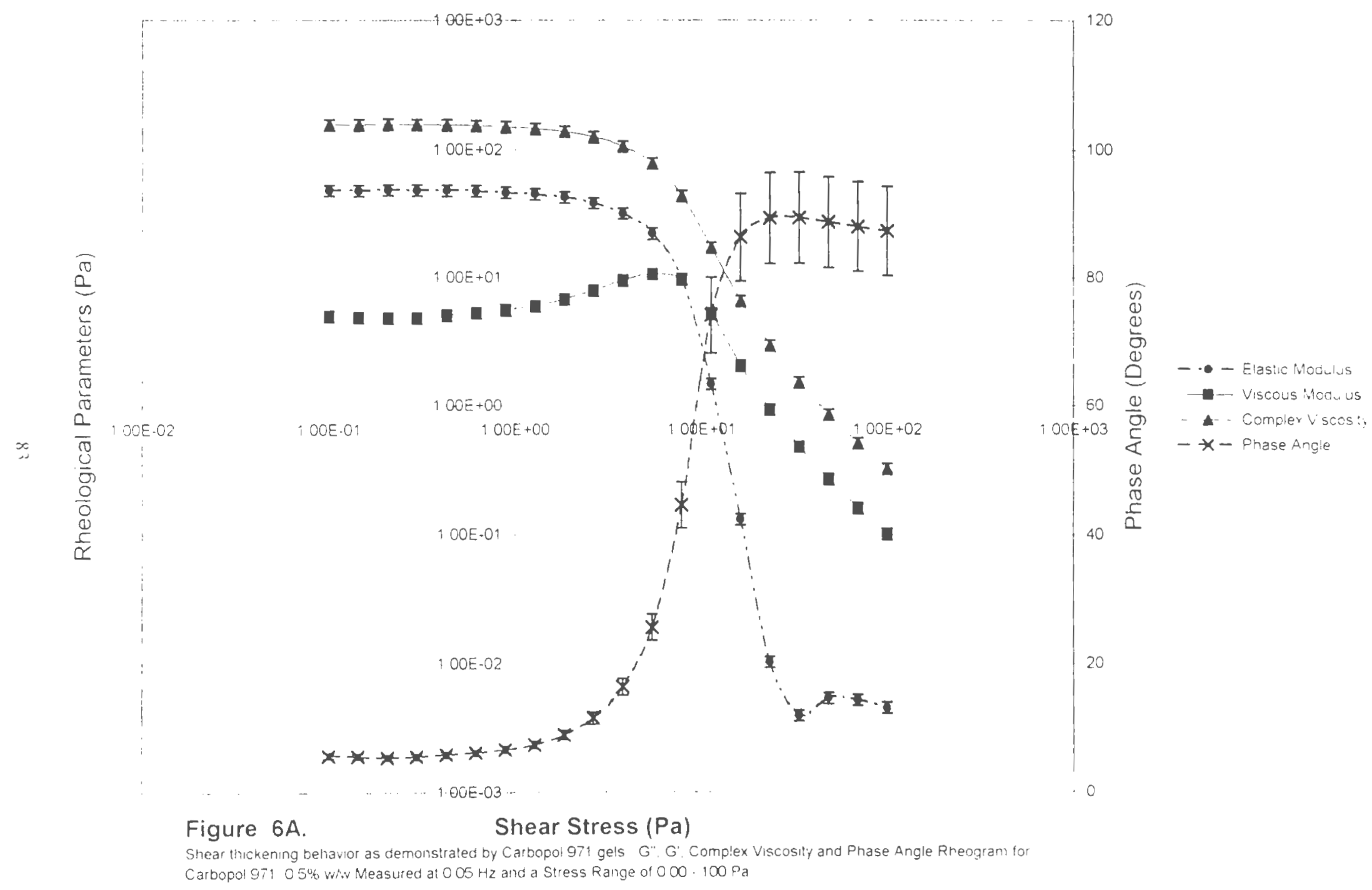




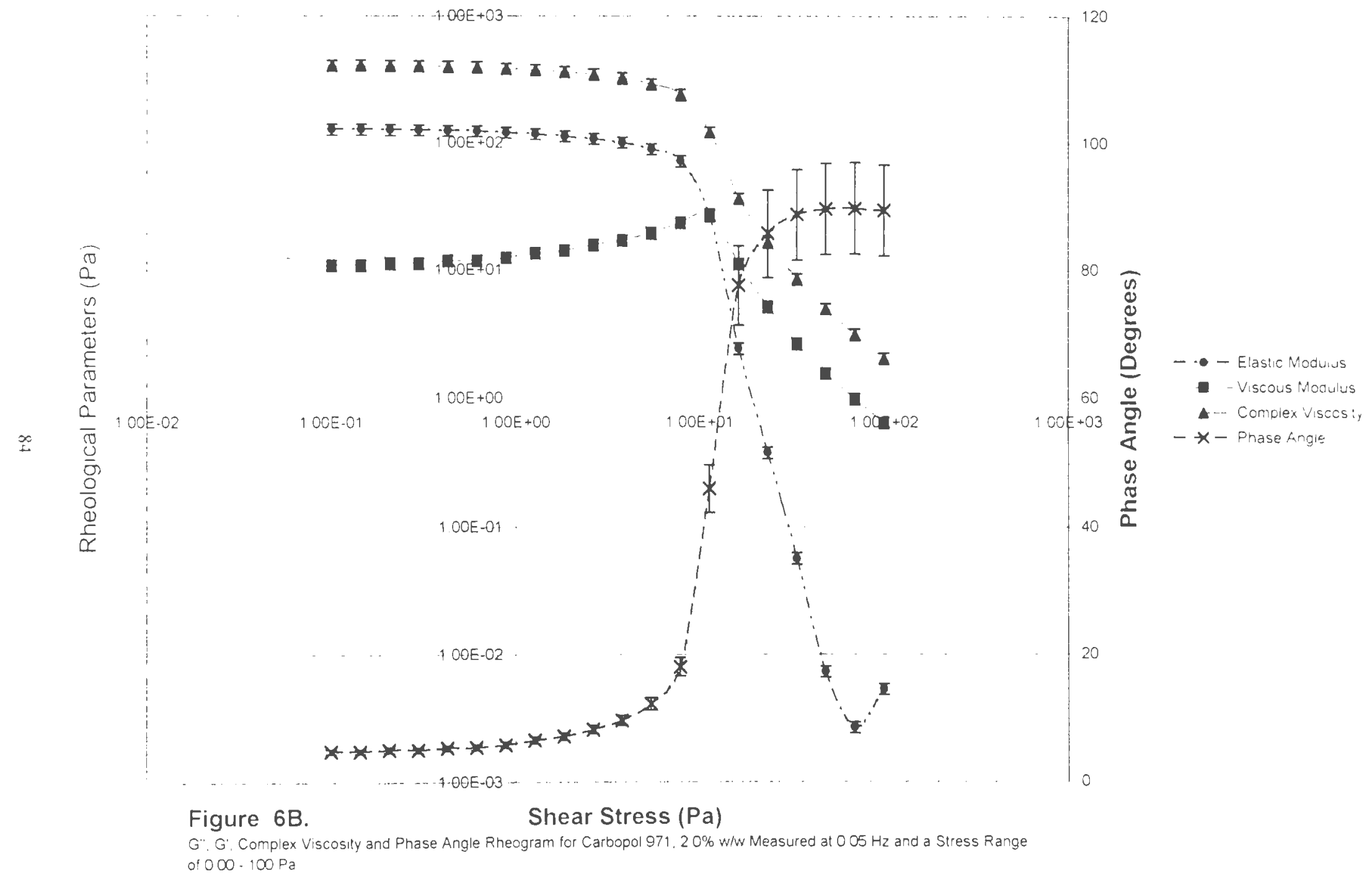




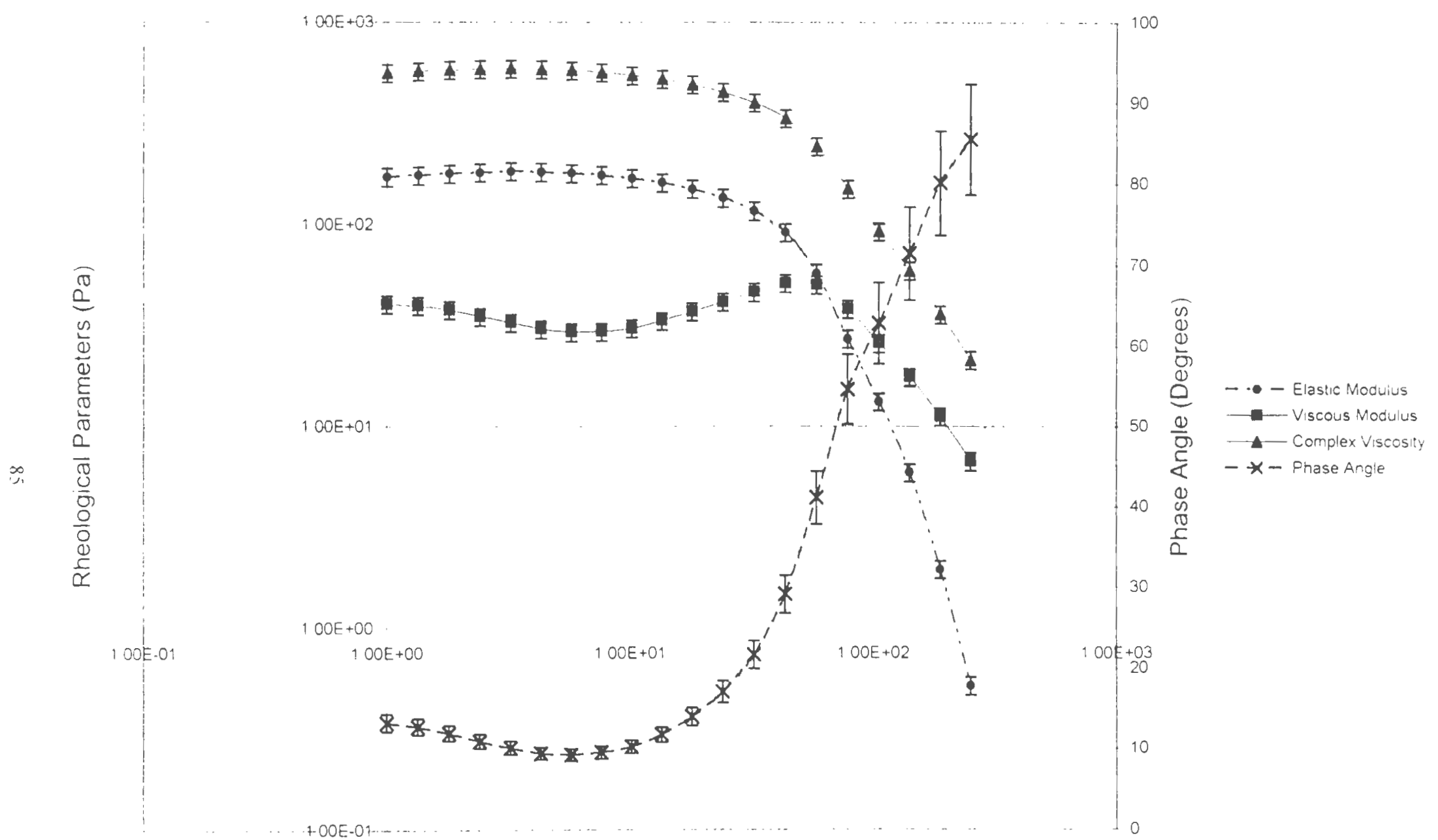

Figure $6 \mathrm{C}$.

Shear Stress $(\mathrm{Pa})$

G" G. Complex Viscosity and Phase Angle Rheogram for Carbopol $97150 \%$ w/w Measured at $005 \mathrm{~Hz}$ and a Stress Range 0 , $000 \cdot 100 \mathrm{~Pa}$ 
angle which remains at 10 between $0.5 \%$ to $5 \%$. Table II. The increase in G" with increasing stress can be explained by an increased entanglement of the chains and formation of solid like cores that is leading to breakage of the gel's internal structure with increasing shear stress. The rheograms for Carbopol 971 show a sharp decline in G' which is typical of high molecular weight cross-linked polymers with a narrow molecular weight distribution. Pectin on the other hand (Figure 4C) demonstrates a gradual decline in $G^{\prime}$ that is characteristic of a low molecular weight polymer with a broad molecular weight distribution. Carbopol 971 behaved as an elastic body throughout the stress range studied, denoting shear thickening properties. Its elastic nature is also obvious from its low phase angle $\left(\alpha=10^{\circ}\right)$ at all concentrations studied $(0.5-5.0 \%)$. There was not much differences between the phase angles of the $0.5 \%$ and $5.0 \%$ concentrations, showing a weak concentration dependence of the degree of elasticity, Figure 6A.

The rheograms for Carrageenans denote the fact that the degree of sulfate esterification influences the viscoelastic properties of the polymer. At $1 \%$ concentration, lambda carrageenan (Carrageenan RLV), the one with the highest degree of esterification shows an $\alpha$ value of almosi $30^{\circ}$ throughout most of the stress range studied. At about $2 \%$ concentration there is little increase in consistency (Table II). It coincides with a low elastic and viscous modulus measured in the order of $0.001-0.01 \mathrm{~Pa}$ (Figure 7A). At the same concentration, iota carrageenan (Carrageenan VV11PF), having a lesser degree of esterification than lambda carrageenan, is showing a similar high phase angle $\alpha$ of almost $90^{\circ}$; but a higher viscous modulus and a well defined linear region in the elastic modulus denotes higher viscoelastic properties than lambda carrageenan (Figure 7B). In both cases, the viscous modulus was found higher than the elastic modulus and almost 


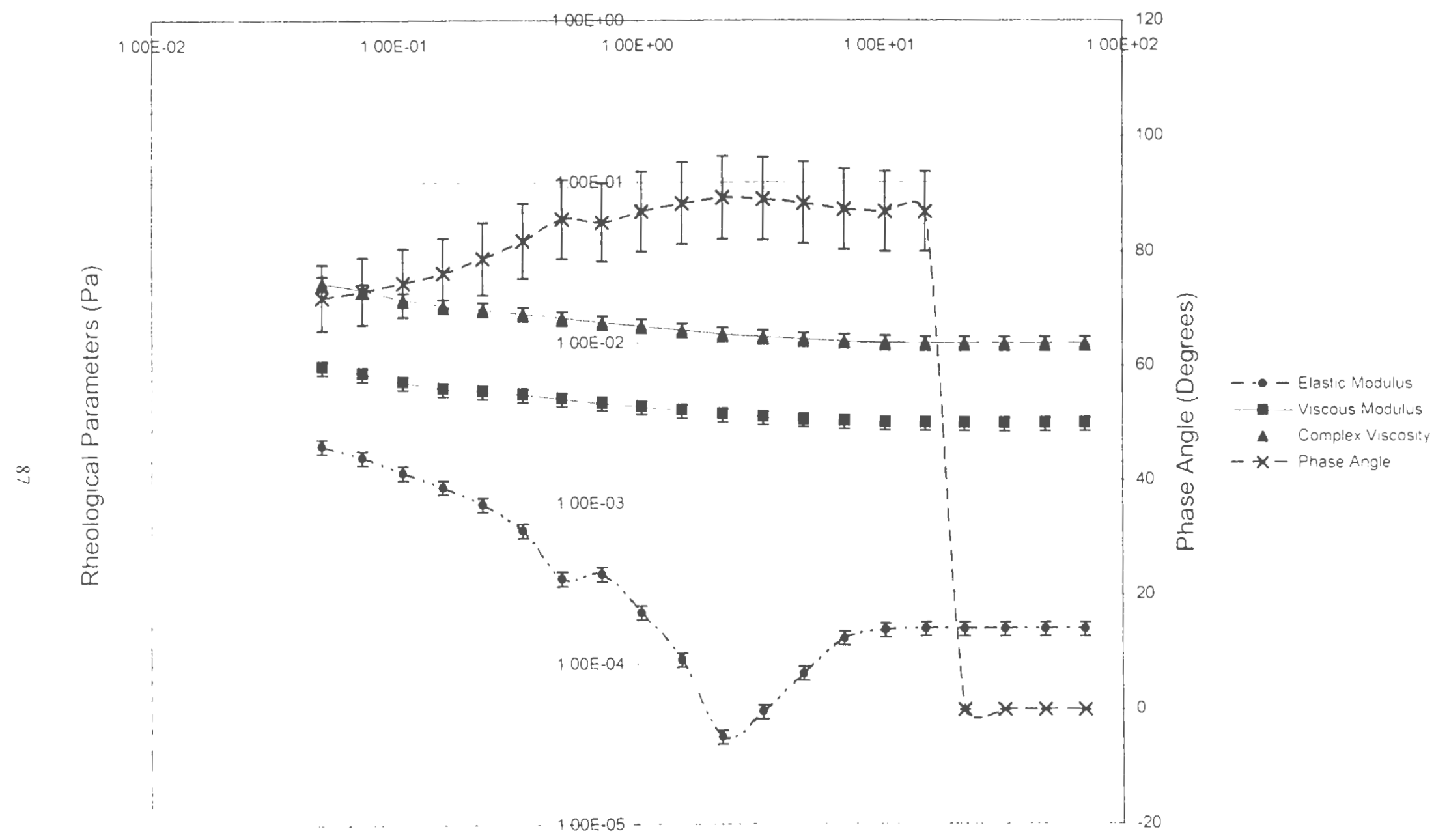

Figure $7 \mathrm{~A}$.

Shear Stress $(\mathrm{Pa})$

G G. Complex Viscosity and Phase Angle Rheogram for lambda carrageenan (Tyep RLV) $10 \%$ wiw Measured at $\mathrm{O} 05 \mathrm{~Hz}$ ard a Stress Range of $000 \cdot 100 \mathrm{~Pa}$ 


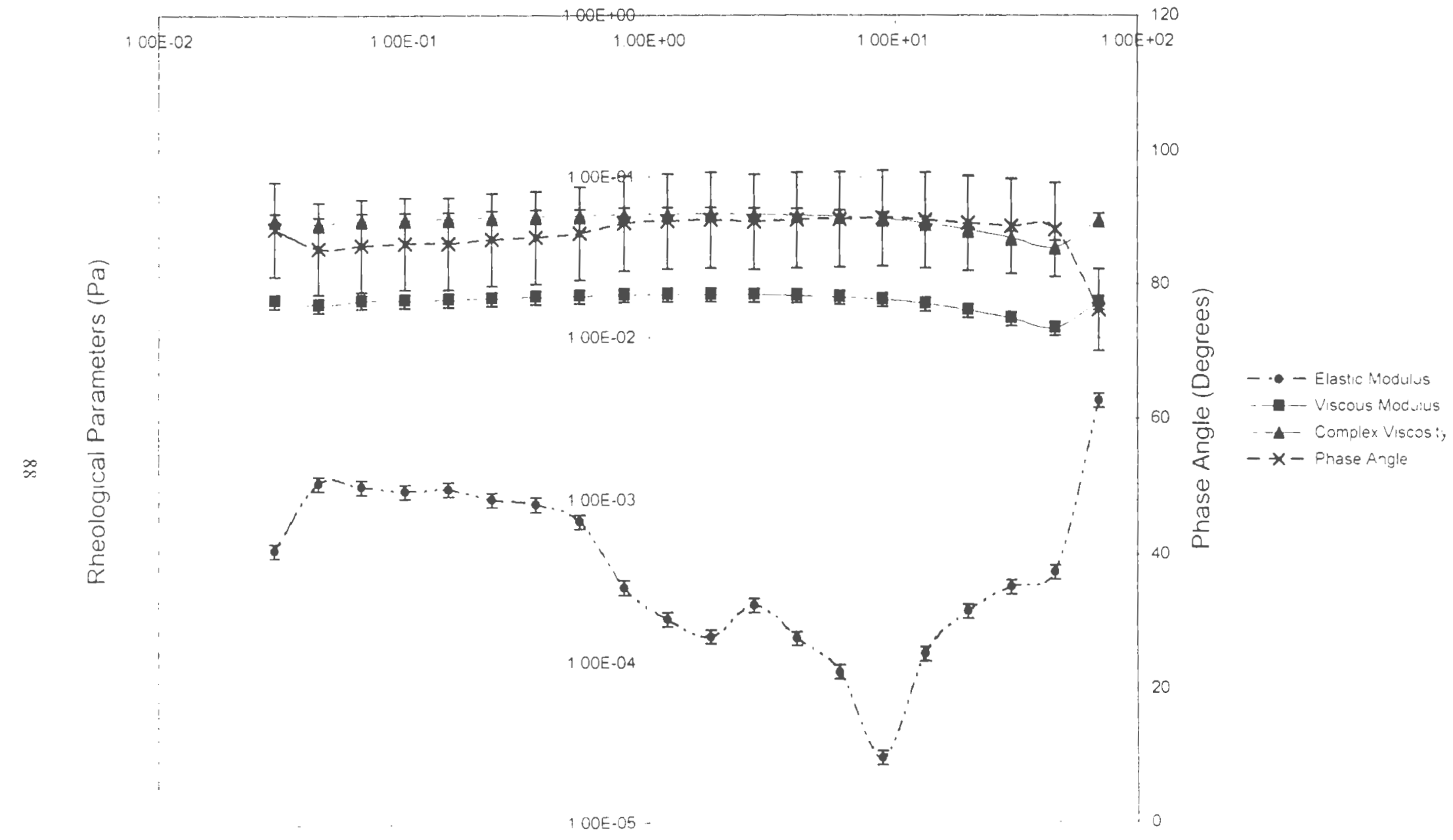

Figure 7B.

Shear Stress $(\mathrm{Pa})$

$G$ G Complex Viscosity and Phase Angle Rheogram for iota carrageenan (Type VV11PF) $10 \%$ w/w Measured at 0 os $\mathrm{Hz}$ and a stress Range of $000100 \mathrm{~Pa}$ 


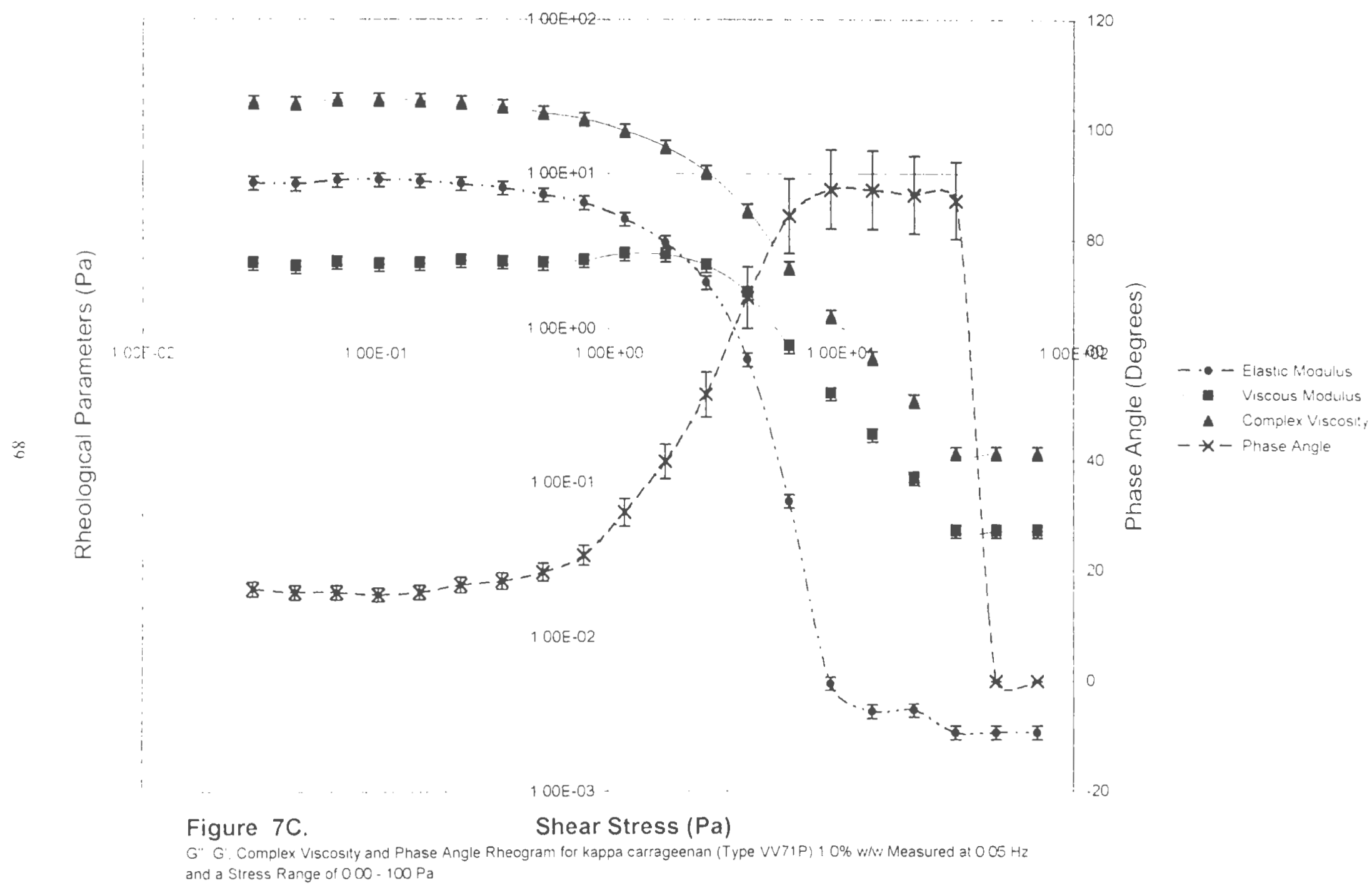


independent of the stress applied. Kappa carrageenan (Carrageenan VV71P), having the least degree of esterification demonstrated purely viscoelastic behavior at $1 \%$ concentration (Figure $7 \mathrm{C}$ ). Its $\alpha$ is of around $20^{\circ}$ and its viscous and elastic moduli are significantly higher than the latter two. The elastic modulus is higher than the viscous modulus and shows a well-defined critical stress, also denoting its viscoelastic nature. The rheograms for carrageenans are in agreement with the literature, which points to an increase in the viscous properties of the gels as the degree of esterification is decreased (16). Table II denotes that the elasticity of iota and kappa carrageenans is highly concentration dependent, whereas the degrees of change $\mathrm{G}^{\prime}$ at the linear region is small for lambda carrageenan compared to the others.

Water Locks presented a very peculiar case. Although the structure of this gel is known, which is a homopolymer grafted with copolymer side chains, the mean molecular weights were not available. All of the Water Locks have similar $\mathrm{G}^{\prime}$ in the order of 500 $1000 \mathrm{~Pa}$ at $1 \%$ concentrations (Figures $8 \mathrm{~A}-\mathrm{D}$ ). Their phase angle were lower than $15^{\circ}$ indicating a strongly elastic nature. Except for Water Lock A-180, they showed an increment in G" with increased stress, denoting dilatant behavior. They also showed a sharp decline in G'. These two factors combined may be denoting entanglement of the chains. On the other hand, Water Lock A-180 shows a broad decline in $\mathrm{G}^{\prime}$ and no increase in G" with increasing stress, probably denoting molecules with shorter chain length and a broader molecular weight distribution. Water Locks form solid gels with high degree of viscosity. Their $\alpha$ value looks as if it is concentration independent above $0.5 \%$ (Table II) 


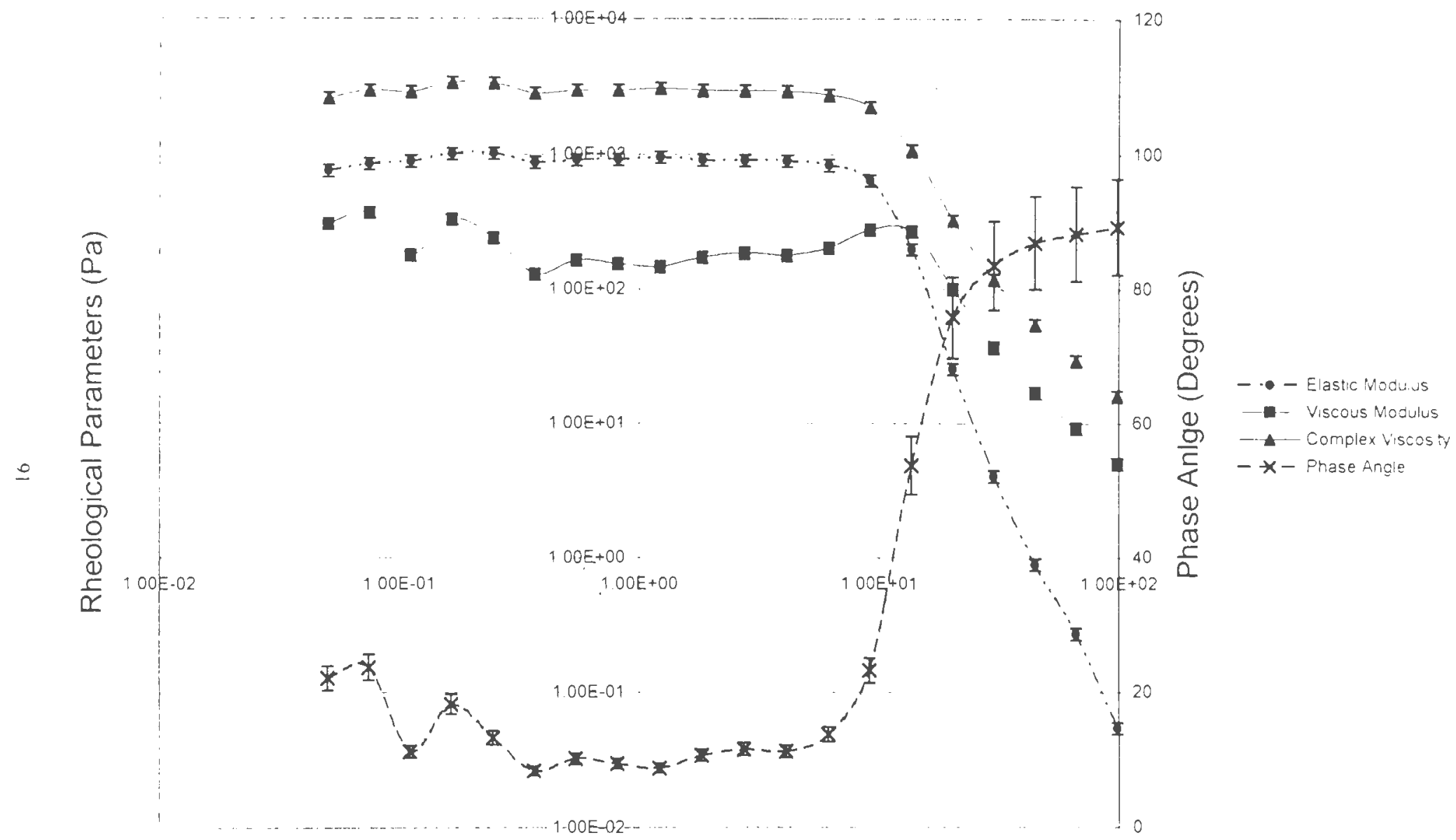

Figure $8 \mathrm{~A}$.

Shear Stress $(\mathrm{Pa})$

G" G', Complex Viscosity and Phase Angle Rheogram for Water Lock A-100. $10 \%$ w/w Measured at $005 \mathrm{~Hz}$ and a Stress Range of $000 \cdot 100 \mathrm{~Pa}$ 


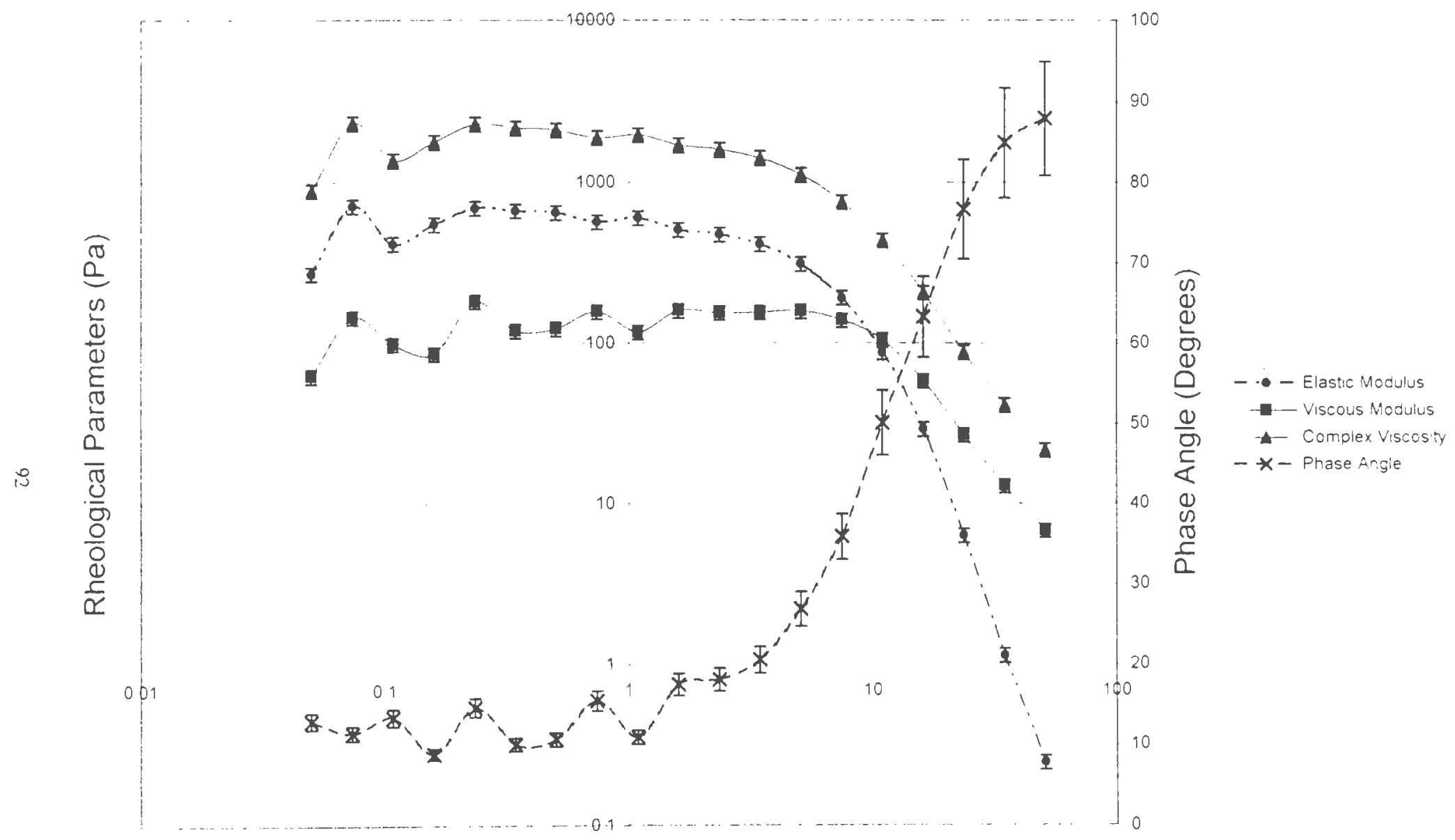

Figure 8B. Shear Stress $(\mathrm{Pa})$

G' G' Complex Viscosity and Phase Angle Rheogram for Water Lock A-180, $10 \%$ v/w Measured at $005 \mathrm{~Hz}$ and a Stress Range of $000-100 \mathrm{~Pa}$ 


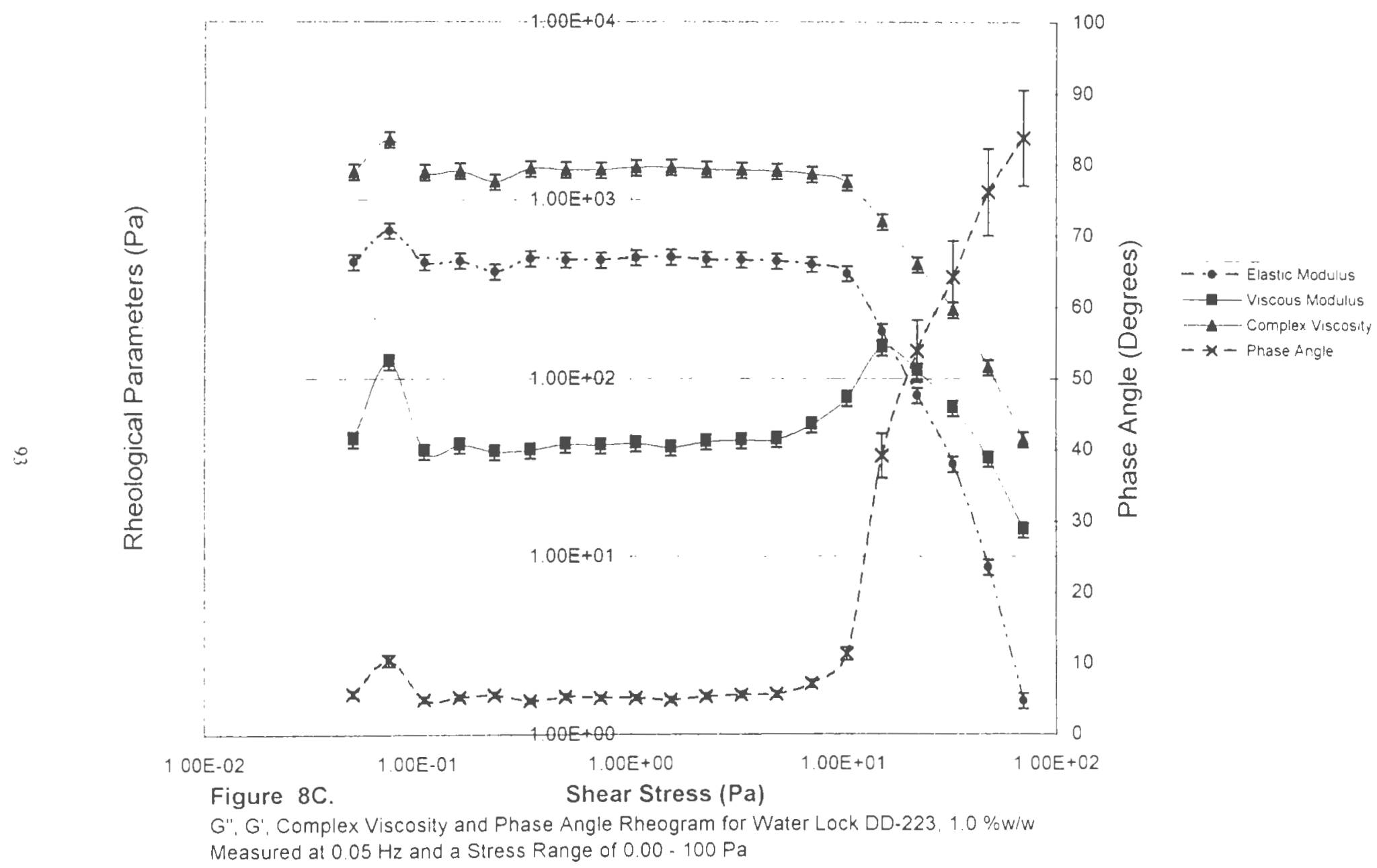




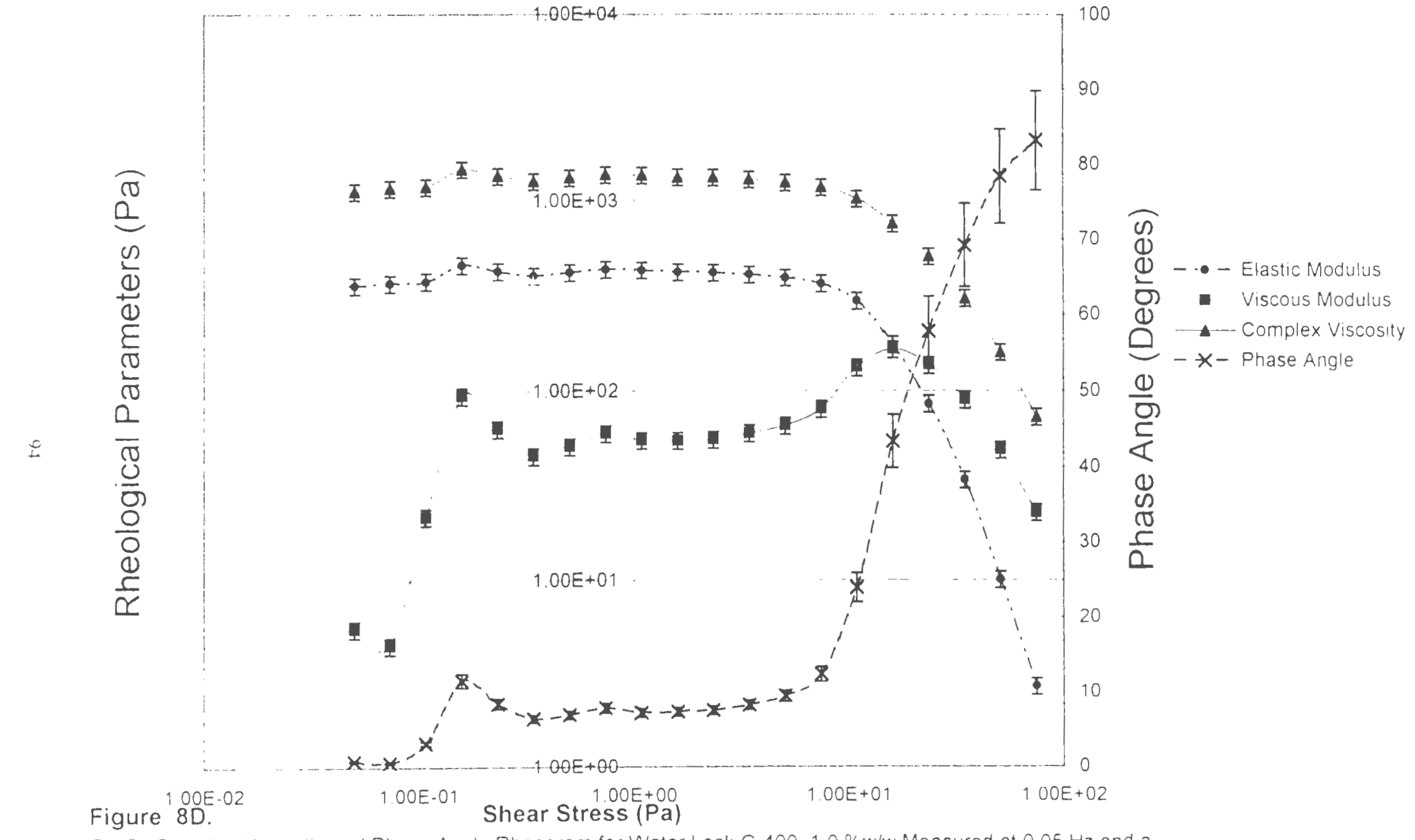

G" G'. Complex Viscosity and Phase Angle Rheogram for Water Lock G-400.10\%w/w Measured at $005 \mathrm{~Hz}$ and a Stress Range of $000-100 \mathrm{~Pa}$ 


\section{Use of Critical Stress as a Parameter for Gel Strength:}

The critical stresses at each concentration were calculated for all the polymers from the rheograms as described in the introduction. In Table II all of the values calculated are shown. They all seem to be concentration dependent therefore, the concentration dependency was statistically analyzed by using a linear function, an exponential function, a logarithmic function and a power function. For all the gels the linear function presented the best correlation coefficients Table III, with R2 changing from 08975 (iota carrageenan) to 0.9949 (Water Lock A-100) and significance changing from 0.48 (kappa carrageenan) to 0.000 (Water Locks). Accordingly, the critical stress and concentration relationship can be described as:

$\sigma_{c}=a_{1}+b_{1} C$

where $\sigma_{\mathrm{c}}$ is the critical stress, $\mathrm{C}$ is the gel concentration and $\mathrm{a}_{1}$ and $\mathrm{b}_{1}$ are correlation parameters (Table III). Figures 9 to 13 demonstrate the relationship between the concentration and critical stress of all the gels studied as obtained by equation 5 .

The most important finding demonstrated in this table is the degree of significance of the model selected. All of the parameters fit the model within at least 95\% confidence limit. Table III. Further, the significances given are demonstrating an excellent fit, with the exception of Carrageenan VV71P, which is still within the selected confidence interval of $95 \%$. The concentration dependence of the critical stress of Water Locks can be described within $99 \%$ confidence, as well as that of Carbopol 971, pectin, Bentonite RV, sodium carboxy muthyl cellulose and methyl cellulose. All of these polymers formed highly elastic gels. 
Table III. Linear Regression Analysis of the Critical Stress Dependence on the Concentration $\sigma_{\mathrm{c}}=\mathrm{al}+\mathrm{b} / \mathrm{C}$ Obtained from Least Square Analysis Data.

\begin{tabular}{|c|c|c|c|c|c|c|c|}
\hline Polymer type & Guar gum & $\begin{array}{c}\text { Lambda } \\
\text { Carrageenan } \\
\text { (type RLV) }\end{array}$ & $\begin{array}{c}\text { lota } \\
\text { Carrageenan } \\
\text { (type VV11PF) }\end{array}$ & $\begin{array}{c}\text { Kappa } \\
\text { Carrageenan } \\
\text { (type VV71P) }\end{array}$ & Bentonite RV & Pectin & $\begin{array}{c}\text { Carbopol 971 } \\
\text { NF }\end{array}$ \\
\hline $\begin{array}{c}\text { Apparent } \\
\text { Viscosity (cP) }\end{array}$ & 400 & 25 & 3,400 & 1,000 & 4.800 & 65 & 185.000 \\
\hline$a_{1}$ & -32.04 & -0.06 & -63.98 & -19.40 & -4.80 & +0.03 & $\cdot 3.41$ \\
\hline$b_{1}$ & 29.10 & 0.10 & 40.08 & 11.55 & 3.69 & 0.03 & 16.26 \\
\hline$R^{2}$ & 0.910 & 0.961 & 0.8975 & 0.9054 & 0.9503 & 0.9829 & 0.9889 \\
\hline Significance & 0.022 & 0.003 & 0.014 & 0.048 & 0.005 & 0.001 & 0.001 \\
\hline Polymer type & Water Lock A- & Water Lock A- & Water Lock & Water Lock G- & Methocel A4C & Methocel K4M & Na CMC \\
\hline $\begin{array}{c}\text { Apparent } \\
\text { Viscosity (cP) }\end{array}$ & 180 & 100 & DD-223 & 400 & & & \\
\hline$a_{1}$ & +1.432 & -4.83 & +4.83 & +3.76 & -0.61 & -5.55 & $\cdot 4.38$ \\
\hline$b_{1}$ & 4.20 & 12.99 & 22.40 & 12.19 & 0.48 & 4.50 & 6.53 \\
\hline$R^{2}$ & 0.9098 & 0.9949 & 0.959 & 0.9953 & 0.9369 & 0.9062 & 0.9822 \\
\hline Significance & 0.012 & 0.000 & 0.004 & 0.000 & 0.007 & 0.013 & 0.001 \\
\hline
\end{tabular}




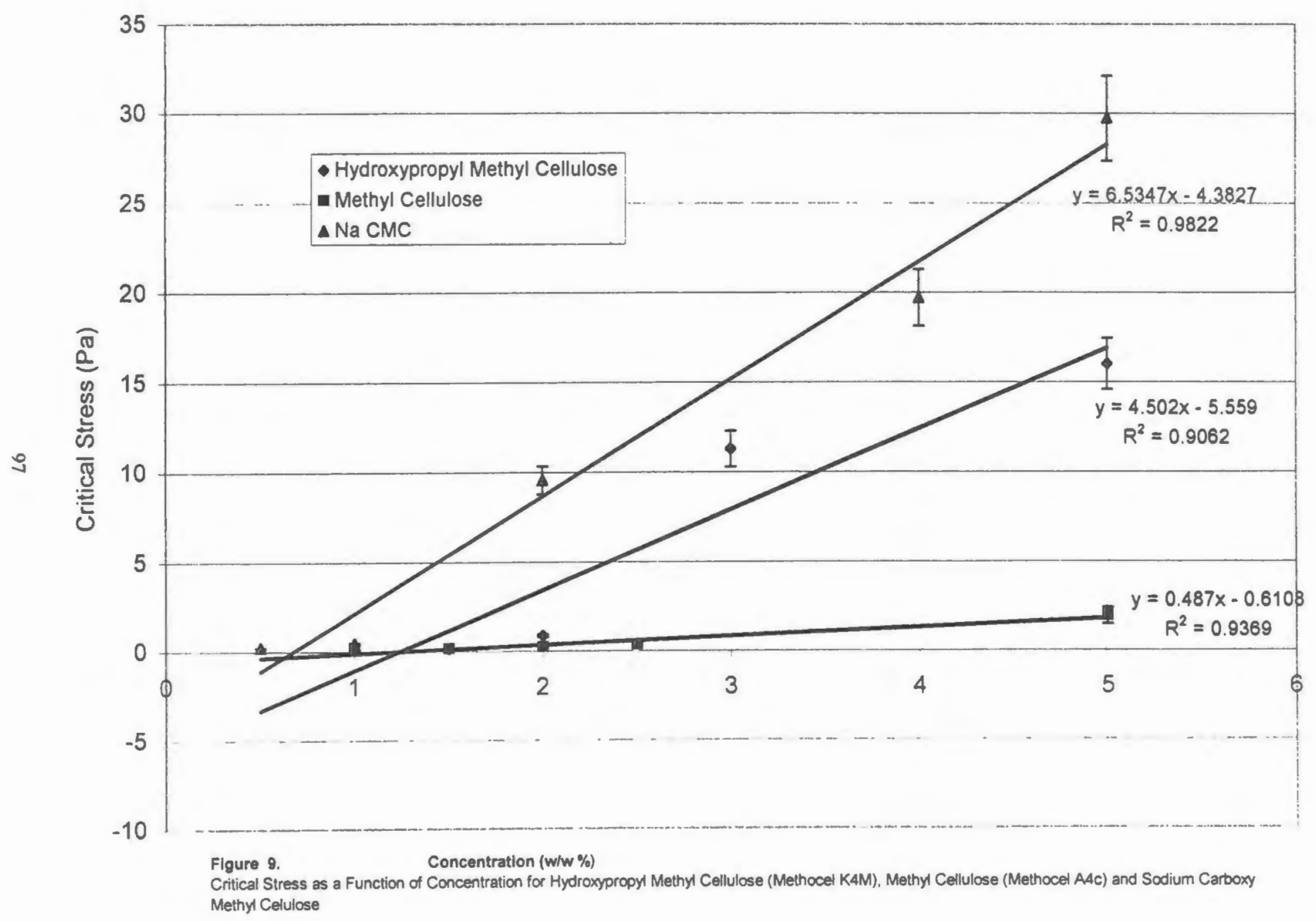




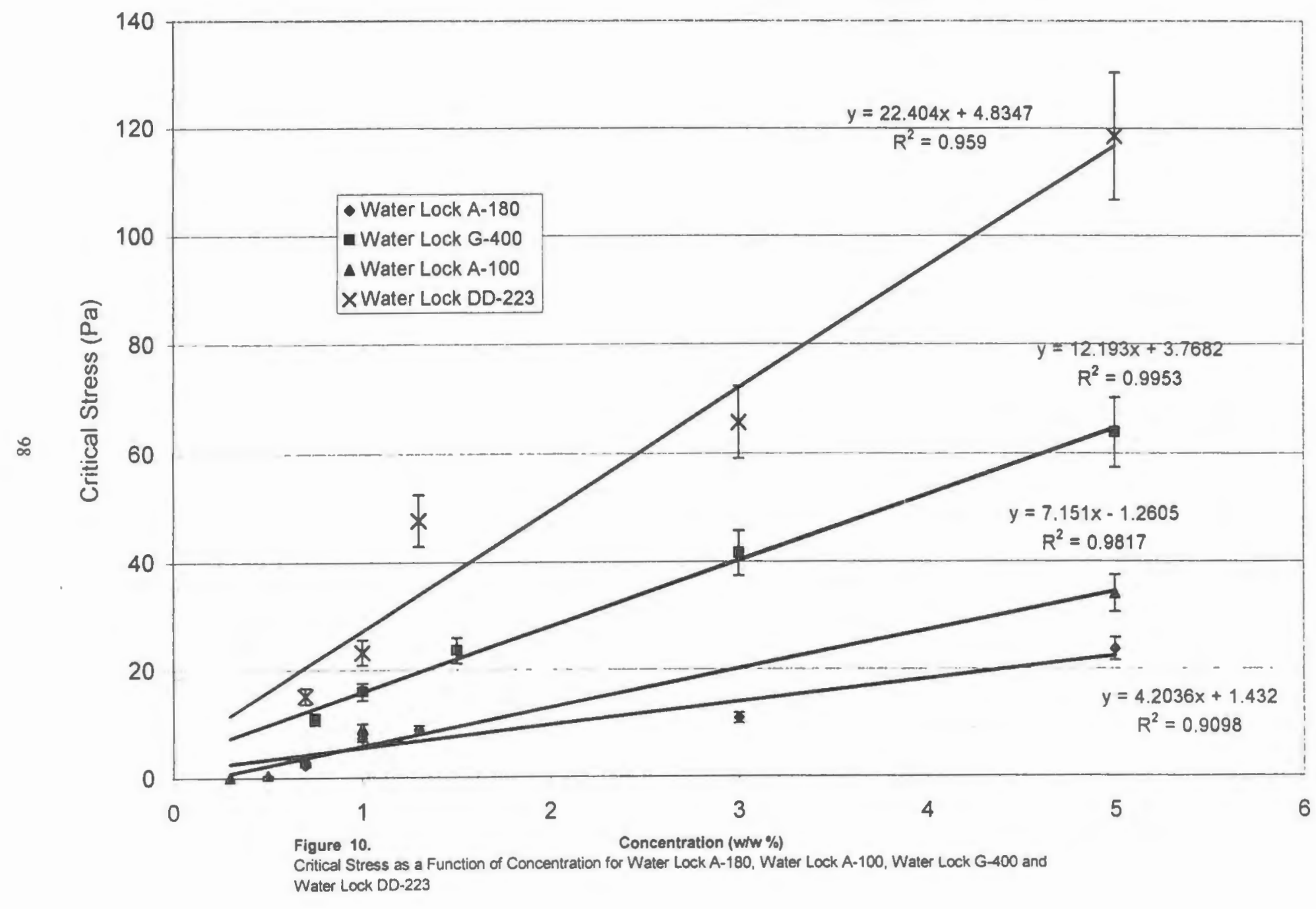




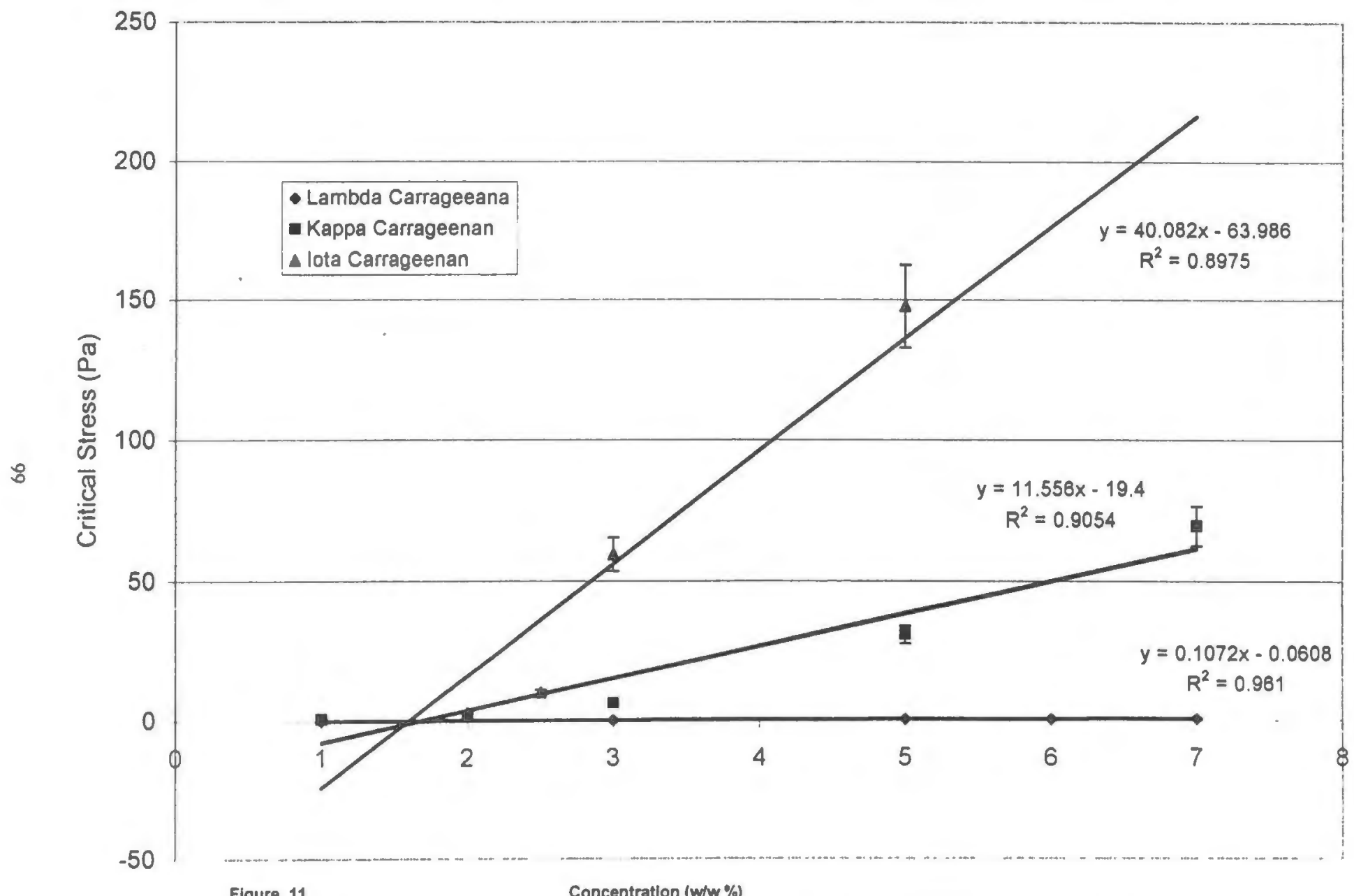

Figure 11. Critical Stress) 


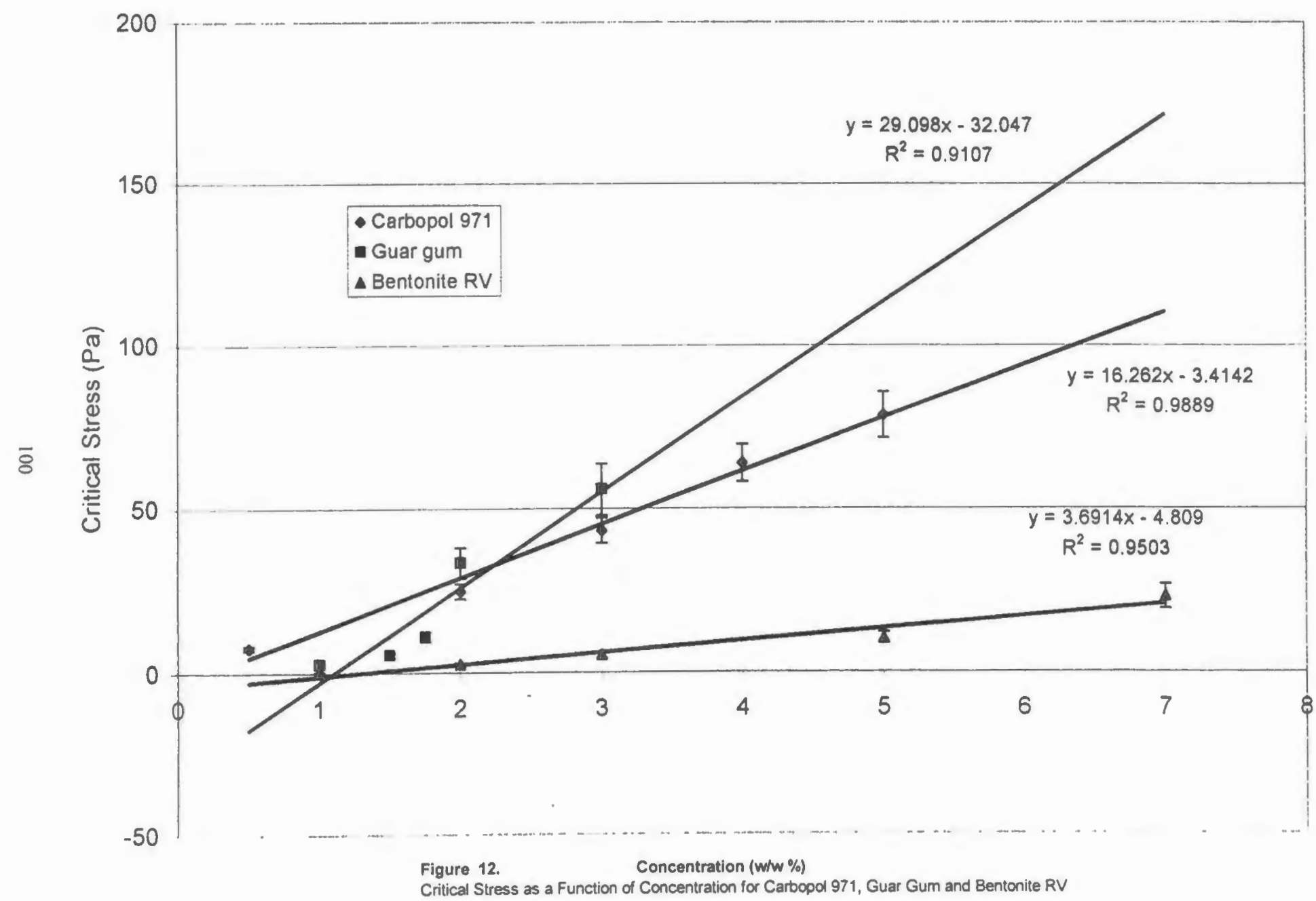




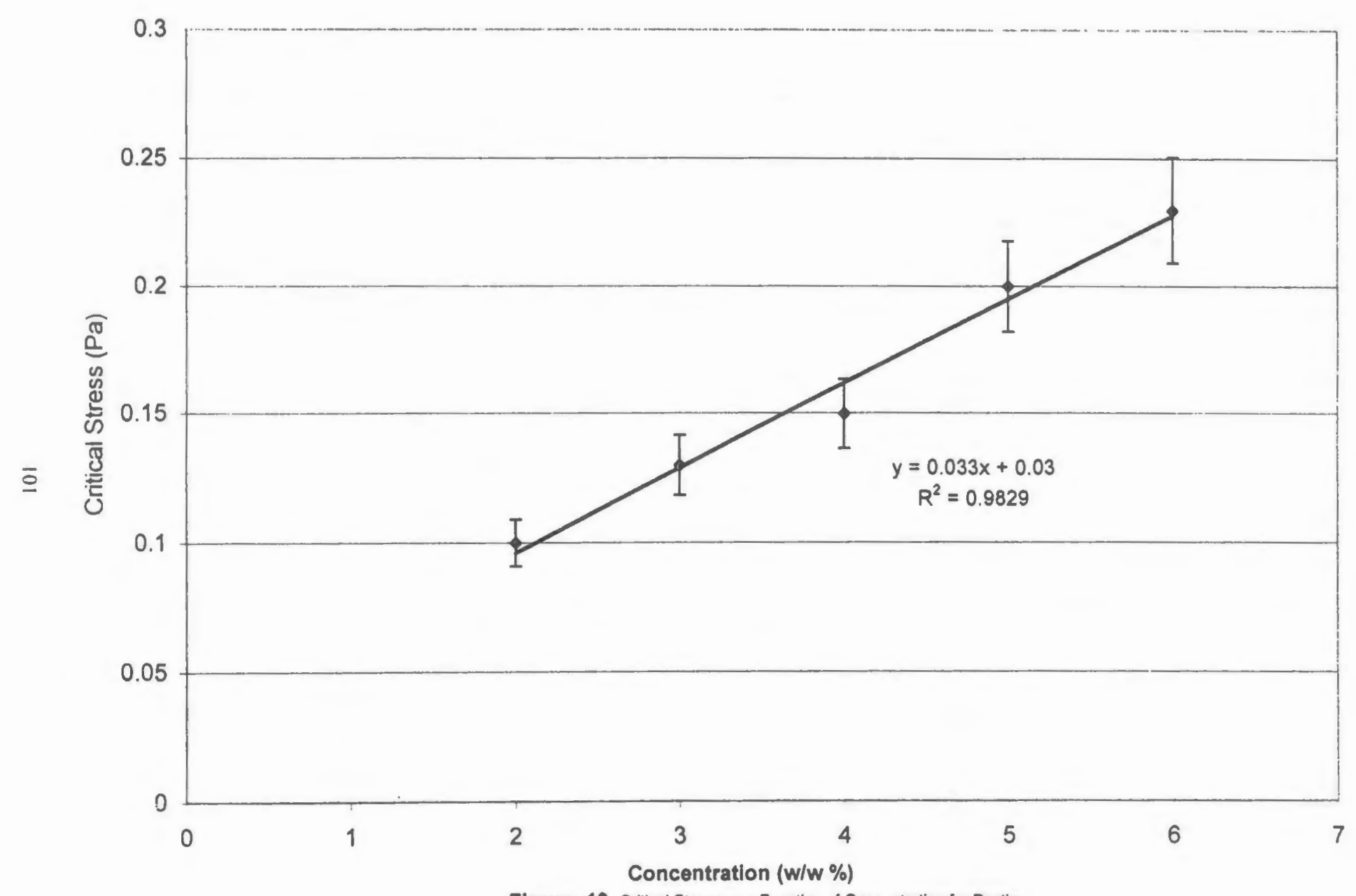

Figure 13. Critical Stress as a Function of Concentration for Pectin 
As described earlier, the rheological behavior of the systems studied varied from free flowing to high-consistency gels. However, regardless of the wide rheological range covered, the critical stress still efficiently explained their gel strength, demonstrating that it is a highly significant parameter to describe gels and it may be considered as an efficient tool for characterization.

Evaluation of the critical stress parameters obtained (Table III) also allows formulators in the cosmetics, pharmaceutical and food industries the possibility of replacing one gel with another having a similar critical stress. One more obvious use of the parameters is the quick evaluation of gelling strength dependence on the concentration. In Figures 9 - 13, and in Table III, the gels having high 'b1' values (Eq. 5) are highly sensitive to small concentration changes, whereas the ones having low 'bl' values may have similar gel strength in a wider concentration range. Table IV lists the gels from highest to lowest "concentration sensitivity" based on their 'b1' parameter. Through personal observation it was found out that the thickness of the gels with 'bl' values higher than $10 \mathrm{~Pa}$ increases sharply with fractional increases in concentration, whereas the ones that have 'bl' values less than 10 can only be thickened by greatly increasing the polymer concentration.

This is the first study in the literature, which demonstrates the value, and use of critical stress and its linear dependence on the concentration regardless of gel chemistry, type and rheological strength. Dooublier and Launay (1994) studying locust bean gum prepared empirical approximations between the critical stress, the specific viscosity and the reduced concentration. Barry and Meyer (1979) working with Carbopol 940 and 941 in creep viscometry proposed a log-linear relationship between the apparent viscosity and 
concentration, and creep compliance $(\mathrm{J})$ and concentration for these gels at a concentration range from 1 to $10 \%$. The advantage of these models may be in its simplicity and applicability to a variety of gels with different chemistry, structure, viscosity type and rheology.

Table IV. Concentration Sensitivity Parameter (b1) for Each Gel Studied Arranged in the Order from Highest to Lowest Sensitivity.

Gel

Iota carrageenan

Guar gum

Water Lock DD-223

Carbopol 971

Water Lock A-100

Water Lock G-400

Kappa carrageenan

Sodium carboxy methyl cellulose

Hydroxypropyl methyl cellulose

Water Lock A-180

Bentonite RV

Methyl cellulose

Lambda carrageenan

Pectin
Concentration Sensitivity Parameter 'bl' (Pa)

40.08

29.10

22.40

16.26

12.99

12.19

11.55

6.53

4.50

4.20

3.69

0.48

0.10

0.03 


\section{References}

Barry, B.W. and Eccleston, G.M., Oscillatory testing of o/w emulsions containing mixed emulsions of the type surfactant-long chain alcohol type: self-bodying action, Journal of Pharmaceutics and Pharmacokinetics, 25:244 - 253, (1973a)

Barry, B.W. and Eccleston, G.M., Oscillatory testing of o/w emulsions containing mixed emulsions of the type surfactant-long chain alcohol type: influence of surfactant chain length, Journal of Pharmaceutics and Pharmacokinetics, 25:394 - 400, (1973b)

Barry, B.W. and Meyer, M.C., The rheological properties of Carbopol gels I: Continuous shear and creep properties of Carbopol gels., International Journal of Pharmaceutics, $2: 1-25,(1979)$

Chen, J. and Dickinson, E., Viscoelastic properties of heat-set whey protein emulsion gels, Journal of Texture Studies, 29:285 - 304 , (1998)

Chereminisoff, N., An introduction to polymer rheology and processing, CRC Press, London, 1993

Clark, A. and Ross-Murphy, S., Structural and mechanical properties of biopolymer gels, Advances in Polymer Science, 83:60-195, (1987)

Davidson, R., Handbook of water soluble polymers and resins, McGraw Hill, 1980

Davis, S., Viscoelastic properties of pharmaceutical semisolids III: Destructive oscillatory testing, Journal of Pharmaceutical Sciences, 60:1357 - 1360, (1971b)

Davis, S., Viscoelastic properties of pharmaceutical semisolids III: Non-destructive oscillatory testing, Journal of Pharmaceutical Sciences, 60:1351 - 1355, (1971a)

Doublier, J.L. and Launay, B., Rheology of galactomannan solutions: comparative study of guar gum and locust bean gum, Journal of Texture studies, 25:119 - 137, (1994) 
Ferry, J., Viscoelastic properties of polymers, 3rd ed., Wiley and Sons, NY. 1980

Giboreau, A., Cuvelier, G. and Launay, B., Rheological behavior of three biopolymer/water systems, with emphasis on yield stress and viscoelastic properties, Journal of Texture Studies, 25:119-137 (1994)

Kamide, K. and Saito, M., Cellulose and cellulose derivatives: recent advances in physical chemistry, Advances in Polymer Science, 83:5-59, (1987)

Lochhead, R. and Fron, W., Encyclopedia for polymers and thickeners for cosmetics, Cosmetics and Toiletries, 108:95-135, (1993)

McCormic, C. Structural design of water soluble polymers, in Water-Soluble Polymers, Synthesis, Solution Properties and Applications (S. Shalaby, C. MacCormick, G. Butler, eds.) pp. 2 -24, ACS, Washington, (1991)

Pans, R., Erra, P., Soians, C., Ravey, J. and Stebe, M., Viscoelastic properties of gelemulsions: Their relationship with structure and equilibrium properties, Journal of Physical Chemistry, 97: 12320-12324 (1993)

Roberts, W., Rapp, G. and Webber, J., Encyclopedia of minerals, VNR Co., NY, 1974

Rochefort and Middleman (1987), Rheology of xanthan gum: salt, temperature and strain oscillatory and steady shear experiments, Journal of Rheology, 31:337-369, (1987)

Terrisse, I., Seiller, M., Rabaron, A. and Grossiord, J.L., Rheology: how to characterize and to predict the evolution of $\mathrm{w} / \mathrm{o} / \mathrm{w}$ multiple emulsions, International Journal of Cosmetic Science, 15:53 - 62, (1993) 
Appendix 1

(Rheograms) 


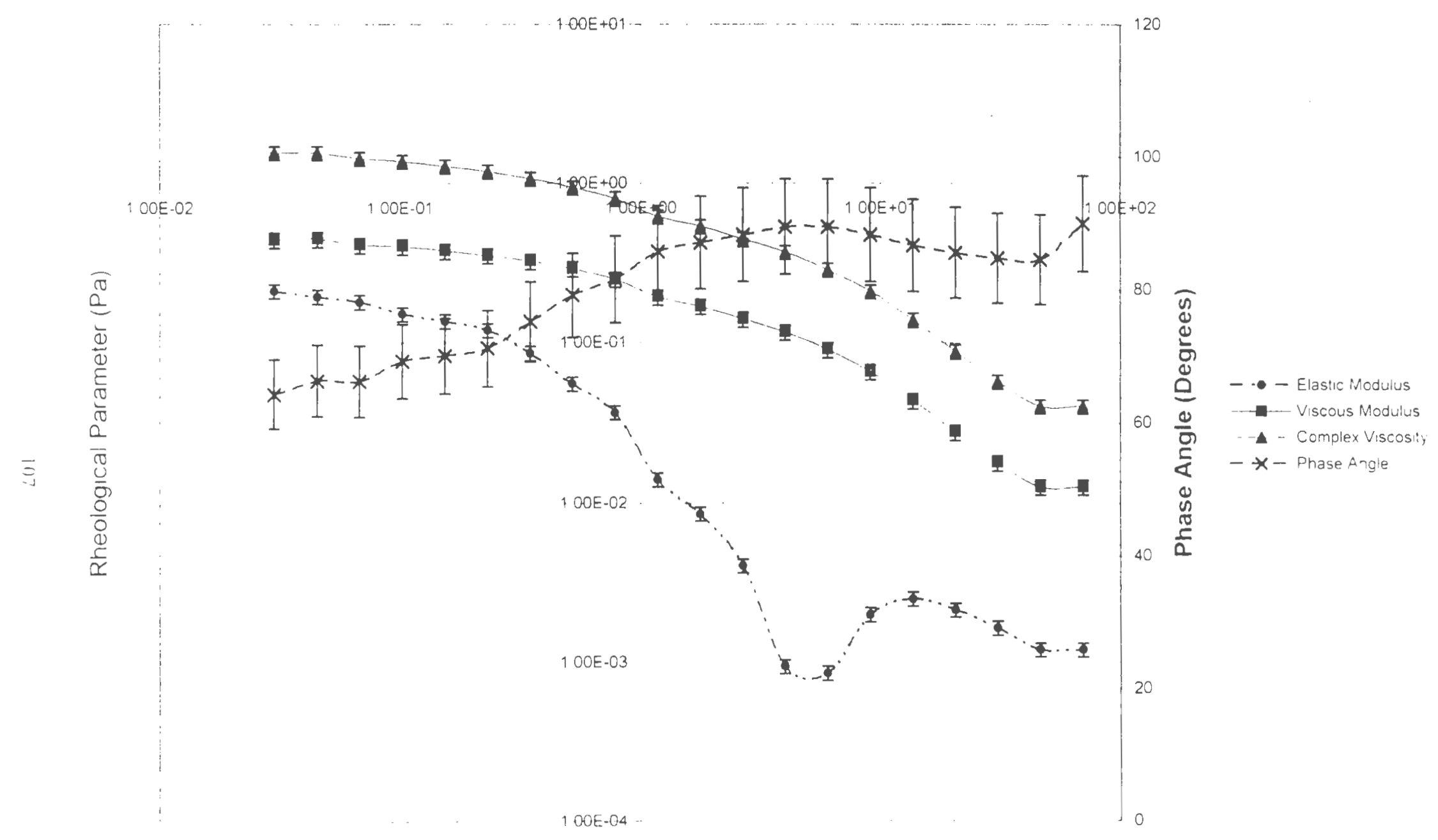

Figure A1.1. Shear Stress (Pa)

G" G' Complex Viscosity and Phase Angle Rheogram for Bentonite RV $10 \%$ w/W Measured at $005 \mathrm{~Hz}$ and a Stress Range of $000 \cdot 100 \mathrm{~Pa}$ 


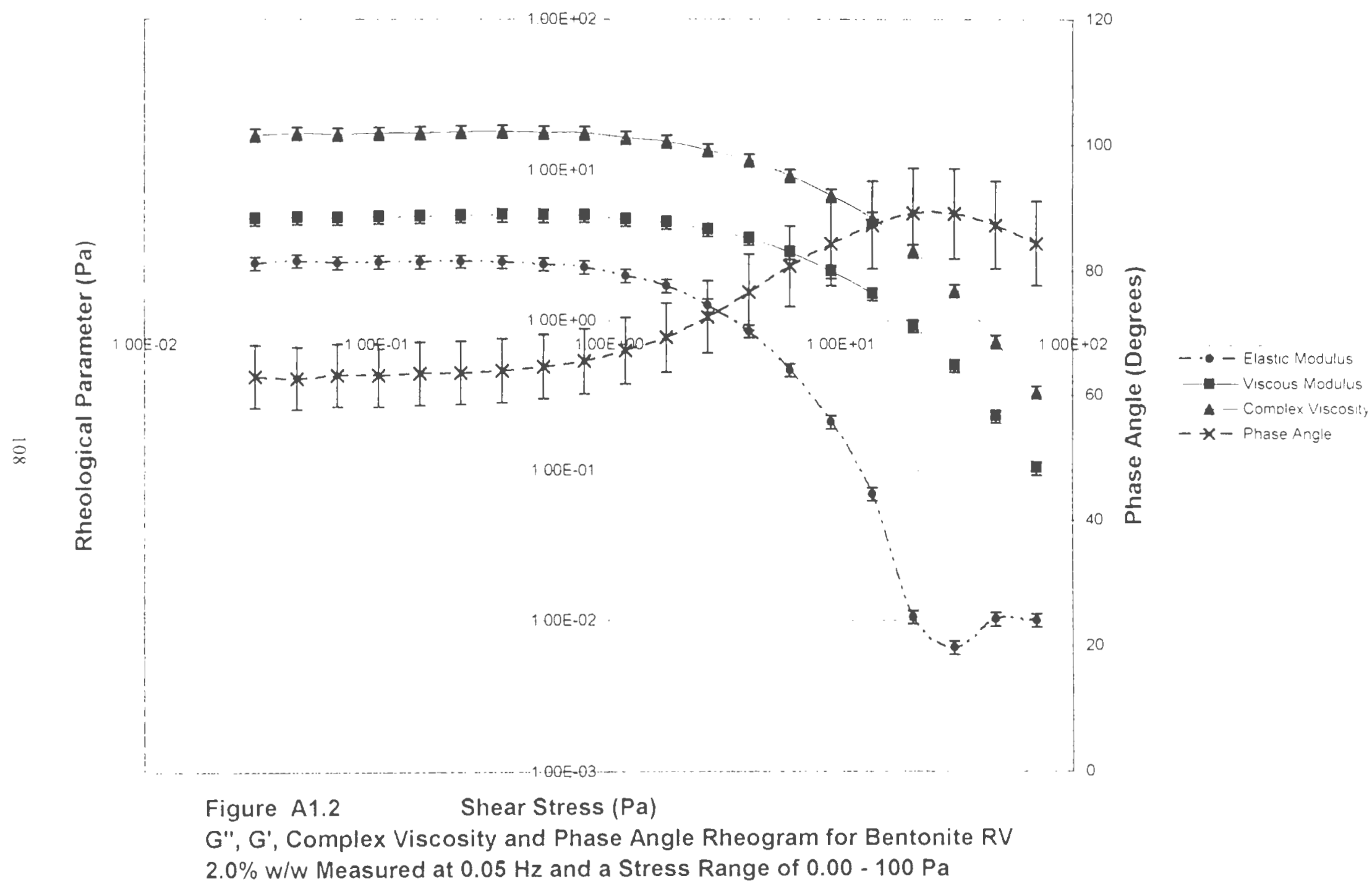




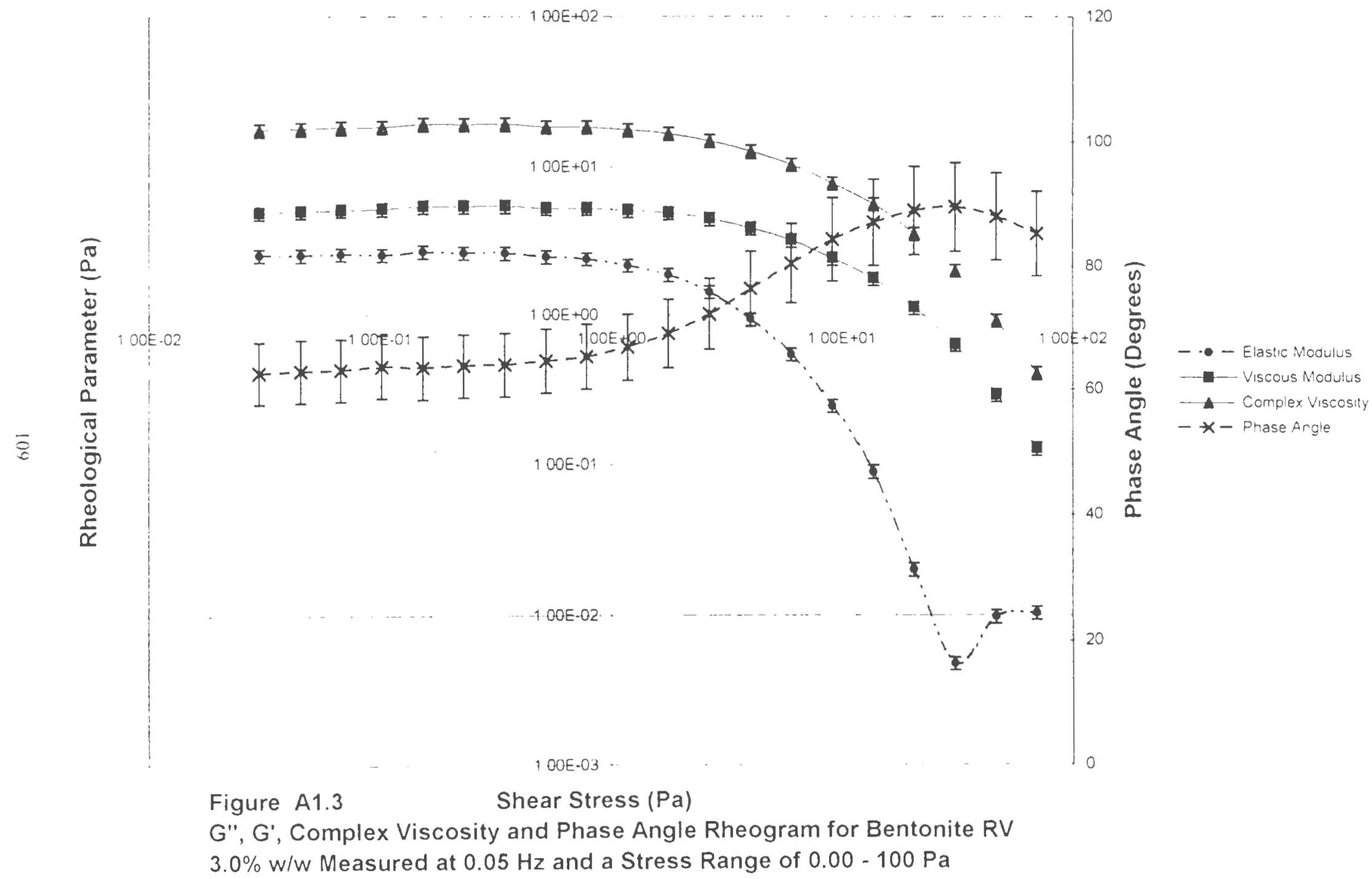




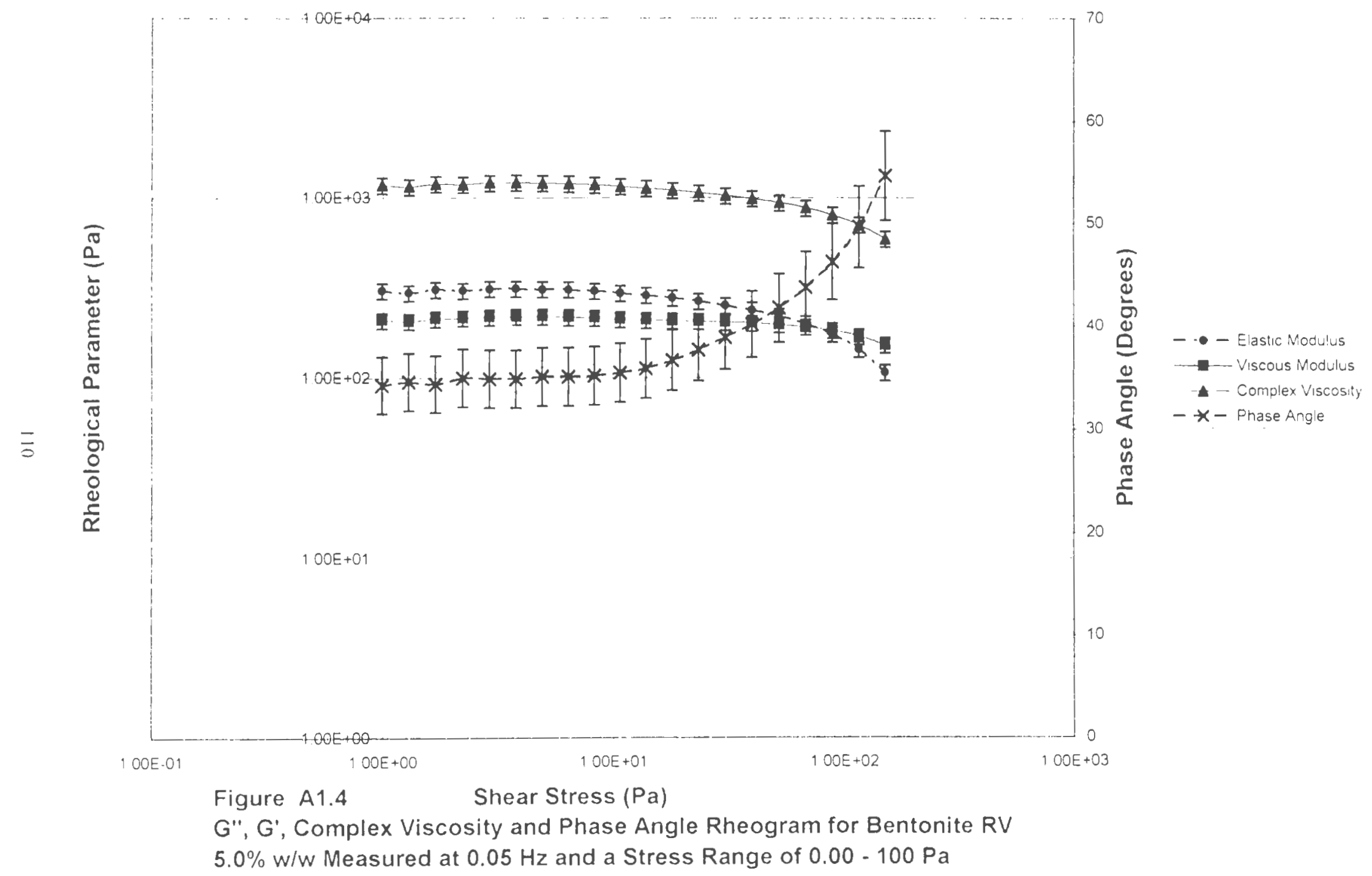




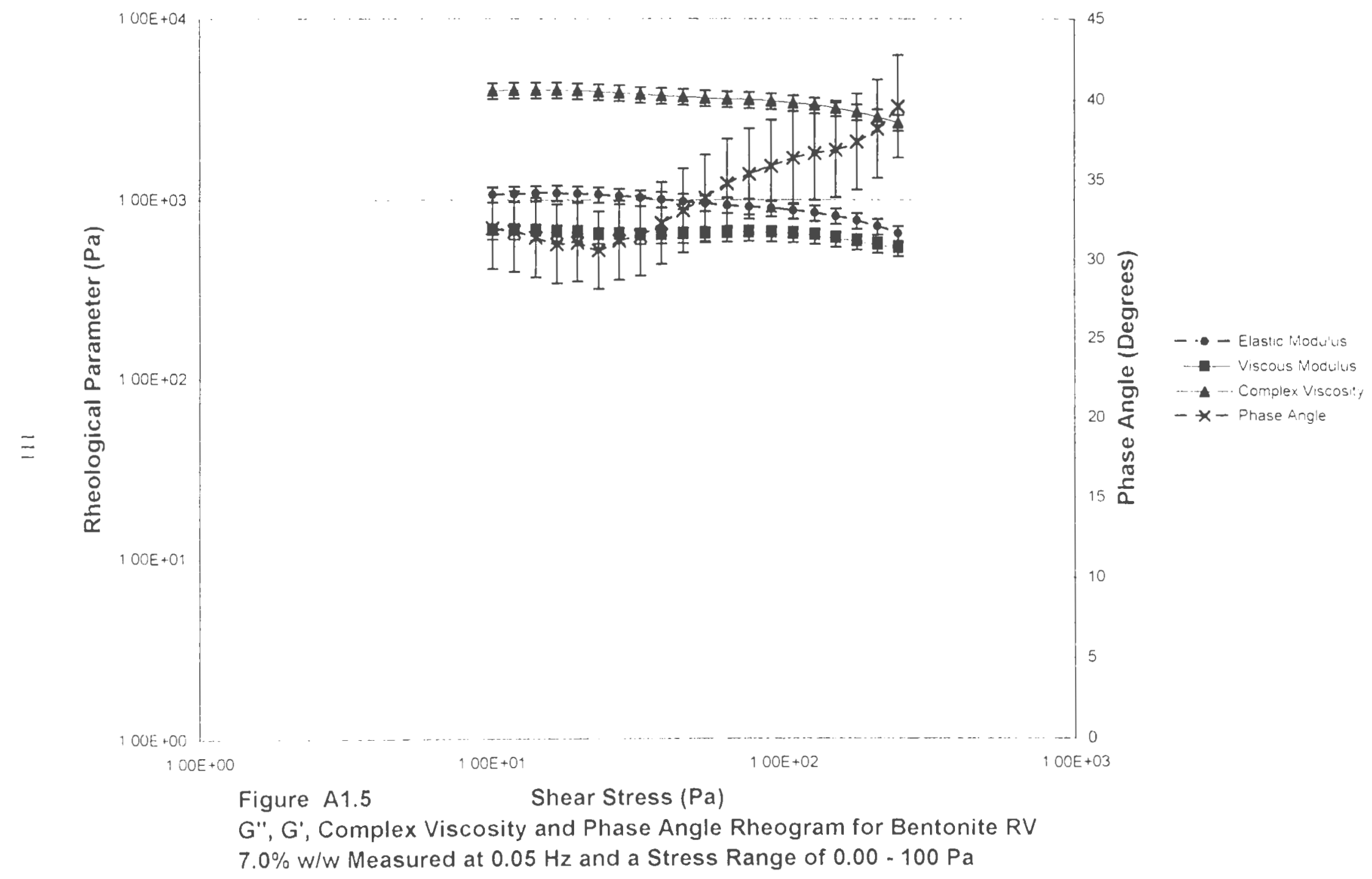




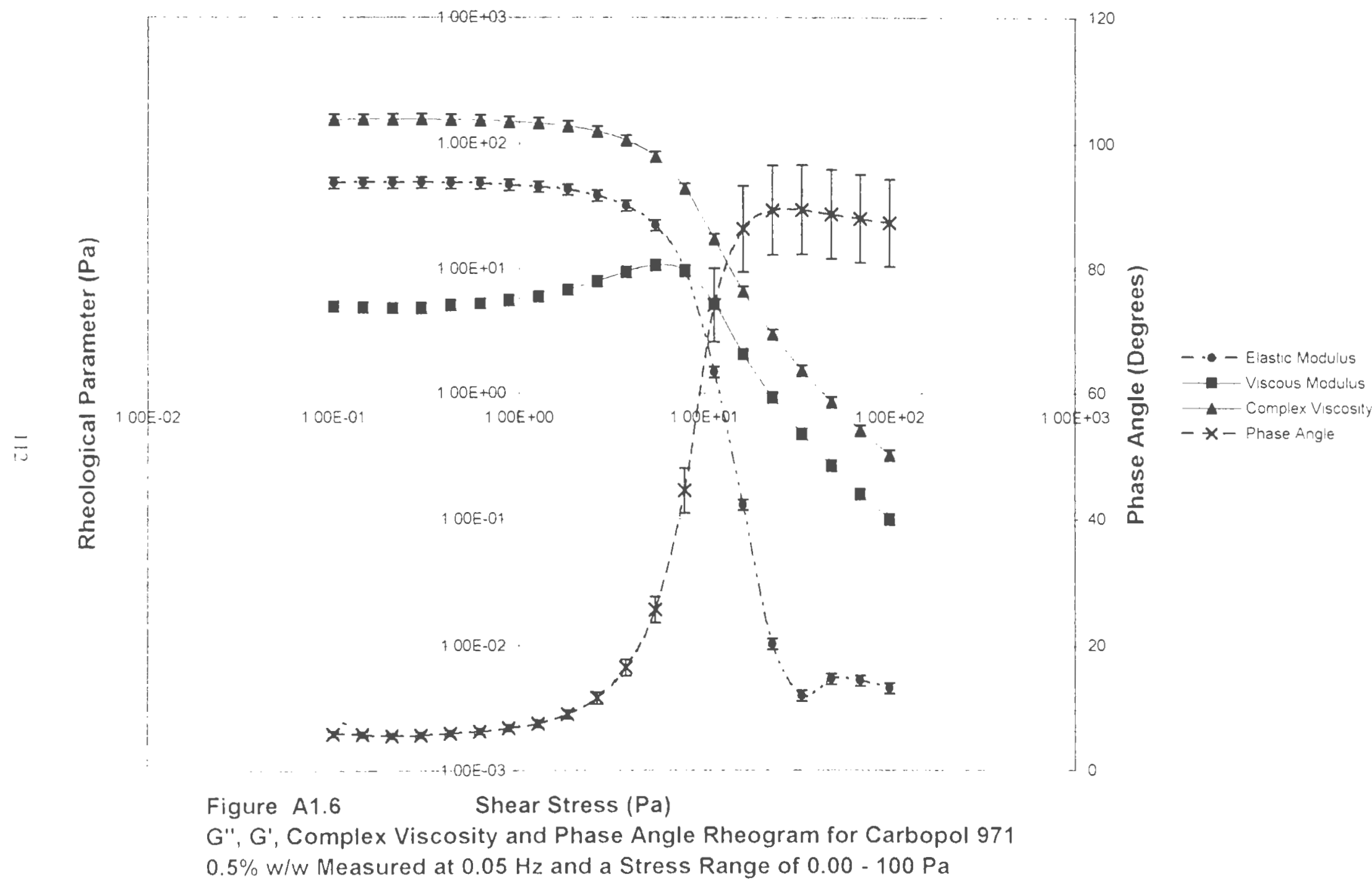



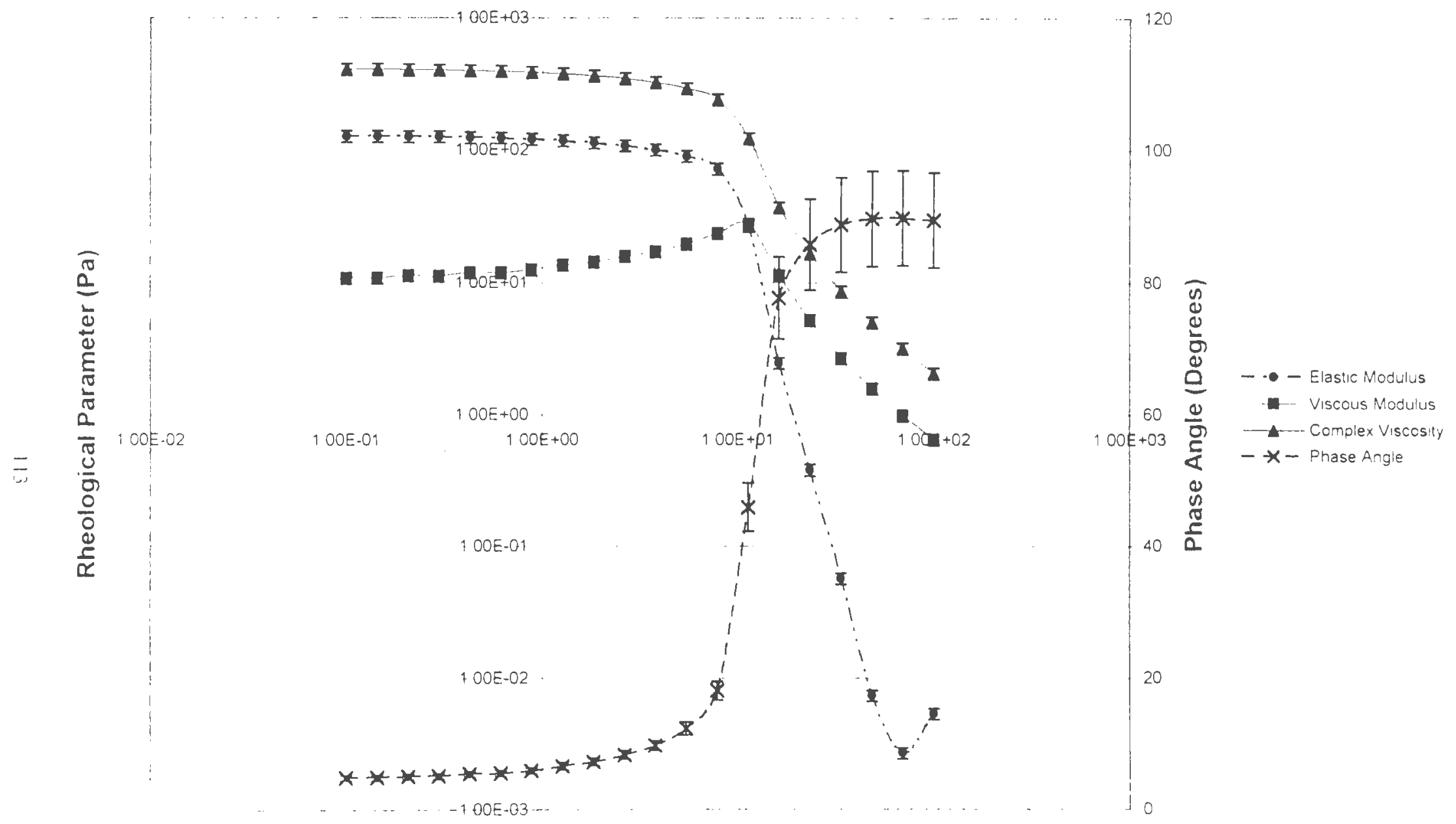

Figure A1.8 Shear Stress $(\mathrm{Pa})$

G', G', Complex Viscosity and Phase Angle Rheogram for Carbopol 971

$2.0 \% \mathrm{w} / \mathrm{w}$ Measured at $0.05 \mathrm{~Hz}$ and a Stress Range of $0.00-100 \mathrm{~Pa}$ 

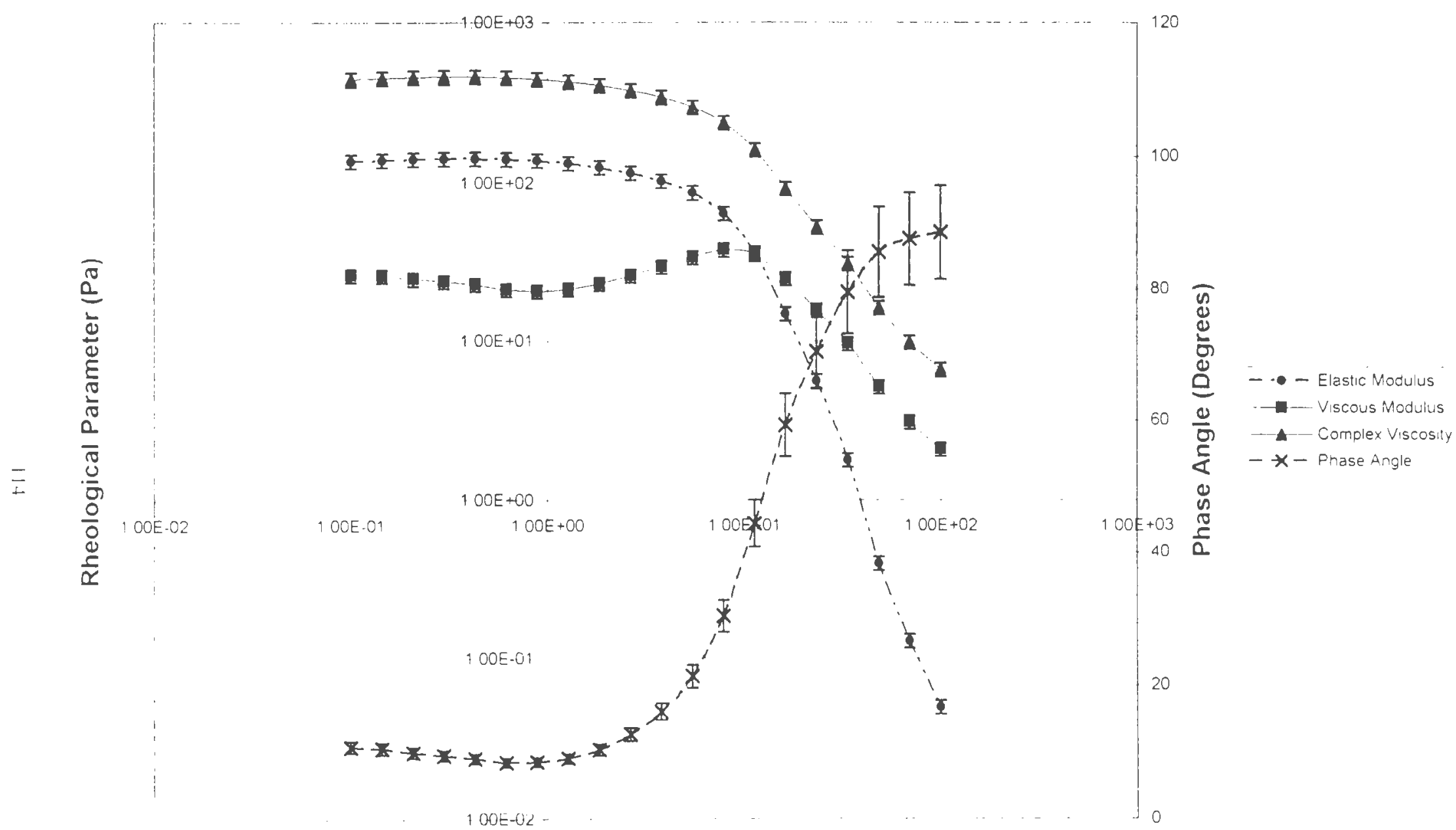

Figure A1.7

Shear Stress ( $\mathrm{Pa}$ )

G", G', Complex Viscosity and Phase Angle Rheogram for Carbopol 971

$3.0 \% \mathrm{w} / \mathrm{w}$ Measured at $0.05 \mathrm{~Hz}$ and a Stress Range of $0.00-100 \mathrm{~Pa}$ 

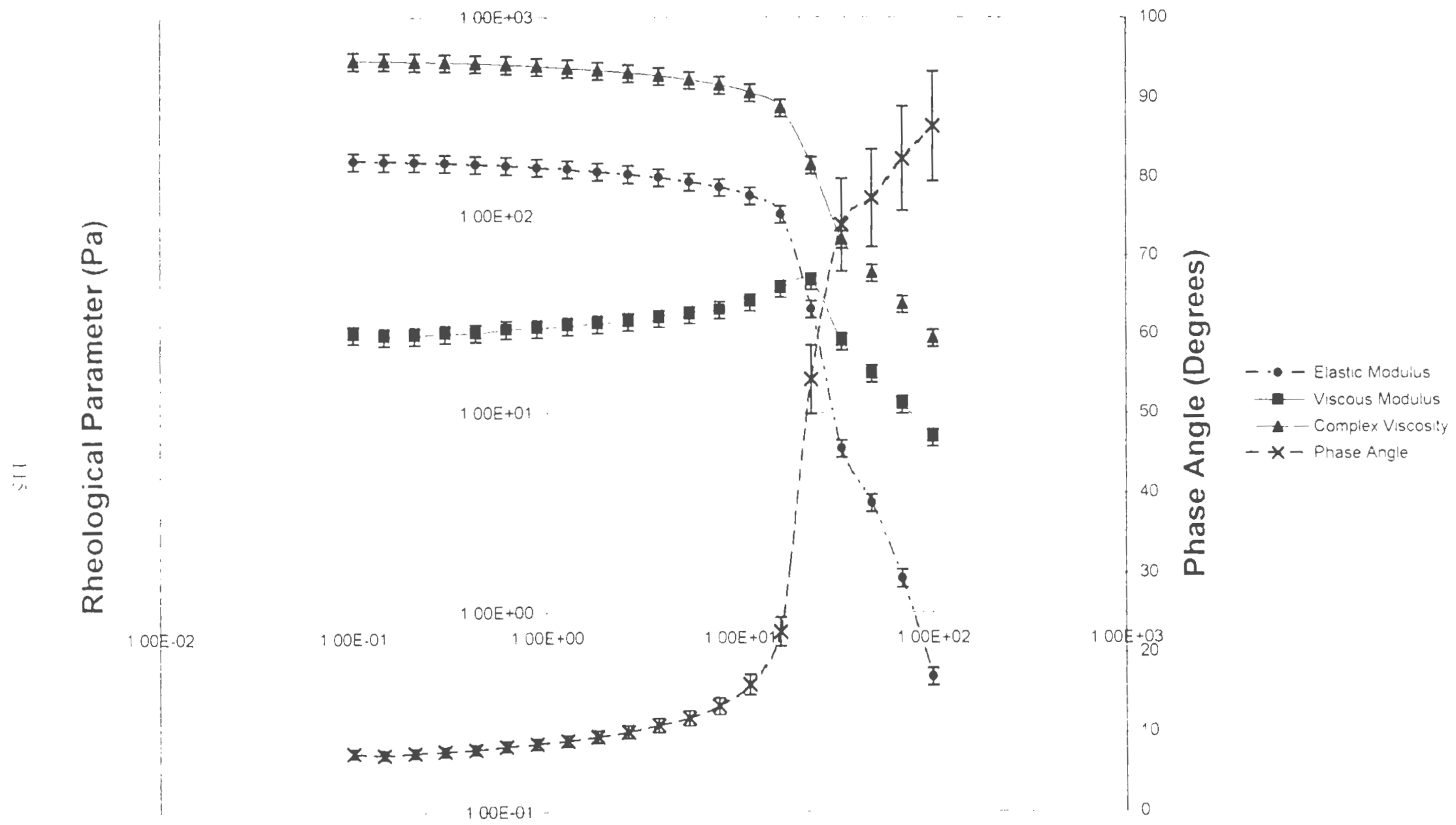

Figure A1.9 Shear Stress (Pa)

G', G', Complex Viscosity and Phase Angle Rheogram for Carbopol 971

$4.0 \% \mathrm{w} / \mathrm{w}$ Measured at $0.05 \mathrm{~Hz}$ and a Stress Range of $0.00-100 \mathrm{~Pa}$ 

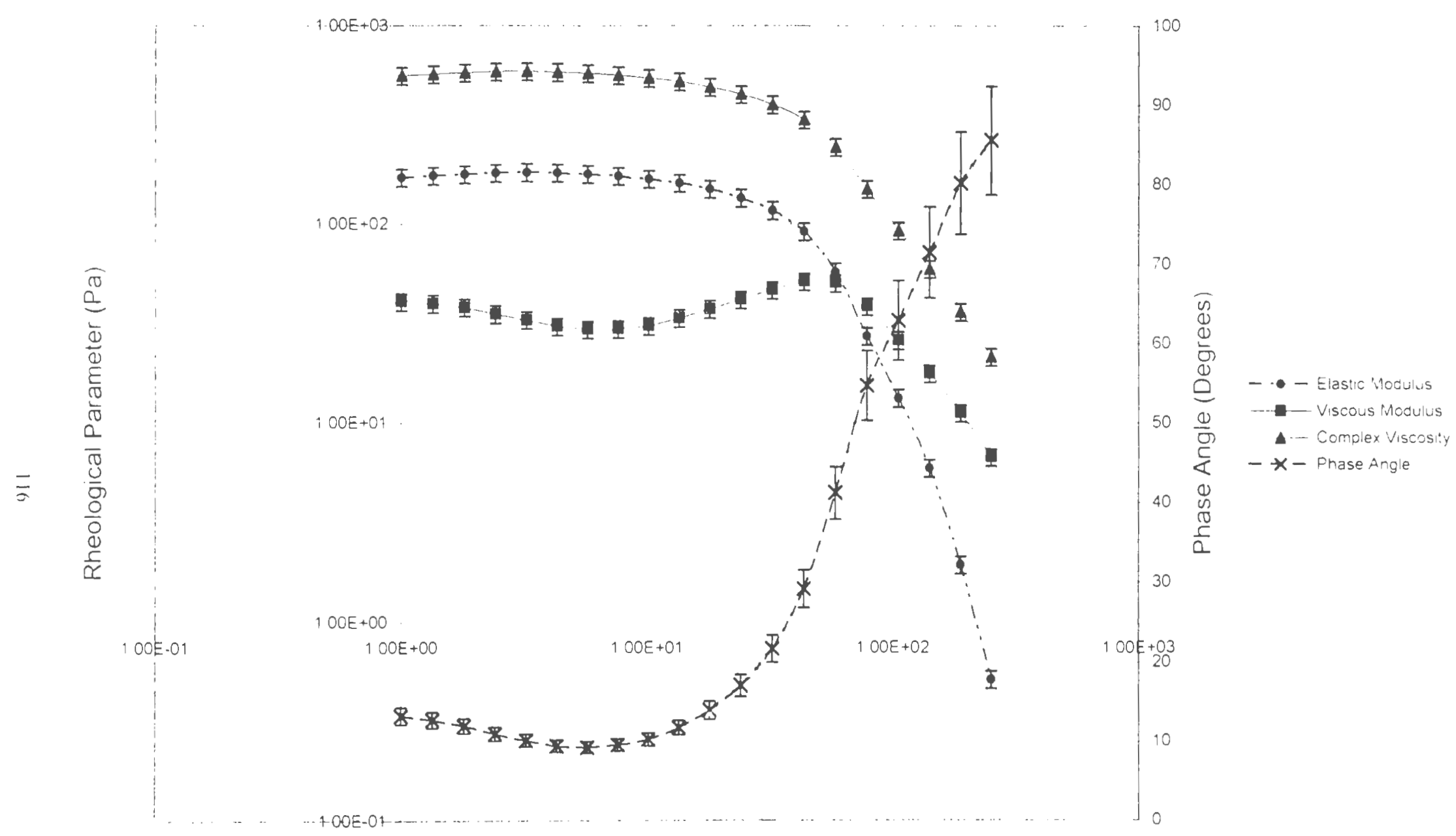

Figure $A 1.10$

Shear Stress $(\mathrm{Pa})$

G". G', Complex Viscosity and Phase Angle Rheogram for Carbopol $9715.0 \%$ w/w Measured at $0.05 \mathrm{~Hz}$ and a Stress Range of $0.00-100 \mathrm{~Pa}$ 


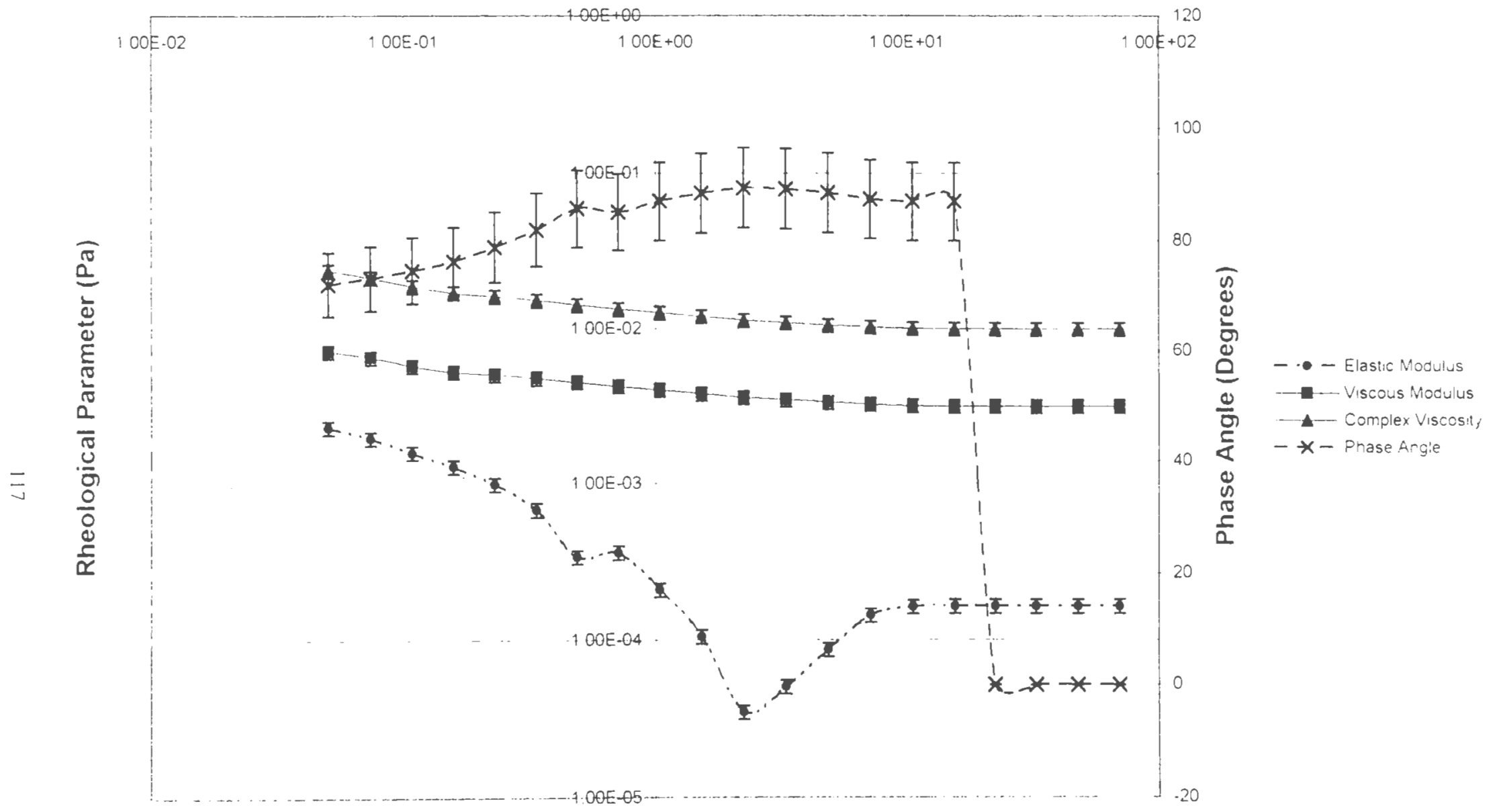

Figure A1.11 Shear Stress $(\mathrm{Pa})$

G", G', Complex Viscosity and Phase Angle Rheogram for lambda Carrageenan (RLV) $1.0 \%$ w/w Measured at $0.05 \mathrm{~Hz}$ and a Stress Range of $0.00-100 \mathrm{~Pa}$ 

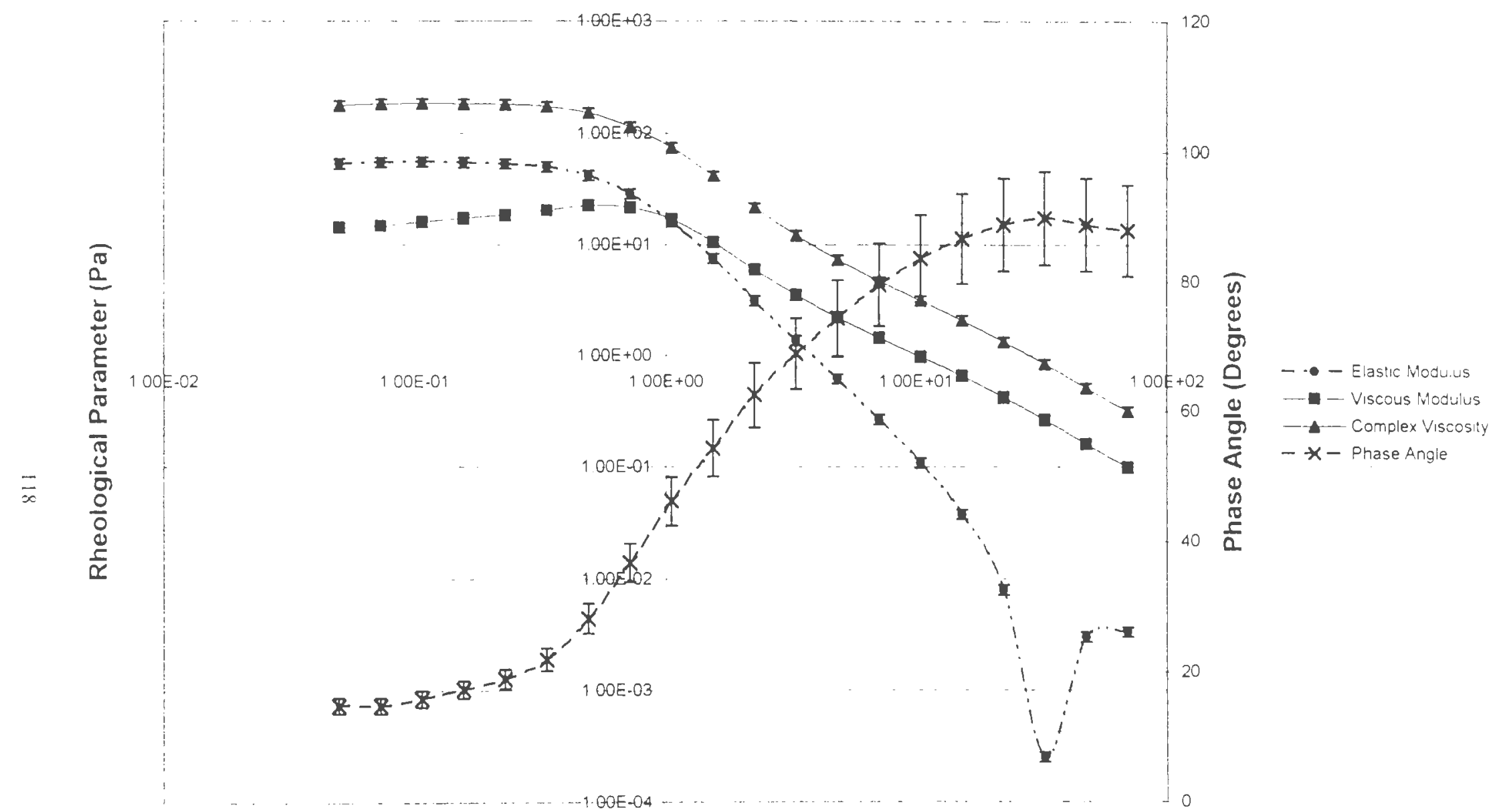

Figure A1.12

Shear Stress $(\mathrm{Pa})$

G", G', Complex Viscosity and Phase Angle Rheogram for lambda

Carrageenan (RLV) $3.0 \% \mathrm{~W} / \mathrm{W}$ Measured at $0.05 \mathrm{~Hz}$ and a Stress Range of $0.00 \cdot 100 \mathrm{~Pa}$ 

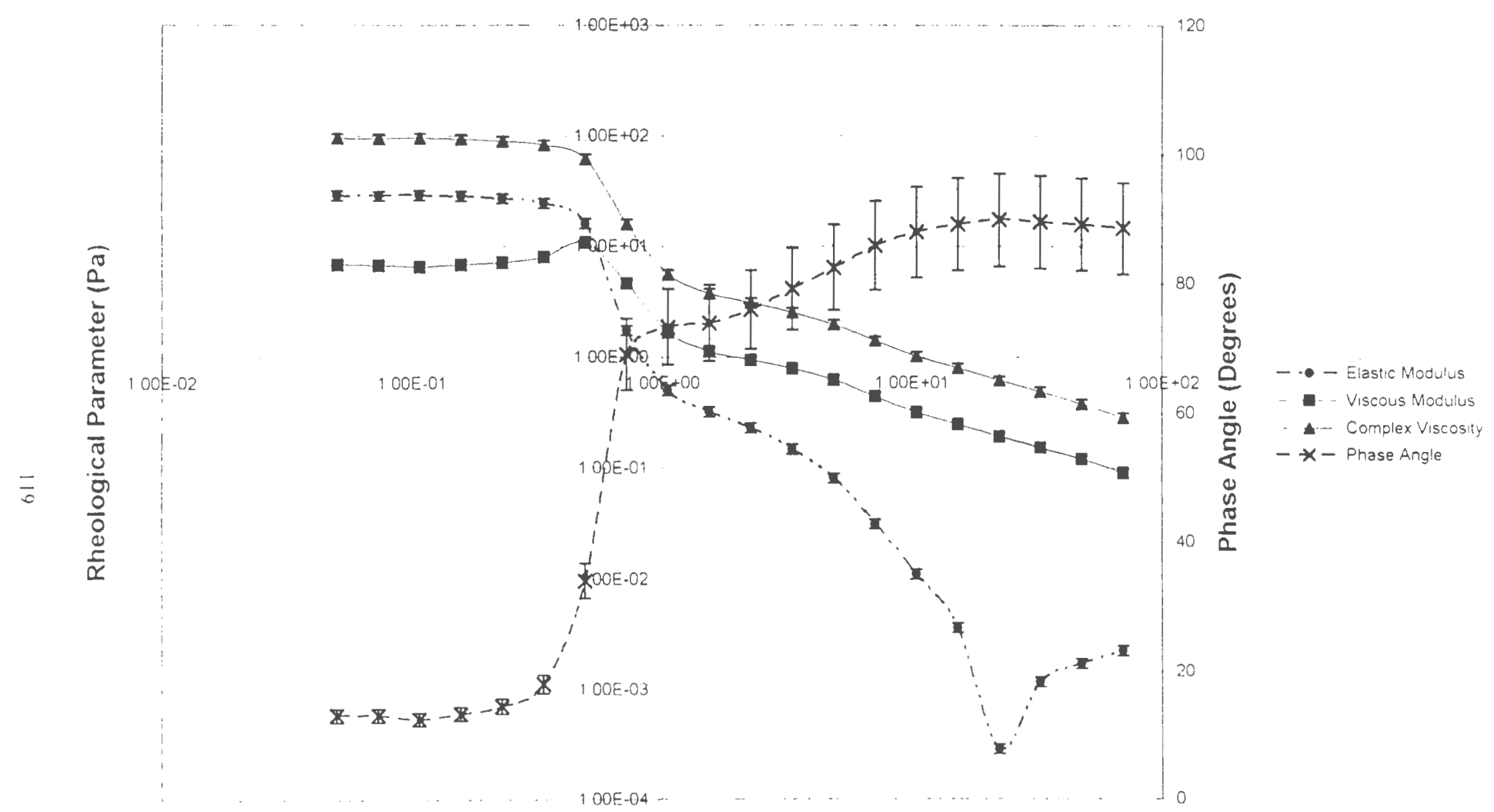

Figure A1.13

Shear Stress $(\mathrm{Pa})$

G", G', Complex Viscosity and Phase Angle Rheogram for lambda

Carrageenan (RLV) $5.0 \%$ w/w Measured at $0.05 \mathrm{~Hz}$ and a Stress Range of $0.00-100 \mathrm{~Pa}$ 


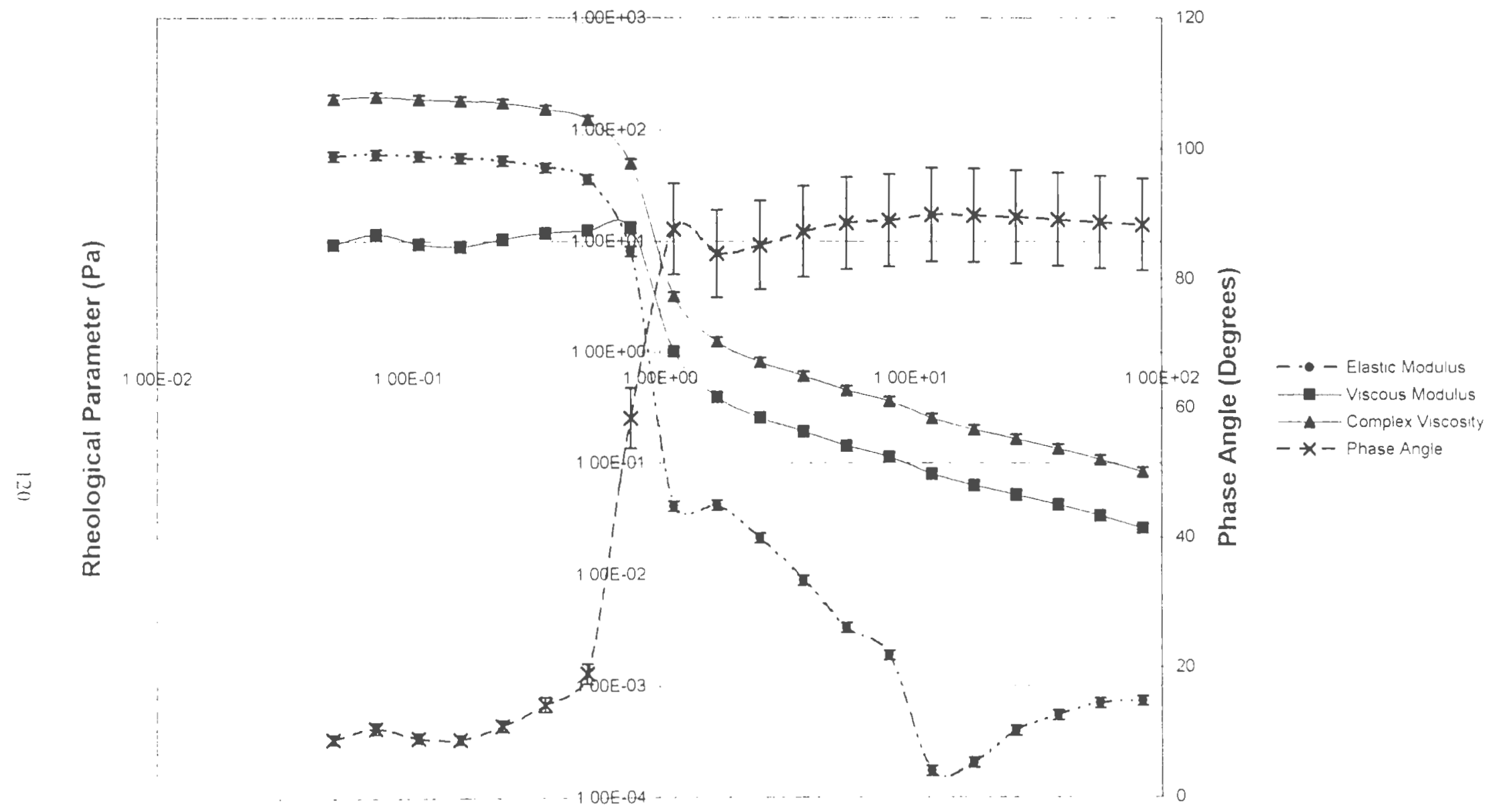

Figure A1.14

Shear Stress $(\mathrm{Pa})$

G", G', Complex Viscosity and Phase Angle Rheogram for lambda

Carrageenan (RLV) $6.0 \%$ w/w Measured at $0.05 \mathrm{~Hz}$ and a Stress Range of $0.00-100 \mathrm{~Pa}$ 

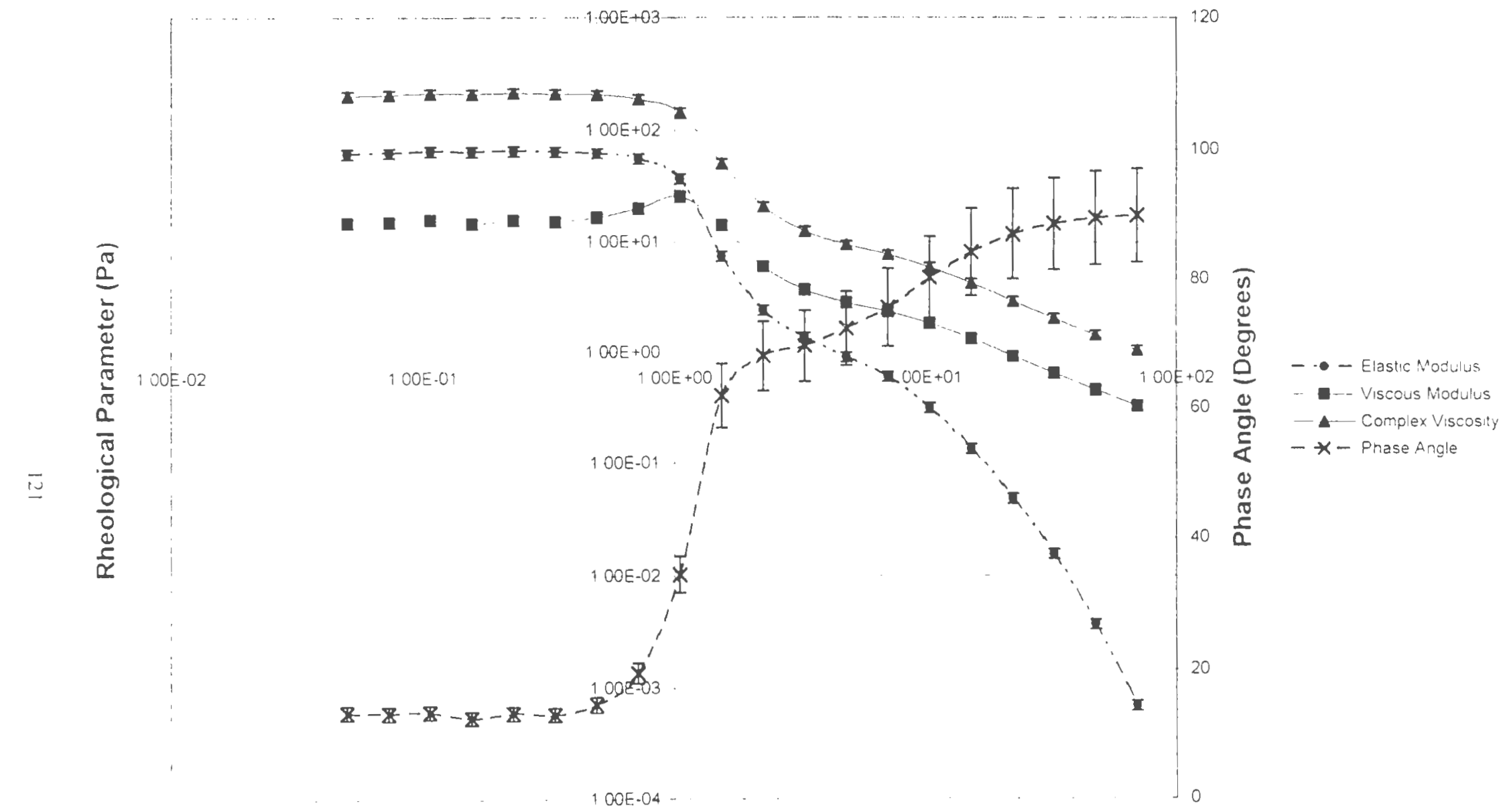

Figure A1.15

Shear Stress ( $\mathrm{Pa}$ )

G', G', Complex Viscosity and Phase Angle Rheogram for lambda

Carrageenan (RLV) $7.0 \%$ w/w Measured at $0.05 \mathrm{~Hz}$ and a Stress Range of $0.00-100 \mathrm{~Pa}$ 


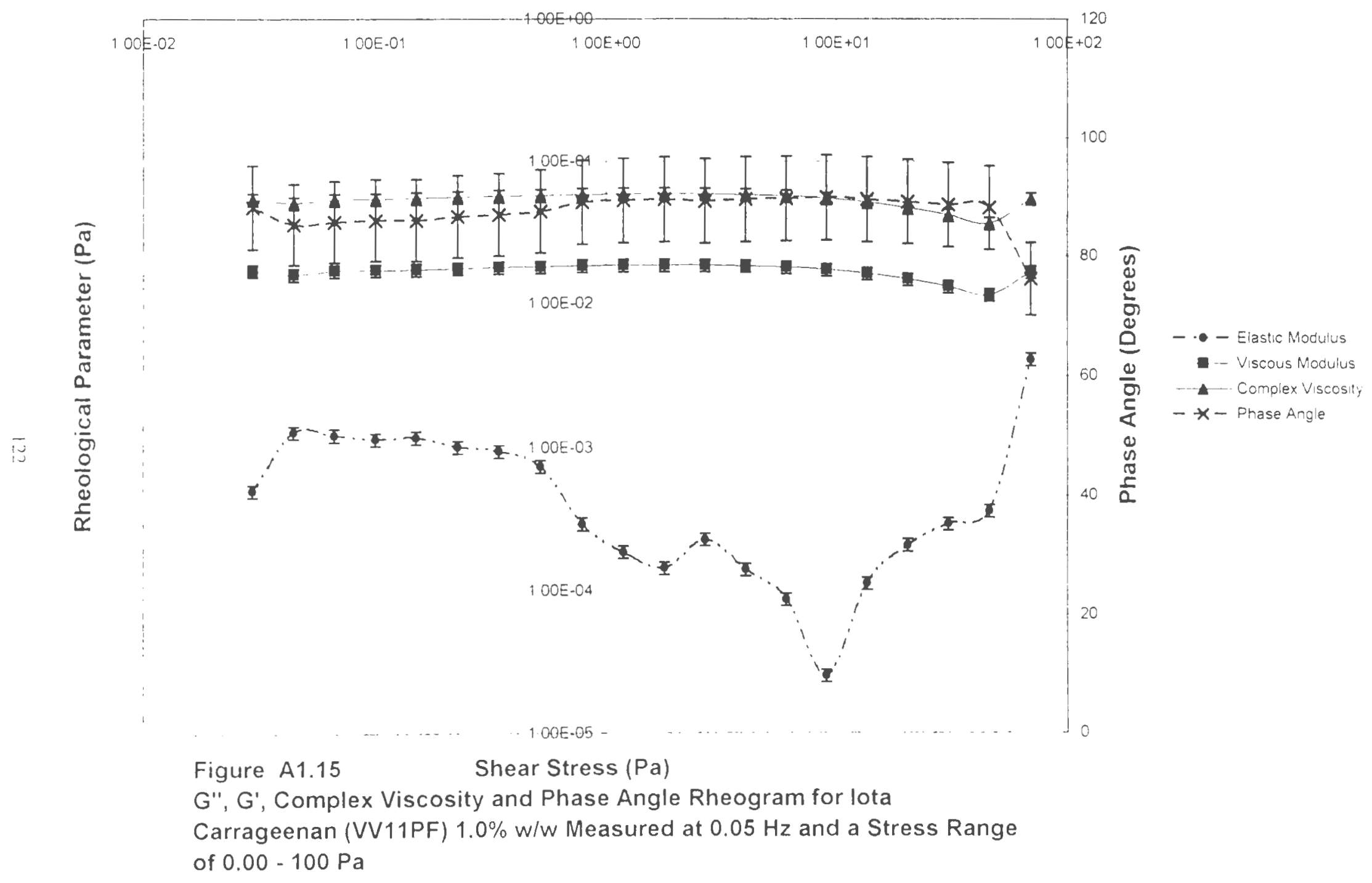




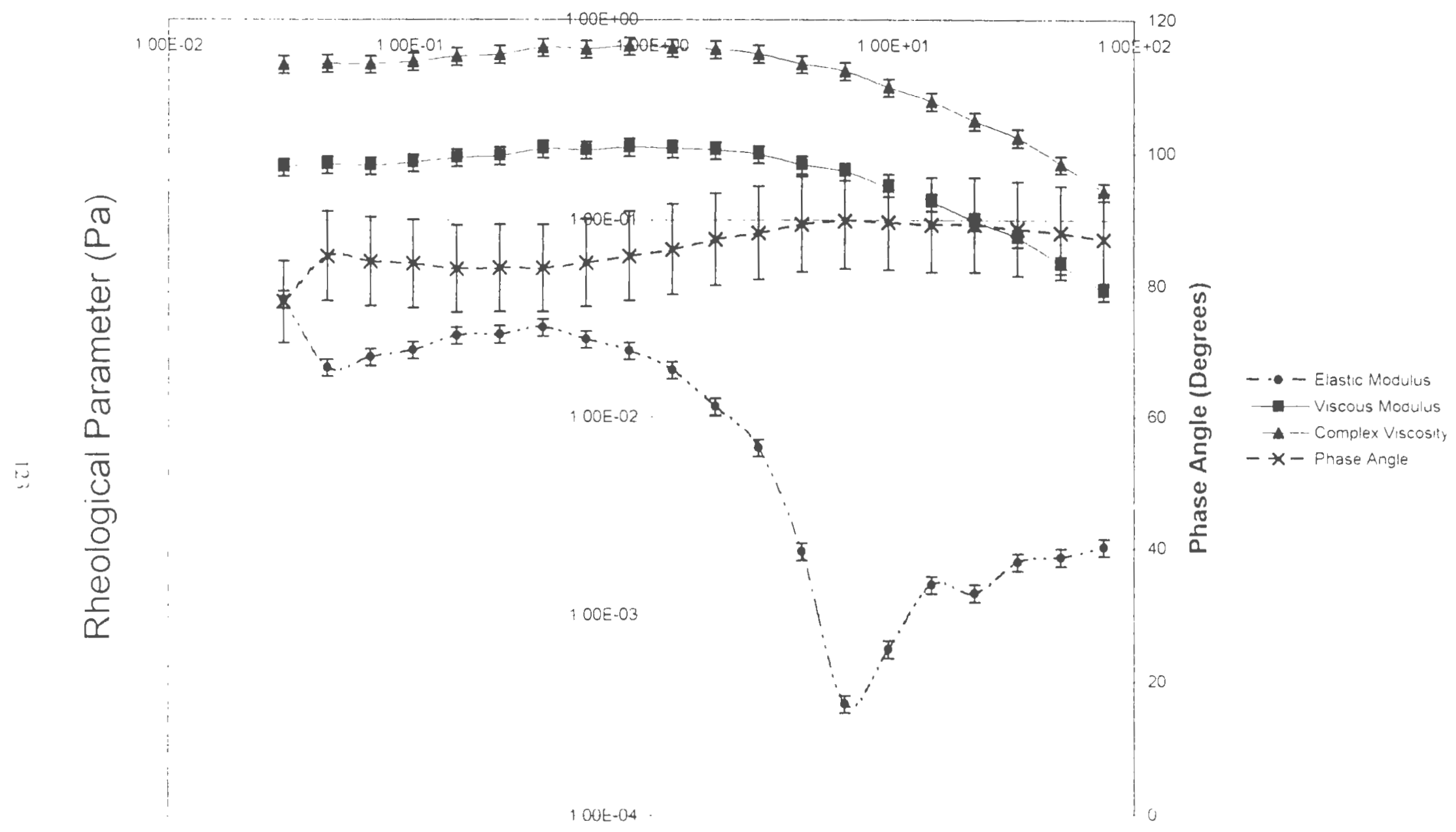

Figure A1.16

Shear Stress $(\mathrm{Pa})$

$G^{\prime \prime}$. G', Complex Viscosity and Phase Angle Rheogram for lota Carrageenan

(VV11PF) $2.0 \% \mathrm{~W} / \mathrm{w}$ Measured at $0.05 \mathrm{~Hz}$ and a Stress Range of $0.00-100 \mathrm{~Pa}$ 


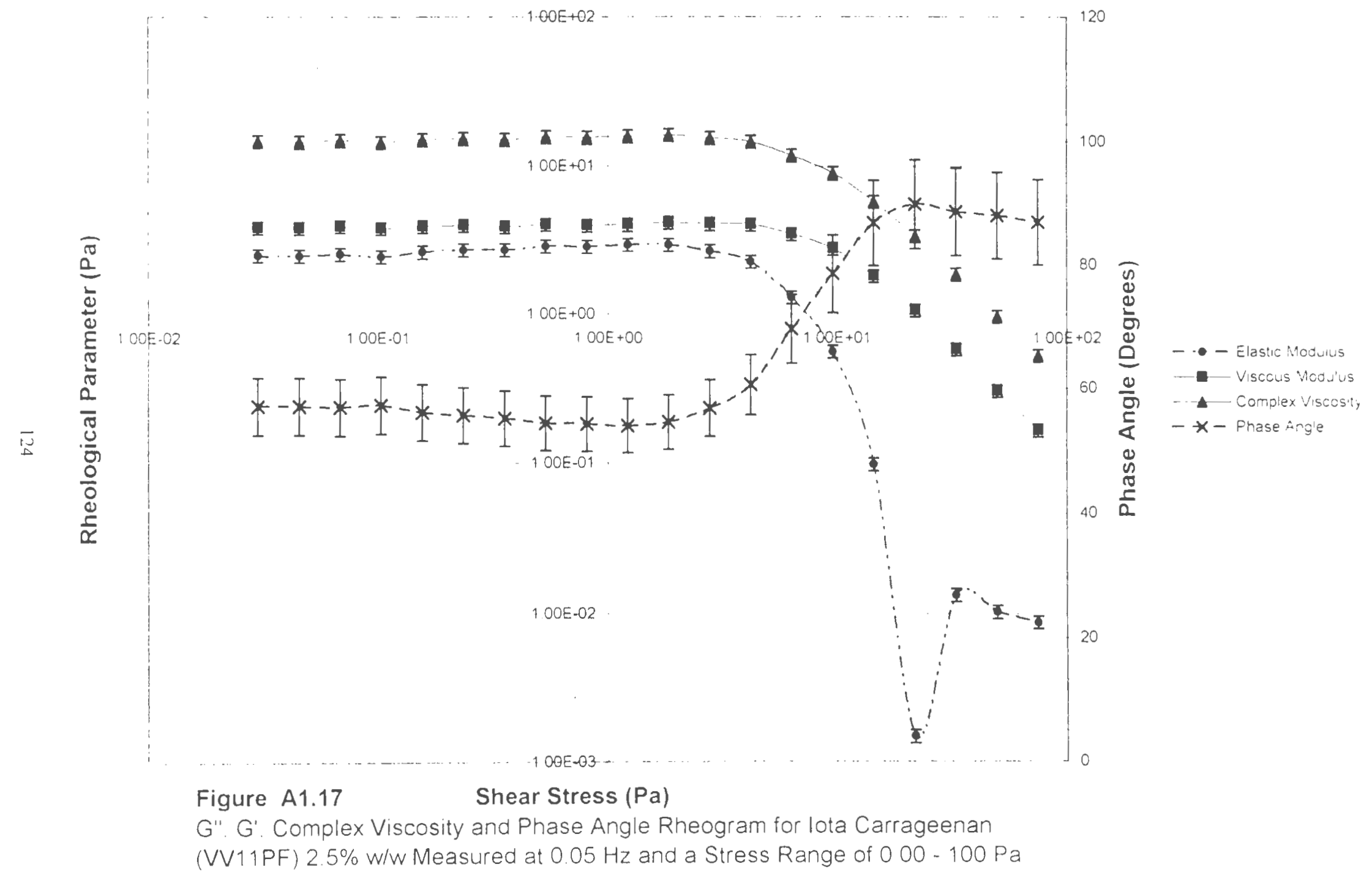




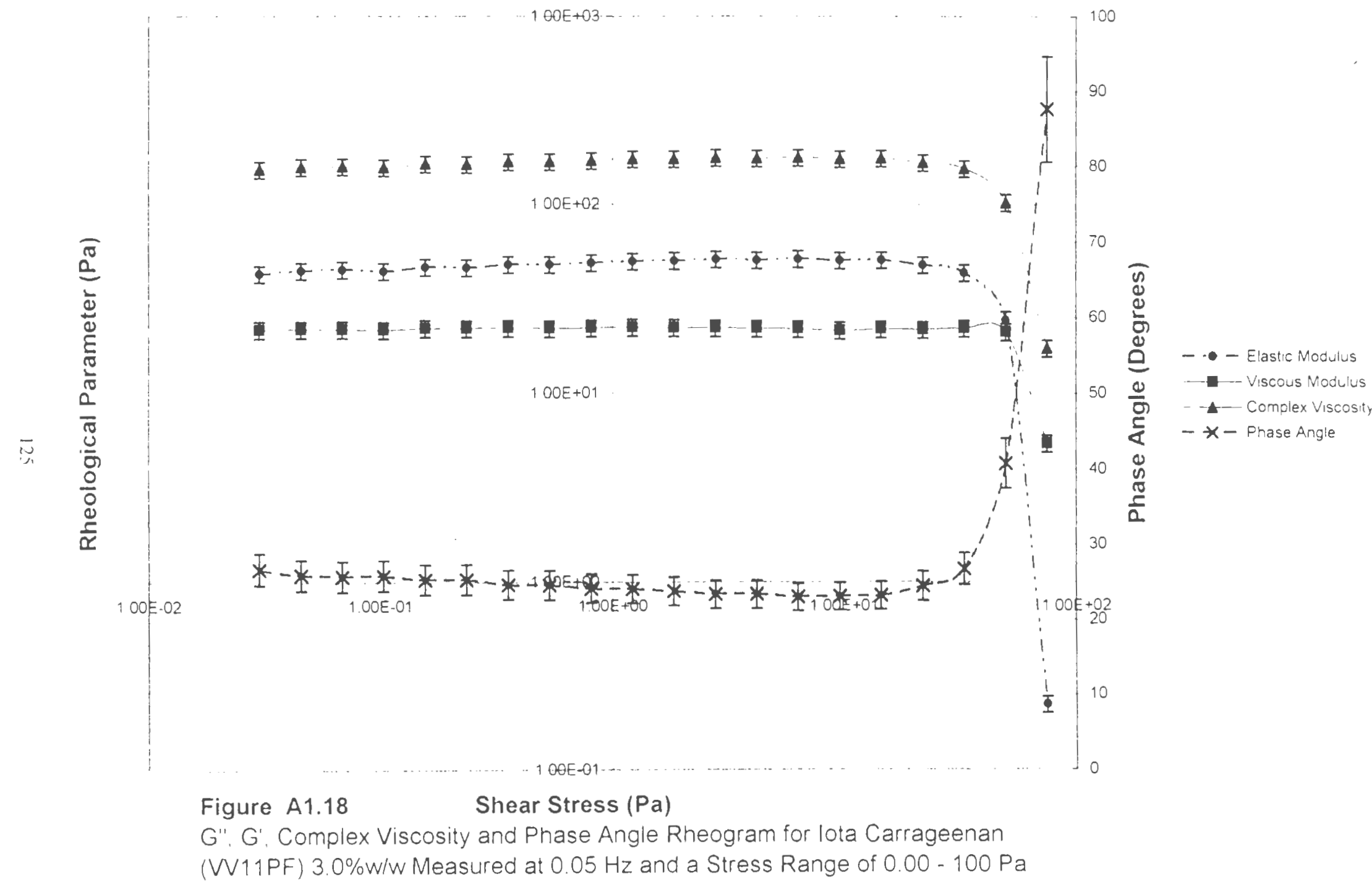




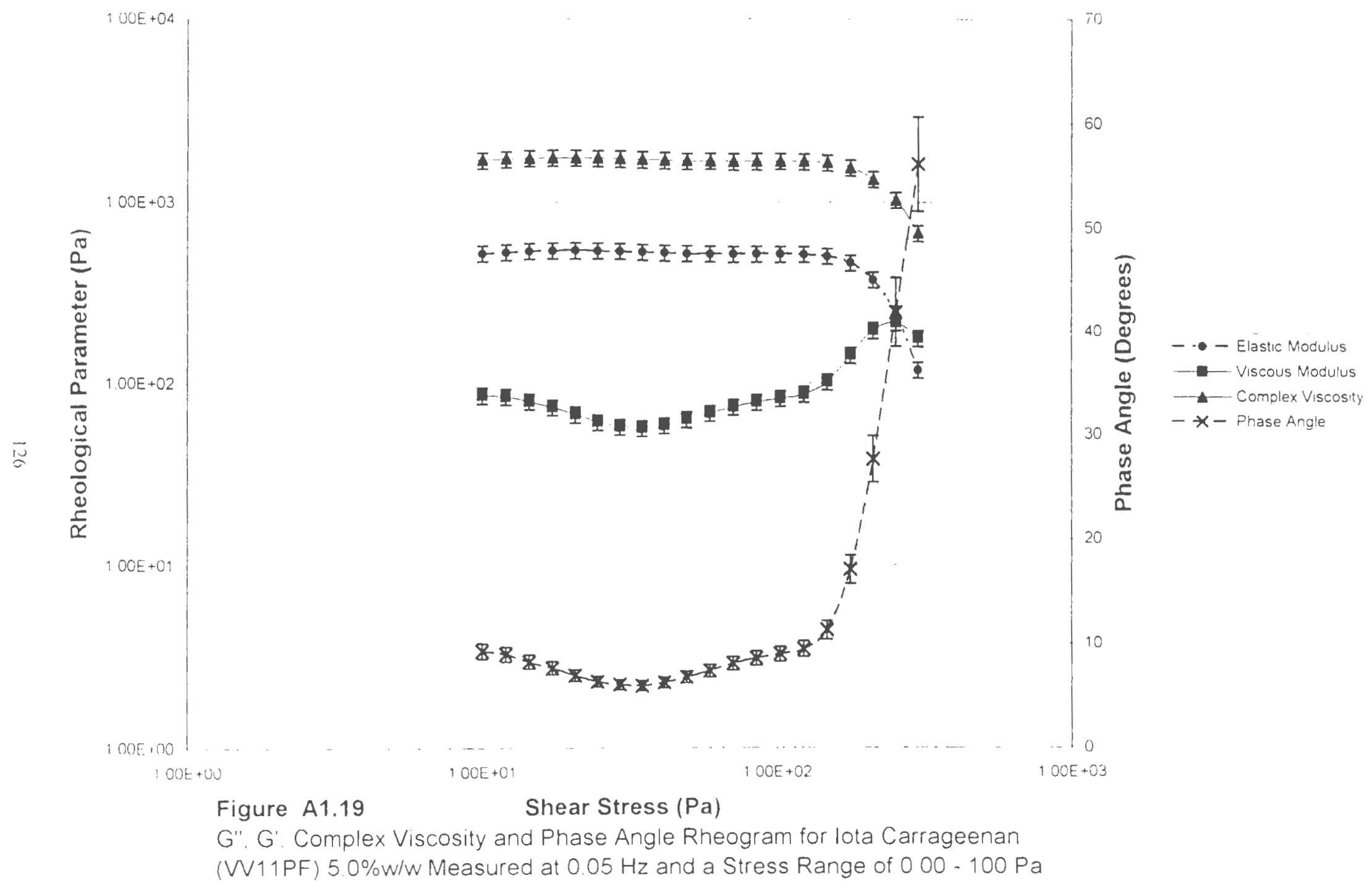




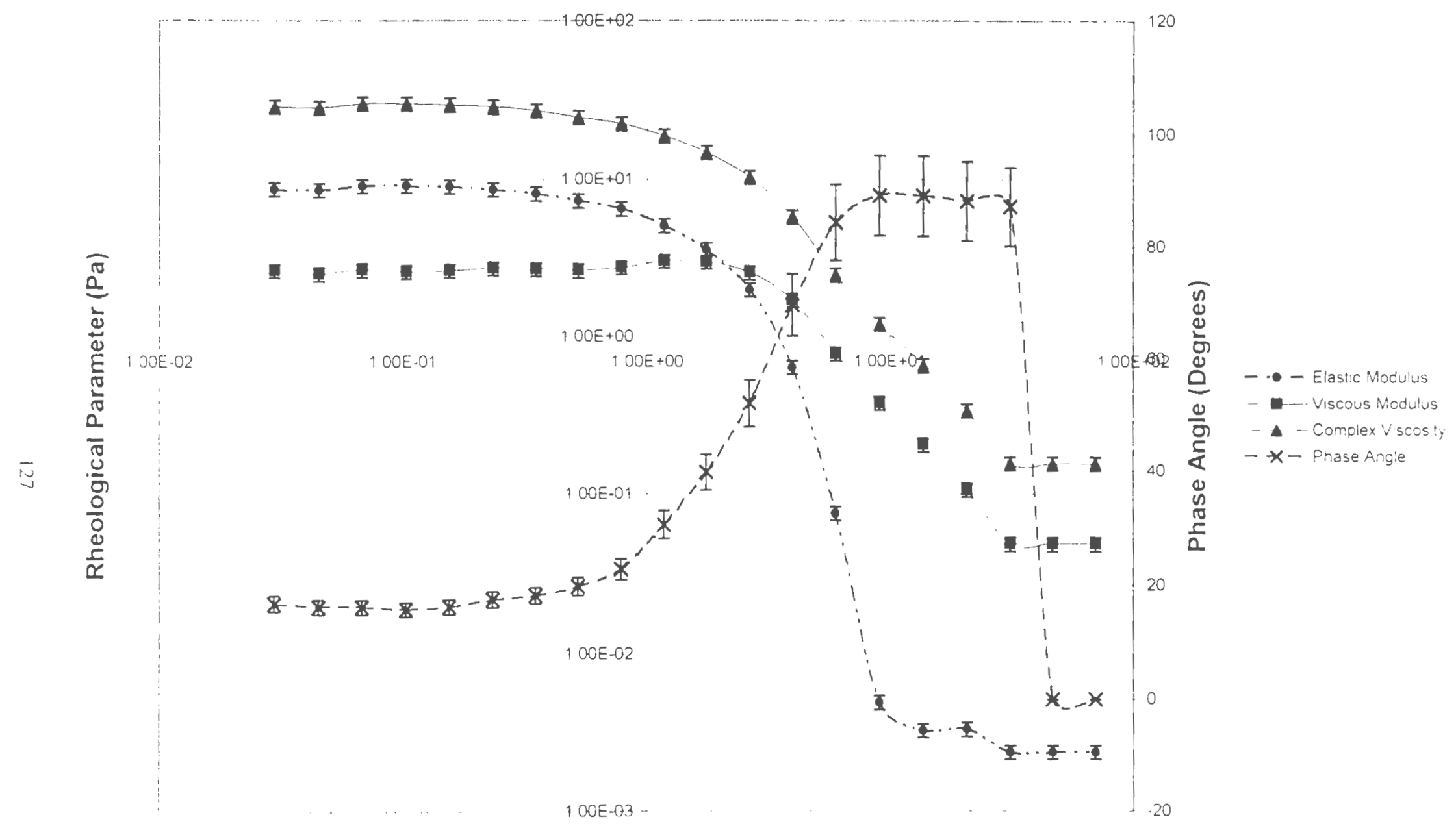

Figure A1.20 Shear Stress (Pa)

G'. G'. Complex Viscosity and Phase Angle Rheogram for Kappa Carrageenan (VV71PF) $10 \% \mathrm{w} / \mathrm{w}$ Measured at $0.05 \mathrm{~Hz}$ and a Stress Range of $000-100 \mathrm{~Pa}$ 


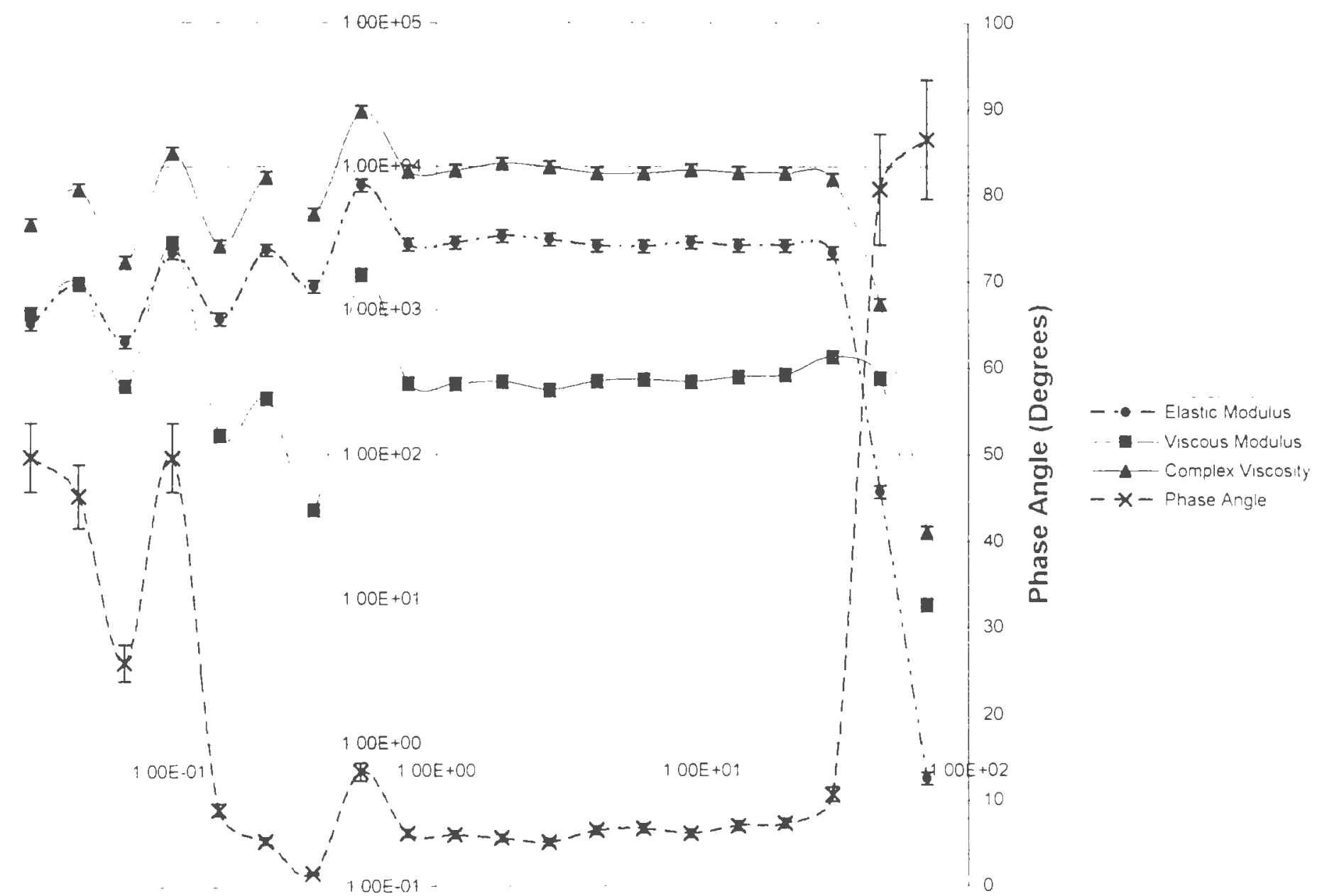

Figure A1.21

Shear Stress $(\mathrm{Pa})$

G" G'. Complex Viscosity and Phase Angle Rheogram for Kappa Carrageenan

(VV71PF) $30 \%$ w/W Measured at $0.05 \mathrm{~Hz}$ and a Stress Range of $0.00-100 \mathrm{~Pa}$ 


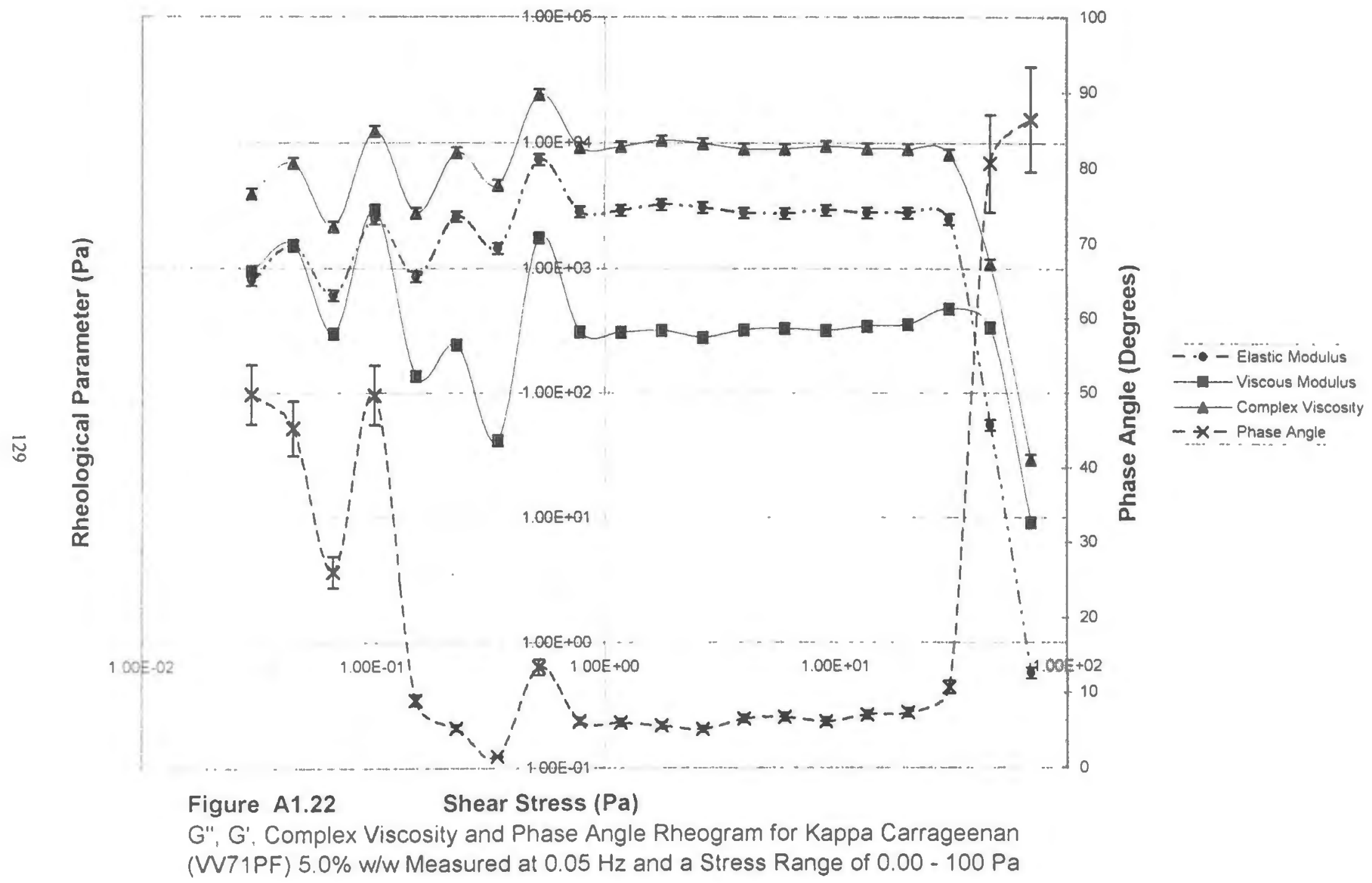




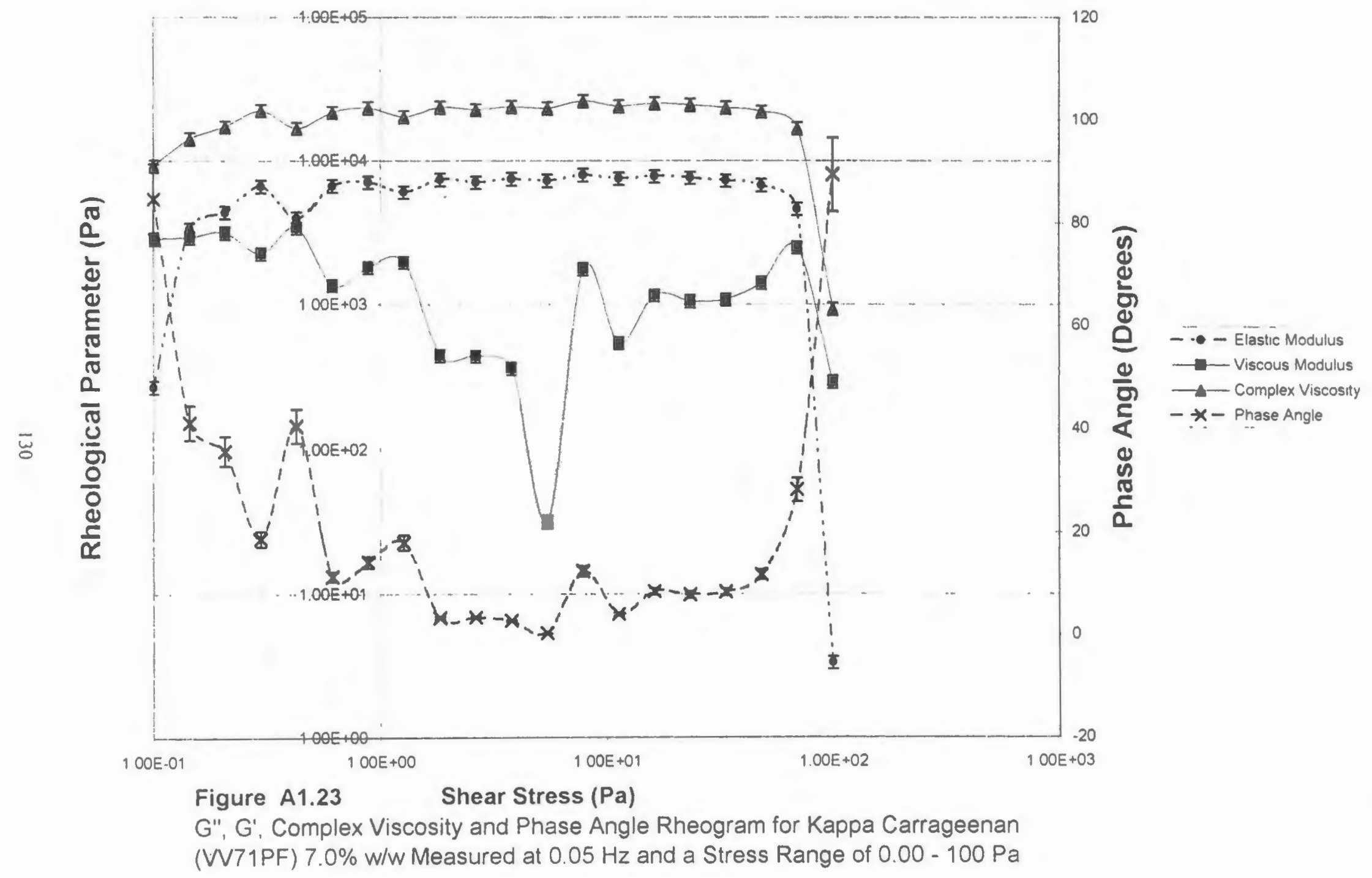




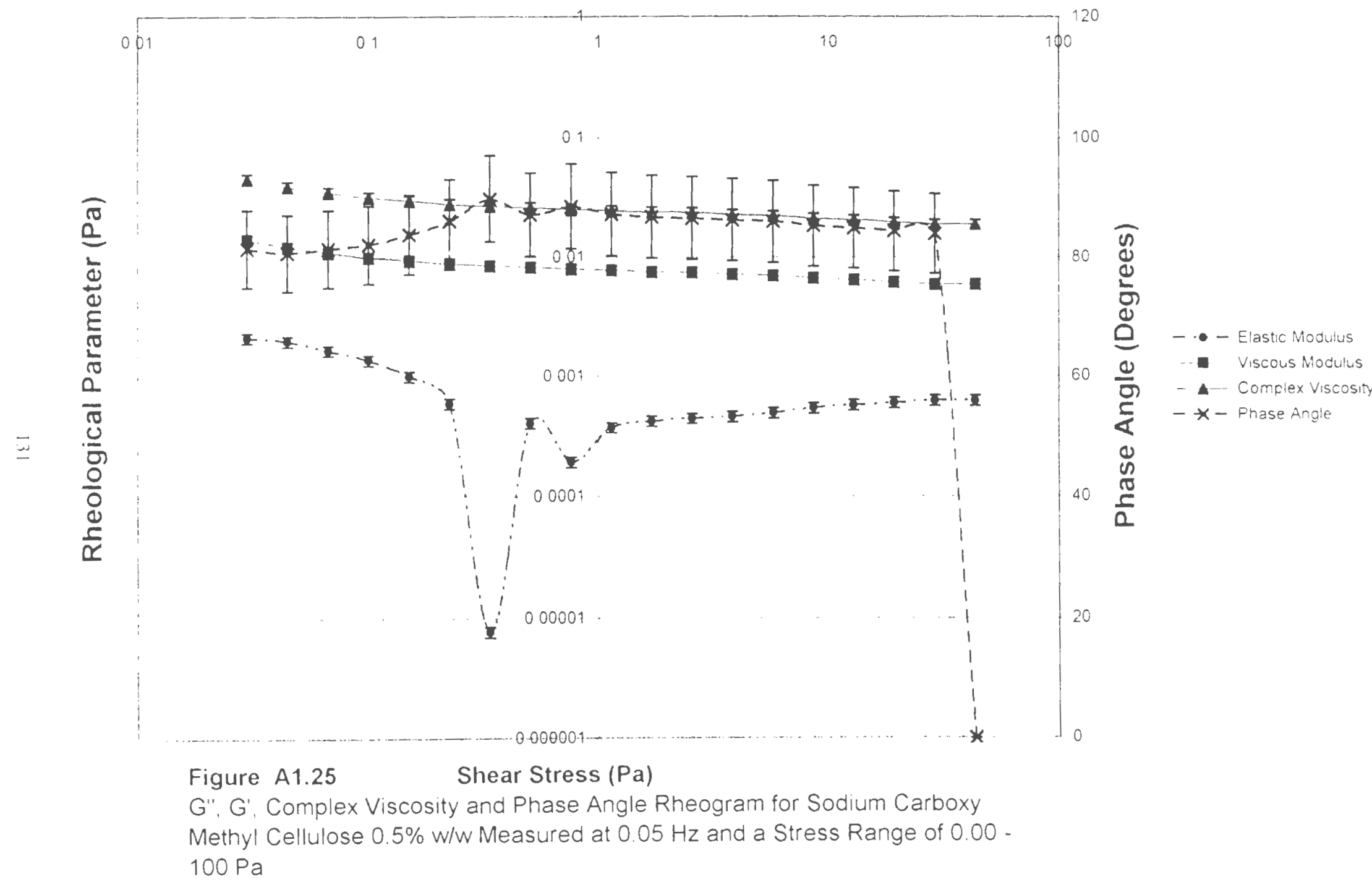




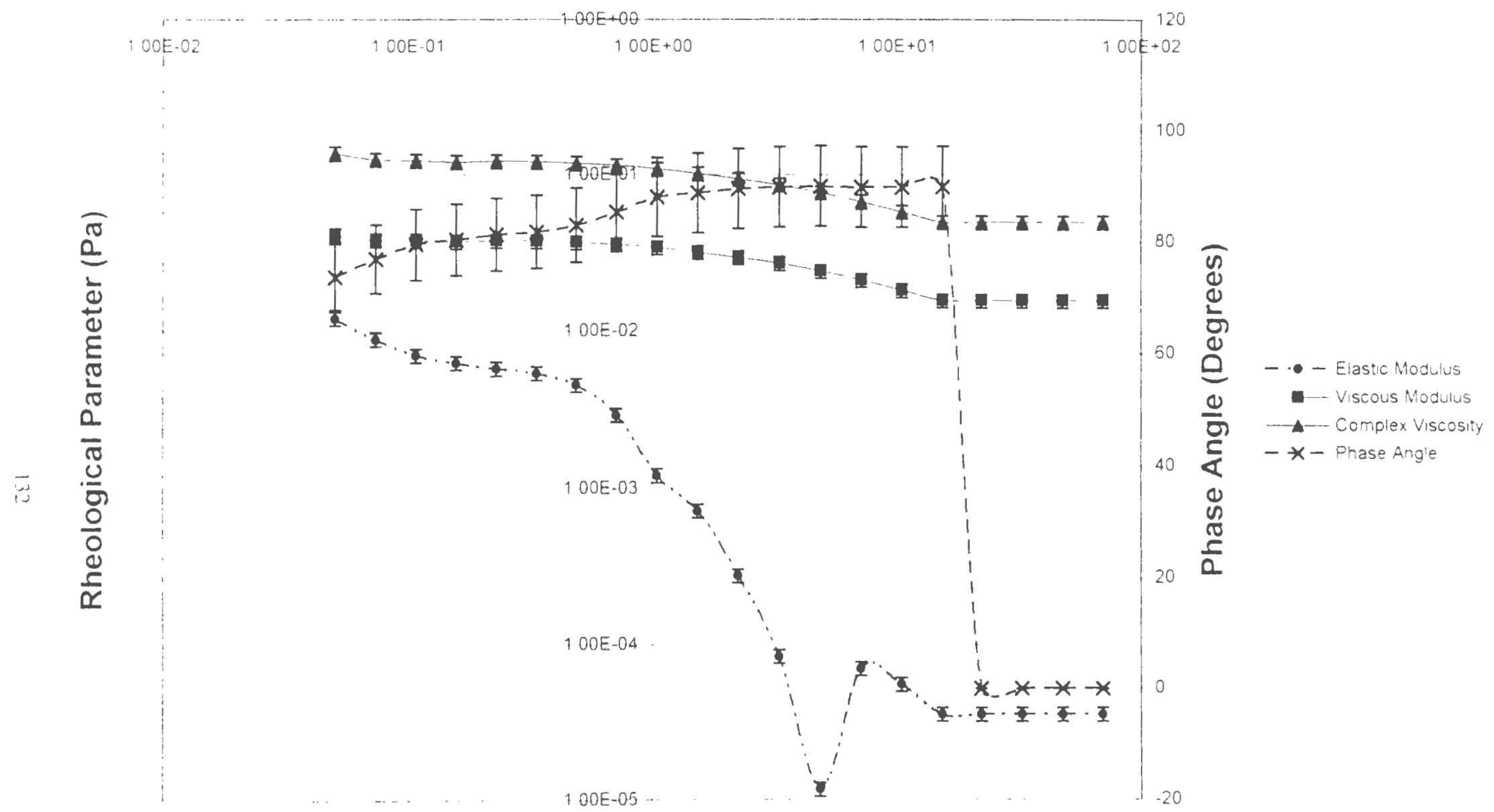

Figure A1.24 Shear Stress (Pa)

G'. G', Complex Viscosity and Phase Angle Rheogram for Sodium Carboxy Methyl Cellulose 1.0\% w/w Measured at $0.05 \mathrm{~Hz}$ and a Stress Range of 0.00 $100 \mathrm{~Pa}$ 


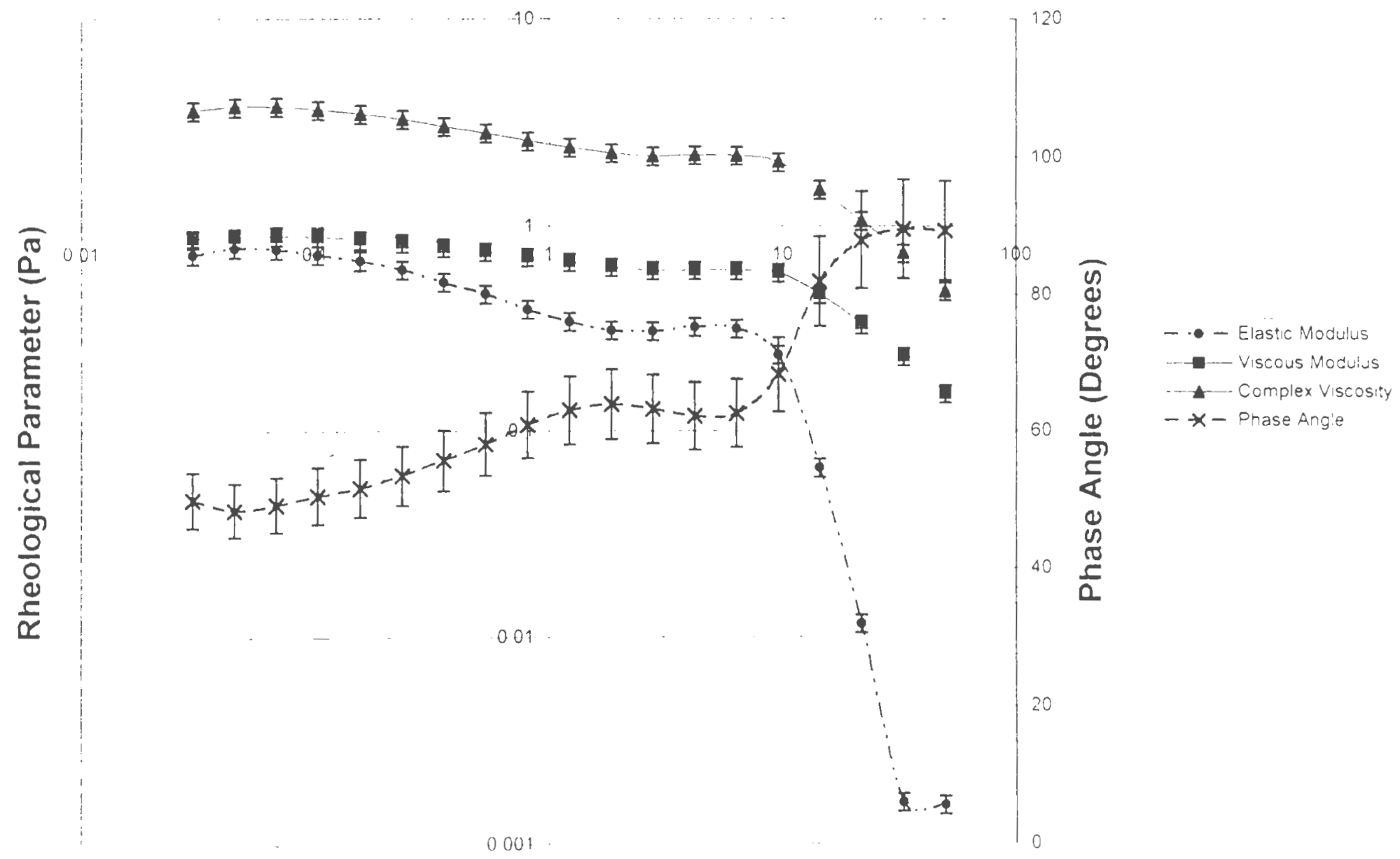

Figure $A 1.26$

Shear Stress $(\mathrm{Pa})$

G'. G'. Complex Viscosity and Phase Angle Rheogram for Sodıum Carboxy Methyl Cellulose $2.0 \% \mathrm{w} / \mathrm{w}$ Measured at $005 \mathrm{~Hz}$ and a Stress Range of 0.00 $100 \mathrm{~Pa}$ 


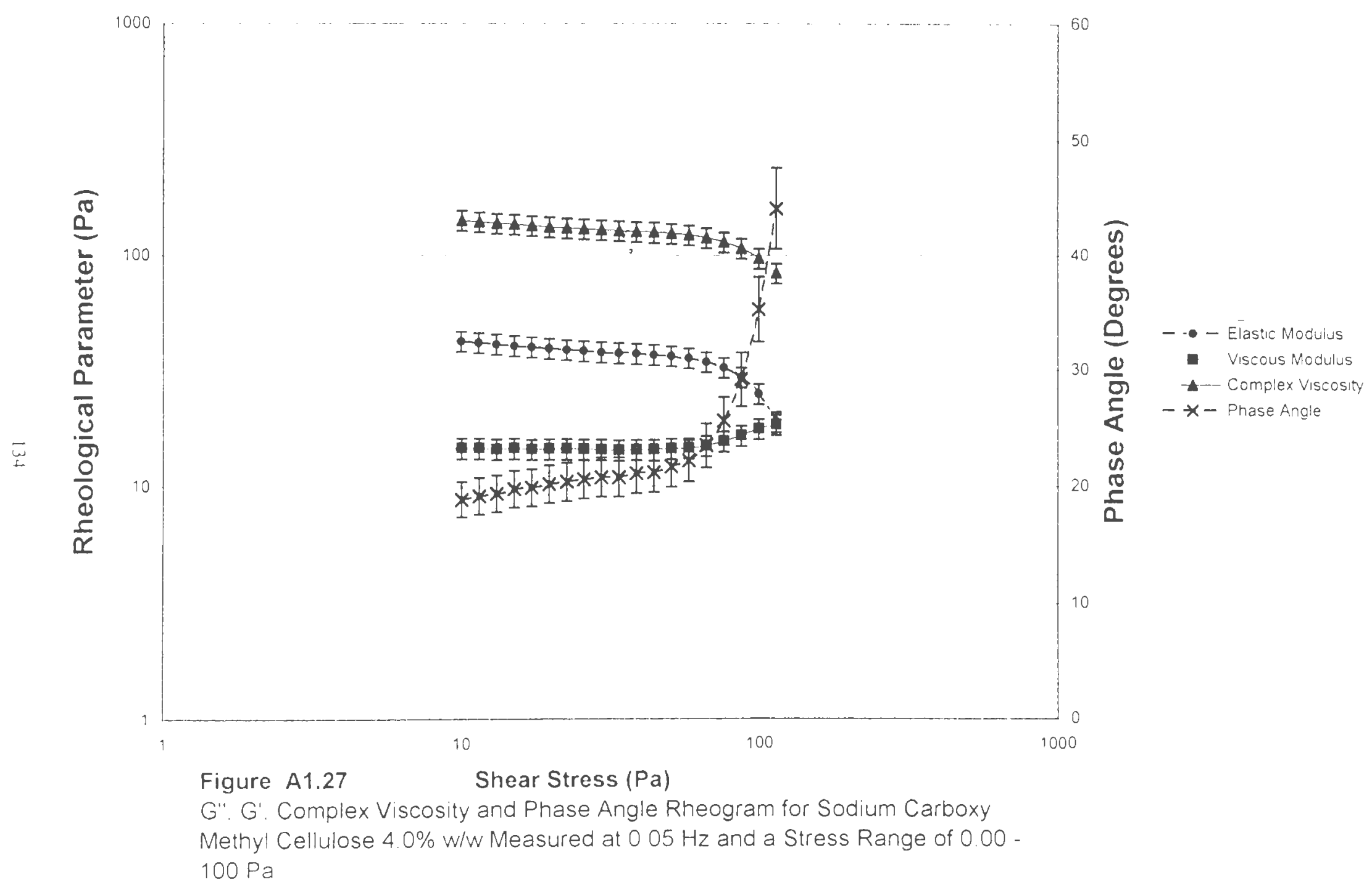




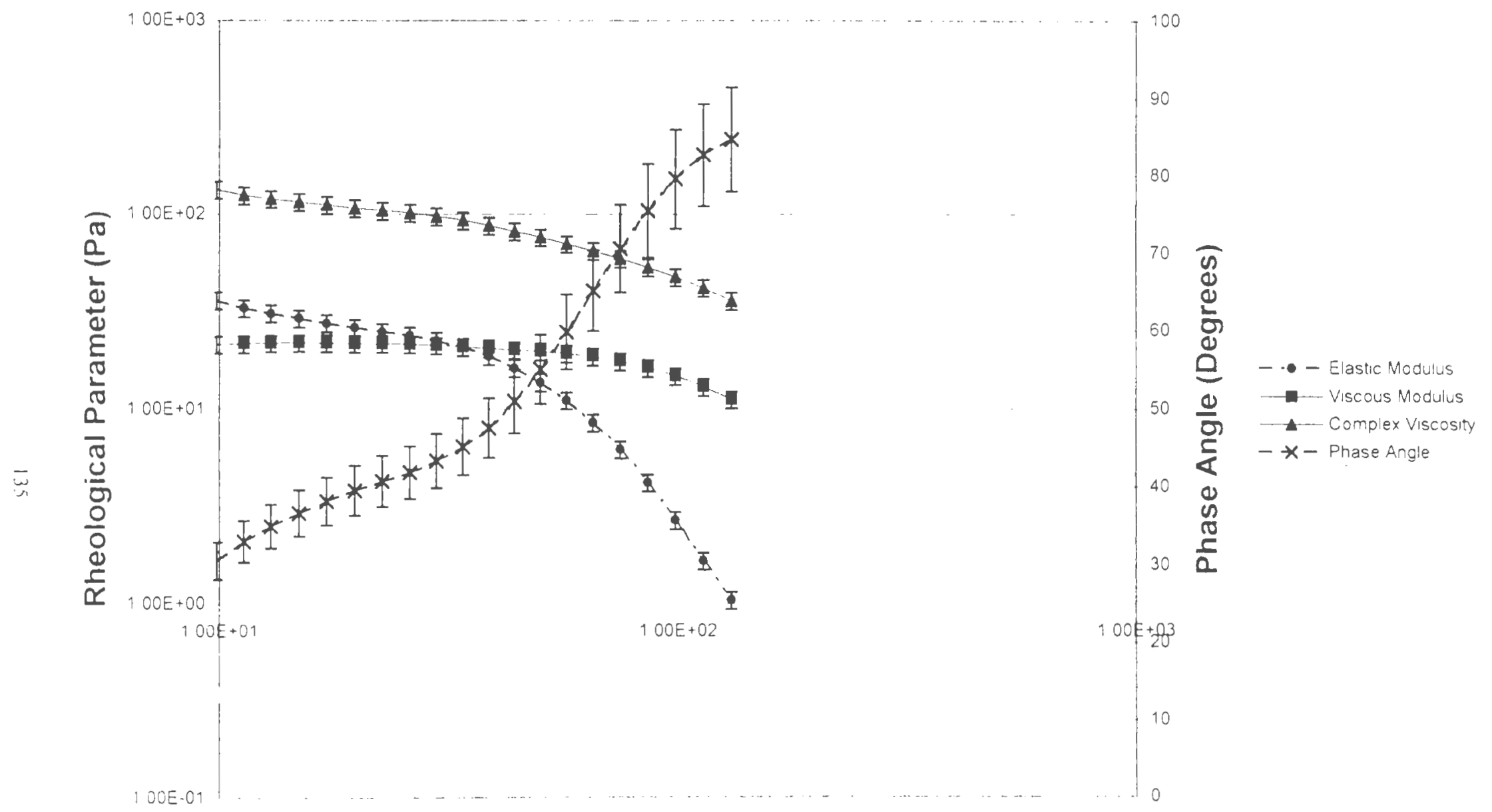

\section{Figure $\mathrm{A} 1.28 \quad$ Shear Stress $(\mathrm{Pa})$}

G'. G' Complex Viscosity and Phase Angle Rheogram for Sodium Carboxy Methyl Celiulose $5.0 \%$ w/w Measured at $0.05 \mathrm{~Hz}$ and a Stress Range of 000 $100 \mathrm{~Pa}$ 


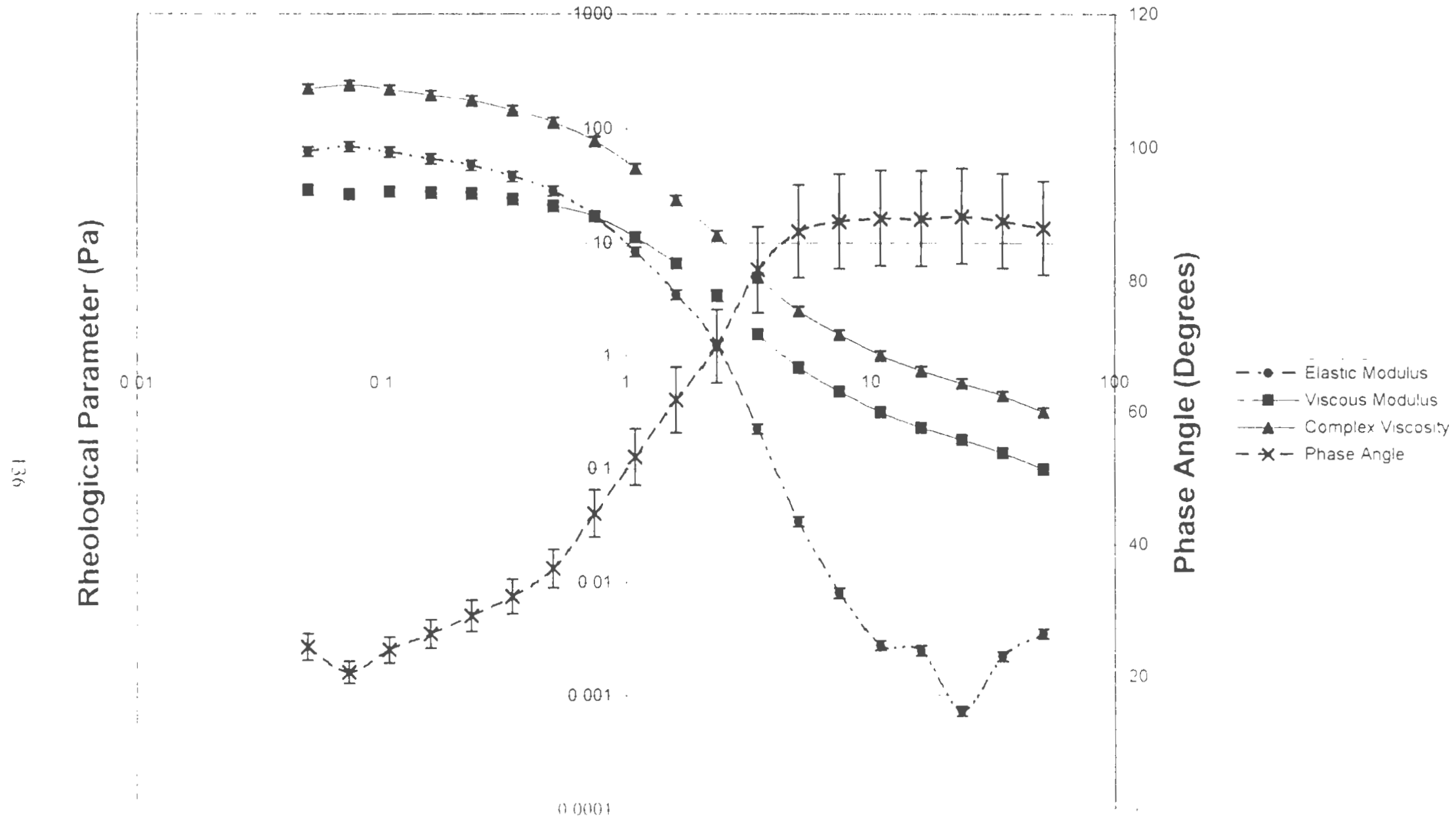

Figure A1.29

Shear Stress (Pa)

G". G' Complex Viscosity and Phase Angle Rheogram for Water Lock A-100

$03 \%$ w/w Measured at $0.05 \mathrm{~Hz}$ and a Stress Range of $0.00-100 \mathrm{~Pa}$ 


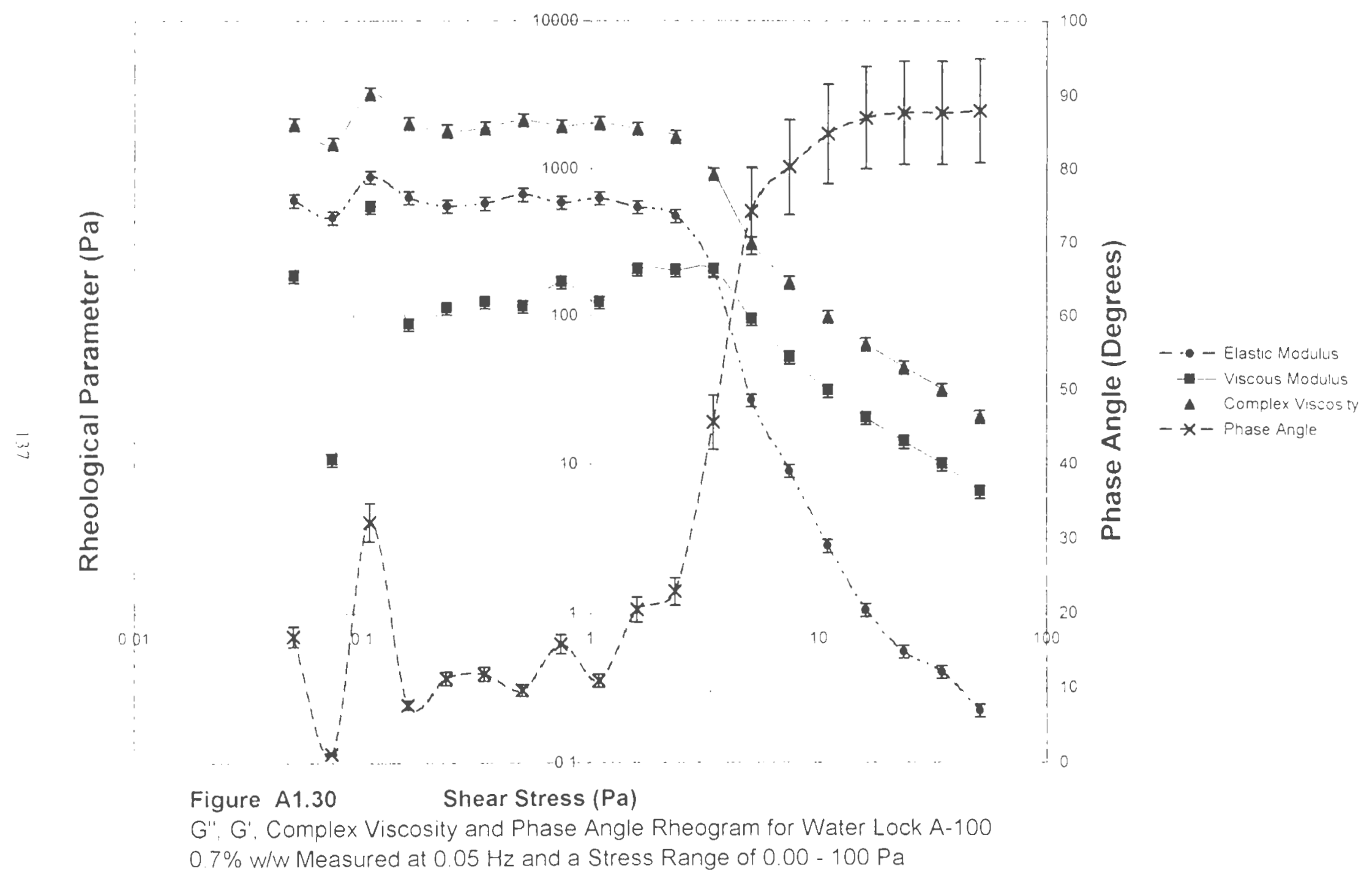




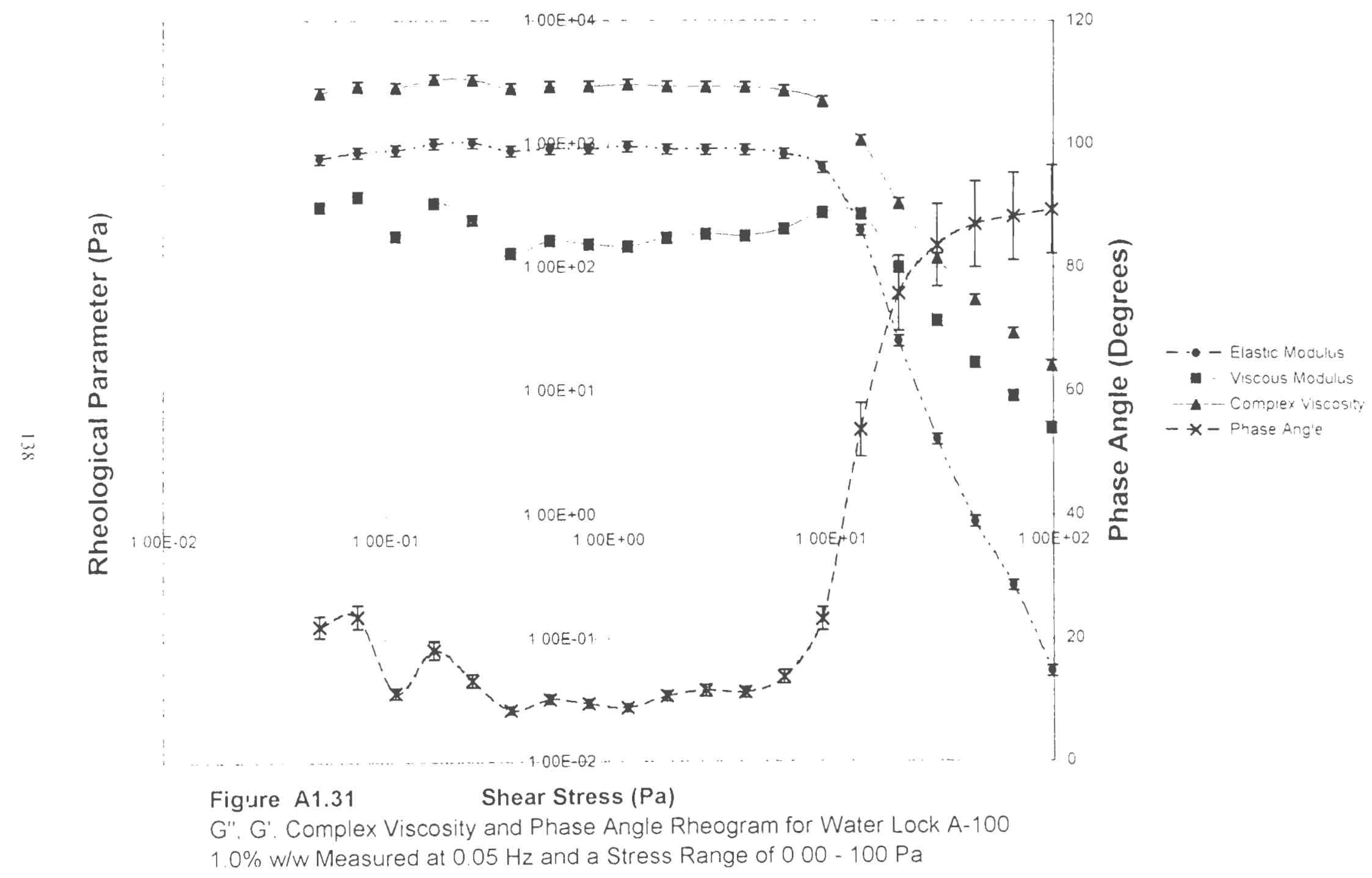




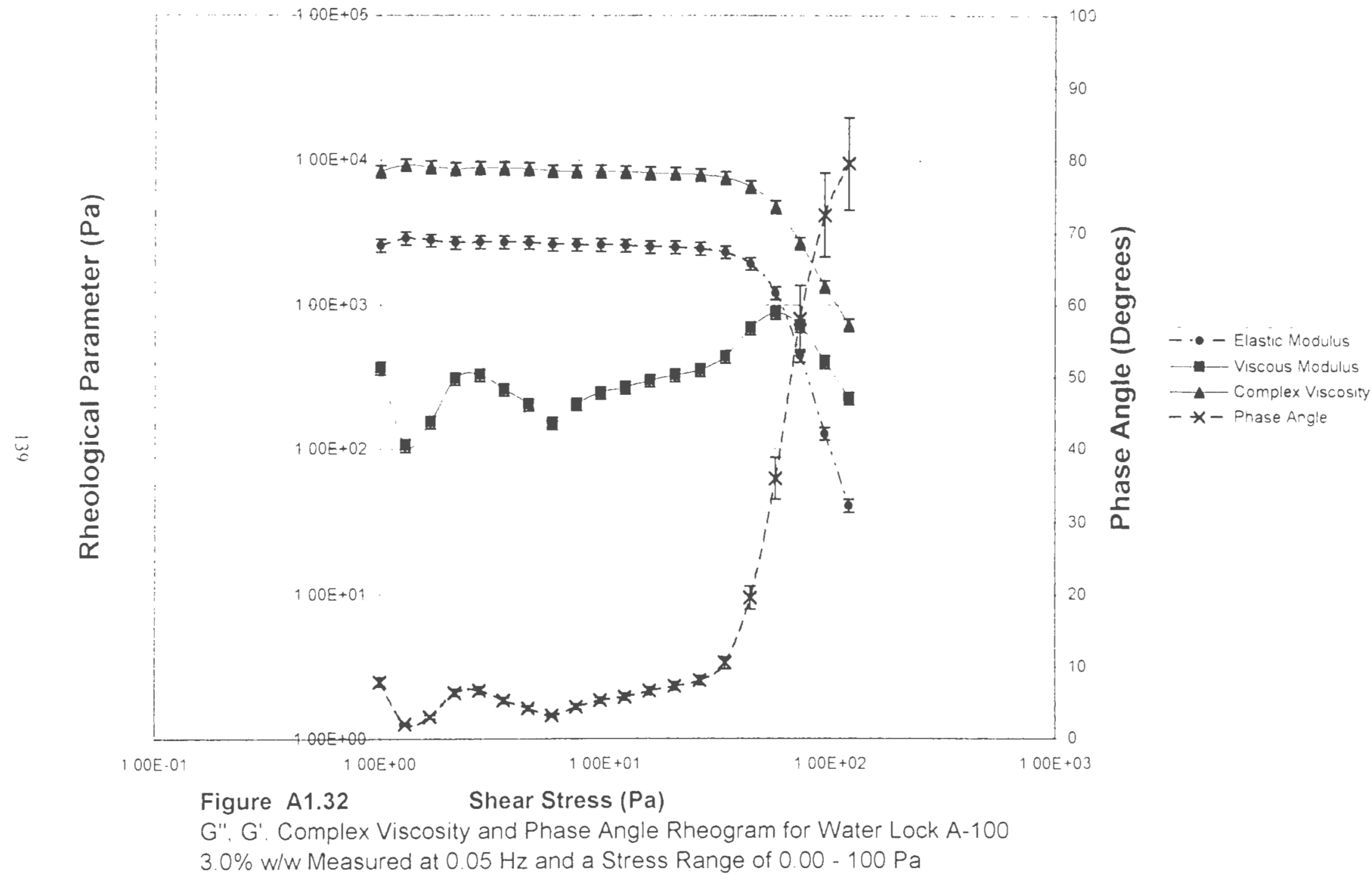



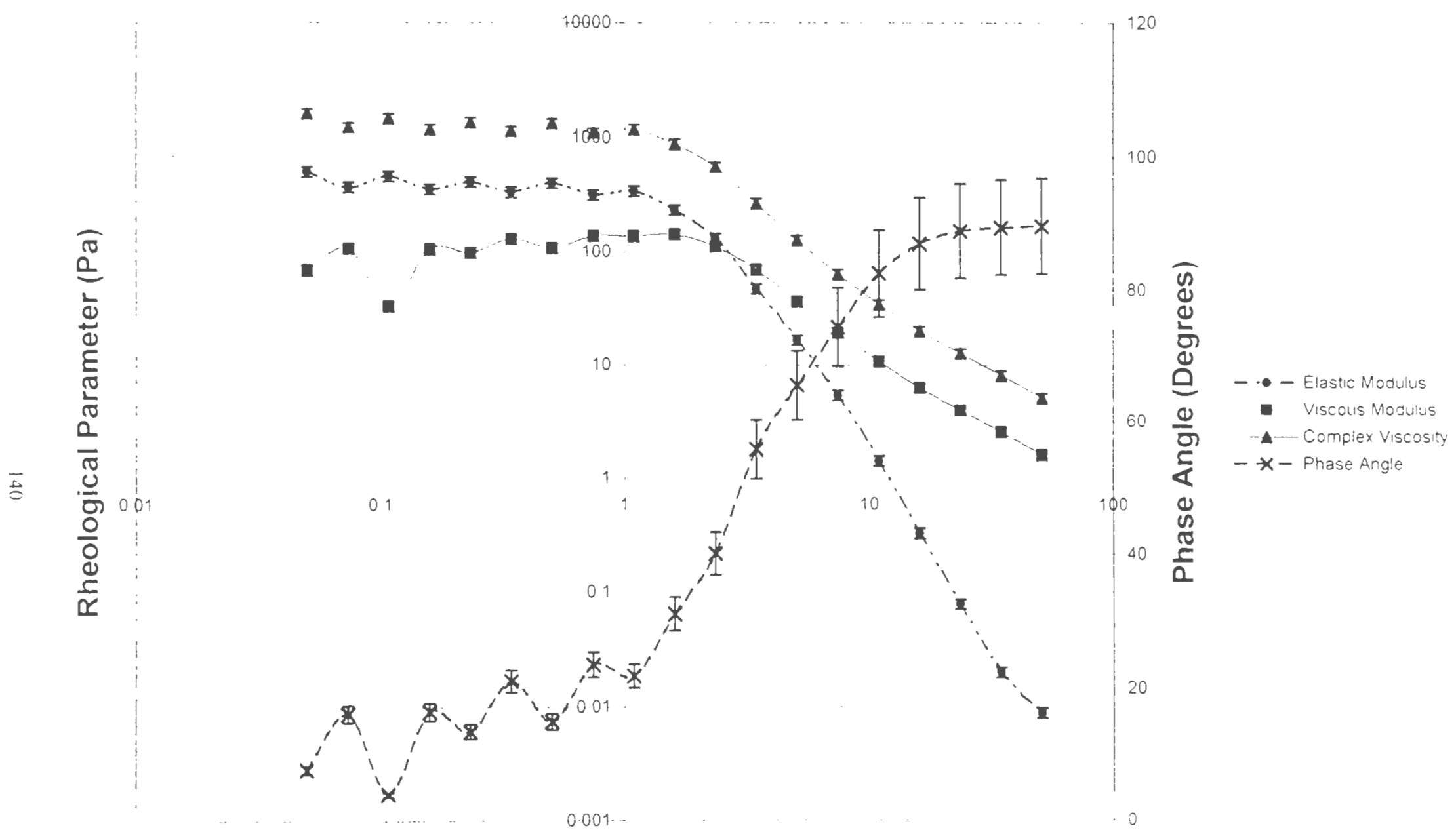

Figure $A 1.33$

Shear Stress $(\mathrm{Pa})$

G', G'. Complex Viscosity and Phase Angle Rheogram for Water Lock A-180

$0.7 \%$ w/w Measured at $0.05 \mathrm{~Hz}$ and a Stress Range of $0.00-100 \mathrm{~Pa}$ 


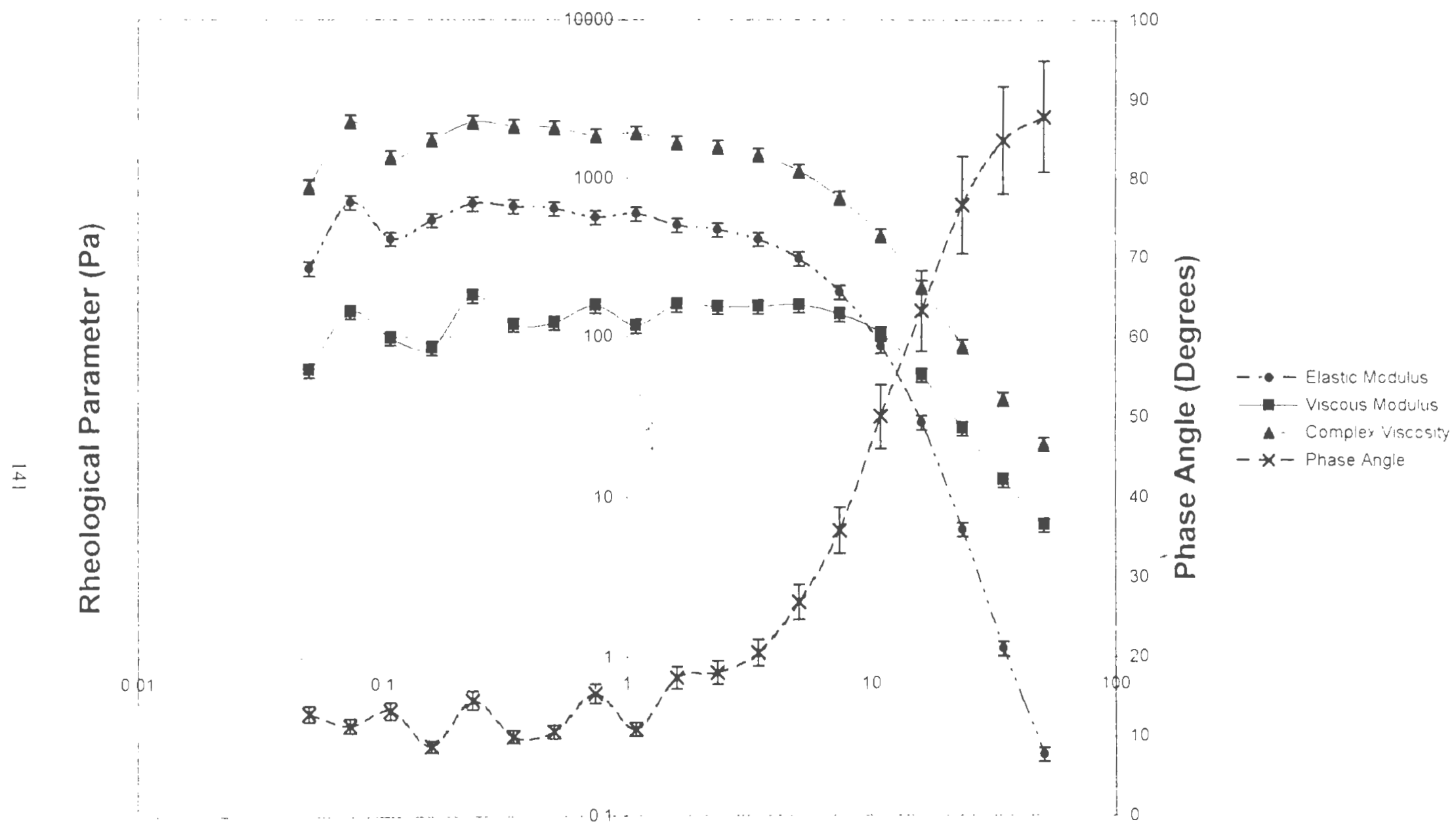

Figure A1.34 Shear Stress $(\mathrm{Pa})$

G". G'. Complex VIscosity and Phase Angle Rheogram for Water Lock A-180

$10 \%$ w/w Measured at $0.05 \mathrm{~Hz}$ and a Stress Range of $0.00-100 \mathrm{~Pa}$ 


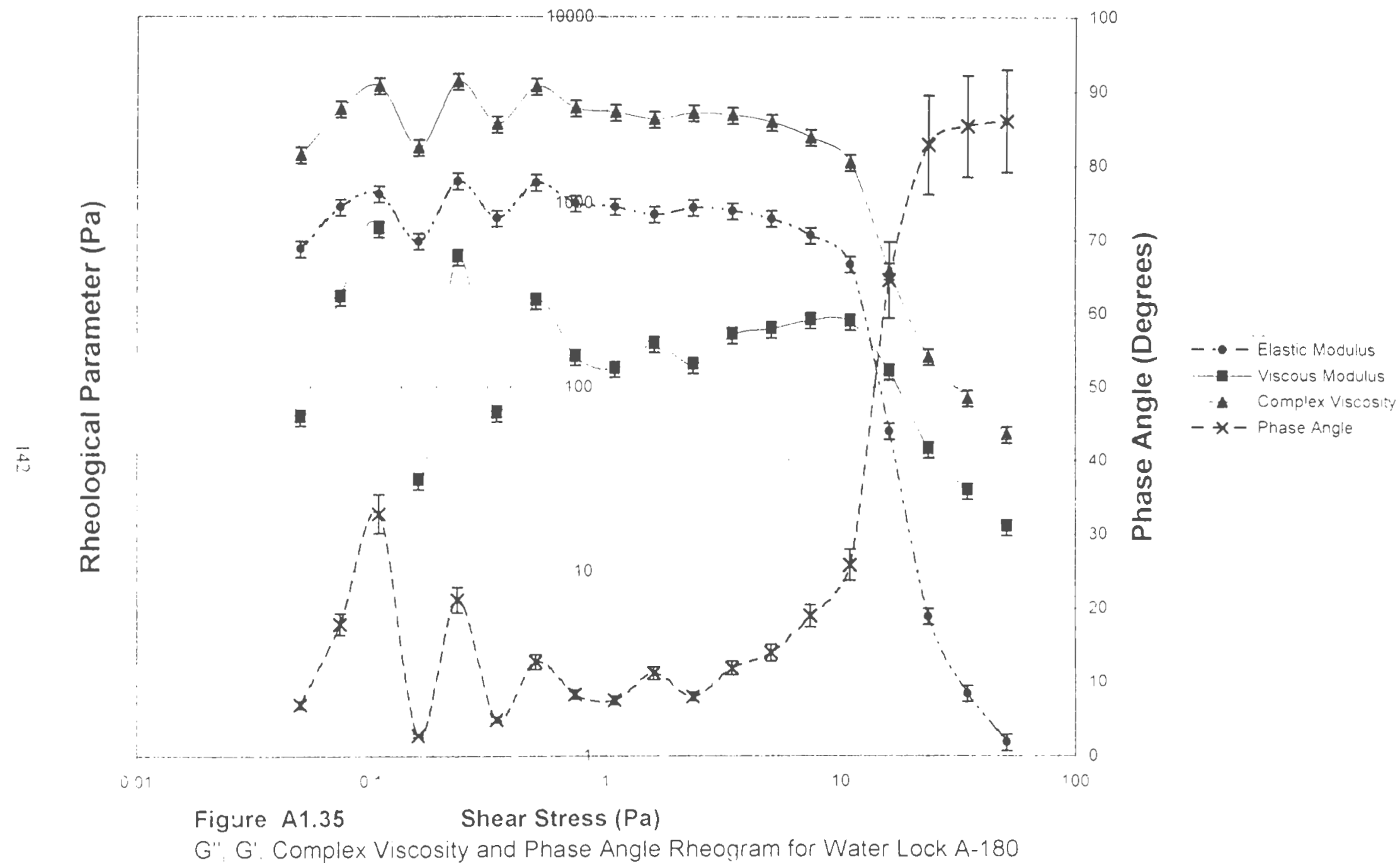

G'. G'. Complex Viscosity and Phase Angle Rheogram for Water Lock A-180

$13 \% \mathrm{w} / \mathrm{w}$ Measured at $0.05 \mathrm{~Hz}$ and a Stress Range of $0.00-100 \mathrm{~Pa}$ 


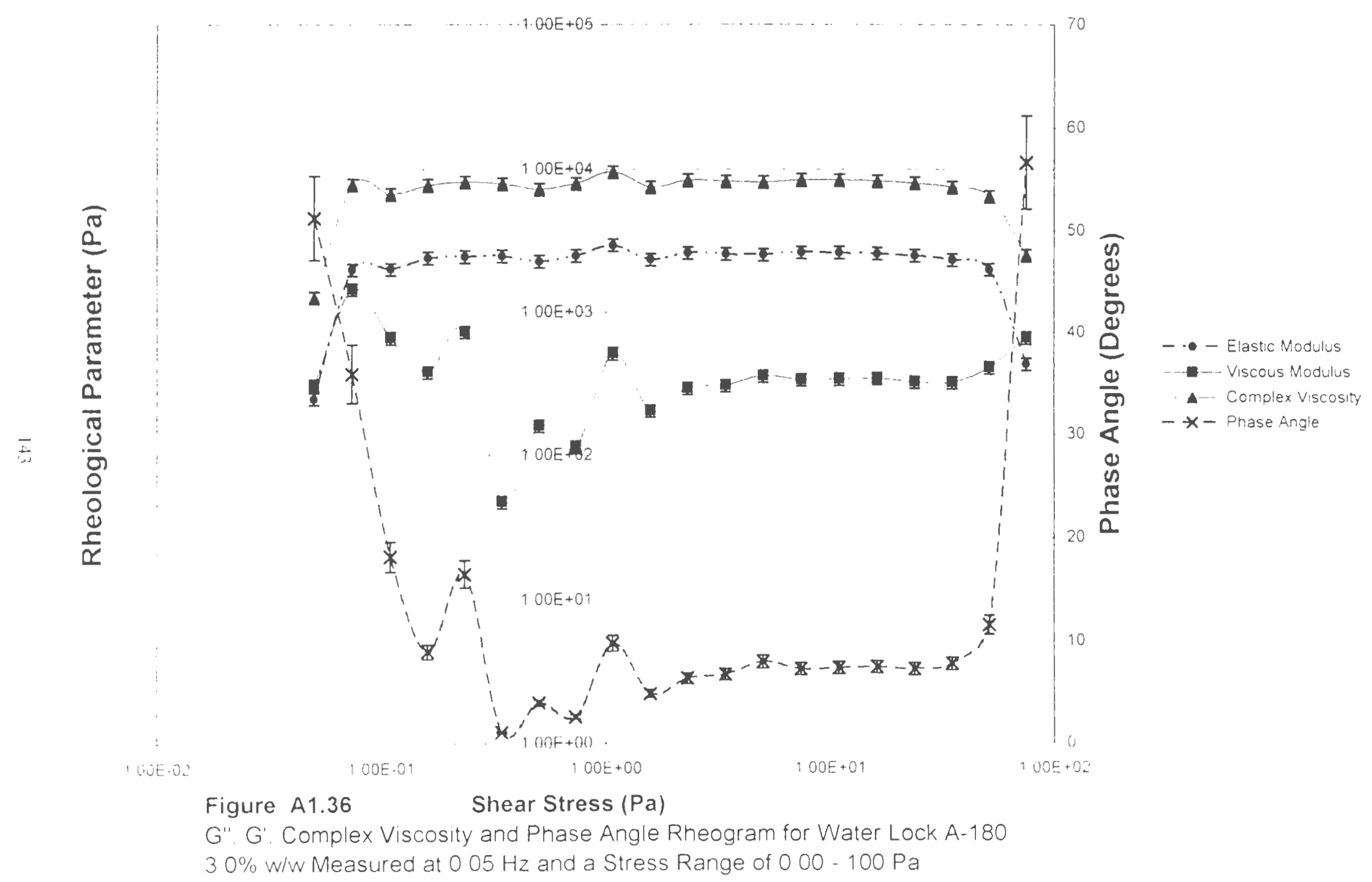




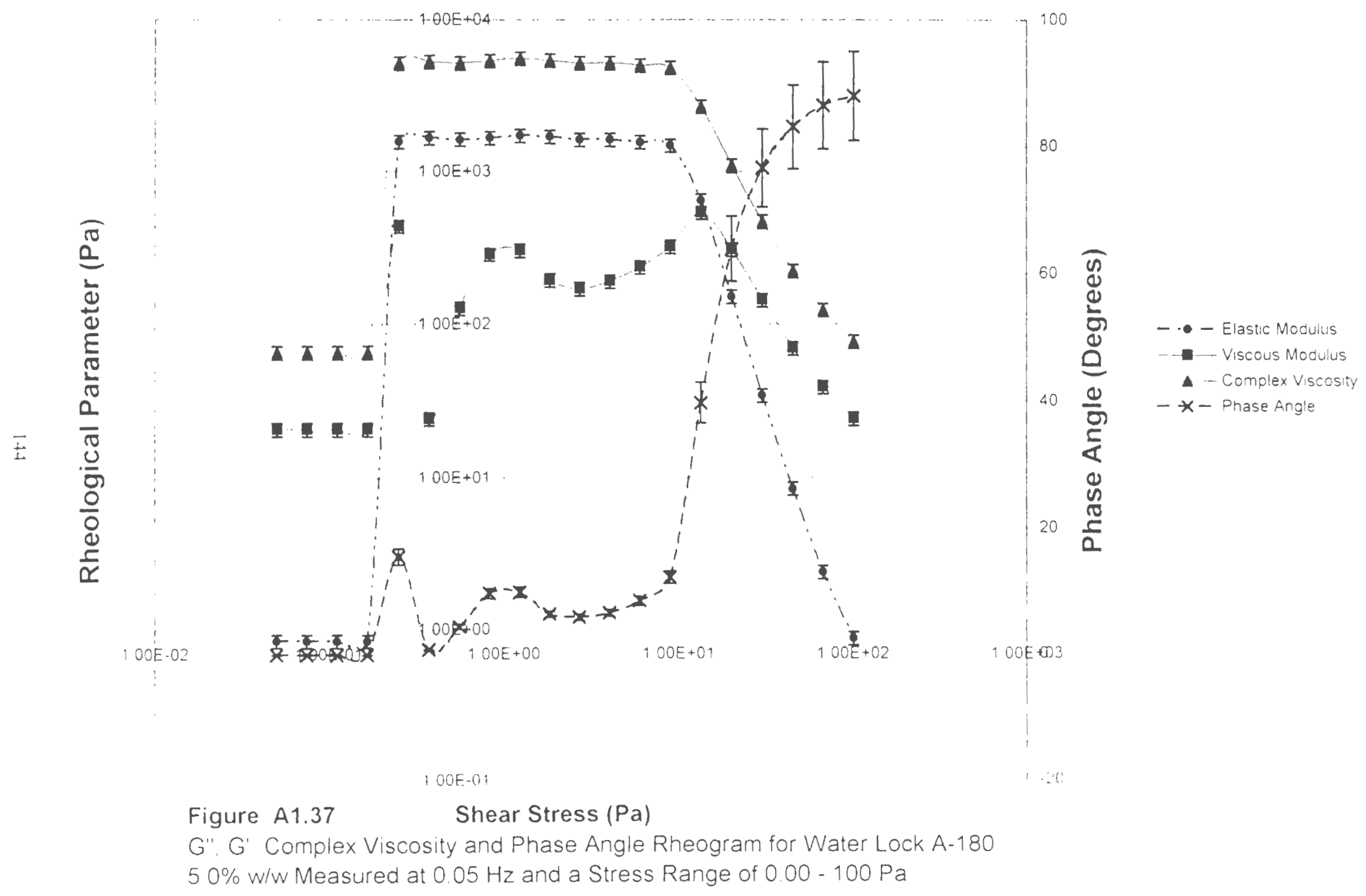




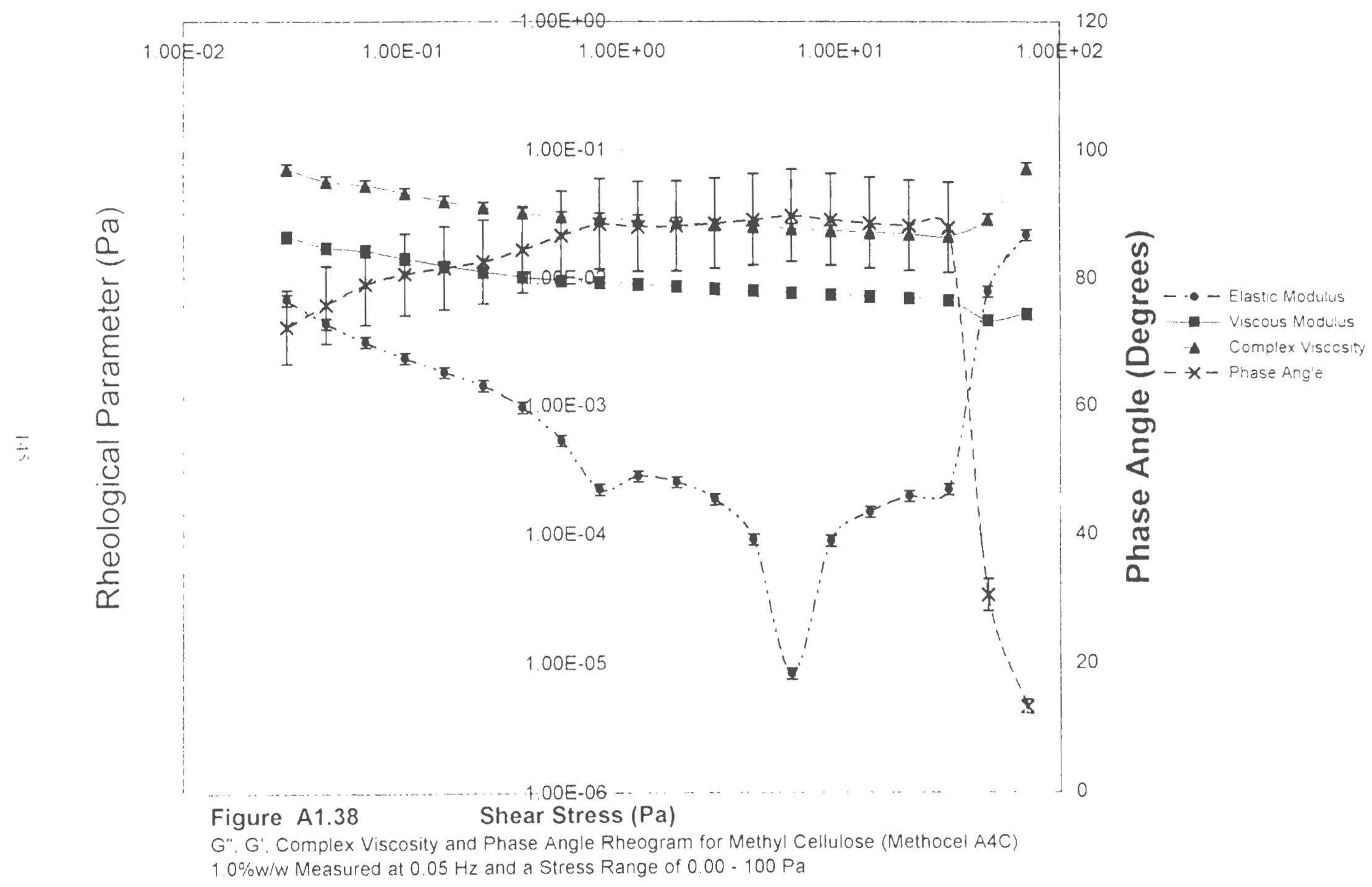




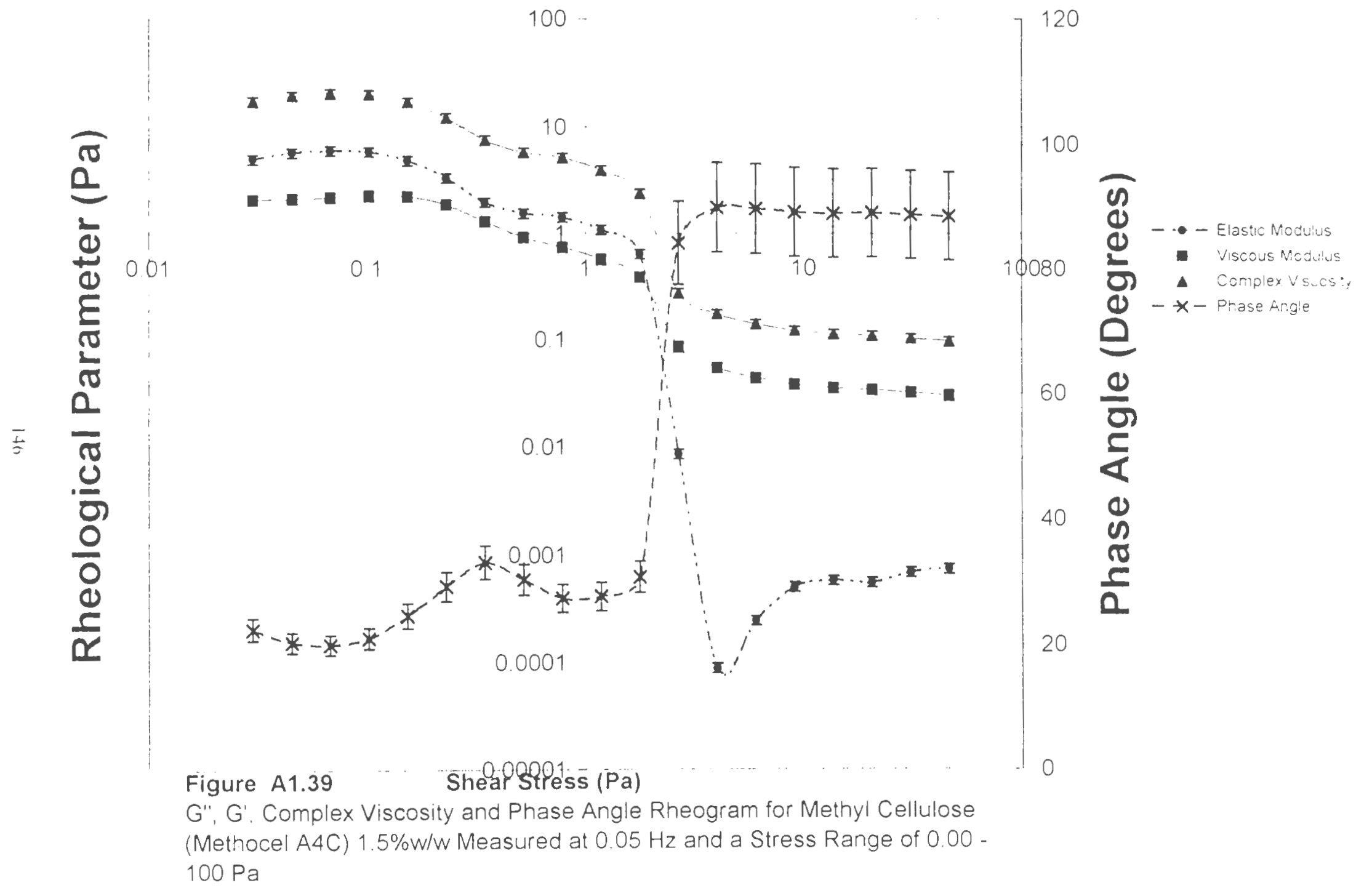




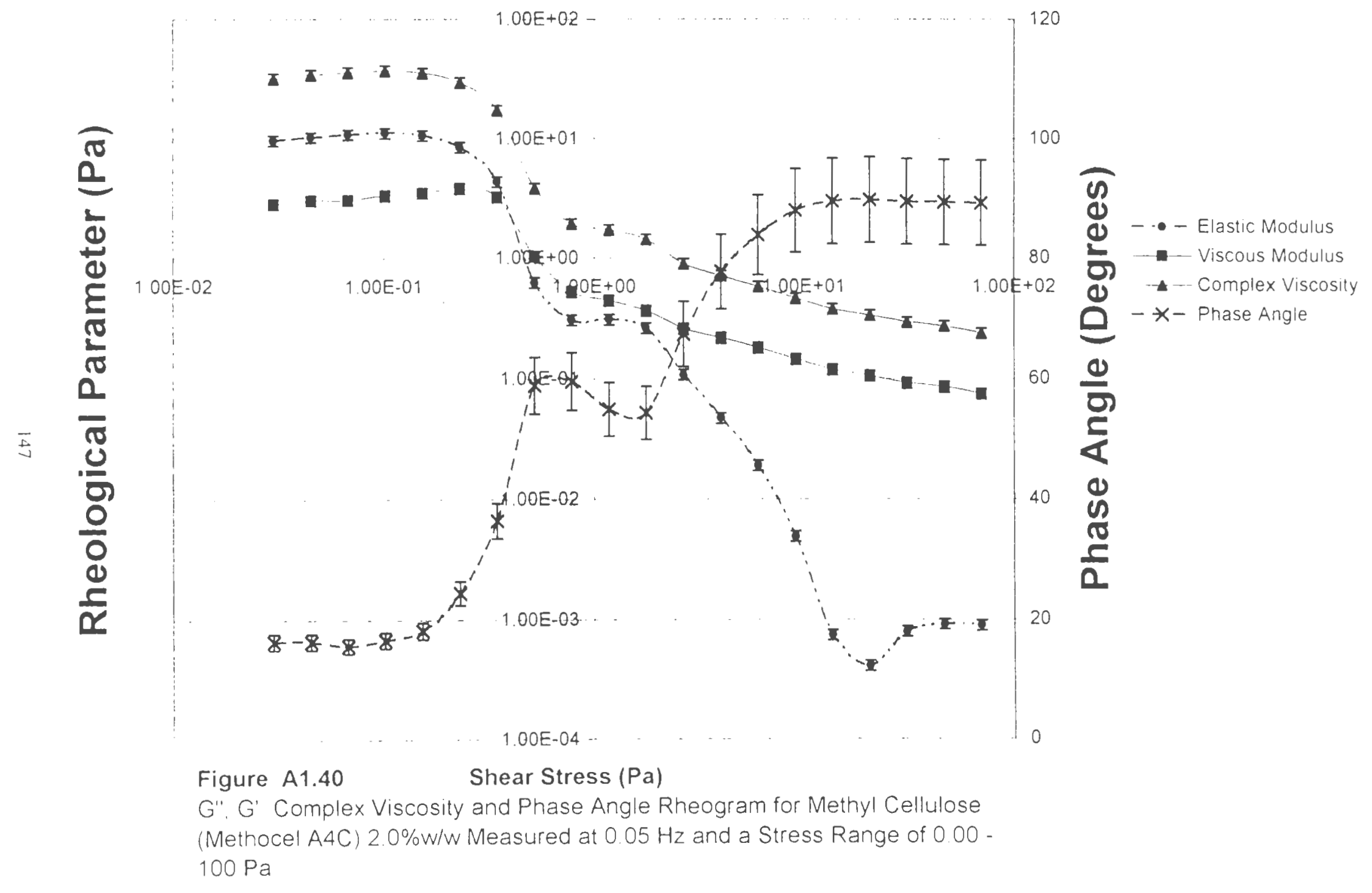




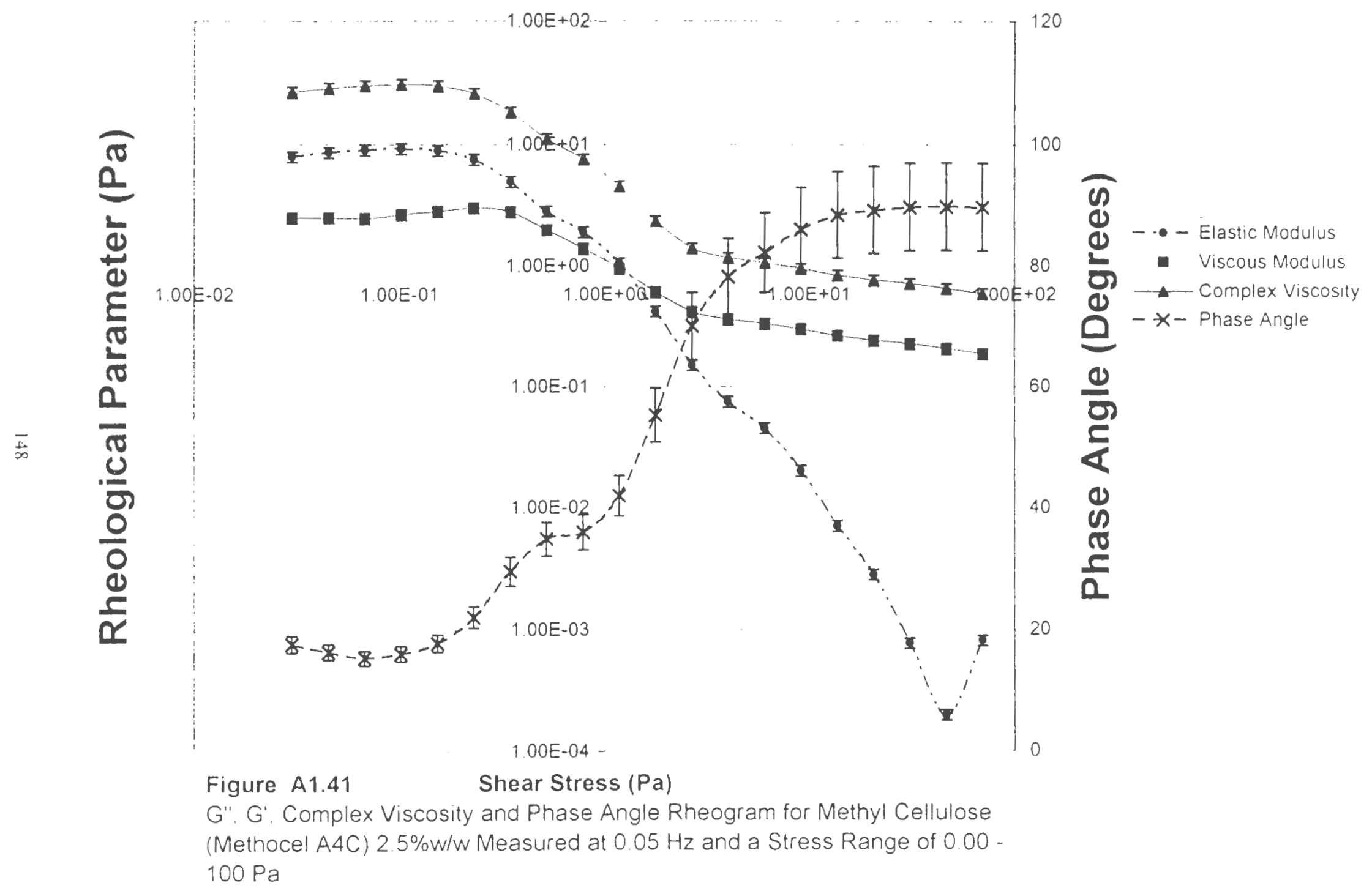




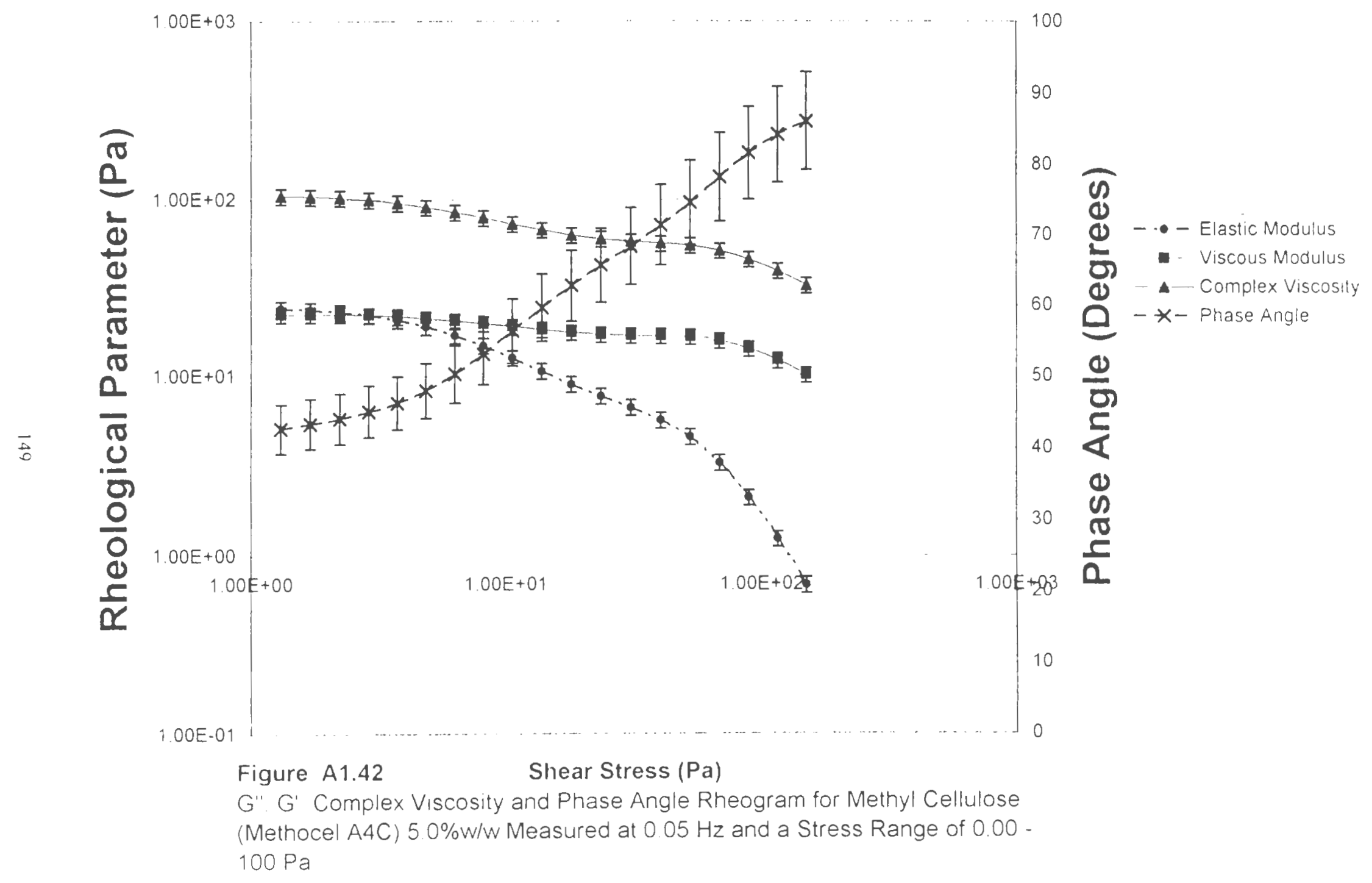




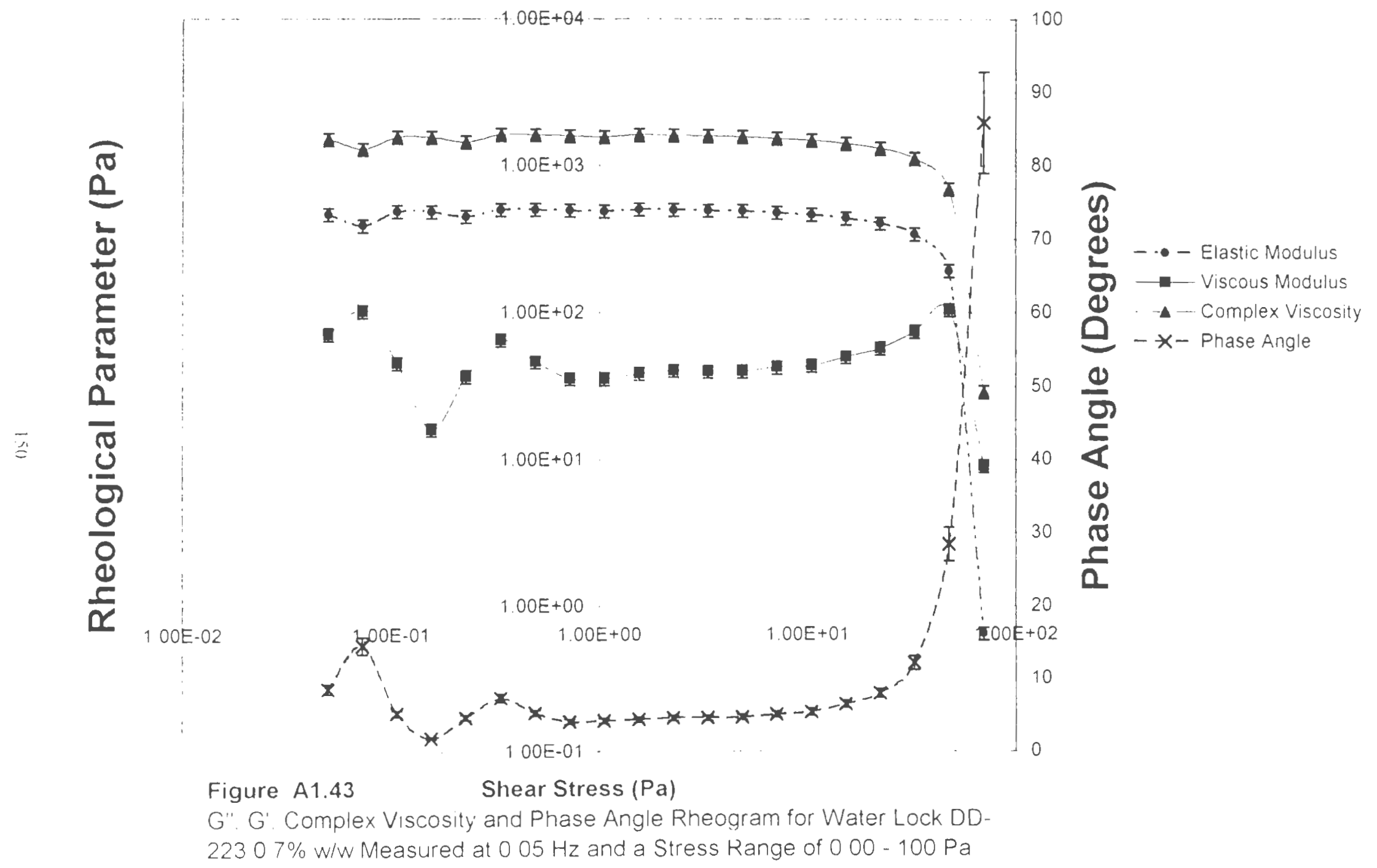




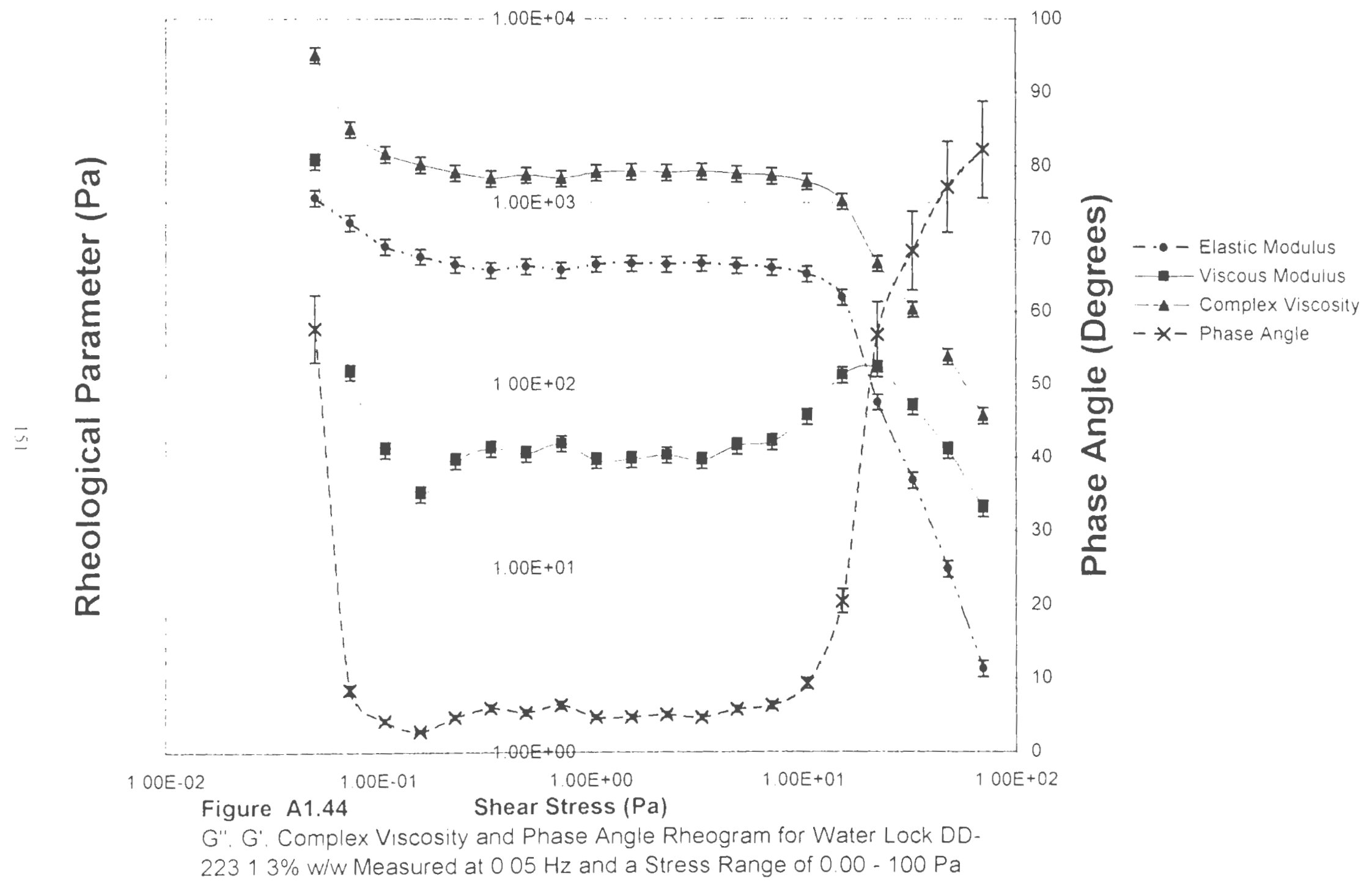




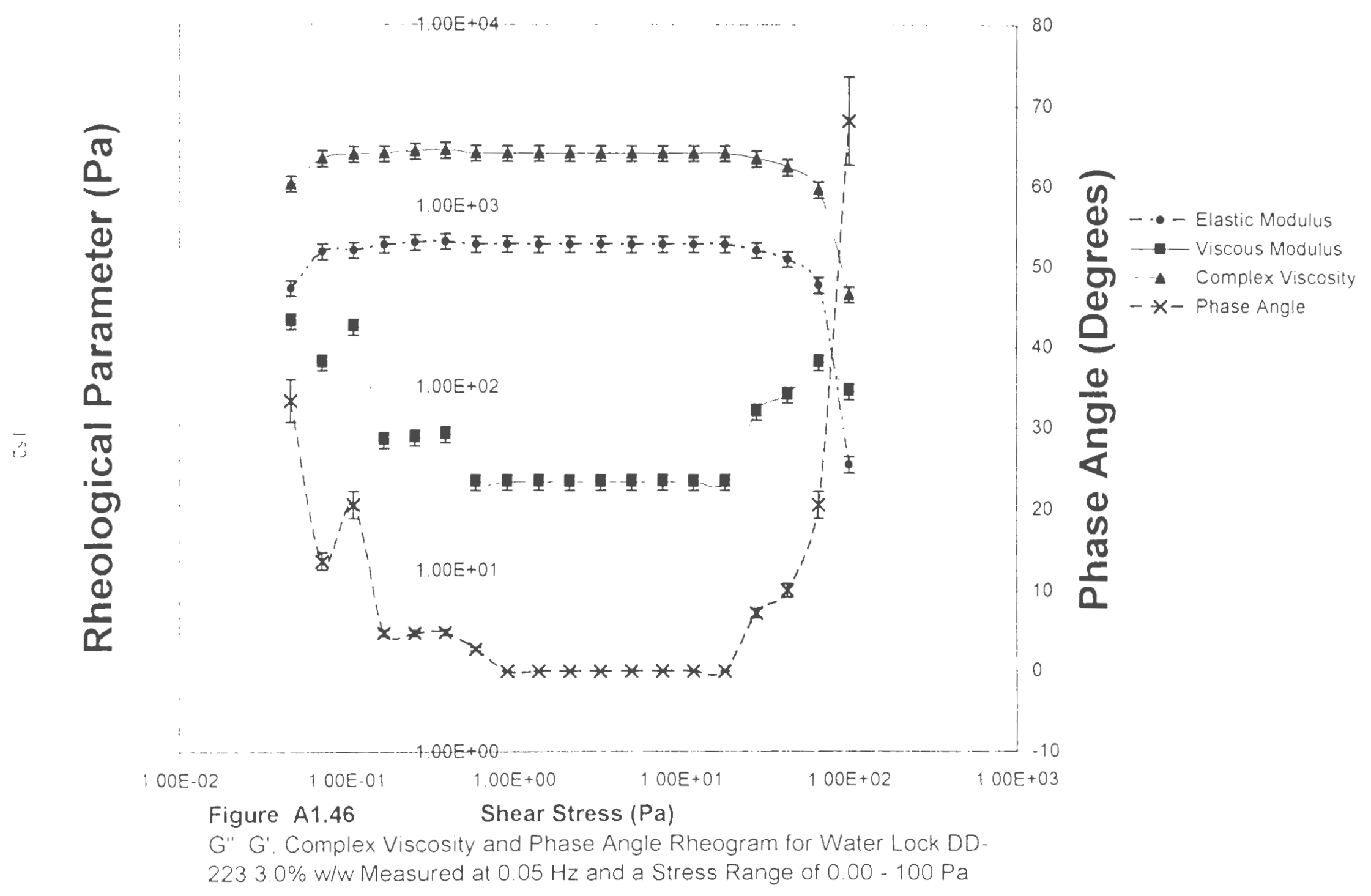




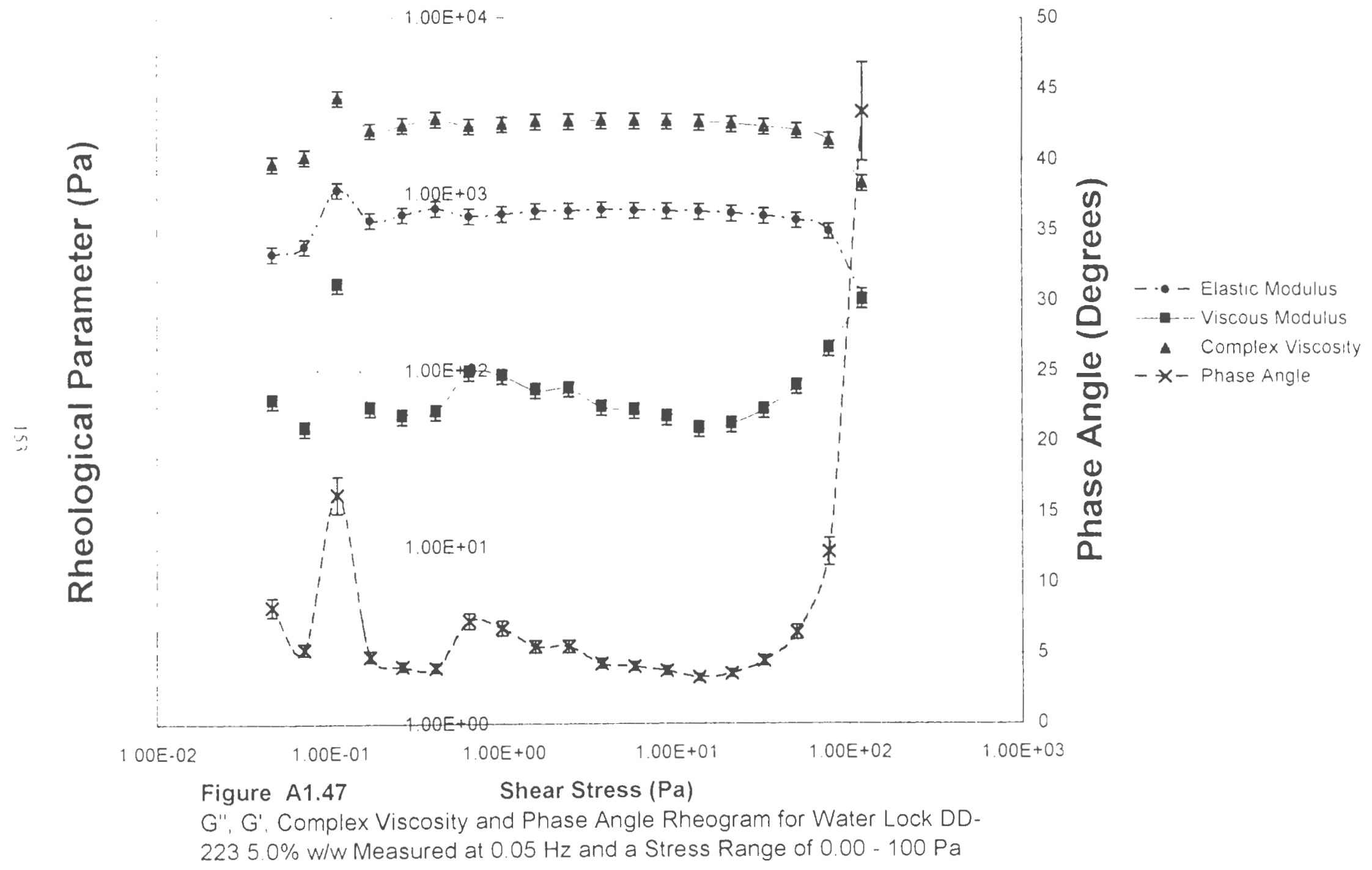




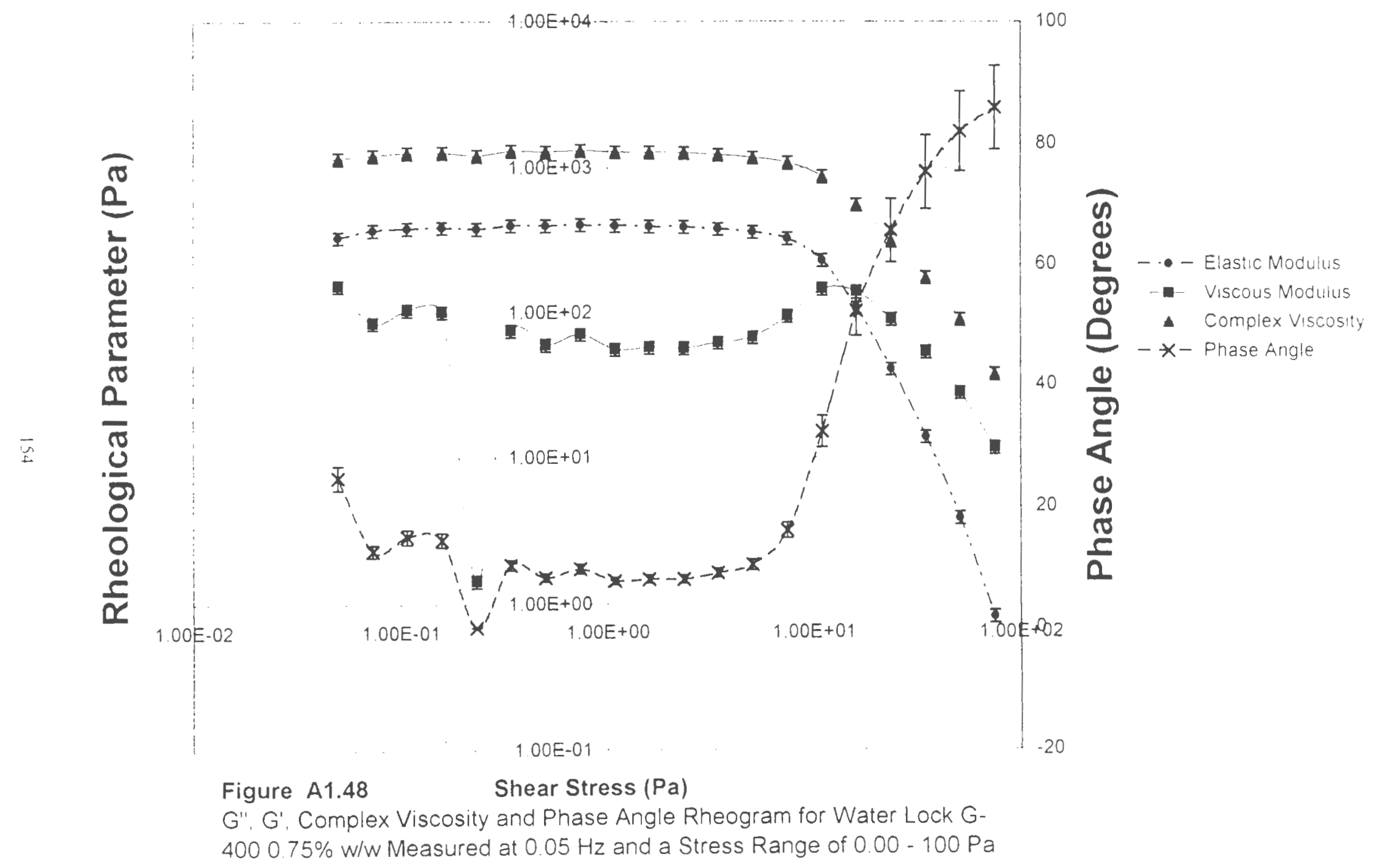




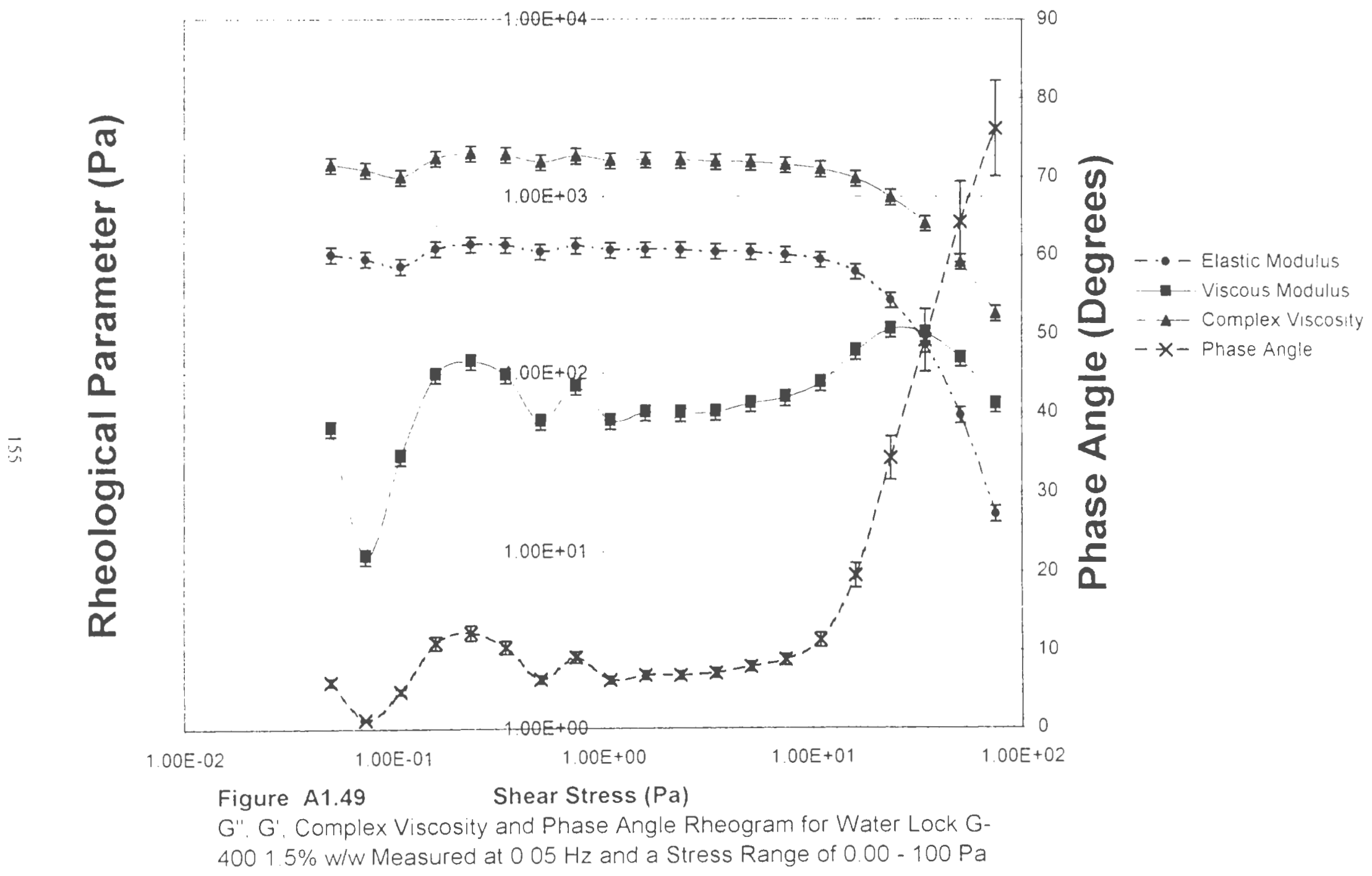




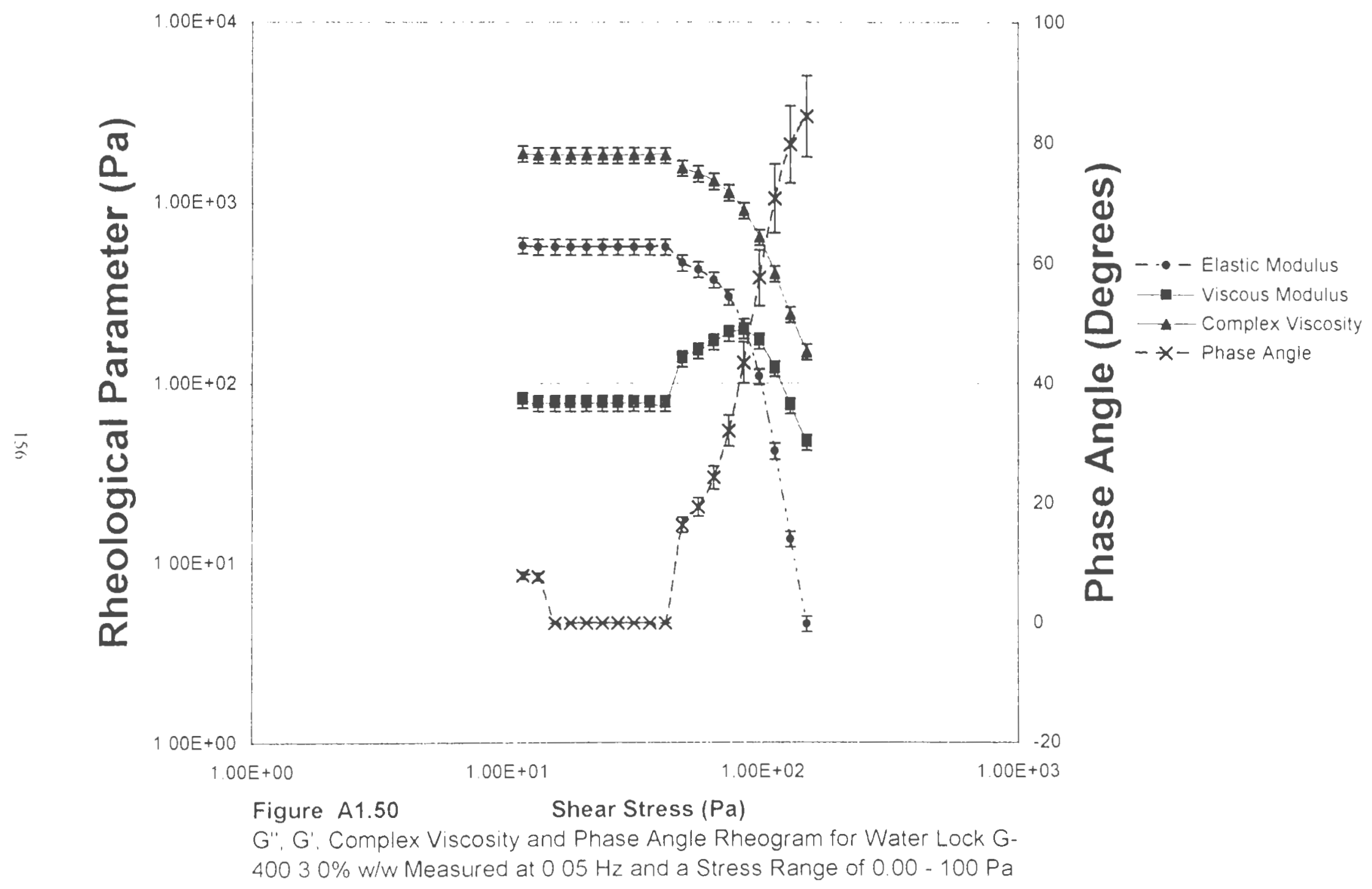




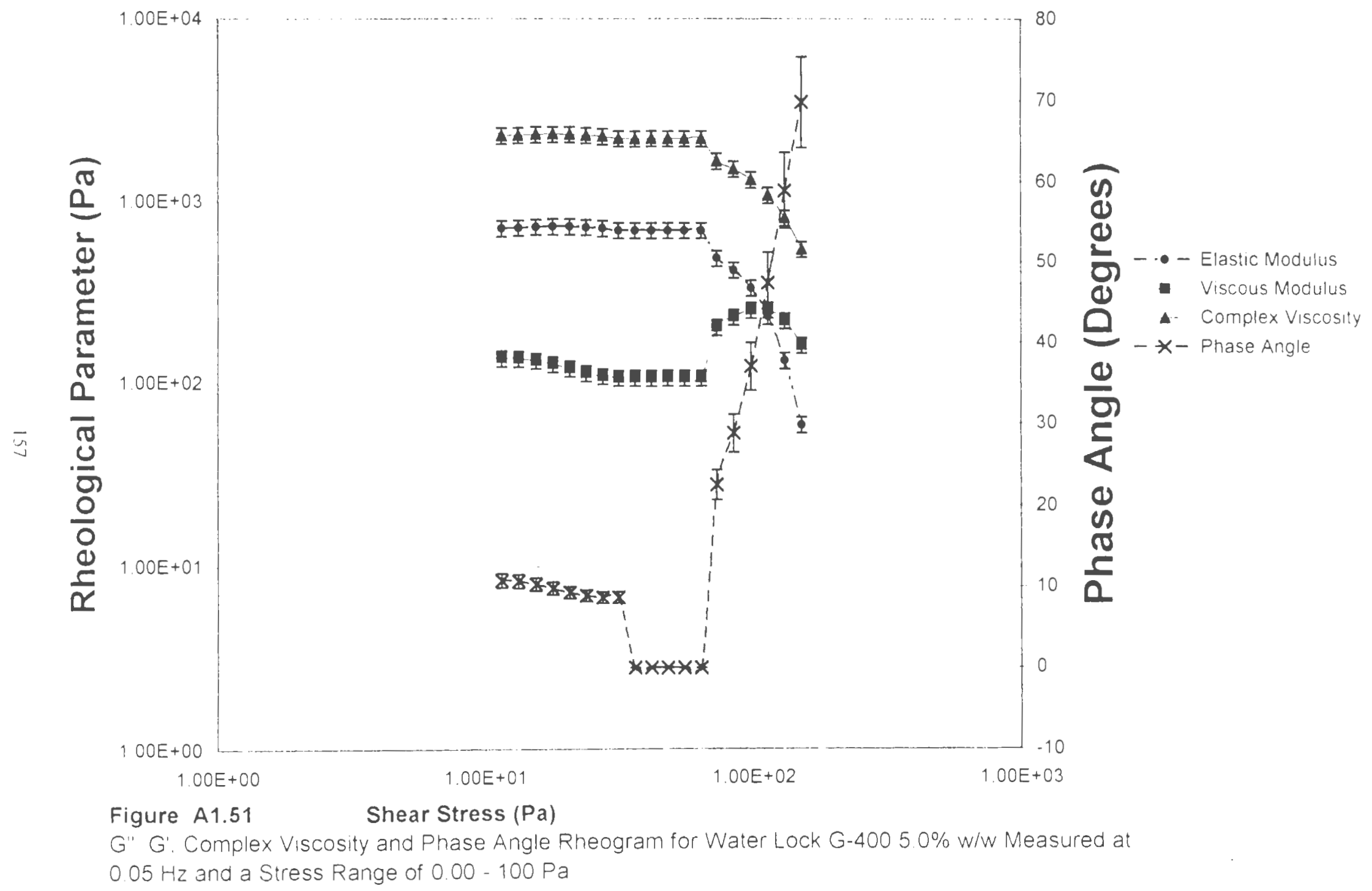




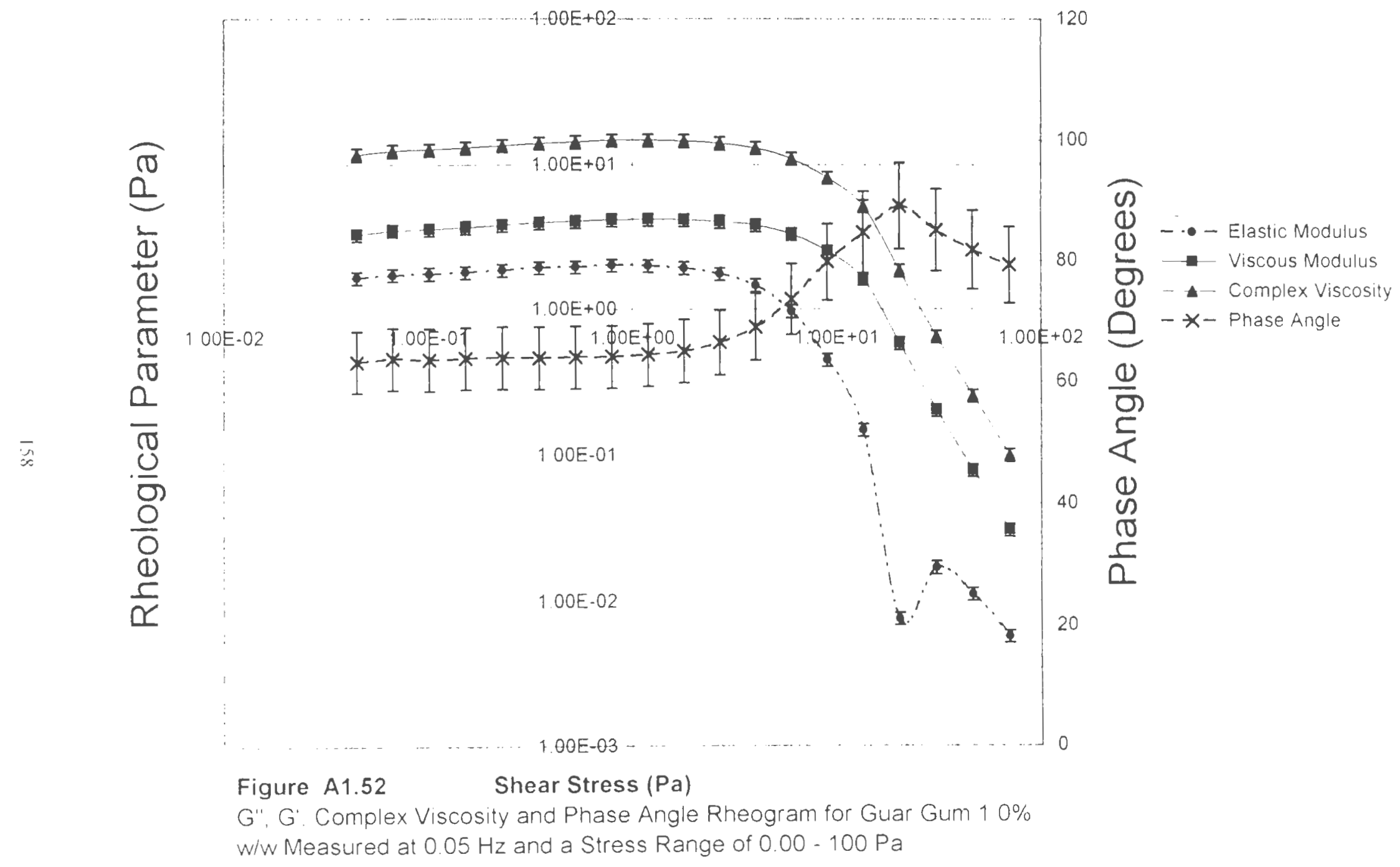




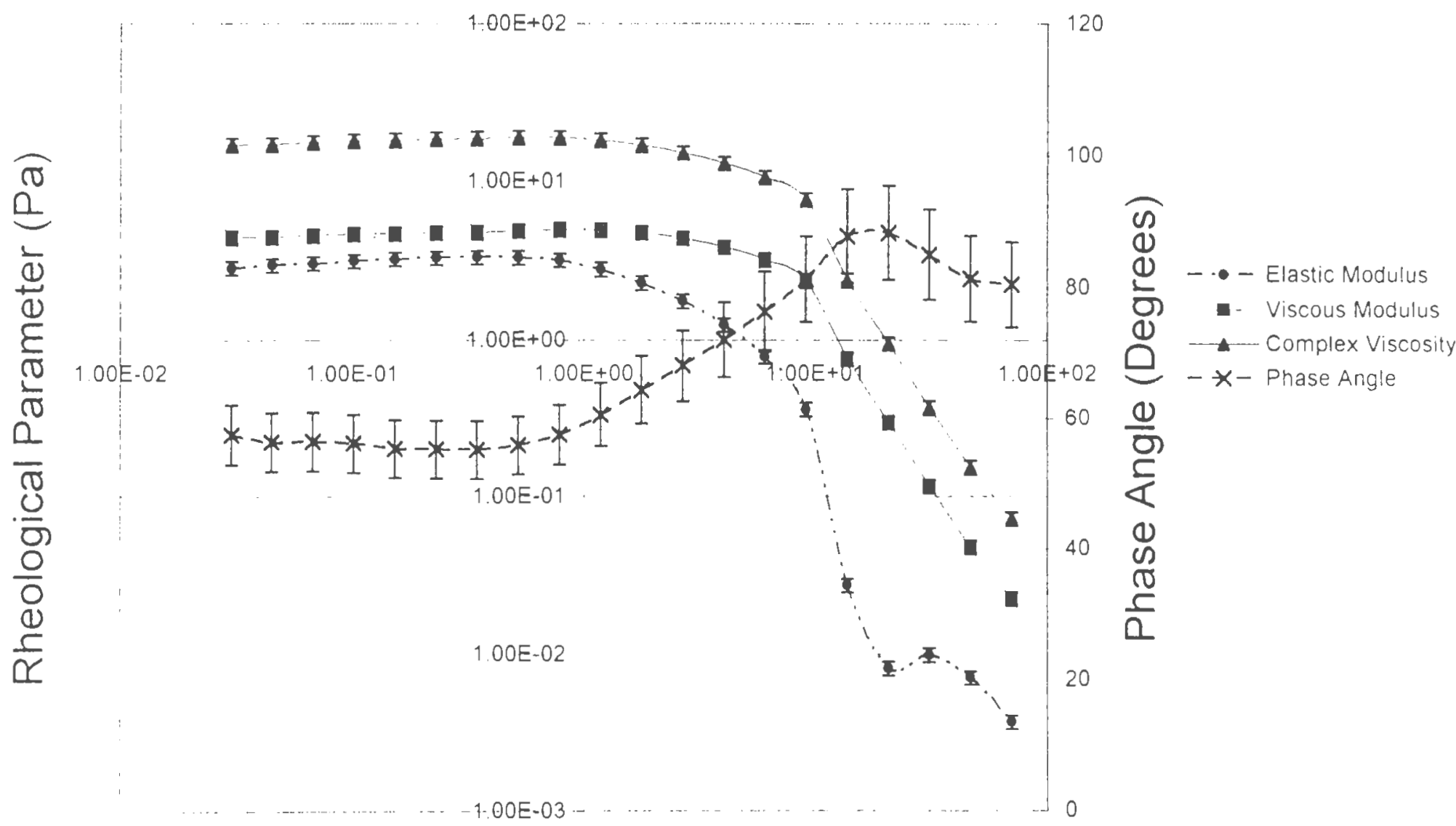

Figure $\mathrm{A} 1.53$

Shear Stress $(\mathrm{Pa})$

G". G'. Complex Viscosity and Phase Angle Rheogram for Guar Gum 1.5\%

w/w Measured at $0.05 \mathrm{~Hz}$ and a Stress Range of $0.00-100 \mathrm{~Pa}$ 


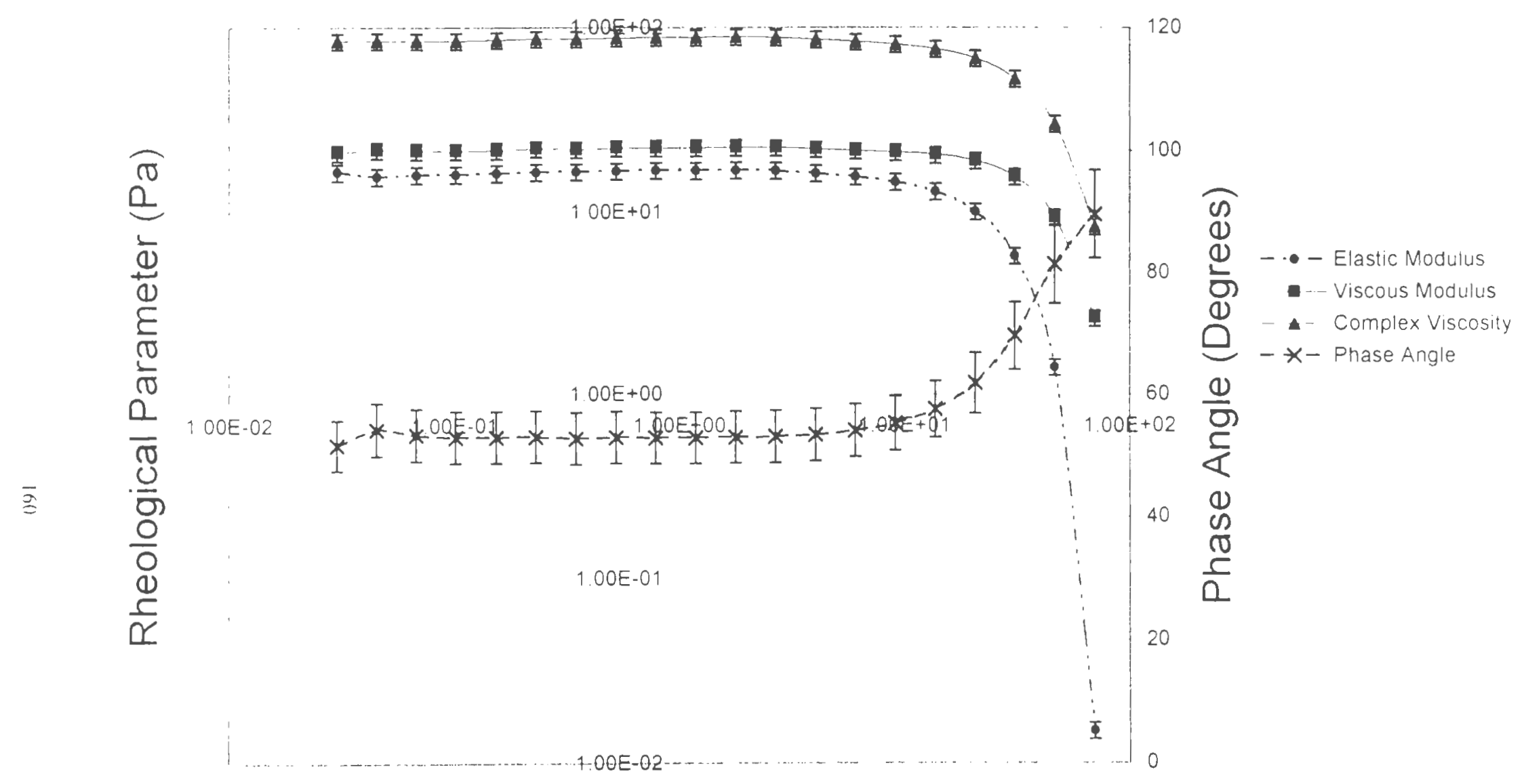

\section{Figure A1.54}

Shear Stress $(\mathrm{Pa})$

G'. G'. Complex Viscosity and Phase Angle Rheogram for Guar Gum 1.75\% w/w Measured at $0.05 \mathrm{~Hz}$ and a Stress Range of $0.00-100 \mathrm{~Pa}$ 


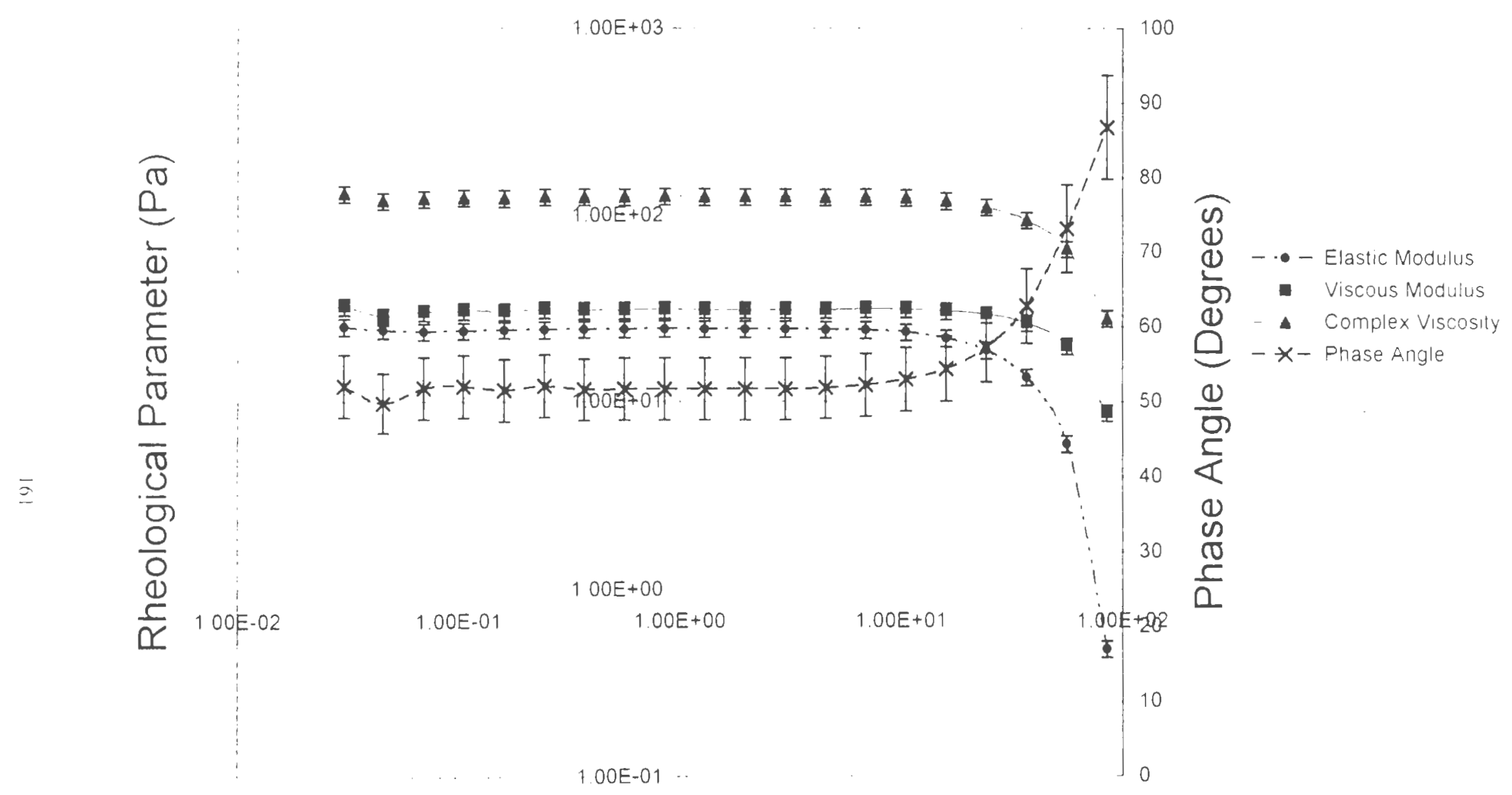

Figure $\mathrm{A} 1.55 \quad$ Shear Stress $(\mathrm{Pa})$

G". G'. Complex Viscosity and Phase Angle Rheogram for Guar Gum 2.0\% w/w Measured at $0.05 \mathrm{~Hz}$ and a Stress Range of $0.00-100 \mathrm{~Pa}$ 


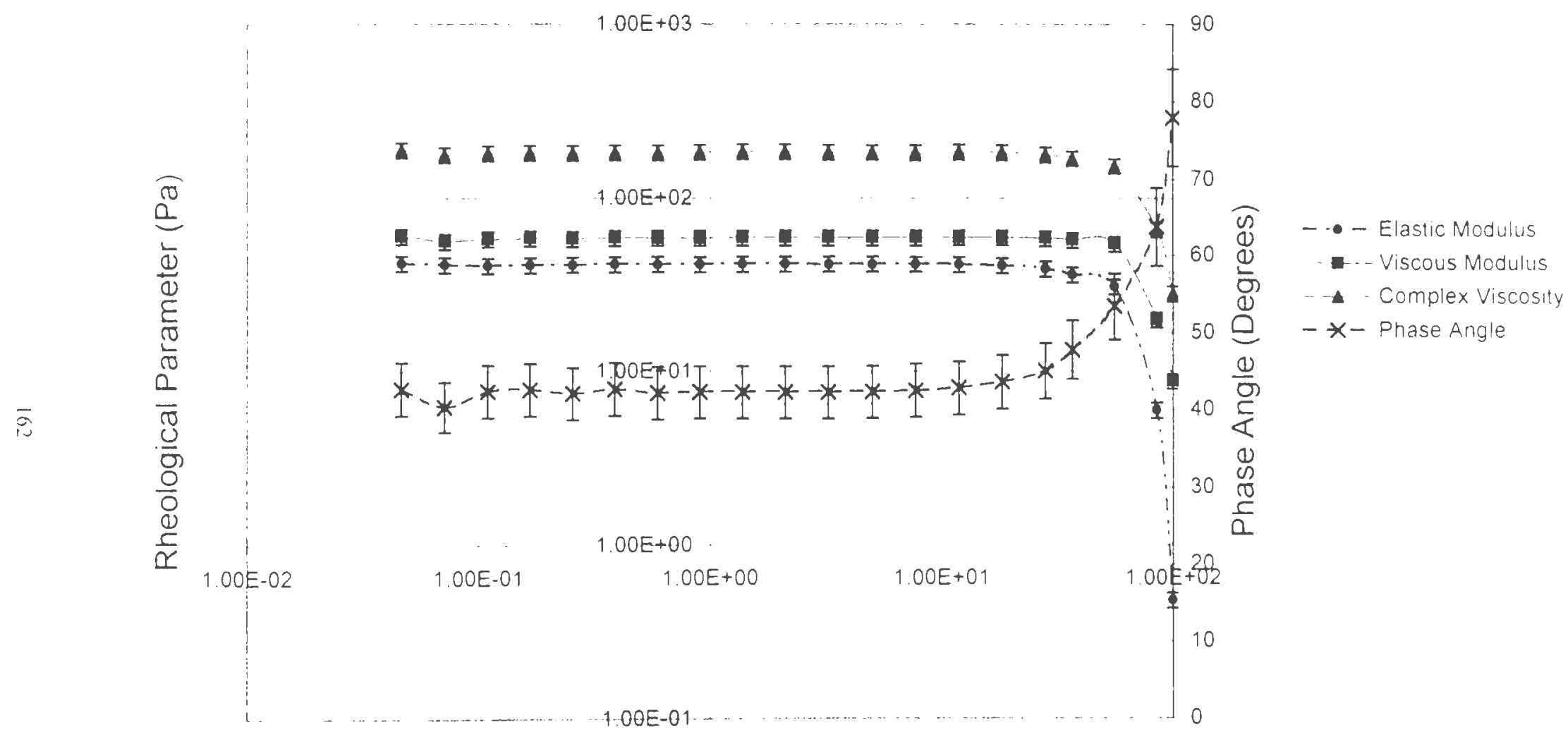

Figure A1.56

Shear Stress (Pa)

G', G', Complex Viscosity and Phase Angle Rheogram for Guar Gum 3.0\% w/w Measured at $0.05 \mathrm{~Hz}$ and a Stress Range of $0.00-100 \mathrm{~Pa}$ 


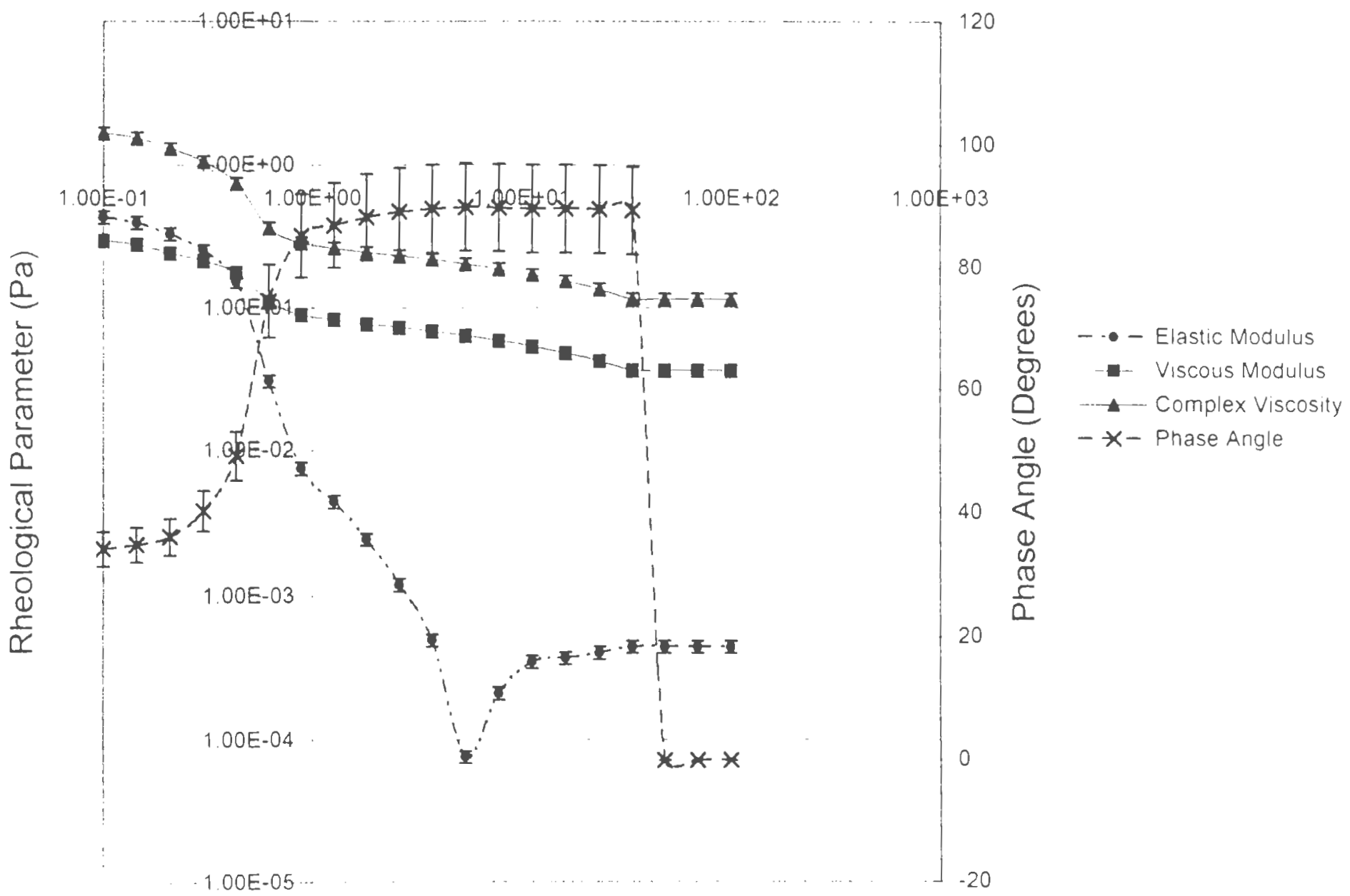

Figure A1.57

Shear Stress $(\mathrm{Pa})$

G" G' Complex Viscosity and Phase Angle Rheogram for Hydroxypropyl Methyl Cellulose $10 \% \% / \%$ Measured at $005 \mathrm{~Hz}$ and a Stress Range of $000 \cdot 100 \mathrm{~Pa}$ 


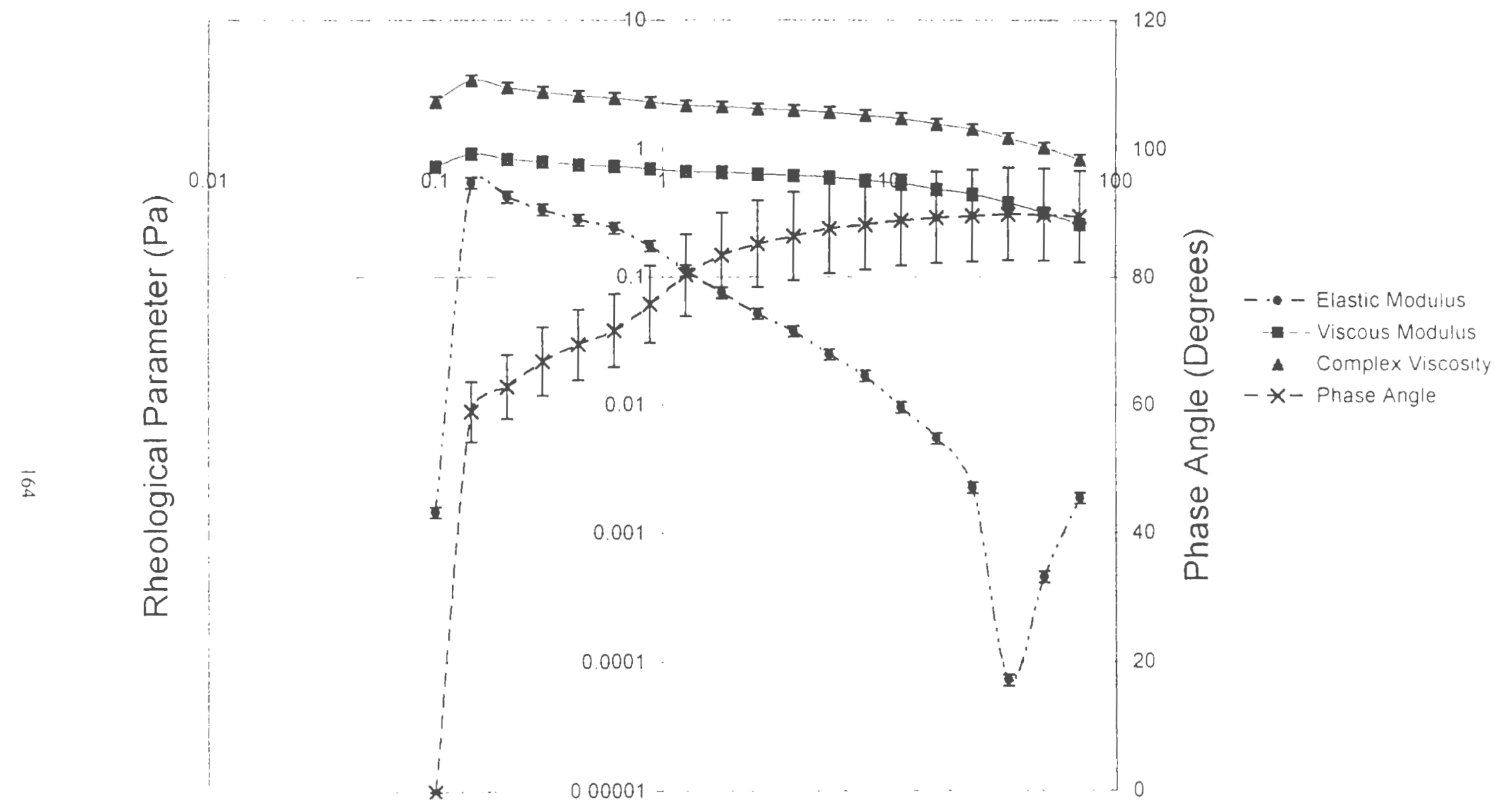

Figure A1.58

Shear Stress $(\mathrm{Pa})$

G', G'. Complex Viscosity and Phase Angle Rheogram for Hydroxypropyl Methyl Celiulose $15 \% \mathrm{w} / \mathrm{w}$ Measured at $0.05 \mathrm{~Hz}$ and a Stress Range of 0.00 $-100 \mathrm{~Pa}$ 


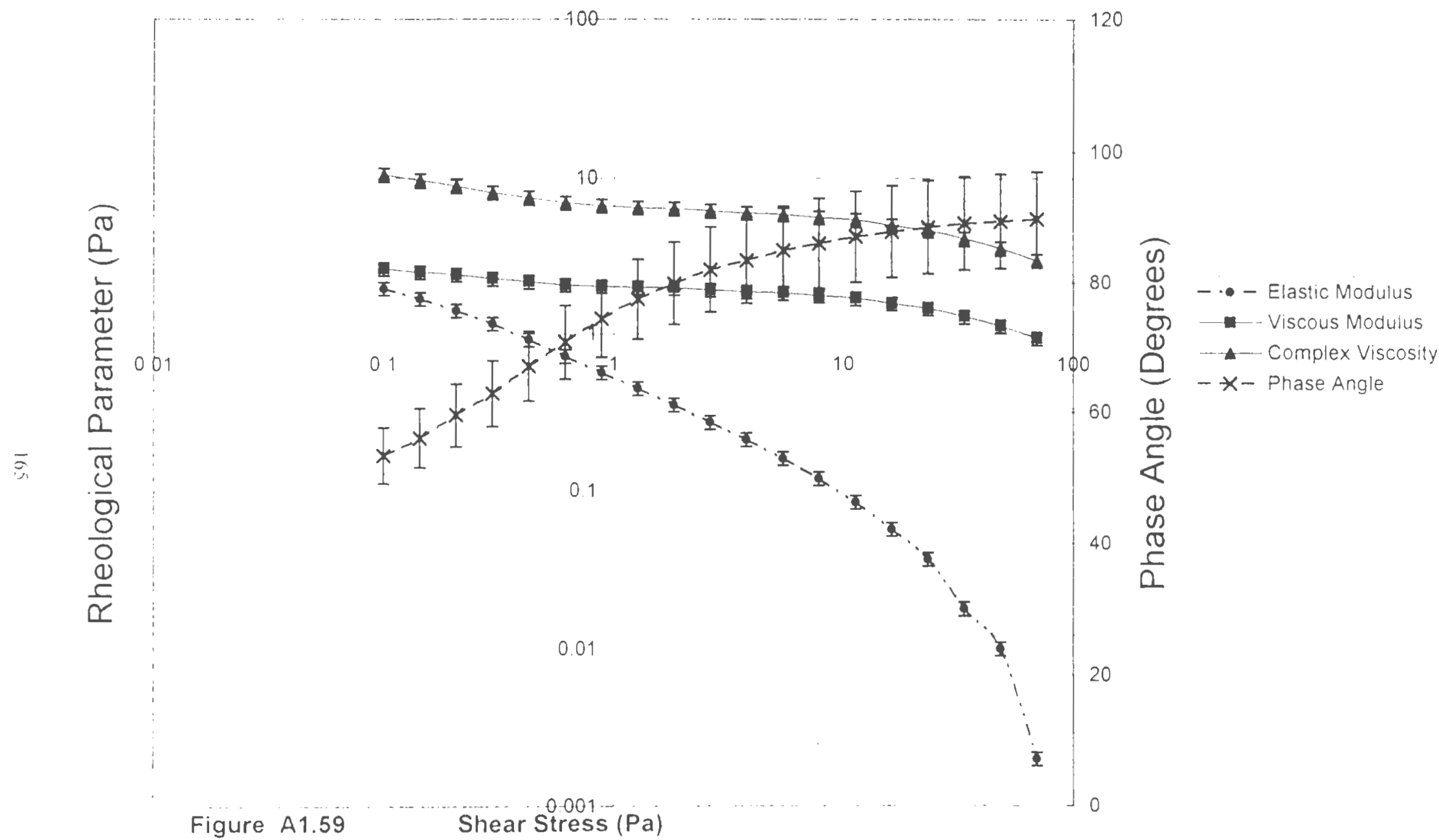

G" G'. Complex Viscosity and Phase Angle Rheogram for Hydroxypropyl

Methyl Cellulose $2.0 \%$ w/w Measured at $0.05 \mathrm{~Hz}$ and a Stress Range of 0.00 $-100 \mathrm{~Pa}$ 


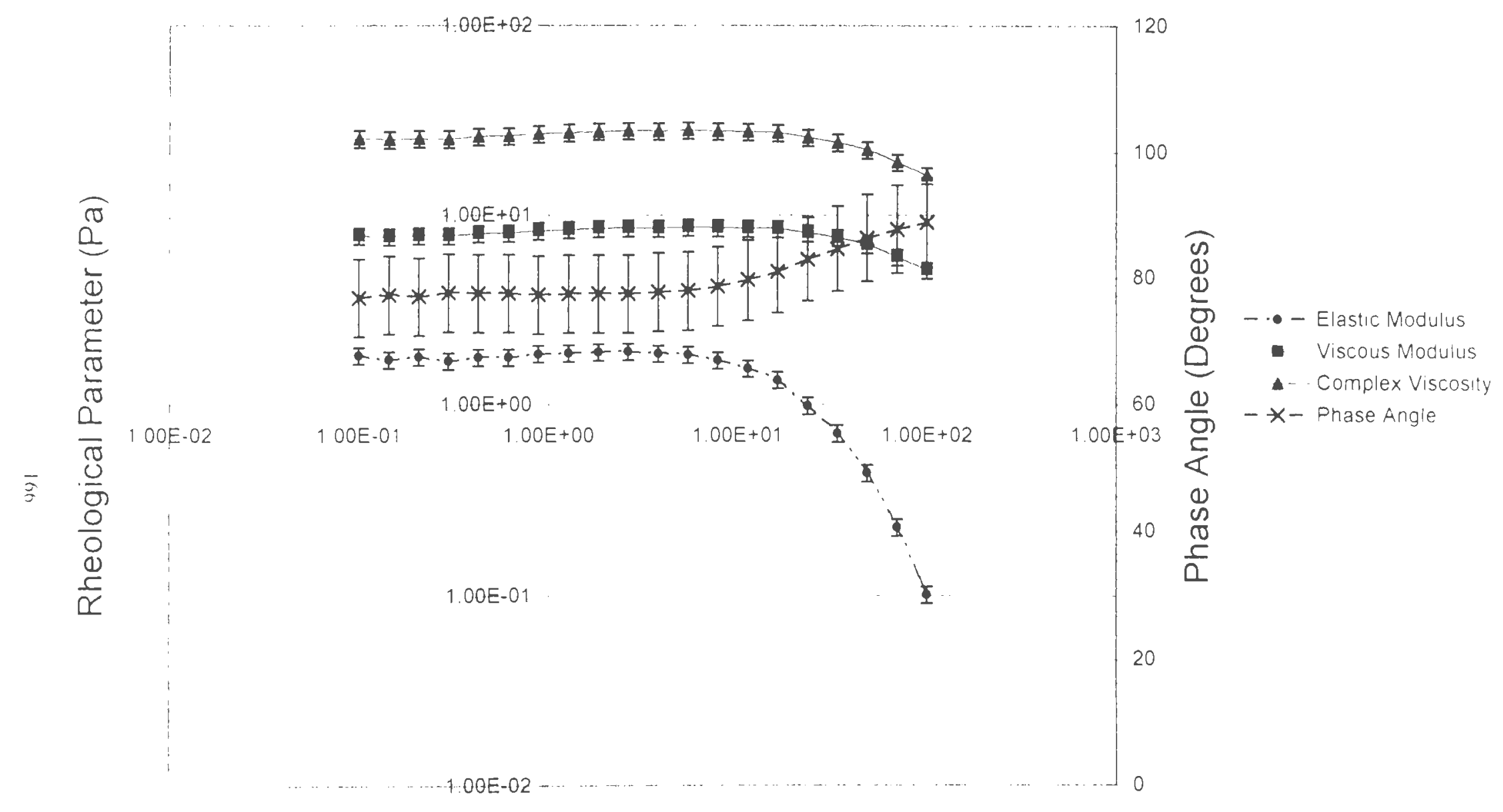




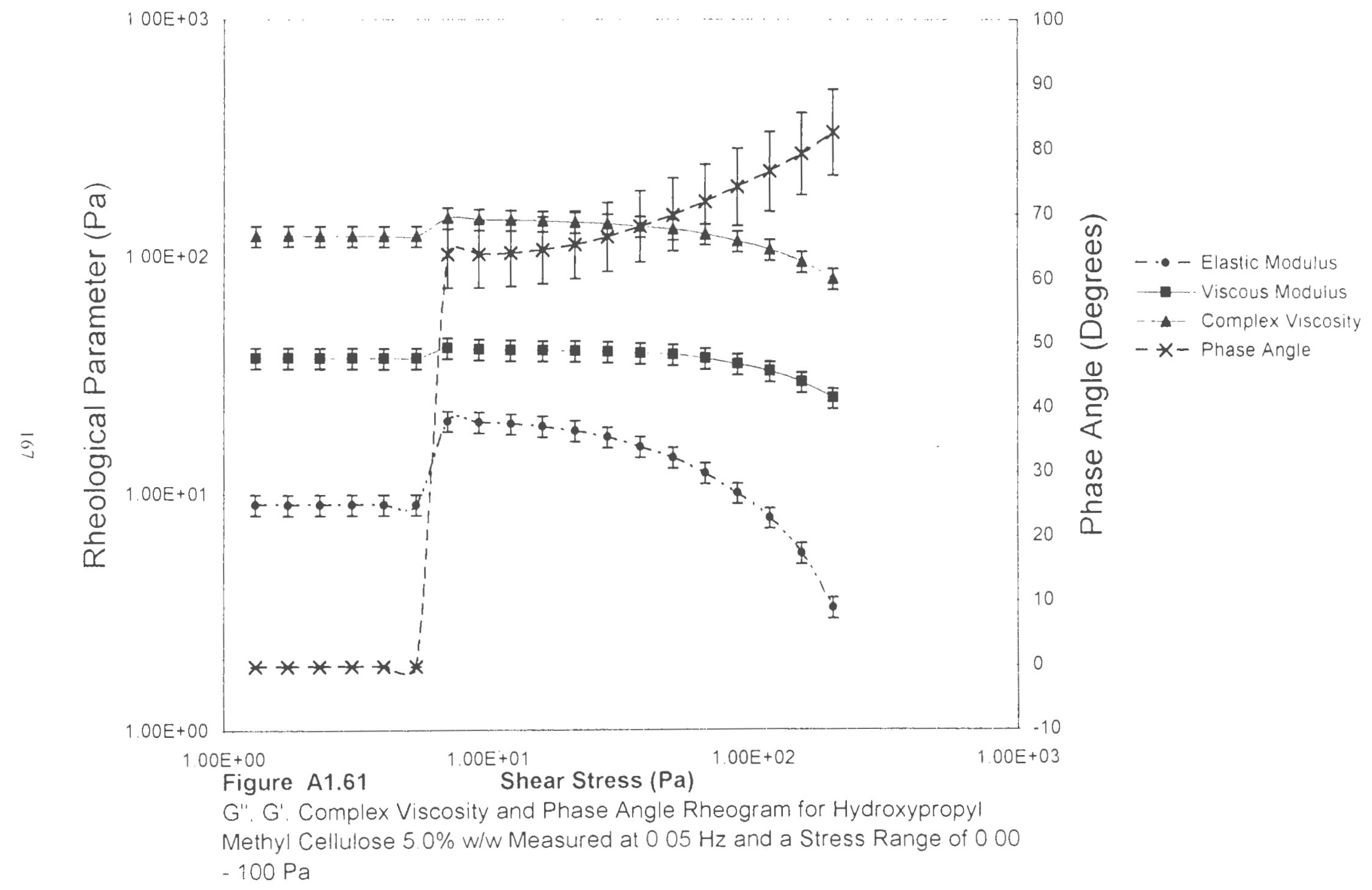




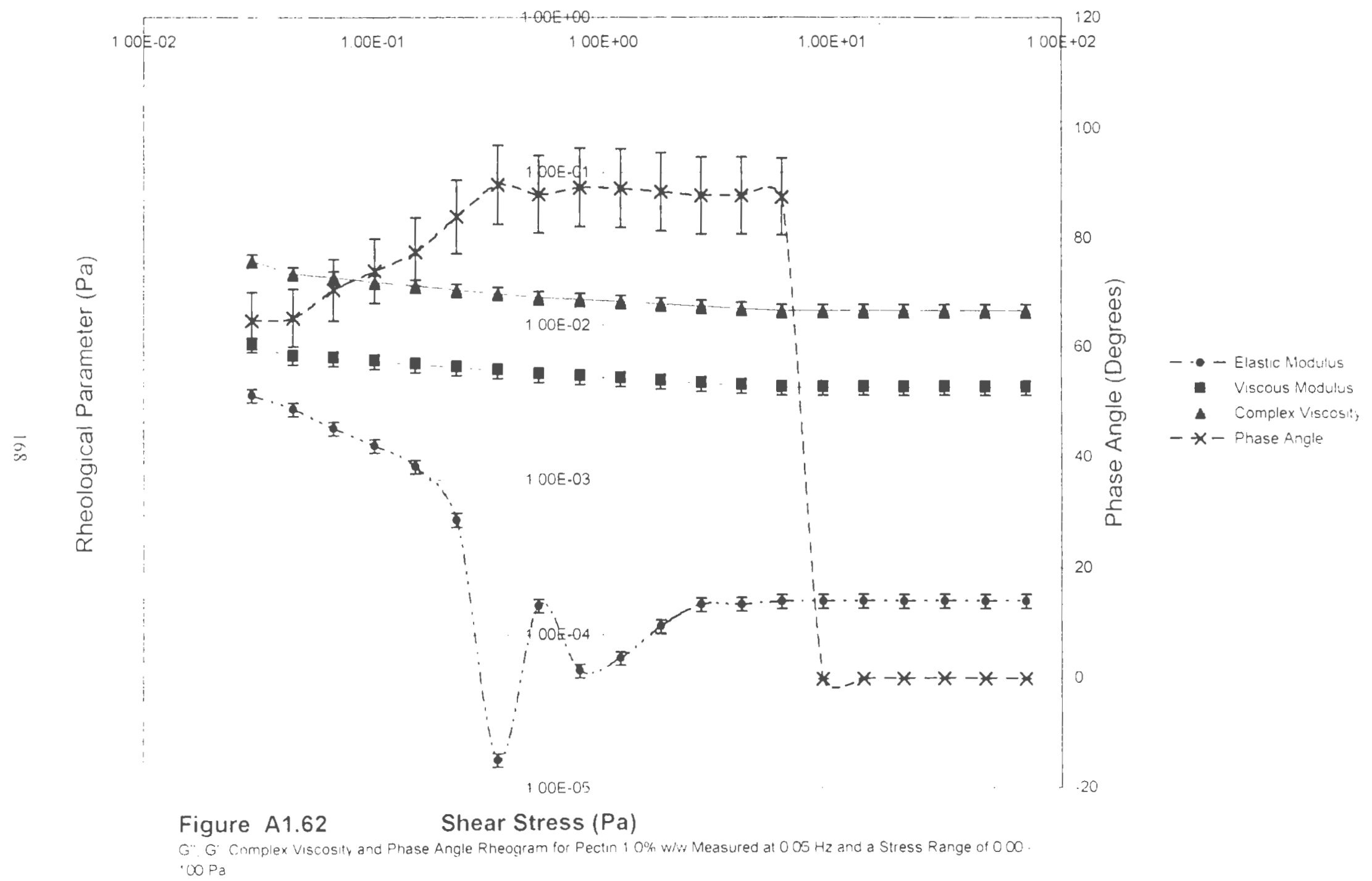




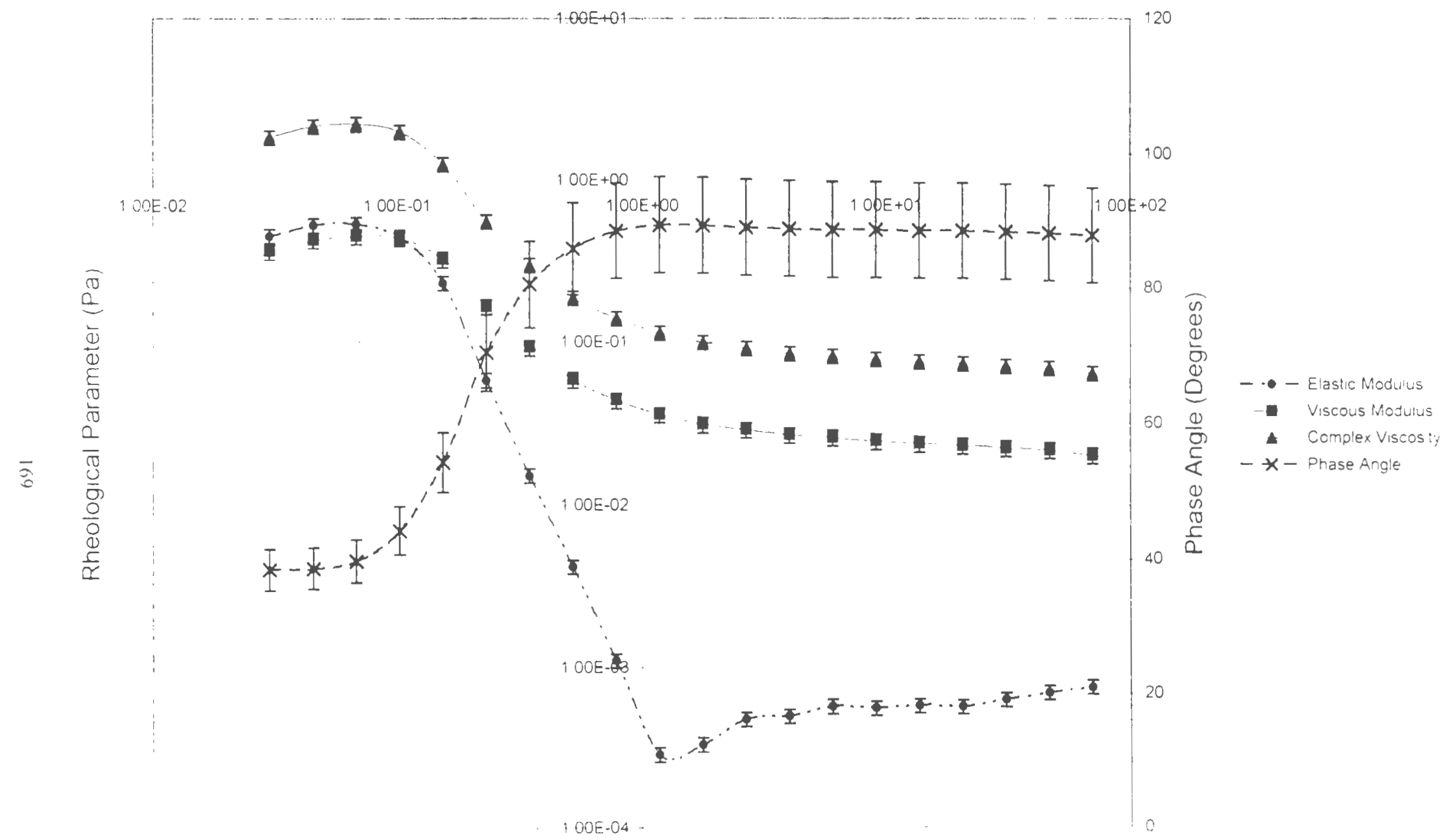

Figure A1.63 Shear Stress (Pa)

G" G Complex $V$ scosily and Phase Angle Rheogram for Pectin $20^{\circ} \%$ wh: Measured at $005 \mathrm{~Hz}$ and a Siress Range of 000

$10 \mathrm{~Pa}$ 

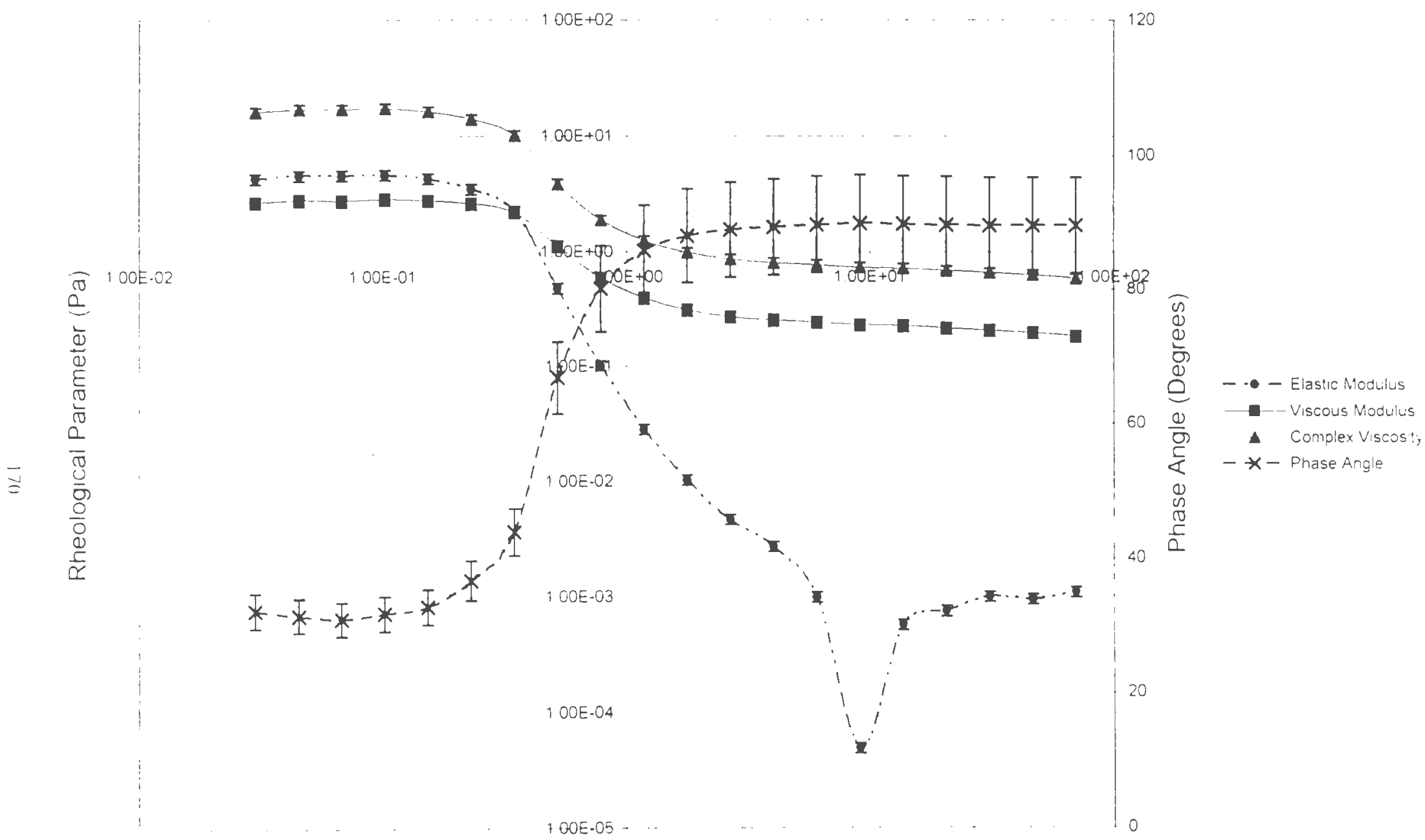

Figure A1.64

Shear Stress $(\mathrm{Pa})$

G". G Complex Viscosity and Phase Angle Rheogram for Pecin $40 \%$ w/W Measured at $005 \mathrm{~Hz}$ and a Stress Range of 000 $100 \mathrm{Fa}$ 


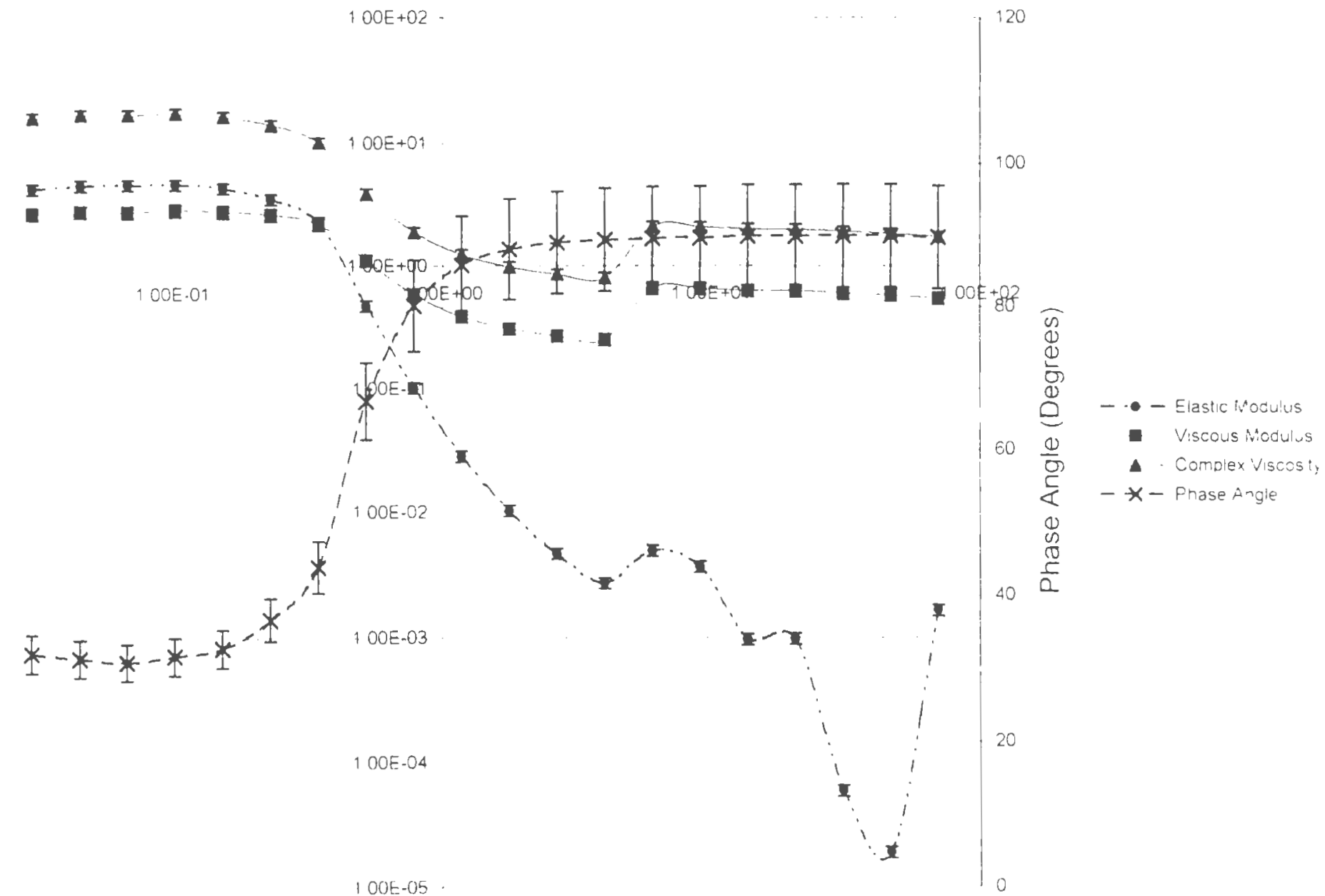

Figure A1.65

Shear Stress $(\mathrm{Pa})$

G". G'. Complex Viscosity and Phase Angle Rheogram for Pectin 5.0\% W/W Measured at $0.05 \mathrm{~Hz}$ and a Stress Range of $000-100 \mathrm{~Pa}$ 


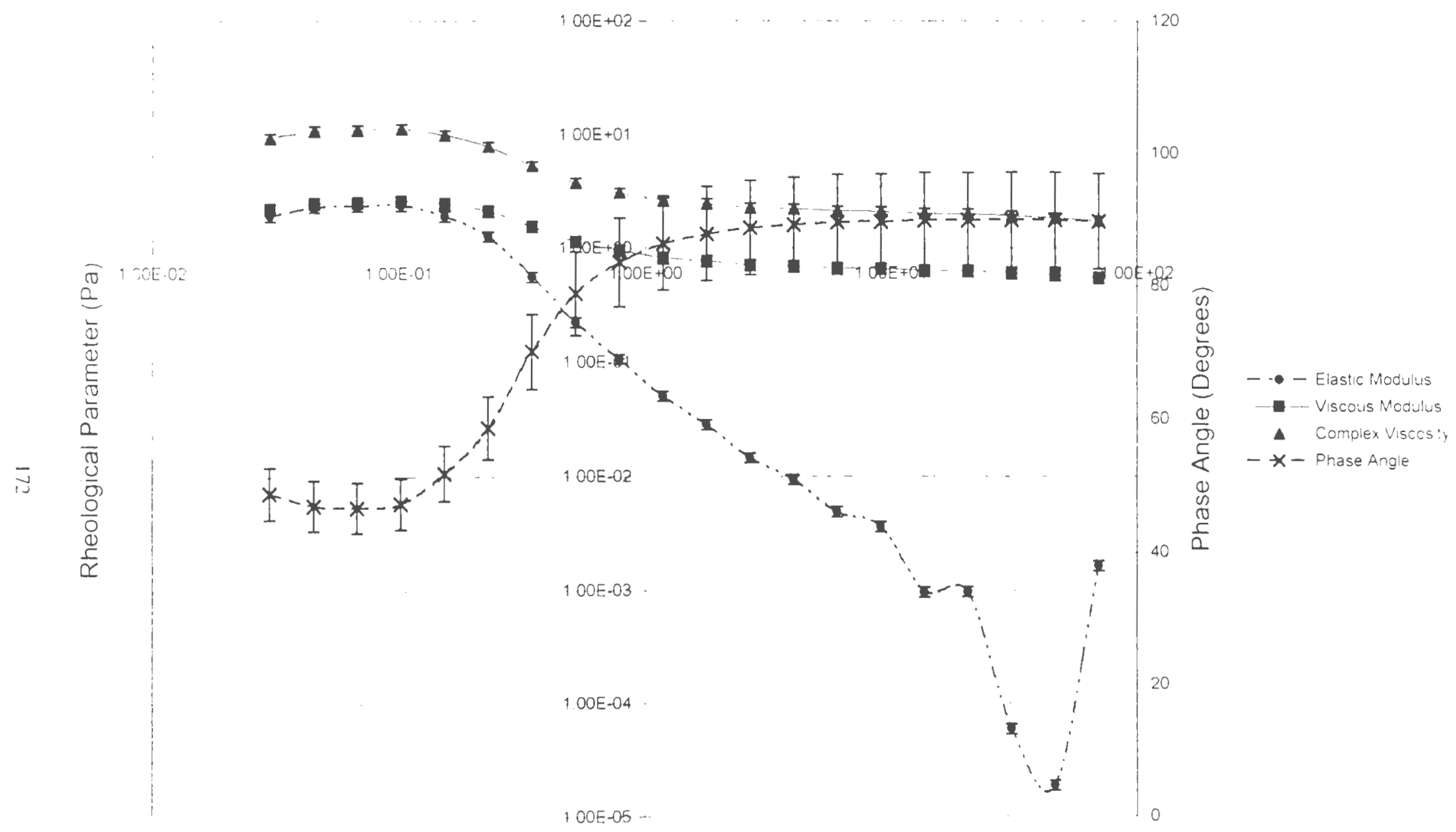

Figure A1.66

Shear Stress $(\mathrm{Pa})$

G". G' Complex Viscosity and Phase Angle Rheogram for Pectin $6.0 \% \mathrm{w} / \mathrm{W}$ Measured at $0.05 \mathrm{~Hz}$ and a Stress Range of $0.00-100 \mathrm{~Pa}$ 
Section III

Appendix 


\section{Calibration Curves}




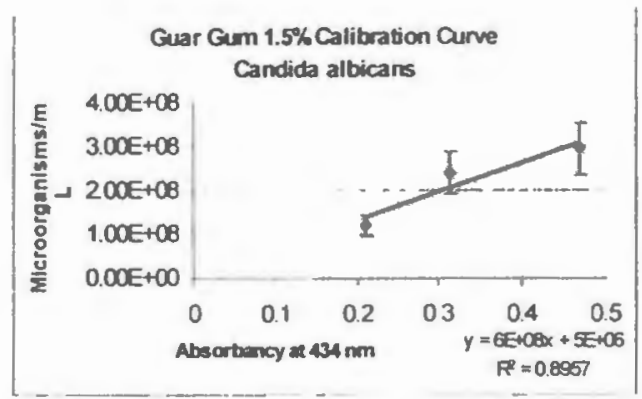

AT1.1.1) Guar gum $1.5 \%$

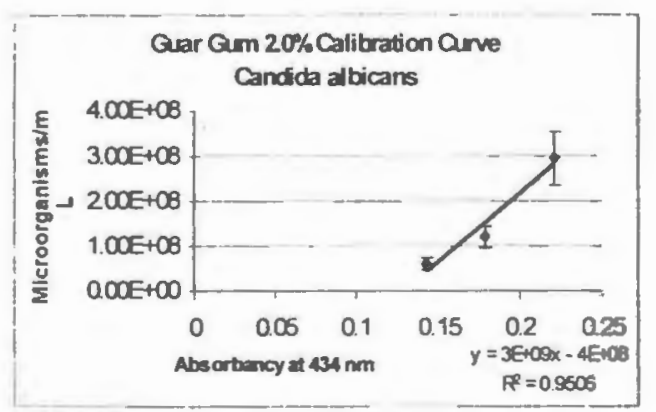

AT1.1.3) Guar gum $2.0 \%$

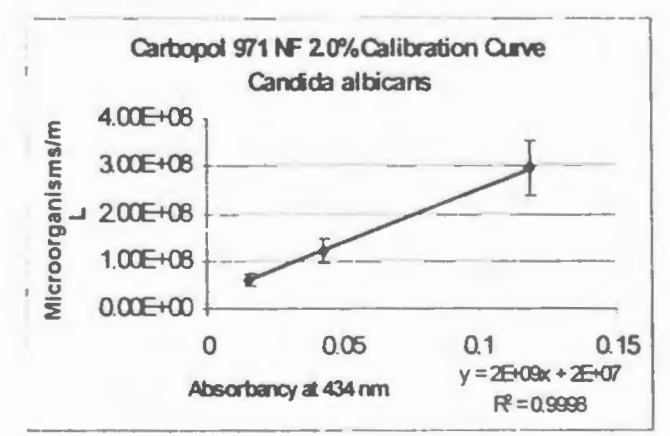

AT1.1.5) Carbopol $9712.0 \%$

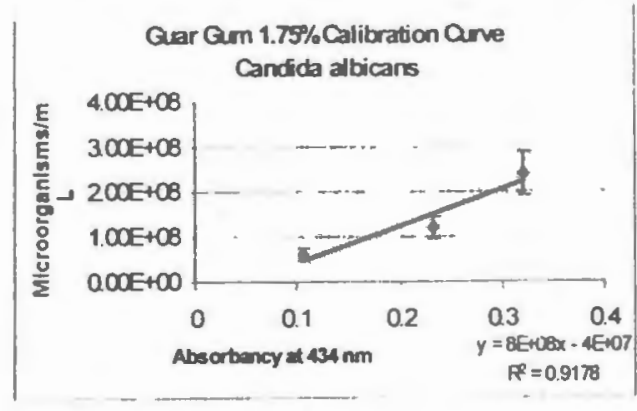

AT1.1.2) Guar gum $1.75 \%$

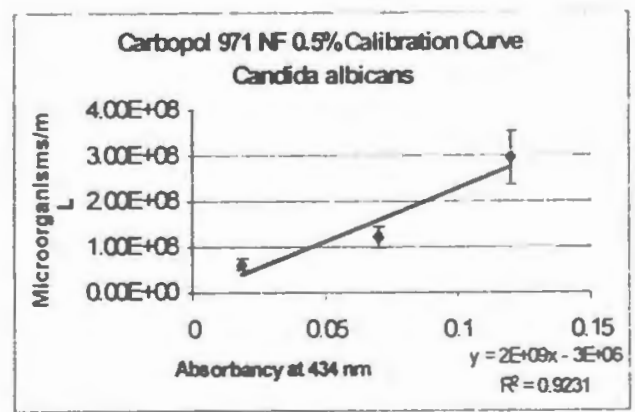

AT1.1.4) Carbopol $9710.5 \%$

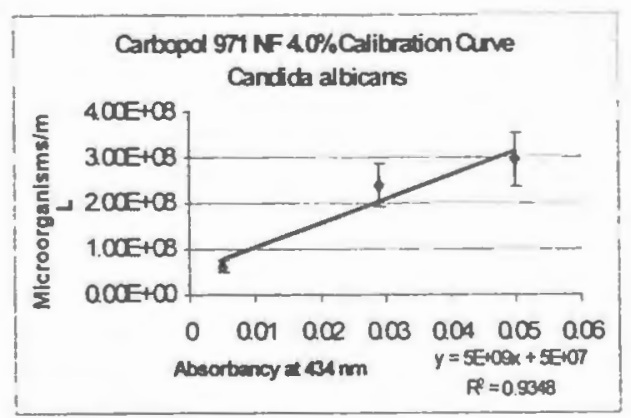

AT1.1.6) Carbopol 971 4.0\%

Figures AT1.1.1-1.1.6, Calibration curves for Candida albicans in Carbopol 971 and Guar gum 


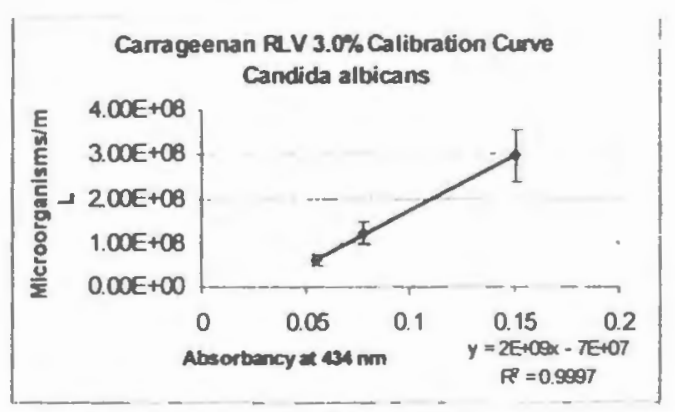

AT1.1.7) Carrageenan RLV 3.0\%

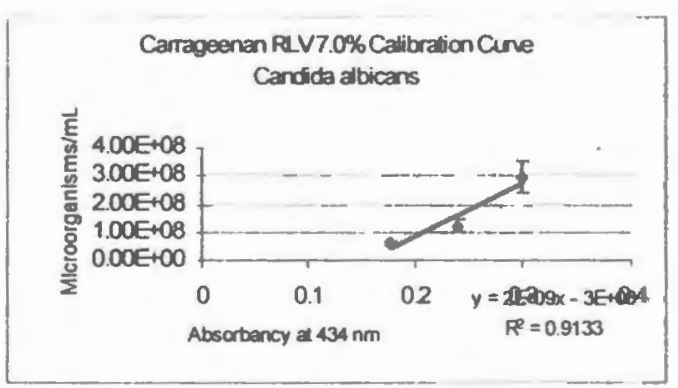

AT1.1.8) Carrageenan RLV 7.0\%

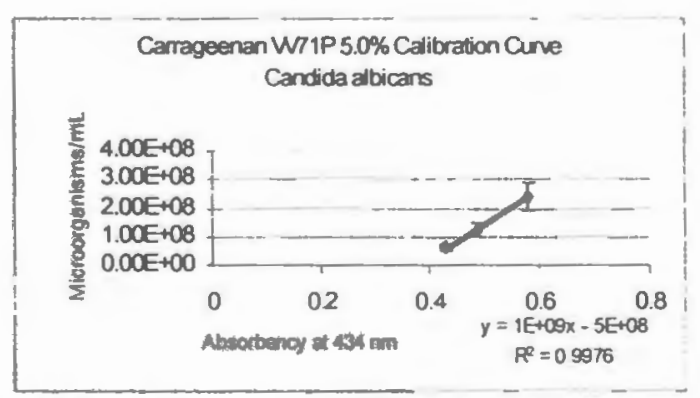

AT1.1.10) Carrageenan VV71P 5.0\%

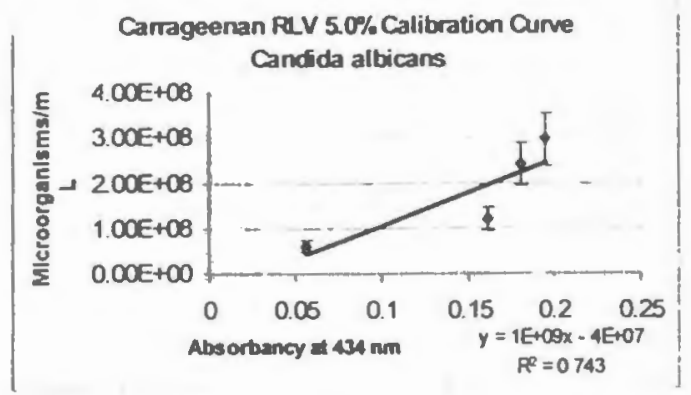

AT1.1.8) Carrageenan RLV 5.0\%

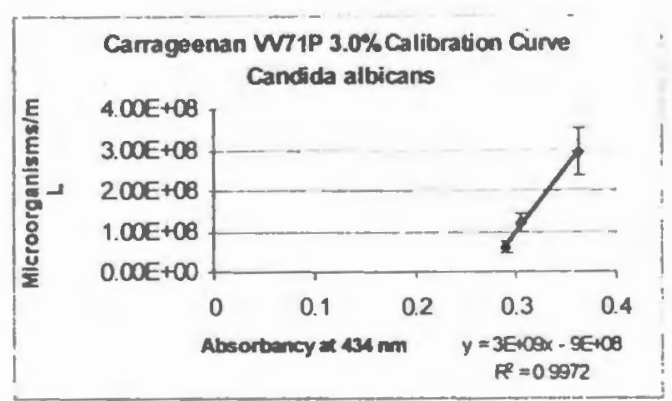

AT1.1.9) Carrageenan VV7IP 3.0\%

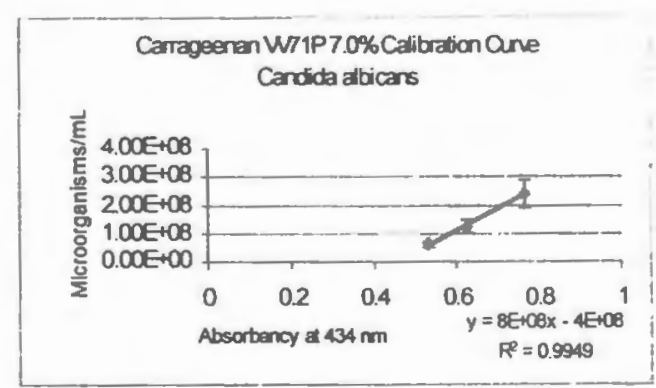

AT1.1.7) Carrageenan VV71P 7.0\%

Figures AT1.1.7-1.1.12, Calibration curves for Candida albicans in Carrageenan RLV and Carrageenan VV71P 


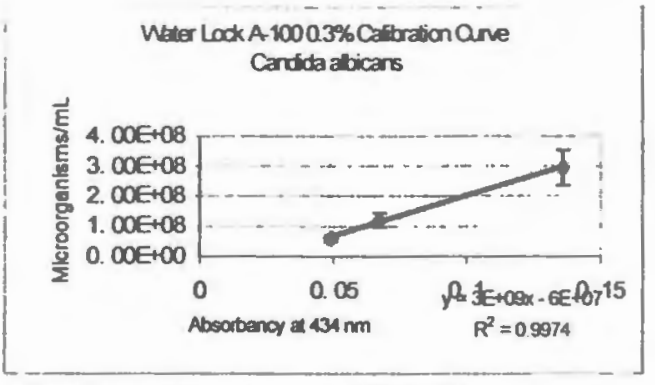

AT1.1.13) Water Lock A-100 0.3\%

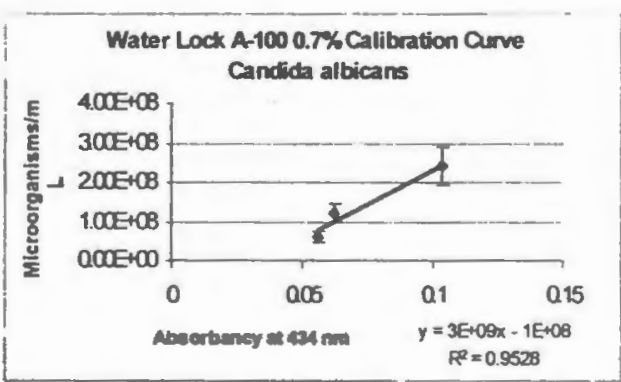

AT1.1.15) Waler Lock A-100 $0.7 \%$

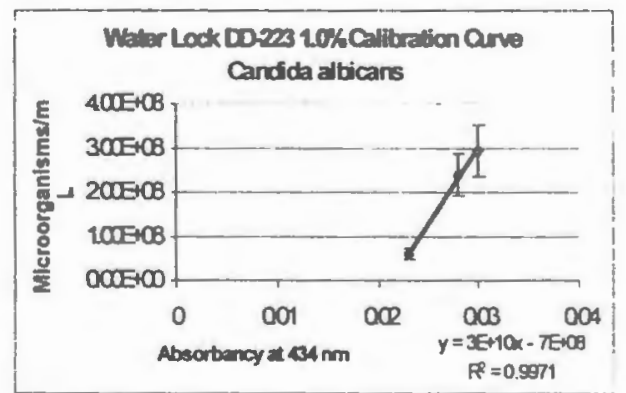

AT1.1.17) Water Lock DD-223 $1.0 \%$

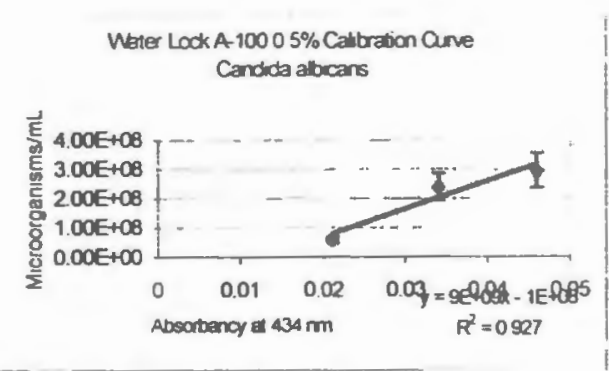

AT1.1.14) Water Lock A-100 0.5\%

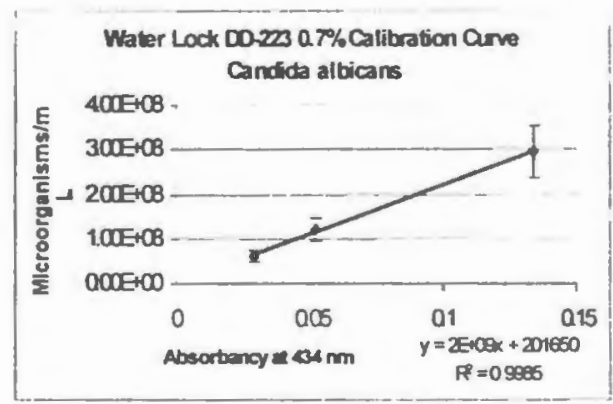

AT1.1.16) Water Lock DD-223 $0.7 \%$

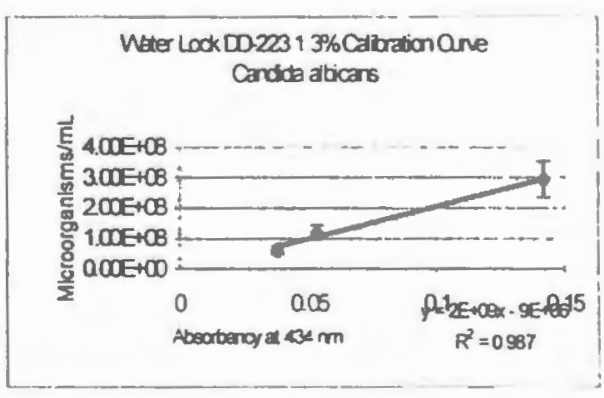

AT1.1.18) Water Lock DD-223 1.3\%

Figures AT1.1.13-1.1.18, Calibration curves for Candida albicans in Water Lock A-100 and Water Lock DD-223 


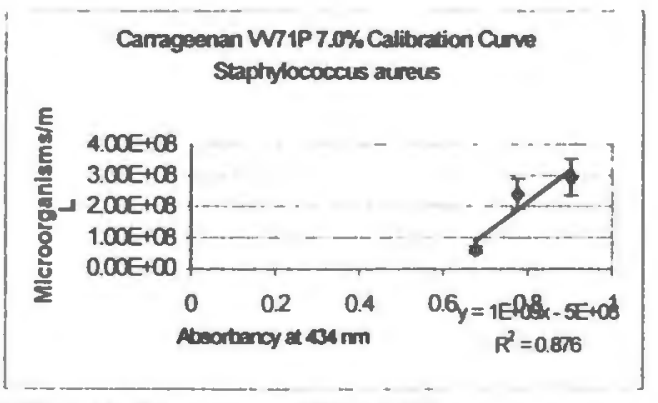

AT1.2.1) Carrageenan RLV 3.0\%

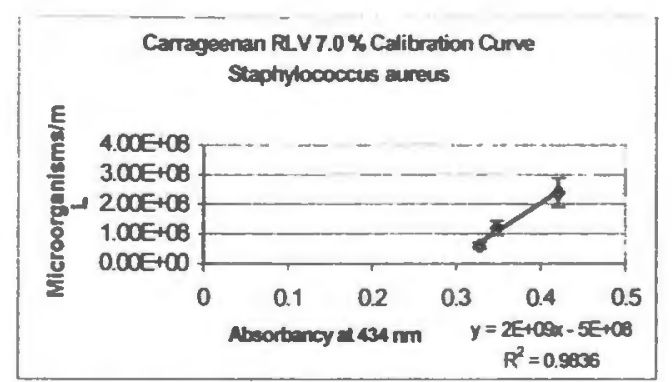

AT 1.2.3) Carrageenan RLV 7.0\%

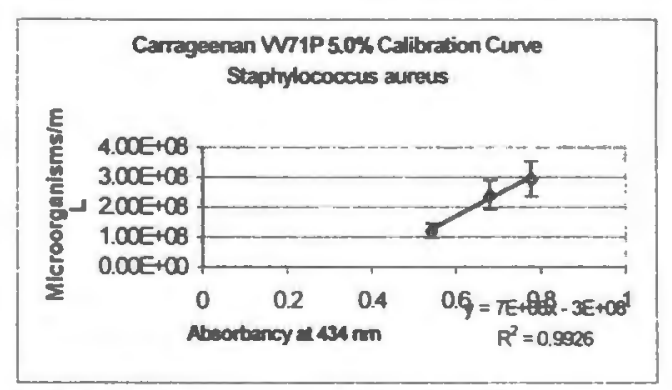

AT1.2.5) Carrageenan VV71P 5.0\%

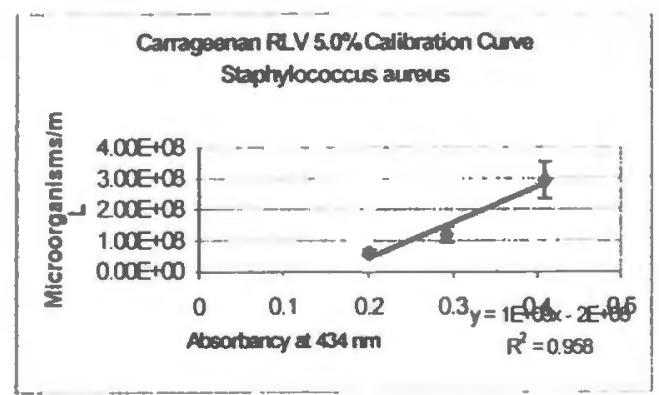

AT1.2.2) Carrageenan RLV 5.0\%

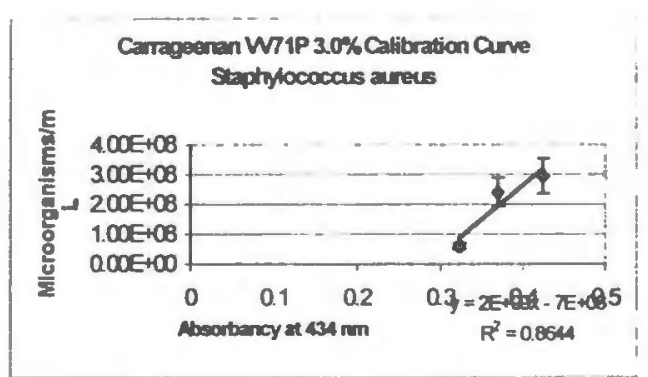

AT1.2.4) Carrageenan VV71P 3.0\%

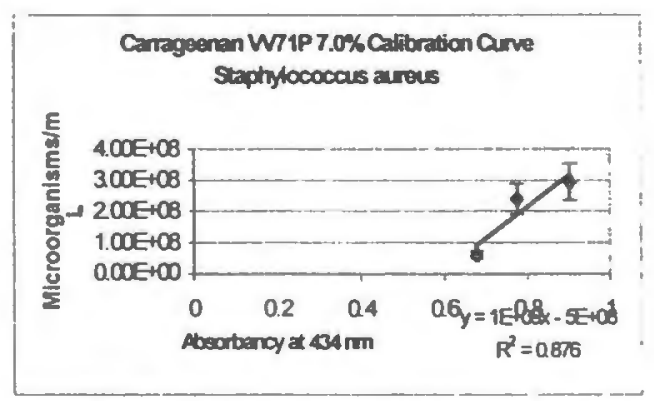

AT1.2.6) Carrageenan VV71P 7.0\%

Figures AT1.2.1-1.2.6, Calibration curves for Staphyloccoccus aureus in Carrageenan RLV and Carrageenan VV71P 


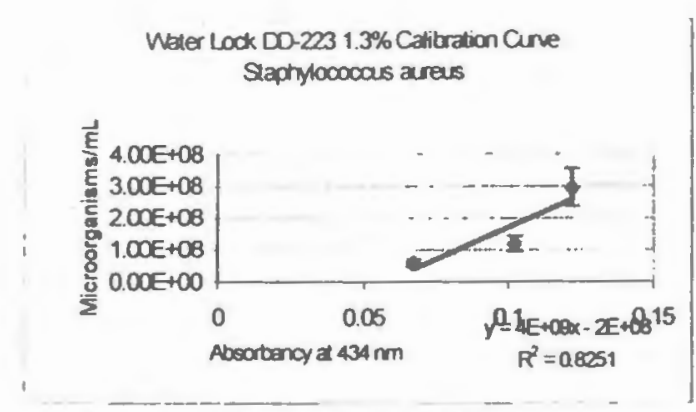

AT1.1.7) Water Lock A-100 $0.3 \%$

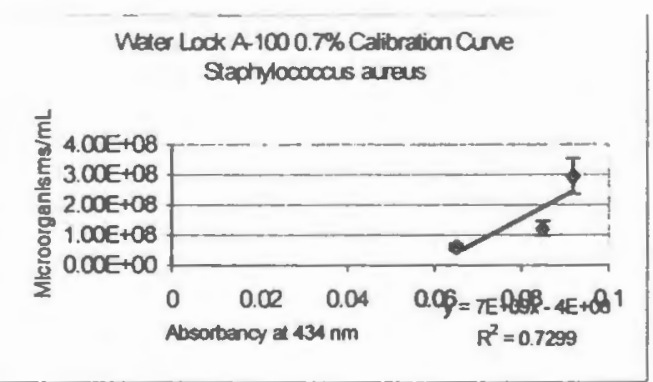

AT1.1.9) Water Lock A-100 $0.7 \%$

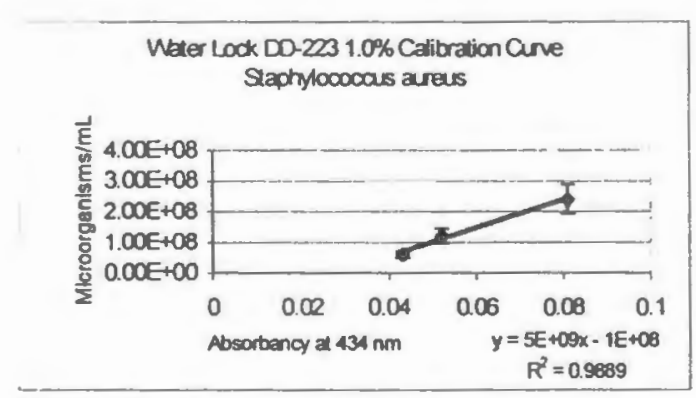

AT1.1.11) Water Lock DD-223 $1.0 \%$

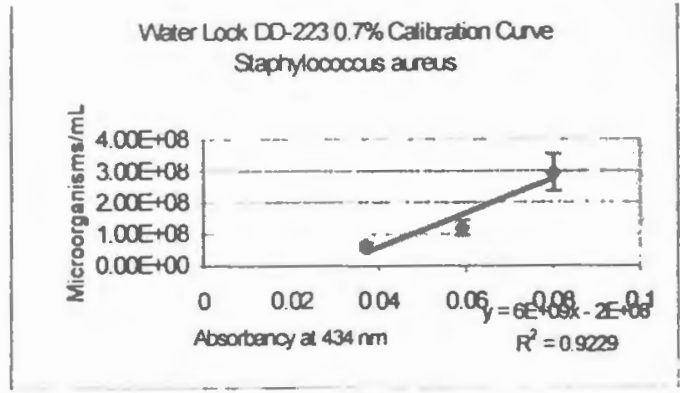

AT1.1.8) Water Lock A-100 $0.5 \%$

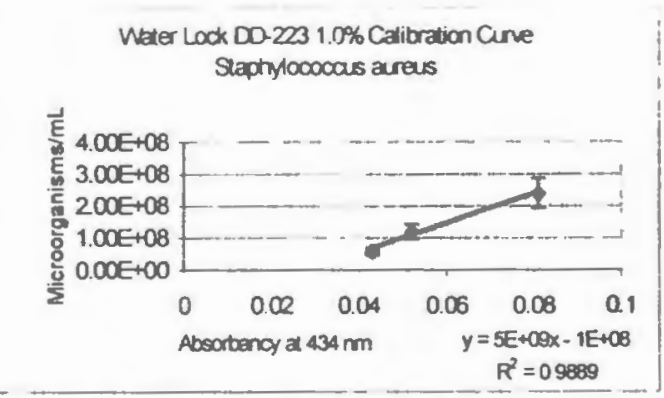

ATI.1.10) Water Lock DD-223 $0.7 \%$

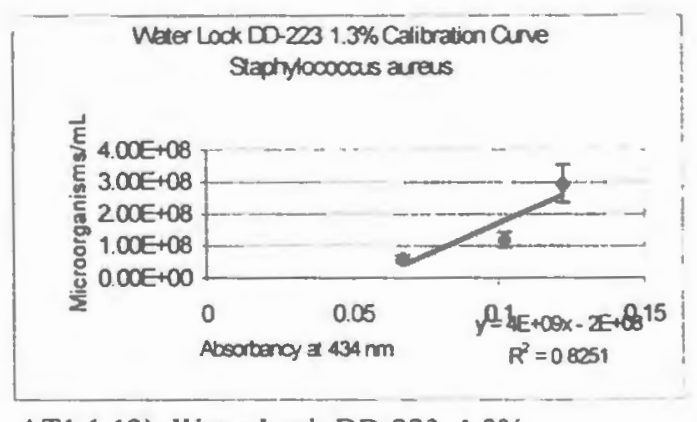

AT1.1.12) Water Lock DD-223 $1.3 \%$

Figures AT1.2.7-1.2.12, Calibration curves for Staphylococcus aureus in Water Lock A-100 and Water Lock DD-223 


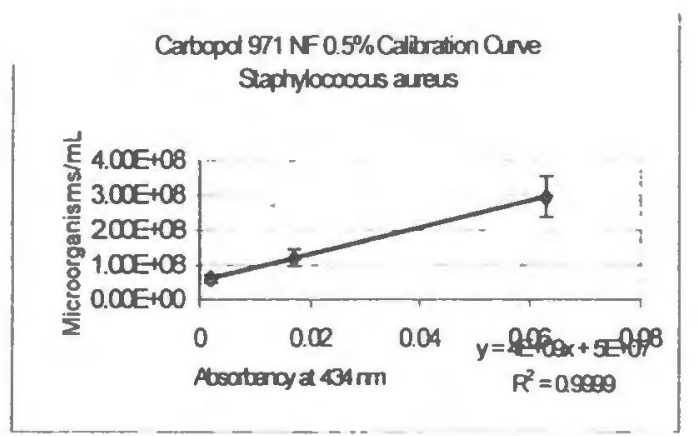

AT1.2.13) Carbopol $9710.5 \%$

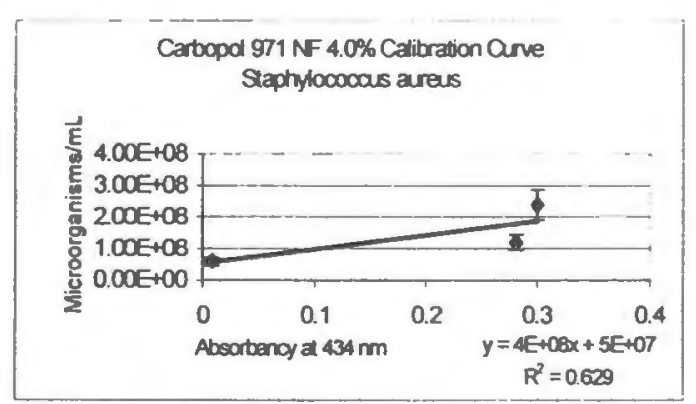

AT1.2.15) Carbopol $971 \quad 4.0 \%$

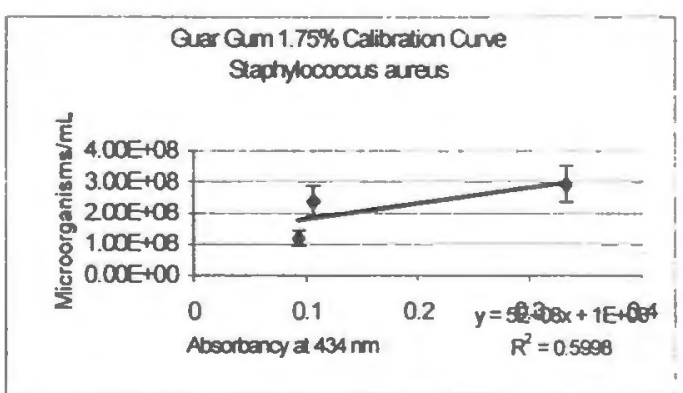

AT1.2.17) Guar gum $1.75 \%$

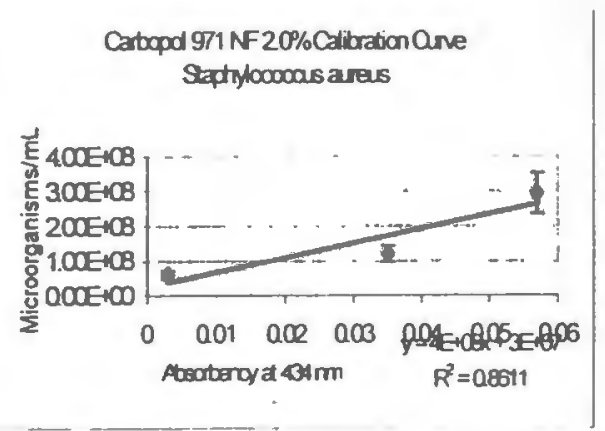

AT1.2.14) Carbopol $9712.0 \%$

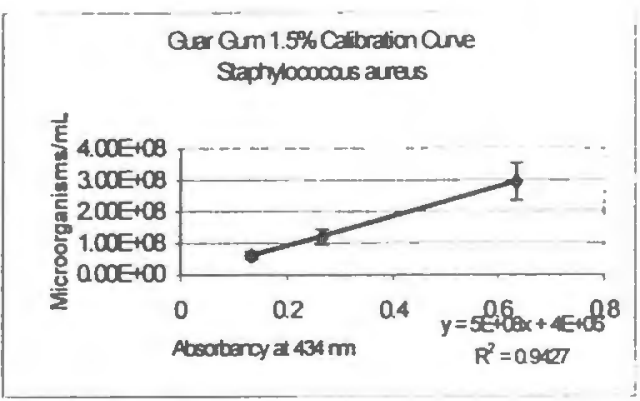

AT1.2.16) Guar gum 1.5\%

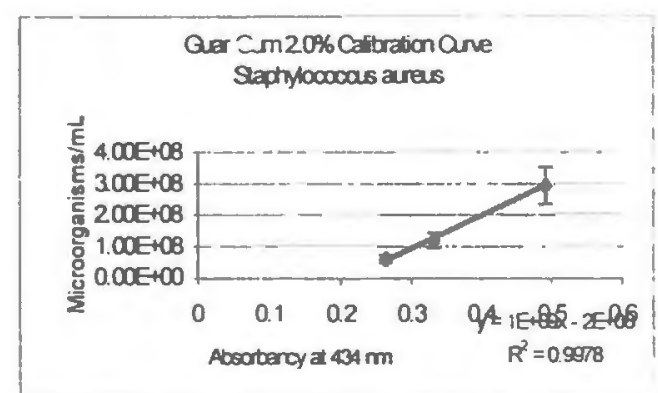

AT1.2.18) Guar gum $2.0 \%$

Figures AT1.2.13-1.2.18, Calibration curves for Staphyloccoccus aureus in Carbopol 971 and Guar gurm 


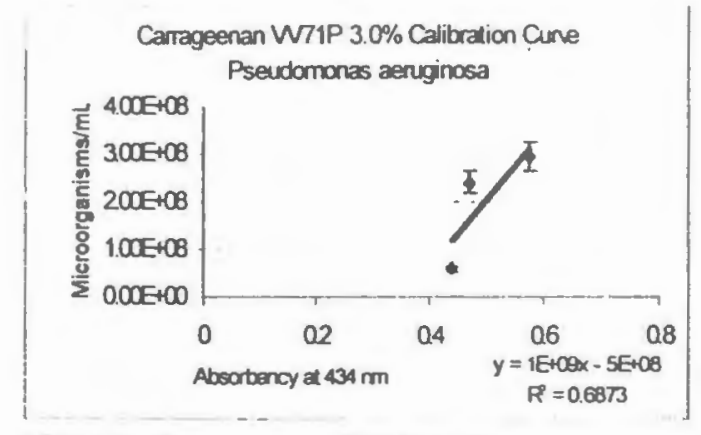

AT1.3.1) Carrageenan VV71P $3.0 \%$

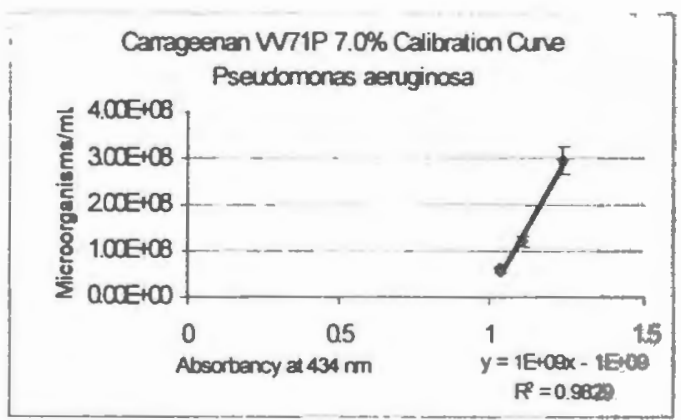

AT1.2.3) Carrageenan VV71P $7.0 \%$

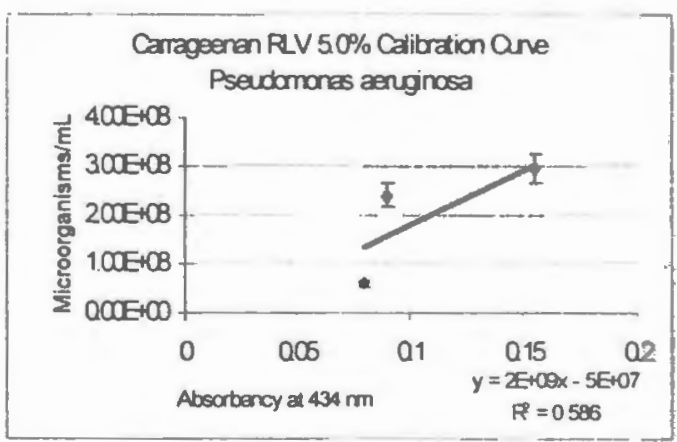

AT1.3.5) Carrageenan RLV 5.0\%

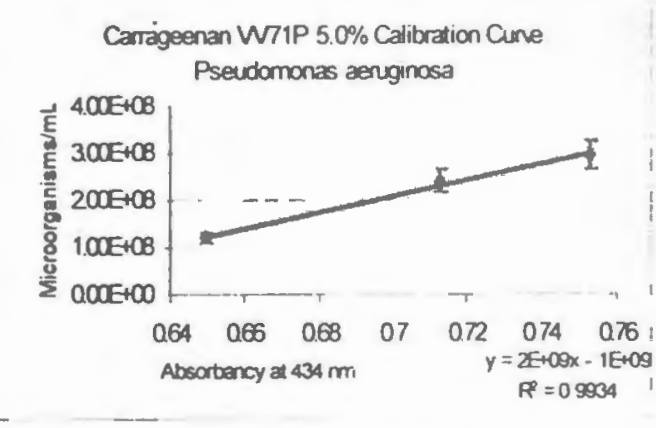

AT1.3.2) Cartageenan VV71P $5.0 \%$

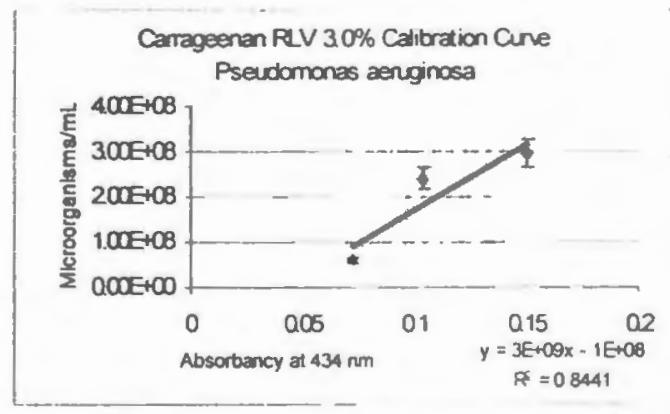

AT1.3.4) Carrageenan RLV $3.0 \%$

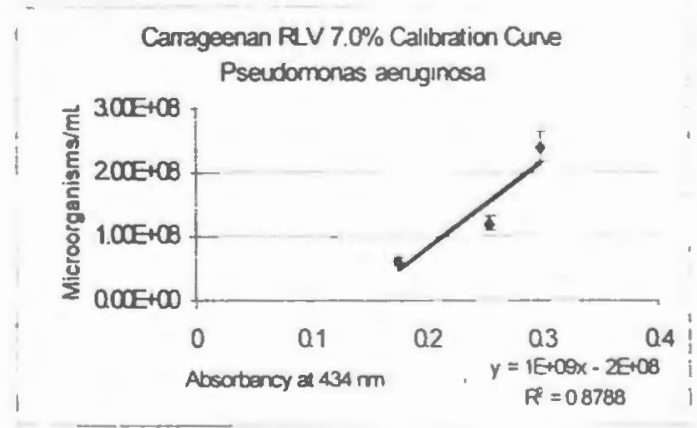

AT1.3.6) Carrageenan RLV $7.0 \%$

Figures AT1.3.1-1.3.6, Calibration curves for Pseudomonas aeruginosa in Carrageenan VV7IP and Carrageenan RLV 


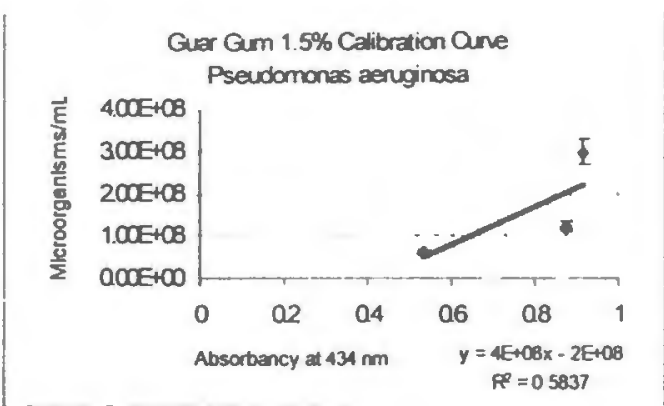

AT1.3.7) Guar gum $1.5 \%$

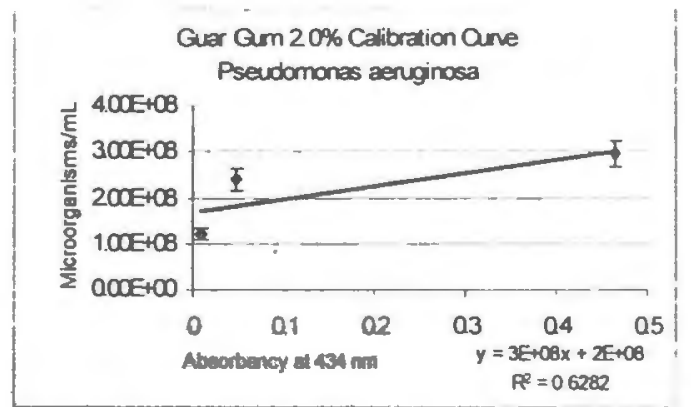

AT1.3.9) Guar gum 2.0\%

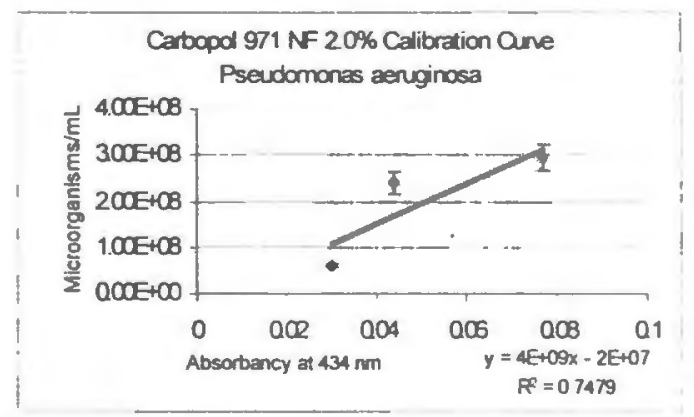

AT1.3.11) Carbopol $9712.0 \%$

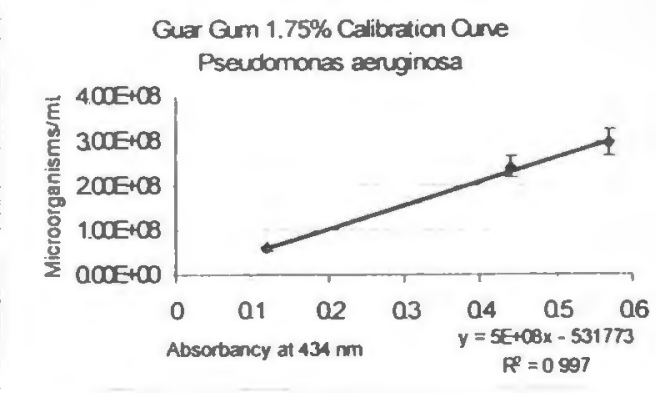

AT1.3.8) Guar gum $1.75 \%$

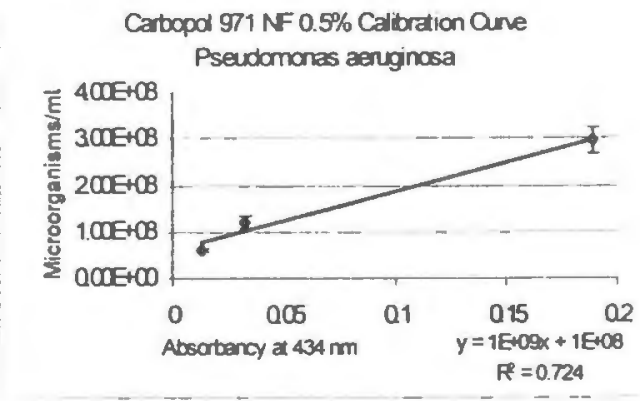

AT1.3.10) Carbopol $971 \quad 0.5 \%$

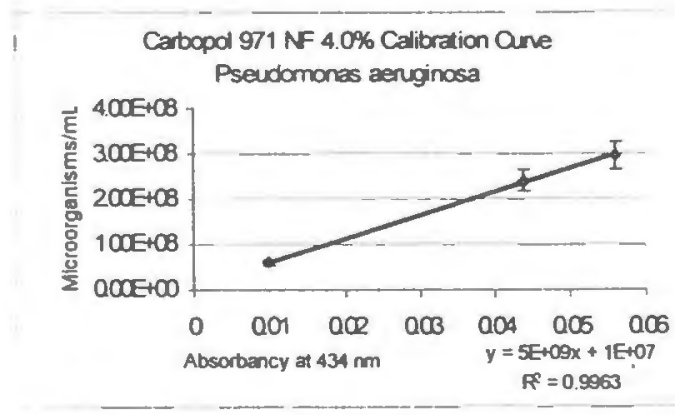

AT1.3.12) Carbopol $9714.0 \%$

Figures AT1.3.7-1.3.12, Calibration curves for Pseudomonas aeruginosa in Guar gum and Carbopol 971 


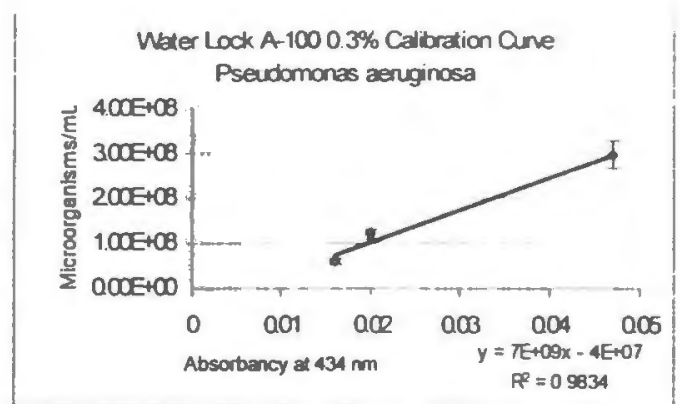

AT1.3.13) Water Lock A-100 $0.3 \%$

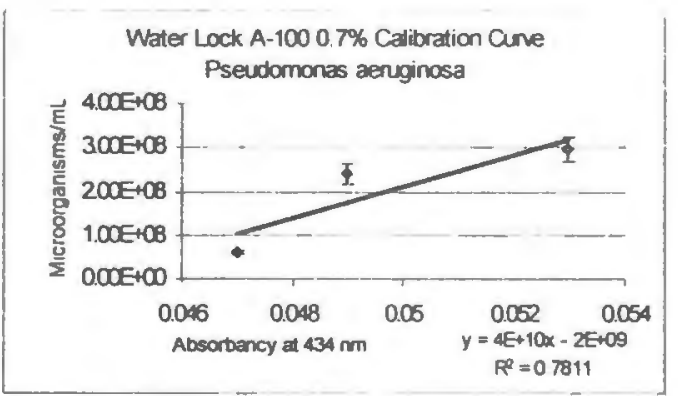

AT1.3.15) Water Lock A-100 $0.7 \%$

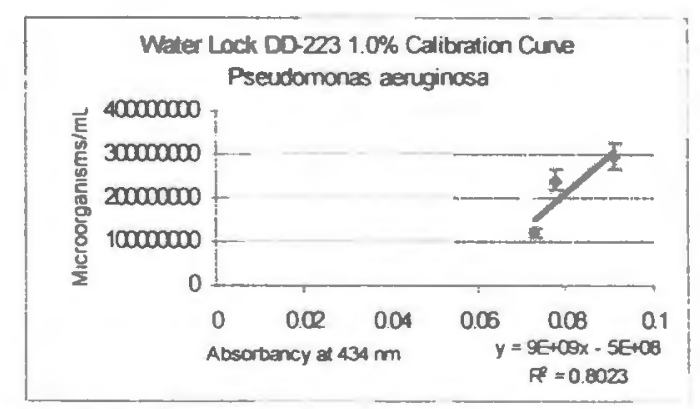

AT1.3.17) Water Lock DD-223 $1.0 \%$

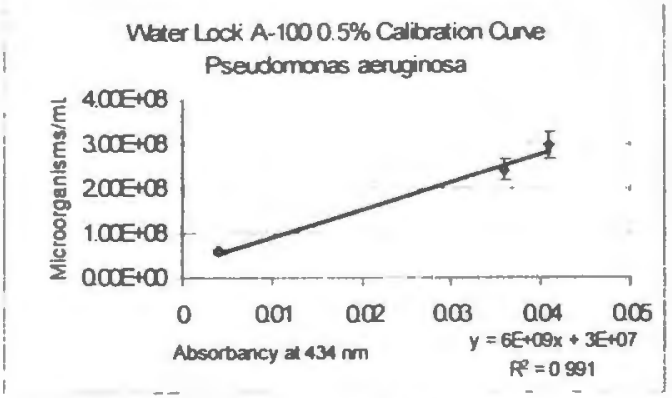

AT1.3.14) Water Lock A-100 $0.5 \%$

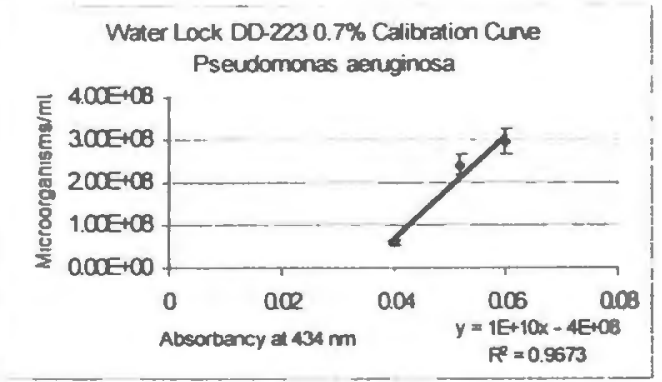

AT1.3.16) Water Lock DD-223 $0.7 \%$

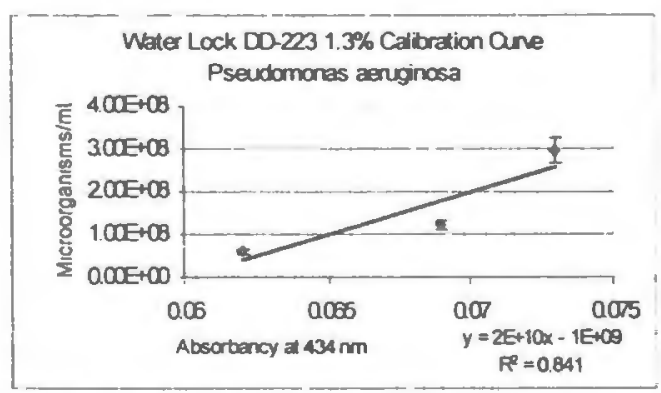

AT1.3.18) Water Lock DD-223 $1.3 \%$

Figures AT1.3.13-1.3.18, Calibration curves for Pseudomonas aeruginosa in Water Lock A-100 and Water Lock DD-223 


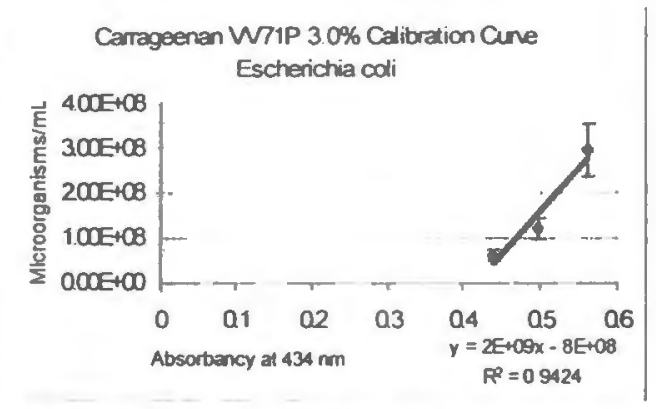

AT1.4.1) Carrageenan VV7IP $3.0 \%$

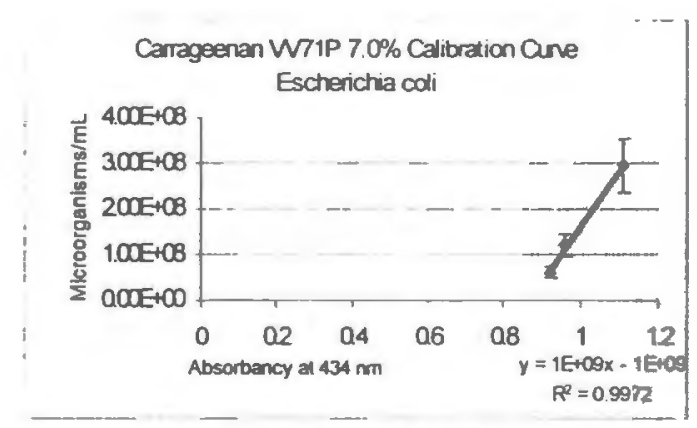

AT1.4.3) Carrageenan VV71P $7.0 \%$

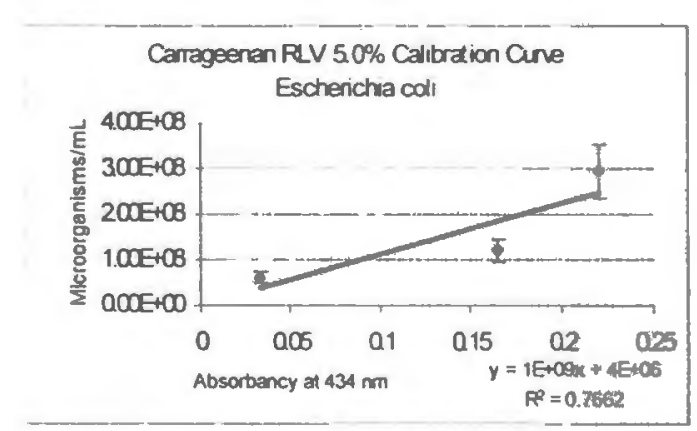

AT1.4.5) Carrageenan RLV 5.0\%

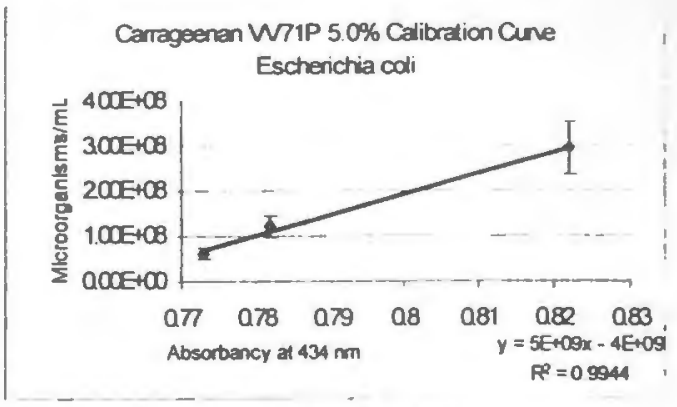

AT1.4.2) Carrageenan VV71P $5.0 \%$

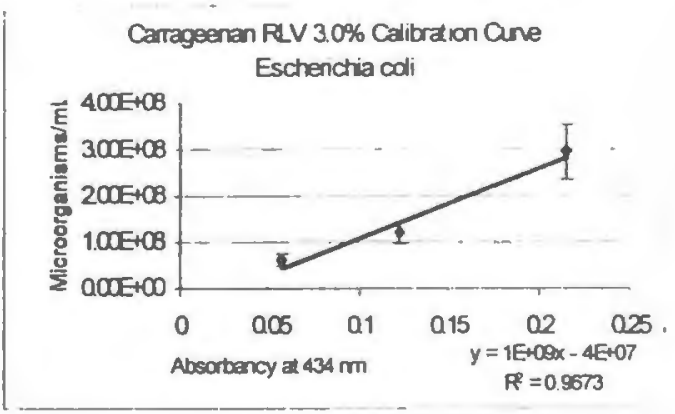

AT1.4.4) Carrageenan RLV $3.0 \%$

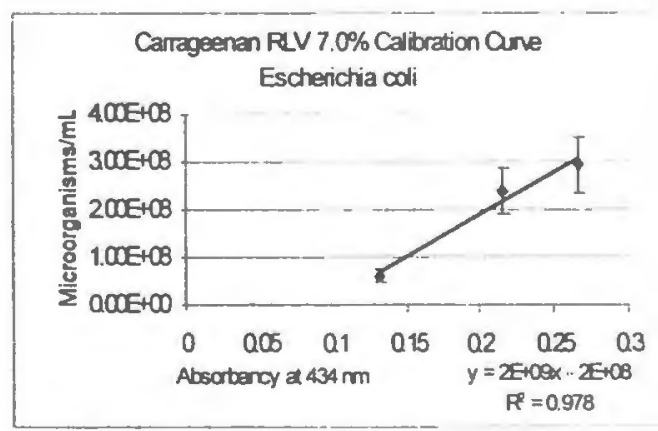

AT 1.4.6) Carrageenan RLV $7.0 \%$

Figures AT1.4.1-AT1.4.6, Calibration curves for Escherichia coli in Carrageenan VV71P and Carrageenan RLV 


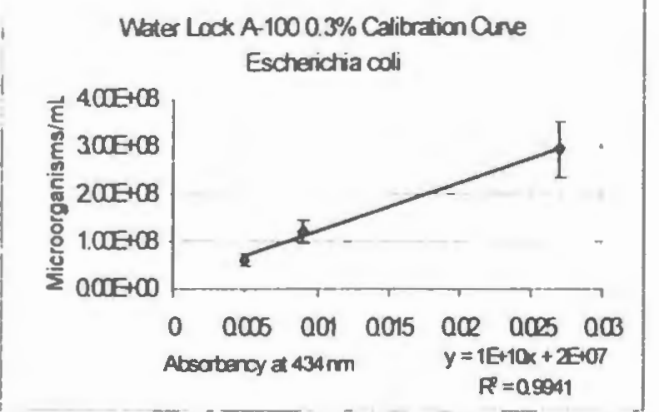

AT1.4.7) Water Lock A-100 $0.3 \%$

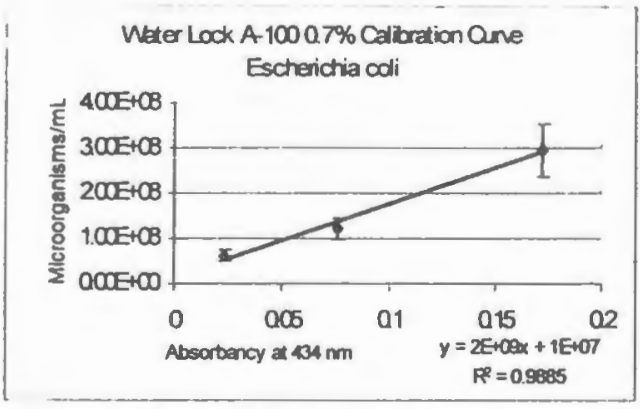

AT1.4.9) Water Lock A-100 $0.7 \%$

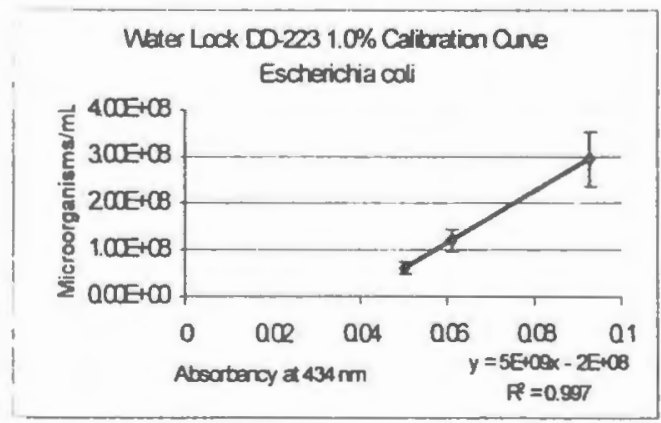

AT 1.4.11) Water Lock DD-223 1.0\%

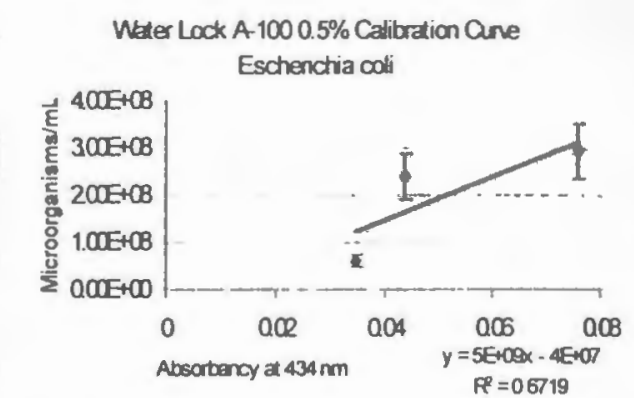

AT1.4.8) Water Lock A-100 $0.5 \%$

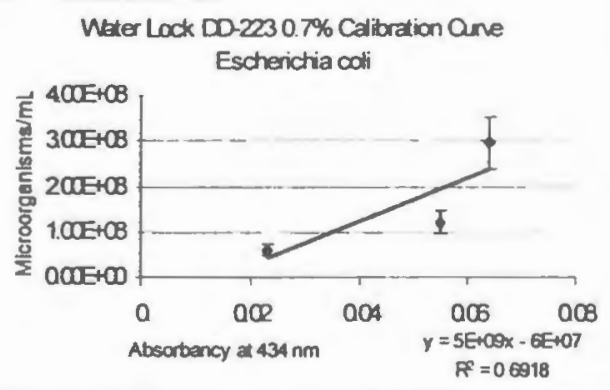

AT1.4.10) Water Lock DD-223 $0.7 \%$

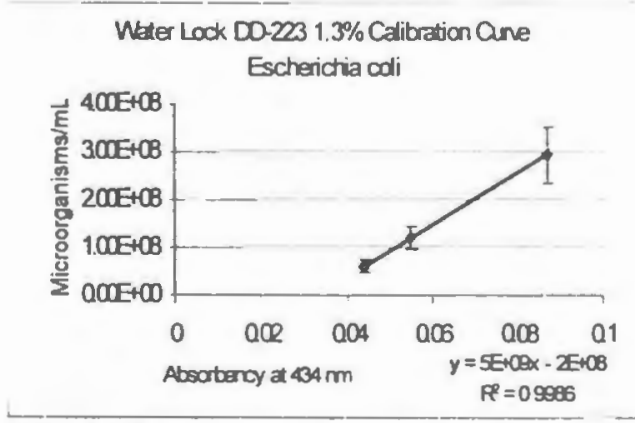

AT1.4.12) Water Lock DD-223 $1.3 \%$

Figures AT1.4.7-AT1.12, Calibration curves for Escherichia coli in Water Lock A-100 and Water Lock DD-223 


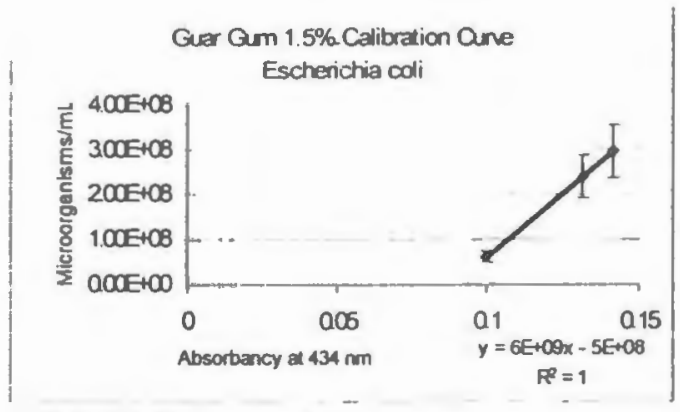

AT1.4.13) Guar gum 1.5\%

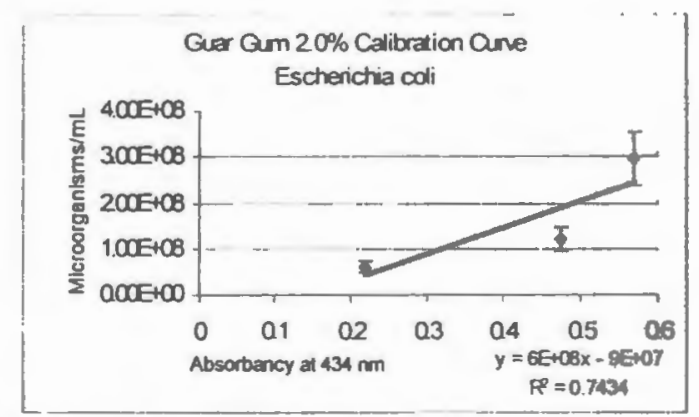

AT1.4.15) Guar gum $2.0 \%$

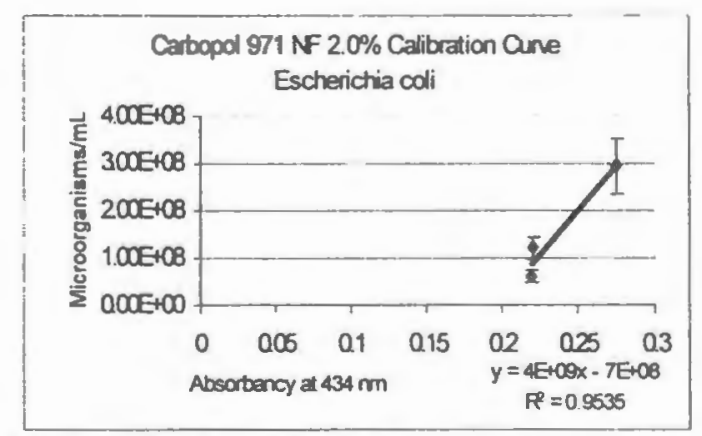

ATI.4.17) Carbopol $9712.0 \%$

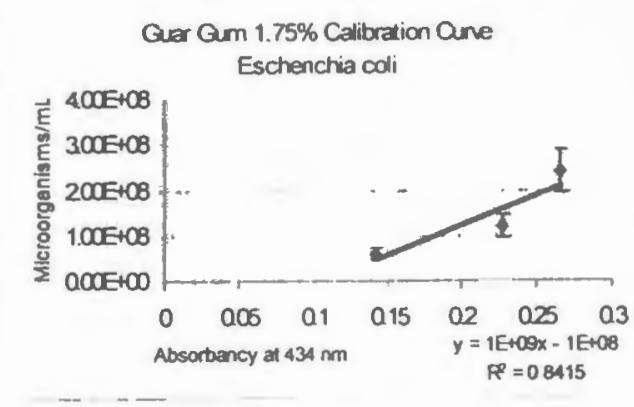

AT1.4.14) Guar gum $1.75 \%$

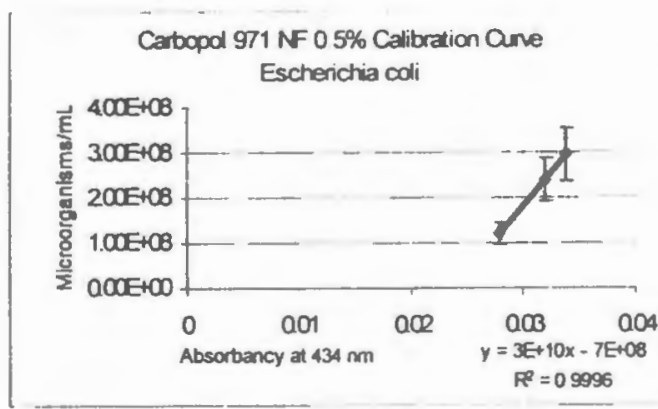

ATI.4.16) Carbopol $9710.5 \%$

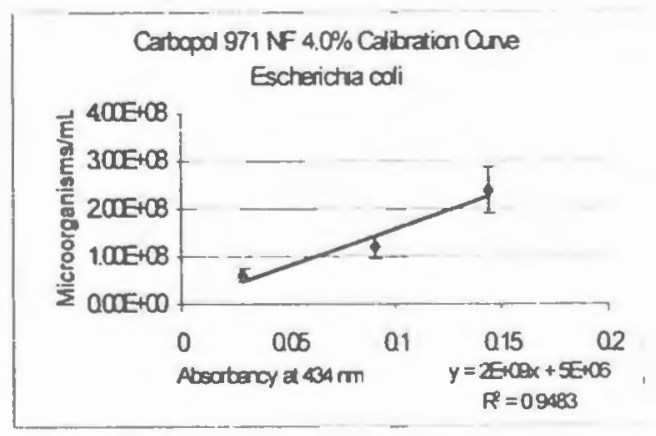

AT1.4.18) Carbopol $9714.0 \%$

Figures AT1.4.13-AT1.18, Calibration curves for Escherichia coli in Guar gum and Carbopol 971 


\section{Bibliography}

Atsumi, T., Maekawa, Y., Yamada, T., Kawagishi, I., Inae, Y. and Hamma, M., Effect of viscosity on swimming by the lateral and polar flagella of Vibrio alginoliticus, Journal of Bacteriology, 178:5024 - 5026, (1996)

Ballesteros, S.A., Chirife, J. and Bozzini, J., Specific solute effects on Staphylococcus aureus cells subjected to reduced water activity, International Journal of Food Microbiology, 20:51 - 66, (1993)

Barry, B.W. and Eccleston, G.M., Oscillatory testing of $\mathrm{o} / \mathrm{w}$ emulsions containing mixed emulsions of the type surfactant-long chain alcohol type: influence of surfactant chain length, Journal of Pharmaceutics and Pharmacokinetics, 25:394 - 400, (1973b)

Barry, B.W. and Eccleston, G.M., Oscillatory testing of o/w emulsions containing mixed emulsions of the type surfactant-long chain alcohol type: self-bodying action, Journal of Pharmaceutics and Pharmacokinetics, 25:244 - 253, (1973a)

Barry, B.W. and Meyer, M.C., The rheological properties of Carbopol gels I: Continuous shear and creep properties of Carbopol gels. International Journal of Pharmaceutics, $2: 1-25,(1979)$

Chen, J. and Dickinson, E., Viscoelastic properties of heat-set whey protein emulsion gels, Journal of Texture Studies, 29:285 - 304, (1998)

Chereminisoff, N., An introduction to polymer rheology and processing, CRC Press, London, (1993)

Clark, A. and Ross-Murphy, S., Structural and mechanical properties of biopolymer gels, Advances in Polymer Science, 83:60-195, (1987) 
Clarke, P. and Richmond. C., Genetics and biochemistry of Pseudomonas, John Wiley and Sons, NY, (1975)

Cohn, J., The Staphylococci, Wiley Interscience, NY, (1972)

Csonka, L.N., Physiological and genetic responses of bacteria to osmotic stress, Microbiological Reviews, 53:121 - 147, (1989)

D.S. Orth, Establishing cosmetic preservative efficacy by use of D-values, Journal of the Society of Cosmetic Chemists, 31: 165-172, (1980)

Davidson, R., Handbook of water soluble polymers and resins, McGraw Hill, (1980)

Davis, S., Viscoelastic properties of pharmaceutical semisolids III: Destructive oscillatory testing, Journal of Pharmaceutical Sciences, 60:1357 - 1360, (1971b)

Davis, S., Viscoelastic properties of pharmaceutical semisolids III: Non-destructive oscillatory testing, Journal of Pharmaceutical Sciences, 60:1351 - 1355, (1971a)

Doublier, J.L. and Launay, B., Rheology of galactomannan solutions: comparative study of guar gum and locust bean gum, Journal of Texture Studies, 25:119 - 137, (1994)

Eisman, P., Cooper, J. and Jaconia, P., Influence of gum tragacanth on the bacteria activity of preservatives, Journal of The American Pharmaceutical Association, 46:144 - 147, (1957)

Ferrero, R.L. and Lee, A., Motility of Campylobacter jejuni in viscous environments: comparison with rod shaped bacteria, Journal of General Microbiology, 134:53 - 59, (1988)

Ferry, J., Viscoelastic properties of polymers, 3rd ed., Wiley and Sons, NY, (1980) 
Giboreau, A., Cuvelier, G. and Launay, B., Rheological behavior of three biopolymer/water systems, with emphasis on yield stress and viscoelastic properties, Journal of Texture Studies, 25:119-137 (1994)

Greenberg, E.P., Canale-Parola, E., relationship between cell coiling and motility of spirochetes in viscous environments, Journal of Bacteriology, 131:960 - 969, (1977)

Guiselly, K.B., Chemical and physical properties of algal polysaccharides used for cell immobilization, Enzyme Microbial Technology, 11:706 - 716, (1989)

Kanide, K. and Saito, M., Cellulose and cellulose derivatives: recent advances in physical chemistry, Advances in Polymer Science, 83:5-59, (1987)

Kets, E.P., de Bont, J.A.M. and Heipieper, H., Physiological responses of Pseudomonas putida 512 subjected to reduced water activity, Microbiology Letters, 139:133 - 137, (1996)

Lawrence, J.R., Korber, D.R. and Caldwell, D.E., Behavioral analysis of Vibrio parahaemolyticus variants in high and low viscosity microenvironments by use of digital image processing, Journal of Bacteriology, 174:5732 - 5739, (1992)

Lochhead, R. and Fron, W., Encyclopedia for polymers and thickeners for cosmetics, Cosmetics and Toiletries, 108:95-135, (1993)

McCarthy, T.J. and Myburgh, J.A., The effect of tragacanth gel on preservative activity, Pharmaceutisch Weekblad, 109:265 - 268, (1974)

McCormic, C. Structural design of water soluble polymers, in Water-Soluble Polymers, Synthesis, Solution Properties and Applications (S. Shalaby, C. MacCormick, G. Butler, eds.) pp. 2 - 24, ACS, Washington, (1991) 
McFarland, J., The Nephelometer, Journal of the American Medical Association, 49:1176, (1907)

Niedhart, F., E. coli and Salmonella typimurin, cellular and molecular biology, American Society for Microbiology, Washington, (1987)

Odds, F.C., Candida and Candidiosis, 2nd ed. Bailliere Tindall, Toronto, Ca., (1988)

Pans, R., Erra, P., Soians, C., Ravey, J. and Stebe, M., Viscoelastic properties of gelemulsions: Their relationship with structure and equilibrium properties, Journal of Physical Chemistry, 97: 12320-12324 (1993)

Robert, W., Rapp, G. and Webber, J., Encyclopedia of minerals, VNR Co., NY, (1974)

Rochefort and Middleman (1987), Rheology of xanthan gum: salt, temperature and strain oscillatory and steady shear experiments, Journal of Rheology, 31:337-369, (1987)

Schlegel, H., General microbiology, 2nd ed., Cambridge University Press, (1993)

Stecchini, M.L., Torre, M., Sorais, I., Soro, O., Messina, M. and Maltini, E., Influence of structural properties and kinetic constraints on Bacillus cereus growth, Applied and Environmental Microbiology, 64:1075 - 1078, (1998)

Terrisse, I., Seiller, M., Rabaron, A. and Grossiord, J.L., Rheology: how to characterize and to predict the evolution of w/o/w multiple emulsions, International Journal of Cosmetic Science, 15:53 - 62, (1993)

Yanagi and Onishi G., Assimilation of selected cosmetic ingredients by microorganisms, Journal of the Society of Cosmetic Chemists. 22:851, (1971) 